NÚBIA DE SOUZA LOBATO

\title{
A OBESIDADE DIMINUI A RESPOSTA DE ARTÉRIAS MESENTÉRICAS DE RESISTÊNCIA A AGONISTAS CANABINÓIDES
}

Tese apresentada ao Programa de PósGraduação em Farmacologia do Instituto de Ciências Biomédicas da Universidade de São Paulo, para obtenção do Título de Doutor em Ciências. 


\section{NÚBIA DE SOUZA LOBATO}

\section{A OBESIDADE DIMINUI A RESPOSTA \\ DE ARTÉRIAS MESENTÉRICAS DE RESISTÊNCIA \\ A AGONISTAS CANABINÓIDES}

Tese apresentada ao Programa de PósGraduação em Farmacologia do Instituto de Ciências Biomédicas da Universidade de São Paulo, para obtenção do Título de Doutor em Ciências.

Área de Concentração: Farmacologia

Orientadora: Profa. Dra. Zuleica Bruno Fortes

São Paulo

2010 
DADOS DE CATALOGAÇÃO NA PUBLICAÇÃO (CIP)

Serviço de Biblioteca e Informação Biomédica do

Instituto de Ciências Biomédicas da Universidade de São Paulo

reprodução não autorizada pelo autor

\section{Lobato, Núbia de Souza.}

A obesidade diminui a resposta de artérias mesentéricas de resistência a canabinóides / Núbia de Souza Lobato. -- São Paulo, 2010.

\section{Orientador: Zuleica Bruno Fortes.}

Tese (Doutorado) - Universidade de São Paulo. Instituto de Ciências Biomédicas. Departamento de Farmacologia. Área de concentração: Farmacologia. Linha de pesquisa: Obesidade, suas complicações e a resposta vascular: efeito da fármacos.

Versão do título para o inglês: Obesity decreases the response of resistance mesentric arteries to cannabinoid agonists.

Descritores: 1. Obesidade 2. Vasos sanguíneos 3. Relaxamento 4. Endotélio vascular I. Fortes, Zuleica Bruno II. Universidade de São Paulo. Instituto de Ciências Biomédicas. Programa de Pós-Graduação em Farmacologia III. Título. 
Candidato(a):

Título da Tese:

Núbia de Souza Lobato.

A obesidade diminui a resposta de artérias mesentéricas de resistência a canabinóides.

Orientador(a): $\quad$ Zuleica Bruno Fortes.

A Comissão Julgadora dos trabalhos de Defesa da Tese de Doutorado, em sessão pública realizada a considerou

\section{( ) Aprovado(a) \\ ( ) Reprovado(a)}

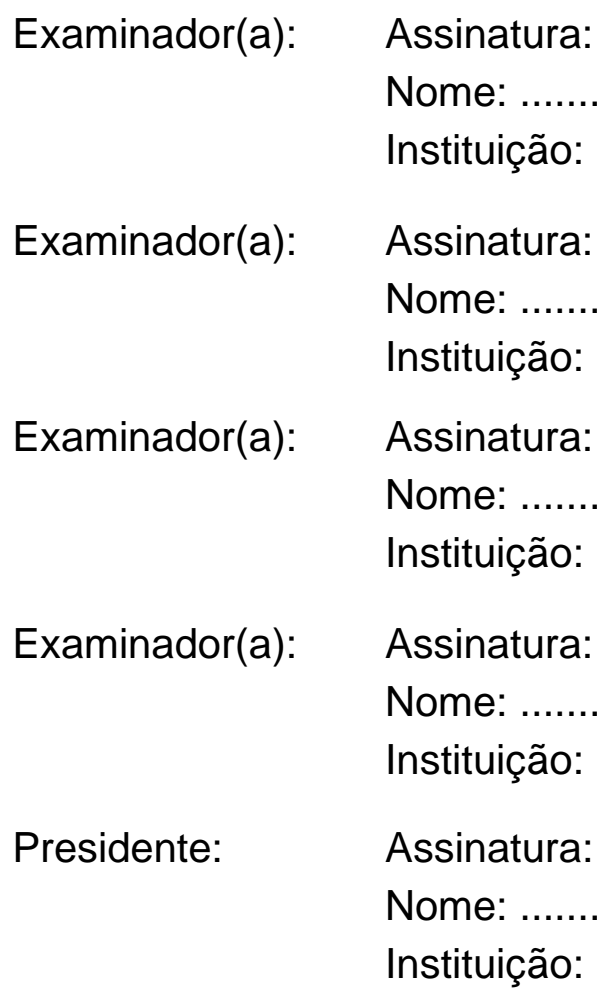


Dedico este trabalho $\mathcal{A}$ minha querida família,

Meus pais, Neury e Maria Aparecida, pelo amor, incentivo e aceitação incondicional da minha dedicação à pesquisa científica

Meus irmãos, Nívea Júnior e Luana, pela compreensão e carinho prestados. Mesmo à distância, fizeram chegar, de diversas formas, incentivos e carinhosos cuidados.

Ao Fernando,

Meu amor, pela paciência, amizade $e$ companheirismo em todos os momentos, dando-me coragem para prosseguir com a confiança necessária para realizar meus sonhos. 


\section{AGRADECIMENTOS}

Dos estágios iniciais do desenvolvimento desta tese até esta versão final, devo um imenso débido de gratidão à minha orientadora, Dra. Zuleica Bruno Fortes, cuja experiência, conhecimento e paciência adicionaram consideravelmente à minha formação acadêmica e científica.

Às professoras do grupo de Hipertensão (Dra. Maria Helena C. Carvalho e Dra. Dorothy Nigro) pelo apoio e estrutura dos laboratórios.

Os meus mais profundos agradecimentos ao professor Dr. Clinton Webb (professor do Medical College of Georgia, Augusta, GA) pela acolhida e pela confiança prestada durante o período de estágio que realizei em seu laboratório, o qual possibilitou o desenvolvimento deste projeto de pesquisa.

Expresso também meus sinceros agradecimentos à professora Dra Rita Tostes, pela orientação excepcional prestada durante o período de estágio que realizei no laboratório do professor $\mathrm{Dr}$ Clinton Webb.

À Dra. Eliana Akamine, agradeço pelas ricas sugestões, assim como pelo incentivo e amizade, que contribuíram para o enriquecimento deste trabalho e também para meu desenvolvimento científico.

Às secretárias do departamento de Farmacologia, Selma e Julieta, pelo auxílio com os assuntos burocráticos, e pela amizade.

Aos funcionários do laboratório de hipertensão e diabetes: Manoel, Ritinha, Martinha, Antônio, Sônia Bá, pela amizade, atenção e auxílio prestados.

À funcionária e amiga Rosângela, que me acolheu com bastante carinho quando da minha chegada em São Paulo, me fornecendo ajuda sempre que precisei.

Aos meus amigos, tanto aos "velhos" e queridos, quanto aos que se revelaram ao longo desse período, por terem me proporcionado tantos momentos felizes: Stephen, Juliana, Fernanda, Bia, Vanessa, Maduka, Rossana, Tiago, Eveline, Graziela Hagihara, Graziela Ceravolo, Rodrigo, Gisele, Paula, Cíntia, Simone, Luciana. Tudo fica mais fácil quando se tem pessoas tão especiais como vocês por perto. 
Finalmente, agradeço também às agências de financiamento que proporcionaram o suporte financeiro para o desenvolvimento desta pesquisa: a Fundação de Amparo à Pesquisa do Estado de São Paulo (Auxílio financeiro e bolsa de doutorado), o Instituto Nacional de Ciência e Tecnologia (INCT) para obesidade e diabetes (Auxílio financeiro) e o Conselho Nacional de Desenvolvimento Científico e Tecnológico (CNPq) (Auxílio financeiro, Edital Universal).

Há muito mais a quem agradecer...

A todos aqueles que, embora não nomeados, me brindaram com seus inestimáveis apoios em distintos momentos e por suas por suas presenças afetivas, o meu reconhecido e carinhoso MUITO OBRIGADA!!! 


\section{RESUMO}

Lobato NS. A obesidade diminui a resposta de artérias mesentéricas de resistência a agonistas canabinóides [tese (Doutorado em Farmacologia)]. São Paulo: Instituto de Ciências Biomédicas da Universidade de São Paulo; 2010.

O sistema endocanabinóide possui papel importante na regulação central e periférica da ingestão alimentar e da homeostase energética, além de apresentar pronunciados efeitos cardiovasculares. Na obesidade, estudos têm relatado que ocorre aumento de ativação deste sistema em tecidos que controlam o metabolismo energético. Entretanto, os efeitos da obesidade sobre as ações vasculares mediadas por agonistas canabinóides não foram ainda investigados. Portanto, o objetivo deste estudo foi investigar as implicações da obesidade para a resposta mediada pelo agonista canabinóide anandamida em artérias mesentéricas de resistência. Utilizamos ratos obesos Zucker (OZRs) e seus respectivos controles da linhagem Zucker (LZRs) com 6-7 semanas de idade. A obesidade foi avaliada pelo peso corporal e pelo acúmulo de gordura visceral. A glicemia foi determinada em ratos submetidos à privação alimentar de 4 horas. A pressão arterial foi determinada por método indireto (pletismografia de cauda). A reatividade de artérias mesentéricas de resistência foi avaliada utilizando um miógrafo para estudo de tensão isométrica. Foram realizadas curvas concentração-efeito à anandamida, aos agonistas de receptores canabinóides CB1 (ACEA) e CB2 (JWH-015) e ao agonista de receptores vanilóides capsaicina em vasos com e sem endotélio. OZRs apresentaram redução do relaxamento dependente de endotélio à acetilcolina e aumento da contração à fenilefrina. A incubação com anandamida corrigiu estas alterações. A anandamida, os agonistas CB1 e CB2, assim como a capsaicina, promoveram vasodilatação, que foi menor em artérias mesentéricas com endotélio de OZRs quando comparados aos LZRs. A expressão protéica dos receptores CB1 e CB2 foi menor em artérias mesentéricas de OZRs. A localização desses receptores (por imunofluorescência) indicou redução na expressão de ambos tanto no endotélio quanto no músculo liso vascular de OZRs. A incubação de artérias mesentéricas com o bloqueador de receptores vanilóides ou com o antagonista de receptores do peptídeo relacionado 
ao gene da calcitonina (CGRP) diminuiu a resposta à anandamida nos dois grupos experimentais, porém, essa redução foi mais pronunciada em LZRs. A incubação com L-NAME (inibidor da óxido nítrico sintase), apamina e caribidotoxina (bloqueadores de canais de $\mathrm{K}+$ ), indometacina (inibidor da cilooxigenase) ou AM404 (inibidor do transporte de canabinóides) reduziu a vasodilatação à anandamida apenas em LZRs. A resposta à anandamida em OZRs foi corrigida pelos agentes: URB597 (inibidor da degradação de anandamida), forskolin (ativador da via do CAMP), AICAR (ativador da AMPK) ou Pd 98059 (inibidor da ERK1/2). A incubação com anandamida aumentou a fosforilação da AMPK, da ACC e da eNOS em LZRs, mas reduziu em OZRs. A expressão da forma fosforilada da ERK1/2 foi maior em vasos de OZRs. A incubação com anandamida aumentou a fosforilação da ERK1/2 em LZRs e a potencializou em OZRs. Em conclusão, demonstramos que a obesidade diminui o relaxamento a agonistas canabinóides. Os mecanismos envolvidos nesta alteração incluem: redução da expressão dos receptores canabinóides CB1 e CB2; prejuízo das vias de sinalização mediadas pela ativação de receptores vanilóides; redução da captação e aumento da degradação de anandamida; redução da ativação da AMPK e da eNOS e aumento da ativação da ERK $1 / 2$.

Palavras-Chave: Obesidade. Sistema endocanabinóide. Anandamida. Artérias mesentéricas de resistência. 


\section{ABSTRACT}

Lobato NS. Obesity decreases the response of resistance mesenteric arteries to cannabinoid agonists [Ph.D. thesis (Pharmacology)]. São Paulo: Instituto de Ciências Biomédicas da Universidade de São Paulo; 2010.

The endocannabinoid system has an important role in the regulation of central and peripheral food intake and energy homeostasis. This system has also pronounced cardiovascular effects. A number of studies have shown that obesity is associated with increased activity of the endocannabinoid system in tissues that control the energy homeostasis. However, the effects of obesity on the vascular actions promoted by cannabinoid agonists have not been elucidated. Therefore, the aim of the present study was to investigate the implications of obesity for the vascular relaxation mediated by anandamide, a cannabinoid agonist, in resistance mesenteric arteries. Young obese Zucker rats (OZRs) and their lean counterparts (LZRs) were studied at 6- to 7-week-old. Obesity was evaluated by increase in body weight and visceral fat accumulation. Glycemia was determined in rats submitted to food deprivation (4 hours). Blood pressure was assessed by an indirect tail cuff metod. The vascular reactivity was evaluated in a small vessel myograph for isometric tension recording. Concentration-response curves to the cannabinoid agonist anandamide, to CB1 (ACEA) and CB2 (JWH-015) agonists as well as to the vanilloid agonist capsaicin were performed in endothelium-intact and endothelium-denuded vessels. OZRs displayed decreased endothelium-dependent relaxation to acetylcholine and increased contraction to phenilephrine. Incubation with anandamide corrected these alterations. The vasorelaxation induced by anandamide as well as by CB1, CB2 and TRPV-1 agonists was impaired in mesenteric arteries with intact endothelium from OZRs. The protein expression of CB1 and CB2 receptors was decreased in mesenteric arteries from OZRs. The localization of these receptors (immunofluorescence) indicated reduced expression of CB1 and CB2 receptors in both endothelium and vascular smooth muscle. Incubation of mesenteric arteries with either the vanilloid receptor blocker or the antagonist of the calcitonin gene related peptide (CGRP) receptor decreased anandamide responses in both 
groups; however, the reduction was higher in LZRs. Incubation with L-NAME (a nitric oxide synthase inhibitor), apamin and charybdotoxin $\left(\mathrm{K}^{+}\right.$channel blockers), indomethacin (cyclooxygenase inhibitor) or AM404 (cannabinoid transport inhibitor) reduced the relaxation induced by anandamide only in LZRs. The decreased response to anandamide in OZRs was corrected by the agents: URB597 (inhibitor of anandamide degradation), forskolin (CAMP pathway activator), AICAR (AMPK activator) or Pd 98059 (ERK1/2 inhibitor). Incubation of mesenteric arteries with anandamide evoked AMPK, acetyl CoA carboxylase and endothelial nitric oxide synthase phosphorylation in LZRs, whereas it decreased the phosphorylation of these proteins in OZRs. Basal ERK1/2 phosphorylation was increased in vessels from OZRs. Incubation with anandamide increased ERK1/2 phosphorylation in LZRs, and this effect was potentiated in OZRs. In conclusion, this study demonstrated that obesity decreases the relaxation to cannabinoid agonists. The mechanisms involved in this alteration include: reduction of CB1 and CB2 cannabinoid receptors expression; impairment of signaling pathways mediated by vanilloid receptors activation; reduction of uptake and increase of anandamide degradation; reduction of AMPK and eNOS activation and increase in ERK1/2 activation.

Key Words: Obesity. Endocannabinoid system. Anandamide. Resistance mesenteric arteries. 


\section{LISTA DE ILUSTRAÇÕES}

Figura 1 - Esquema ilustrativo dos mecanismos gerais envolvidos no relaxamento à anandamida 24

Figura 2 - Esquema ilustrativo da preparação em miógrafo para vasos de resistência isolados .36

Figura 3 - llustração do procedimento de normalização .37

Figura 4 - Contração ao cloreto de potássio em artérias mesentéricas de resistência de ratos controles Zucker e obesos Zucker.

Figura 5 - Curvas concentração-efeito à acetilcolina na ausência e na presença de anandamida em artérias mesentéricas de resistência de ratos controles Zucker e obesos Zucker. 46

Figura 6 - Curvas concentração-efeito à fenilefrina na ausência e na presença de anandamida em artérias mesentéricas de resistência de ratos controles Zucker e obesos Zucker.

Figura 7 - Curvas concentração-efeito à anandamida em artérias mesentéricas de resistência com e sem endotélio de ratos controles Zucker e obesos Zucker. .50

Figura 8 - Curvas concentração-efeito aos agonistas específicos de receptores canabinóides CB1 e CB2 em artérias mesentéricas de resistência com e sem endotélio de ratos controles Zucker e obesos Zucker

Figura 9 - Curvas concentração-efeito à anandamida na ausência e na presença de antagonistas específicos dos receptores canabinóides CB1 ou CB2 em artérias mesentéricas de resistência de ratos controles Zucker e obesos Zucker .53

Figura 10 - Curvas concentração-efeito à anandamida na ausência e na presença de bloqueadores de receptores vanilóides em artérias mesentéricas de resistência de ratos controles Zucker e obesos Zucker.

Figura 11 - Curvas concentração-efeito à anandamida na ausência e na presença de antagonistas dos receptores do peptídeo relacionado ao gene da calcitonina e da substância $P$ em artérias mesentéricas de resistência de ratos controles Zucker e obesos Zucker.

Figura 12 - Curvas concentração-efeito à capsaicina em artérias mesentéricas de resistência de ratos controles Zucker e obesos Zucker .58 
Figura 13 - Curvas concentração-efeito à anandamida na ausência e na presença de inibidores da óxido nítrico sintase e da ciclooxigenase e de bloqueadores de canais de $\mathrm{K}^{+}$em artérias mesentéricas de resistência de ratos controles Zucker e obesos Zucker.

Figura 14 - Curvas concentração-efeito à anandamida na ausência e na presença dos inibidores do transporte e da degradação de anandamida em artérias mesentéricas de resistência de ratos controles Zucker e obesos Zucker

Figura 15 - Curvas concentração-efeito à anandamida na ausência e na presença do ativador da via do AMP cíclico, do inibidor da adenilil ciclase e do ativador da quinase ativada por AMP, em artérias mesentéricas de resistência de ratos controles Zucker e obesos Zucker

Figura 16 - Curvas concentração-efeito à anandamida na ausência e na presença do inibidor da ERK1/2 em artérias mesentéricas de resistência de ratos controles Zucker e obesos Zuckers .65

Figura 17 - Análise da expressão protéica por western blotting dos receptores canabinóides CB1 e CB2, e do receptor vanilóide TRPV-1 em artérias mesentéricas de ratos controles Zucker e obesos Zuckers.

Figura 18 - Western blotting para a proteína quinase ativada por AMP e para a acetil coA carboxilase em artérias mesentéricas de ratos controles Zucker e obesos Zuckers com endotélio, submetidas ou não à incubação com anandamida. .68

Figura 19 - Western blotting para a proteína ERK1/2 em artérias mesentéricas de ratos controles Zucker e obesos Zuckers com endotélio, submetidas ou não à incubação com anandamida.

Figura 20 - Western blotting para a proteína eNOS em artérias mesentéricas de ratos controles Zucker e obesos Zuckers com endotélio, submetidas ou não à incubação com anandamida .70

Figura 21 - Imagens de microscopia confocal com a localização dos receptores canabinóides CB1 e CB2 em artérias mesentéricas com endotélio de ratos controles Zucker e obesos Zuckers .72 


\section{LISTA DE TABELAS}

Tabela 1 - Características gerais de ratos Zucker controles e obesos Zucker .43

Tabela 2 - Diâmetro luminal efetivo das artérias mesentéricas de resistência de ratos controles Zucker e obesos Zucker

Tabela 3 - Efeito da incubação com anandamida sobre a resposta máxima à acetilcolina em artérias mesentéricas de resistência de ratos controles Zucker e obesos Zucker

Tabela 4 - Efeito da incubação com anandamida sobre a resposta máxima à fenilefrina em artérias mesentéricas de resistência de ratos controles Zucker e obesos Zucker.

Tabela 5 - Resposta à anandamida e aos agonistas canabinóides CB1 e CB2 em artérias mesentéricas de resistência de ratos controles Zucker e obesos Zucker ....52 Tabela 6 - Participação dos receptores canabinóides CB1 e CB2 e do receptor vanilóide TRPV-1 na resposta à anandamida em artérias mesentéricas de resistência de ratos controles Zucker e obesos Zucker .55

Tabela 7 - Participação do receptor do peptídeo relacionado ao gene da calcitonina e do receptor da substância $P$ na resposta à anandamida em artérias mesentéricas de resistência de ratos controles Zucker e obesos Zucker.

Tabela 8 - Resposta à capsaicina em artérias mesentéricas de resistência de ratos controles Zucker e obesos Zucker

Tabela 9 - Participação dos fatores relaxantes derivados do endotélio na resposta à anandamida em artérias mesentéricas de resistências de ratos controles Zucker e obesos Zucker.

Tabela 10 - Participação dos mecanismos de transporte e de metabolização da anandamida em artérias mesentéricas de resistência de ratos controles Zucker e obesos Zucker

Tabela 11 - Participação de vias de sinalização intracelulares na resposta à anandamida em artérias mesentéricas de resistência isoladas de ratos controles Zucker e obesos Zucker. .66 


\section{LISTA DE ABREVIATURAS E SIGLAS}

2-AG 2-araquidonoilglicerol

AA Ácido araquidônico

ACC Acetil CoA carboxilase

ACEA Araquidonil-2-cloroetilamida

ACh Acetilcolina

AICAR Aminoimidazol carboxamida ribonucleotídeo

AMPK Proteína quinase ativada pelo monofosfato de adenosina

Ang II Angiotensina II

ANOVA Análise de variância

ATP Trifosfato de adenosina

BCA Ácido bicincônínico

BSA Albumina de soro fetal bovino

$\mathrm{Ca}^{2+} \quad$ Cálcio

$\mathrm{CaCl}_{2} \quad$ Cloreto de Cálcio

cAMP Monofosfato de adenosina cíclico

cGMP Monofosfato de guanosina cíclico

CGRP Peptídeo relacionado ao gene da calcitocina

$\mathrm{CO}_{2} \quad$ Dióxido de carbono

COX Ciclooxigenase

DAGs Diacilgliceróis

DAPI 4'-6'-diamidino-2-fenil-indol

dL Decilítro

DTT Ditiotreitol

$\mathrm{EC}_{50} \quad$ Concentração que promove $50 \%$ da resposta máxima

EDCF Fatores contráteis derivados do endotélio

EDHF Fator hiperpolarizante derivado do endotélio

EDRF Fatores relaxantes derivados do endotélio

EDTA Ácido etilenodiamino tetra-acético

eNOS Óxido nítrico sintase endotelial

epm Erro padrão da média 


\begin{tabular}{|c|c|}
\hline ERK $1 / 2$ & Quinases 1 e 2 reguladas por sinal extracelular \\
\hline EROs & Espécies reativas de oxigênio \\
\hline ET-1 & Endotelina - 1 \\
\hline FAAH & Hidrolase de amida de ácido graxo \\
\hline FE & Fenilefrina \\
\hline g & Gramas \\
\hline GTP & Trifosfato de guanosina \\
\hline h & Horas \\
\hline HDL & Lipoproteína de alta densidade \\
\hline IC & Circunferência interna \\
\hline Indo & Indometacina \\
\hline JNK & Quinase do terminal c-jun \\
\hline JWH-015 & (2-metil-1-propil-1H-indol-3-il)-1-naftalenilmetanona \\
\hline $\mathrm{K}^{+}$ & Potássio \\
\hline KCL & Cloreto de potássio \\
\hline L-arg & L-arginina \\
\hline L-NAME & Éster de N-metil-L-arginina \\
\hline LZRs & Lean Zucker rats \\
\hline MAGL & lipase de monoacilglicerol \\
\hline MAPK & Proteína quinase ativada por mitógeno \\
\hline $\mathrm{mg}$ & Miligrama \\
\hline $\mathrm{MgSO}_{4}$ & Sulfato de magnésio \\
\hline $\mathrm{mmHg}$ & Milímetro de mercúrio \\
\hline $\mathrm{NaCl}$ & Cloreto de sódio \\
\hline $\mathrm{NaHCO}_{3}$ & Bicarbonato de sódio \\
\hline NArPE & $\mathrm{N}$-araquiidonoil-fosfatidiletanolamina \\
\hline NO & Óxido nítrico \\
\hline NOS & Óxido nítrico sintase \\
\hline $\mathrm{O}^{2-}$ & Ânion superóxido \\
\hline OZRs & Obese Zucker rats \\
\hline PBS & Tampão de fosfato salina \\
\hline $\mathrm{pD}_{2}$ & Logaritmo negativo da $\mathrm{EC}_{50}$ \\
\hline PFA & Paraformaldeído \\
\hline
\end{tabular}


PGs Prostaglandinas

$\mathrm{PGI}_{2} \quad$ Prostaciclina

PKA Proteína quinase $\mathrm{A}$

PMSF Fluoreto de fenilmetil-sulfonil

$\mathrm{R}_{\text {MAX }} \quad$ Resposta máxima

Ser Serina

THC [delta]-9-tetrahidrocanabinol

Thr Treonina

TRPV-1 Receptor de potencial transitório de vanilóide tipo-1

$\mathrm{TXA}_{2} \quad$ Tromboxano $\mathrm{A}_{2}$

VLDL Lipoproteína de muito baixa densidade 


\section{SUMÁRIO}

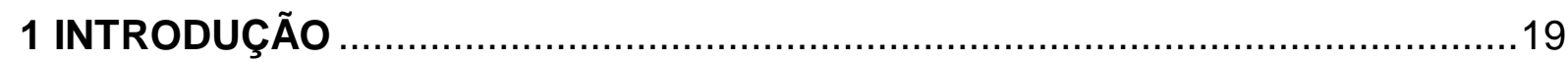

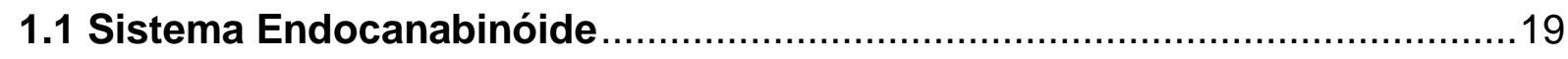

1.2 Ações Cardiovasculares dos Canabinóides ............................................22

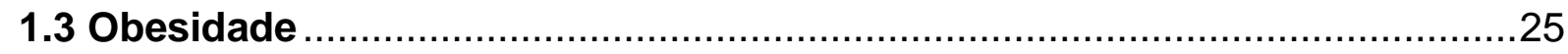

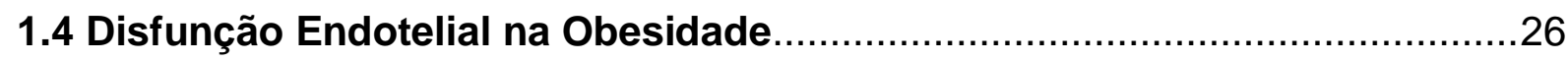

1.5 O Modelo de Obesidade Monogenética Zucker ......................................27

1.6 Ativação do Sistema Endocanabinóide na Obesidade ………....................29

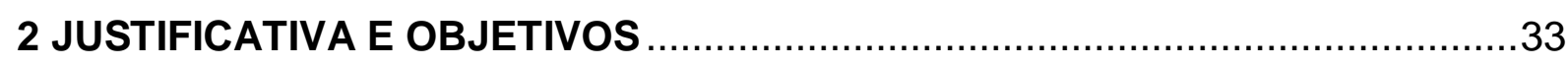

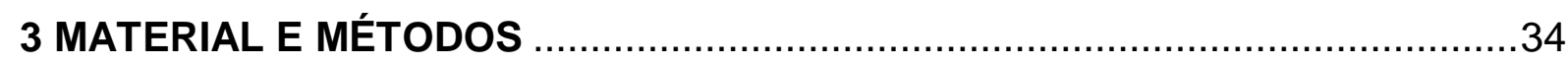

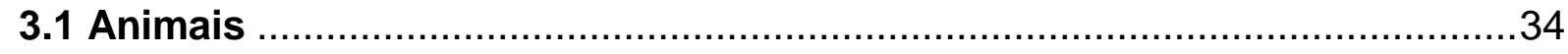

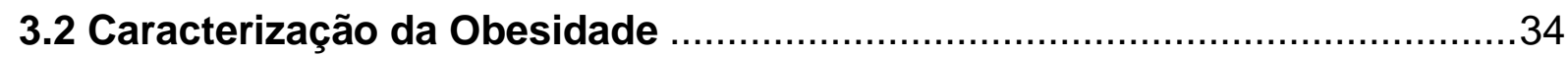

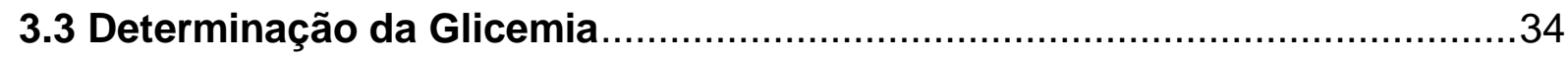

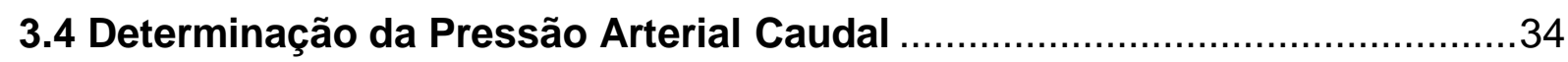

3.5 Estudo da Reatividade Vascular em Artérias Mesentéricas de Resistência 35

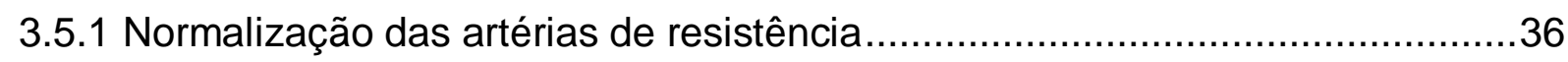

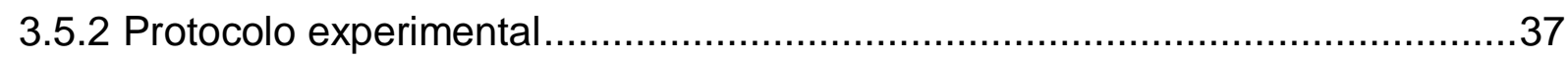

3.6 Quantificação Protéica por Western Blotting ................................................39

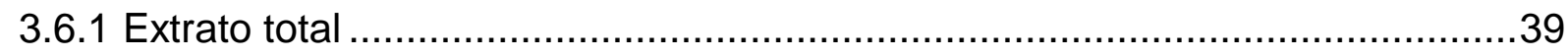

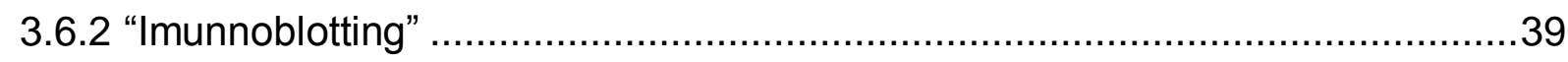

3.7 Imunofluorescência e Microscopia Confocal ........................................... 40

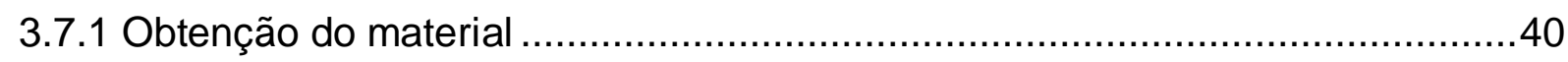

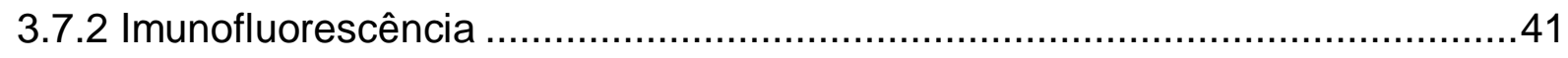

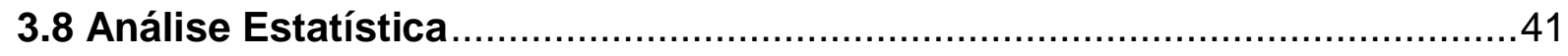

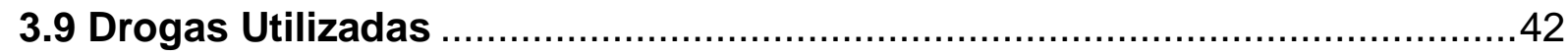

4 RESULTADOS

4.1 Características Gerais do Modelo de Obesidade Monogenética Zucker......43

4.2 Medida do Diâmetro Luminal Efetivo das Artérias Mesentéricas ................44

4.3 Avaliação da Contração ao $\mathrm{KCl}$ em Artérias Mesentéricas de Resistência. 45 4.4 Avaliação do Relaxamento Dependente de Endotélio à ACh em Artérias Mesentéricas de Resistência e o Efeito da Incubação com Anandamida..........46 
4.5 Avaliação da Resposta Contrátil à FE em Artérias Mesentéricas de Resistência e o Efeito da Incubação com Anandamida .................................48 4.6 Avaliação do Relaxamento à Anandamida em Artérias Mesentéricas de Resistência .50

4.7 Avaliação do Relaxamento aos Agonistas CB1 e CB2 em Artérias Mesentéricas de Resistência.

4.8 Papel dos Receptores Canabinóides CB1 e CB2 no Relaxamento Promovido pela Anandamida .53

4.9 Papel dos Receptores Vanilóides (TRPV-1) na Resposta à Anandamida ....54 4.10 Participação do Receptor do Peptídeo Relacionado ao Gene da Calcitonina e do Receptor da Substância $P$ na Resposta à Anandamida ..........56

4.11 Avaliação da Resposta Vasodilatadora à Capsaicina .............................58

4.12 Participação dos EDRFs na Resposta à Anandamida ............................60

4.13 Participação dos Mecanismos de Transporte e de Metabolização da Anandamida em LZRs e OZRs ...........................................................62

4.14 Participação da Via do cAMP e da AMPK na Resposta à Anandamida ......64

4.15 Participação da ERK1/2 na Resposta à Anandamida .............................65

4.16 Análise da Expressão Protéica dos Receptores Canabinóides (CB1 e CB2) e do Receptor Vanilóide (TRPV-1) ...........................................................67

4.17 Efeito da Anandamida sobre a Fosforilação da AMPK e da ACC .............68

4.18 Efeito da Anandamida sobre a Fosforilação da ERK 1/2 ........................69

4.19 Efeito da Anandamida sobre a Fosforilação da eNOS ..........................70

4.20 Localização dos Receptores Canabinóides CB1 e CB2 ...........................71

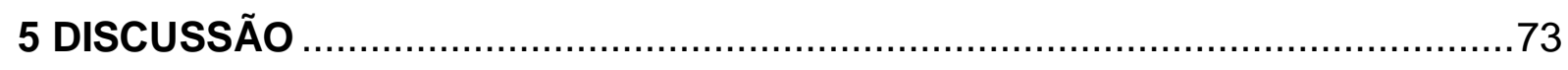

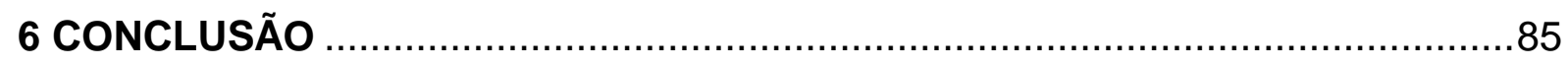

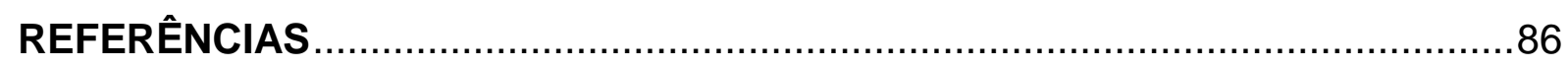

ANEXO A - Obesity decreases the vascular relaxation to anandamide, a cannabinoid agonist. NS Lobato, FP Filgueira, R Prakash, FR Giachini, A Ergul, MHC Carvalho, RC Webb, RC Tostes, ZB Fortes ....................................101

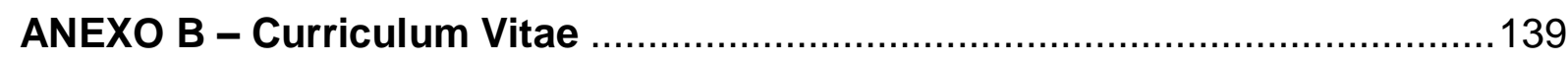




\section{INTRODUÇÃO}

\subsection{Sistema Endocanabinóide}

O sistema endocanabinóide é um sistema endógeno que possui papel importante na regulação central e periférica da ingestão alimentar e da homeostase energética ${ }^{1}$. A descoberta desse sistema iniciou-se a partir de estudos investigando os efeitos do uso da planta Cannabis sativa. A mistura das folhas e flores desta planta é denominada marijuana ou maconha. Considerada como uma droga de uso recreacional na maior parte do mundo, a Cannabis exerce ainda uma série de outros efeitos incluindo analgesia, ação antiinflamatória, imunossupressão, efeito anticonvulsivante, alívio da pressão intra-ocular no glaucoma, efeito antiemético e orexígeno ${ }^{2}$.

Por muitos séculos as bases biológicas e moleculares do uso das preparações da planta Cannabis sativa permaneceram não explicadas. Em 1965, o composto [delta]-9-tetrahidrocanabinol (THC) foi isolado e identificado como sendo o principal metabólito secundário desta planta ${ }^{3}$. A identificação do THC ajudou a explicar a maior parte das ações farmacológicas da planta ${ }^{1-2}$.

Como outras drogas, o THC exerce seus efeitos ligando-se a receptores localizados na superfície de neurônios e de outras células. Esses sítios de ligação do componente ativo da maconha foram identificados no cérebro em $1988{ }^{4}$. Essa descoberta abriu caminho para a identificação e clonagem dos receptores específicos para o composto THC (CB1 e CB2), que foram clonados em 1990 e 1993, respectivamente ${ }^{5-6}$. Este achado foi logo seguido pela descoberta de que esses receptores são alvos de moléculas regulatórias de ocorrência natural no organismo, denominadas endocanabinóides. Em 1992, o primeiro composto endocanabinóide foi identificado, o composto denominado anandamida (araquidonoil etanolamida), principal ligante endógeno do sistema endocanabinóide ${ }^{7}$. Este achado foi logo seguido pela identificação das propriedades canabimiméticas de um metabólito endógeno já conhecido, o composto 2-araquidonoilglicerol (2-AG) ${ }^{8}$. Embora diversos outros compostos similares aos endocanabinóides tenham sido identificados nos últimos dez anos, a anandamida e o 2-AG permanecem como os 
compostos canabinóides cuja atividade farmacológica tem sido mais intensamente investigada, sendo assim considerados como os principais ligantes endógenos do sistema endocanabinóide.

Os estudos avaliando as vias biossintéticas e catabólicas para a anandamida e o 2-AG começaram imediatamente após a descoberta destes compostos. O composto $\mathrm{N}$-araquiidonoil-fosfatidiletanolamina (NArPE) foi identificado como sendo o precursor biossintético da anandamida, e os diacilgliceróis (DAGs) com o ácido araquidônico (AA) na posição 2, como sendo os mais prováveis compostos a partir dos quais o 2-AG é gerado. O NArPE é produzido a partir da transferência do AA de fosfolipídios para o átomo de nitrogênio do composto fosfatidiletanolamina. O precursor DAG para o composto 2-AG é produzido pela hidrólise, catalisada pela fosfolipase- $C$, do fosfatidilinositol ou da hidrólise do ácido fosfatídico. Tanto a anandamida quanto o 2-AG são inativados principalmente por hidrólise enzimática pelas enzimas hidrolase de amida de ácido graxo (FAAH) ${ }^{9}$ e lipase de monoacilglicerol (MAGL), respectivamente ${ }^{10-11}$.

Processos específicos através dos quais os endocanabinóides são captados pelas células após a ativação de receptores, ou liberados das células logo após a biossíntese intracelular, também já foram descritos. Estes processos funcionam na direção do gradiente de concentração dos endocanabinóides através da membrana plasmática ${ }^{12}$, porém, não foram ainda identificados do ponto de vista molecular. As enzimas envolvidas na degradação de canabinóides (FAAH e MAGL) e o receptor CB1 parecem não estarem envolvidos nestes processos de captação dos compostos canabinóides pela célula.

Além de ativar receptores CB1 e CB2, está bem estabelecido que os compostos canabinóides, principalmente a anandamida, ativam o receptor de potencial transitório de vanilóide tipo-1(TRPV-1), um canal catiônico não seletivo que pertence à família de receptores de potencial transitório, que é ativado pelo calor, pelo baixo $\mathrm{pH}$ e pela capsaicina, componente ativo da pimenta ${ }^{13}$.

Os estudos realizados imediatamente após a caracterização molecular dos receptores $\mathrm{CB} 1$ e CB2 estabeleceram a distribuição dos mesmos em diversos tecidos, com alta abundância do receptor CB1 no cérebro e dos receptores CB2 em células imunes. Entretanto, sabe-se atualmente que ambos os receptores, principalmente o $\mathrm{CB1}$, encontra-se muito mais amplamente distribuído do que originalmente se acreditava. No sistema nervoso central, o receptor CB1 está 
localizado na região anterior cerebral, no gânglio basal, cerebelo, hipocampo, hipotálamo e córtex cerebral ${ }^{14-16}$, e perifericamente no sistema nervoso ${ }^{17-18}$, no trato gastrointestinal ${ }^{19}$, no tecido adiposo ${ }^{20}$, no fígado ${ }^{21}$, no músculo esquelético ${ }^{22-23} \mathrm{e}$ no pâncreas ${ }^{24}$. O receptor CB2 é expresso primariamente nas células imunes ${ }^{17}$, mas também pode ser encontrado no baço, no timo, no pâncreas, nos adipócitos e, em menor grau, no sistema nervoso central ${ }^{6,17}$. A ampla expressão dos receptores CB1 e CB2 explica a lista cada vez maior de funções atribuídas ao sistema endocanabinóide.

Pouco é conhecido sobre os mecanismos envolvidos na síntese e nas ações dos compostos endocanabinóides em tecidos periféricos ${ }^{25}$. Como ligantes de receptores acoplados à proteína $G$, inicialmente foi descrito que seus efeitos biológicos em células neuronais são exercidos pela ativação de proteínas $G$ heterodiméricas do tipo Gi/0. Como conseqüência desse acoplamento ocorreria inibição da adenilil ciclase e diminuição de monofosfato de adenosina cíclico (cAMP) nestes tecidos. Além disso, receptores CB1 e CB2 regulam a fosforilação e ativação de diversos membros da família das proteínas quinases ativadas por mitógenos (MAPKs), incluindo as quinases 1 e 2 reguladas por sinal extracelular (ERK1/2), a p38MAPK e a quinase do terminal c-jun (JNK). O receptor CB1 pode ainda se acoplar a canais de cálcio $\left(\mathrm{Ca}^{2+}\right)$ operados por voltagem do tipo $\mathrm{N}, \mathrm{P}$ ou $\mathrm{Q}$, inativando-os, ou a canais retificadores de potássio $\left(\mathrm{K}^{+}\right)$, ativando-os. O receptor CB1 pode também induzir aumento do $\mathrm{Ca}^{2+}$ intracelular pela ativação da fosfolipase $\mathrm{C}$ do tipo beta, um processo que depende da ativação de proteína $\mathrm{G}$.

Assim, as diversas atividades biológicas moduladas pelos receptores canabinóides são garantidas por vias de sinalização bem complexas. As MAPKs medeiam, por exemplo, a regulação da sobrevivência ou morte celular e o metabolismo glicêmico pelos canabinóides. Já os canais iônicos estão envolvidos na regulação da liberação de neurotransmissores pelos canabinóides. Um segundo nível de complexidade da sinalização celular mediada pelos canabinóides surge da capacidade de uma única proteína $G$, através de suas subunidades a ou $\beta$ e $\gamma$, direcionar a atividade de efetores intracelulares não relacionados. Isso quer dizer que a ativação do receptor CB1, por exemplo, pode simultaneamente levar à inibição da adenilil ciclase pela subunidade $G \alpha$ e à ativação de diferentes membros da cascata das MAPKs pelas subunidades $\mathrm{G} \beta \mathrm{Y}^{26}$. 


\subsection{Ações Cardiovasculares dos Canabinóides}

Os compostos canabinóides apresentam pronunciados efeitos cardiovasculares, os quais têm sido intensamente estudados. Estes efeitos são complexos e parecem ser alterados em diferentes condições patológicas. A anandamida apresenta ações pleiotrópicas sobre o sistema cardiovascular in vivo. Em ratos anestesiados, este agonista causa uma breve resposta pressora seguida de resposta depressora mais prolongada ${ }^{27}$. Em camundongos anestesiados a anandamida e o THC promovem bradicardia e hipotensão ${ }^{28}$. Estes efeitos são menos pronunciados ou ausentes nos animais quando os mesmos não se encontram anestesiados, mas são potencializados na hipertensão ${ }^{29}$. Os mecanismos envolvidos neste último efeito envolvem a diminuição da atividade simpática pela inibição da liberação de noradrenalina a partir de terminais nervosos simpáticos após a ativação de receptores $\mathrm{CB} 1$ pré-sinápticos, bem como efeito direto sobre a vasculatura e o miocárdio ${ }^{28}$. Em humanos, tanto o cigarro da maconha quanto a administração intravenosa de THC, resultaram em vasodilatação periférica e taquicardia, que evoluíram para a queda da resistência periférica e, conseqüentemente, da pressão arterial ${ }^{30}$.

As ações vasculares dos compostos canabinóides variam dependendo da espécie e do território vascular estudado ${ }^{13,31-34}$. A anandamida pode promover relaxamento vascular tanto por atuar nas células endoteliais quanto por agir diretamente no músculo liso vascular. Diversos mecanismos podem estar envolvidos nestas ações (Figura 1).

Estudos utilizando vasos sanguíneos isolados mostram que tanto os canabinóides endógenos quanto os exógenos promovem vasodilatação. Diversos grupos têm relatado que o efeito vasodilatador da anandamida depende da liberação de fatores relaxantes derivados do endotélio (EDRFs) ${ }^{32,35}$. Em ratos, demonstrou-se que a exposição de cultura de células endoteliais renais à anandamida estimula a liberação de óxido nítrico (NO), enquanto a presença de éster de N-metil-L-arginina (L-NAME), inibidor da enzima óxido nítrico sintase (NOS), abole essa resposta ${ }^{36}$.

Outro vasodilatador dependente de endotélio, o fator hiperpolarizante derivado do endotélio (EDHF) (Figura 1), tem sido sugerido como um dos envolvidos na vasodilatação induzida pela anandamida ${ }^{32,37-38}$. Um estudo indicou ainda que a anandamida induz hiperpolarização de membrana por meio de outro intermediário 
diferente do EDHF, mas ainda desconhecido ${ }^{39}$. Sugere-se que, em artérias mesentéricas de coelho, o componente endotelial do relaxamento vascular promovido pela anandamida se difunde para as células do músculo liso vascular por meio de junções comunicantes ${ }^{34}$. Demonstrou-se ainda in vitro que a anandamida promove relaxamento vascular que, em artéria mesentérica e coronária, foi dependente do metabolismo do $A A^{36}$.

A anandamida pode também exercer alguns de seus efeitos diretamente sobre o músculo liso vascular via receptores $\mathrm{CB} 1$, independentemente da presença do endotélio ${ }^{40}$. Dentre os mecanismos envolvidos, inserem-se a inibição da abertura de canais de $\mathrm{Ca}^{2+}$ do tipo $\mathrm{L}^{40}$, a redução dos estoques de $\mathrm{Ca}^{2+}$ intracelulares ${ }^{39}$, bem como a modulação da entrada de $\mathrm{Ca}^{2+}$ através de canais de $\mathrm{Ca}^{2+}$ operados por voltagem ${ }^{40}$.

Outro mecanismo independente do endotélio responsável pelo efeito vasodilatador da anandamida é a liberação do peptídeo relacionado ao gene da calcitonina (CGRP), um vasodilatador liberado por nervos sensoriais perivasculares, que atua sobre receptores no músculo liso ou no endotélio vascular ${ }^{13,41}$. Propõe-se que a vasodilatação induzida pelo CGRP seja mediada por dois mecanismos: um deles é a estimulação da enzima adenilil ciclase no músculo liso, com subseqüente acúmulo de cAMP ${ }^{42}$. O outro mecanismo é a ativação de canais de $\mathrm{K}^{+}$nas células de músculo liso vascular ${ }^{43}$, com conseqüente vasodilatação.

Propõe-se que os efeitos vasodilatadores dos compostos canabinóides sejam mediados pela ativação de receptores CB1 e de receptores vanilóides ${ }^{37,44}$. O papel dos receptores $\mathrm{CB} 2$ no efeito relaxante promovido pelos endocanabinóides não foi ainda descrito.

A relevância fisiológica dos efeitos cardiovasculares dos endocanabinóides não está totalmente esclarecida. Estudos sugerem que estes compostos apresentam papel mais importante em condições patológicas. Neste sentido, em um modelo animal de choque hemorrágico, Wagner e colaboradores (1997) ${ }^{45}$ demonstraram que há liberação de anandamida por macrófagos ativados, a qual pode contribuir para a hipotensão observada. Similarmente, no choque endotóxico, a síntese de 2AG nas plaquetas e de anandamida nos macrófagos é aumentada ${ }^{46}$. A liberação de anandamida por neurônios centrais sob condições de hipóxia, levando à proteção contra a isquemia já foi também descrita ${ }^{40}$. Estudo recente demonstrou ainda que a anandamida reduz a contratilidade cardíaca na hipertensão. Adicionalmente, a 
potencialização desta ação cardíaca bem como da ação vasodilatadora da anandamida após bloqueio de sua hidrólise pela enzima $\mathrm{FAHH}$, pode normalizar a pressão sanguínea nesta condição ${ }^{29}$. Em conjunto, esses dados indicam que 0 sistema endocanabinóide constitui um mecanismo importante no controle da função cardiovascular em condições patológicas.

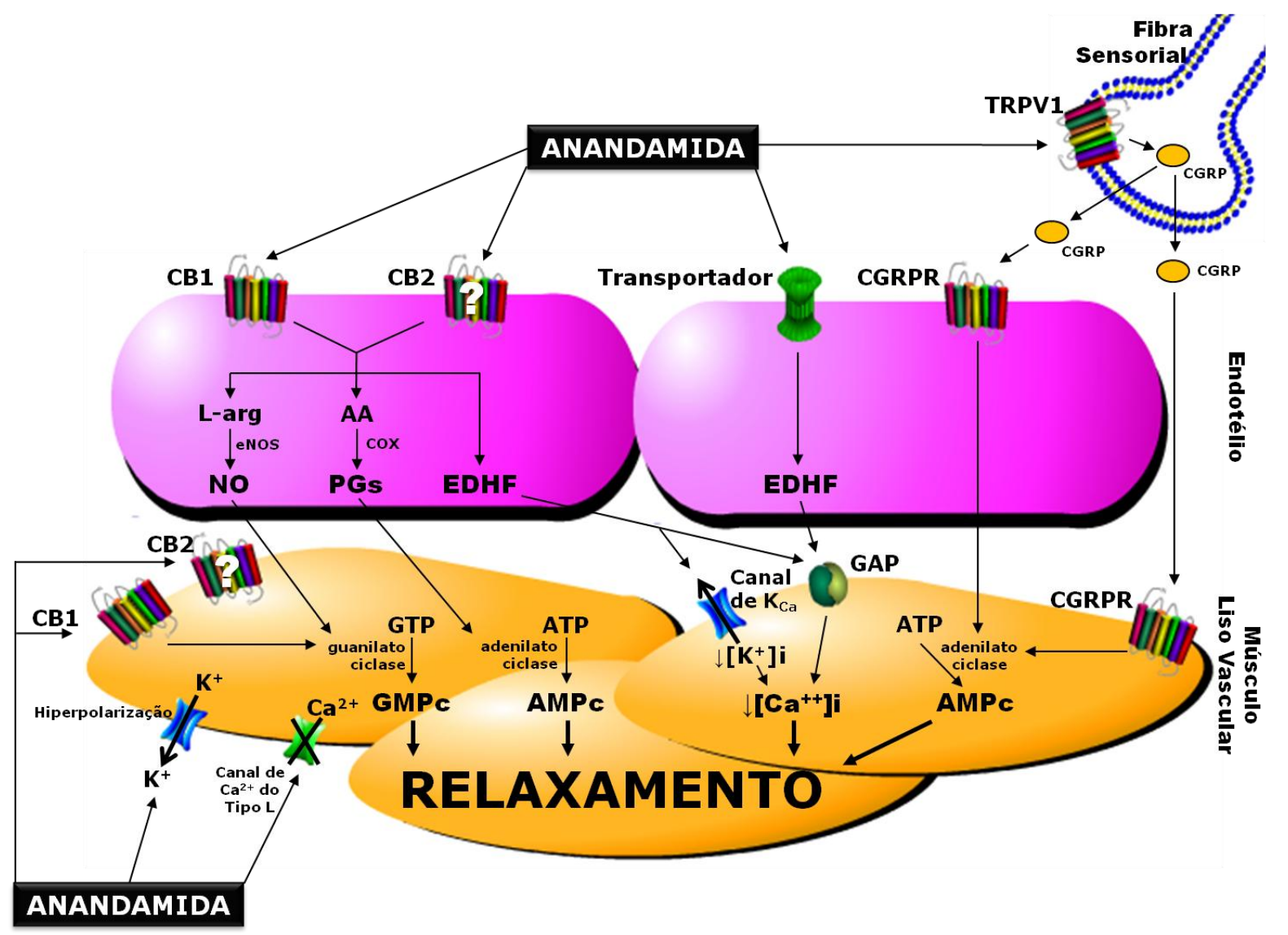

Figura 1 - Esquema ilustrativo dos mecanismos gerais envolvidos no relaxamento à anandamida. $\mathrm{CB} 1$ = receptor cannabinóide $1 ; \mathrm{CB} 2$ = receptor cannabinóide 2 ; $\mathrm{PGs}=$ prostaglandinas; eNOS = óxido nítrico sintase endotelial; L-arg = Larginina; $\mathrm{NO}=$ óxido nítrico; $\mathrm{EDHF}=$ fator hiperpolarizante derivado do endotélio; $A A$ = ácido araquidônico; $C O X=$ ciclooxigenase; GTP = trifosfato de guanosina; $\mathrm{cGMP}=$ monofosfato de guanosina cíclico; $\mathrm{ATP}=$ trifosfato de adenosina; $\mathrm{CAMP}=$ monofosfato de adenosina cíclico; $\mathrm{Ca}^{2+}=$ cálcio; $\mathrm{K}^{+}=$ potássio; CGRPR = receptor do peptídeo relacionado ao gene da calcitonina; GAP = junção comunicante.

\subsection{Obesidade}

A prevalência de obesidade aumentou de modo bastante acelerado a partir do final do século $X X$, tanto em países industrializados quanto em países em desenvolvimento, como é o caso do Brasil. Dados da Sociedade Brasileira de 
Endocrinologia e Metabolismo mostram que 18 milhões de brasileiros são obesos e que cerca de 70 milhões apresentam sobrepeso. Atualmente a obesidade é considerada uma das principais causas de morbidade e mortalidade em todo o mundo ${ }^{47}$.

A obesidade, de modo independente, ou em associação com outras doenças, é considerada um dos principais fatores de risco para o desenvolvimento de diabetes tipo 2, hipertensão, doença coronariana, certos tipos de câncer, complicações respiratórias, dentre outras. $O$ aumento da ingestão de alimentos calóricos e do estilo de vida sedentário com a conseqüente redução do gasto energético em indivíduos geneticamente predispostos são fatores fortemente implicados como causas primárias da epidemia mundial de obesidade ${ }^{48}$. 0 aumento da prevalência de obesidade não está restrito apenas à população adulta. Em diversas regiões do mundo o sobrepeso e a obesidade infantil têm aumentado substancialmente nos últimos 20 anos. Este quadro tem sido acompanhado pelo aumento concomitante de hipertensão, dislipidemia e diabetes tipo 2 , doenças que, anteriormente, eram quase que exclusivamente presentes apenas em adultos ${ }^{49}$.

O peso corporal é determinado por uma interação de fatores genéticos, ambientais e psicossociais que atuam por meio de mediadores fisiológicos que controlam a ingestão e o gasto energético. Embora as diferenças genéticas sejam de importância inquestionável, o desenvolvimento da obesidade é mais bem explicado pelas mudanças comportamentais e ambientais que resultaram dos avanços tecnológicos. Assim, a obesidade pode ser definida como uma condição na qual ocorre acúmulo de gordura corporal em tal extensão que pode afetar adversamente a saúde. O acúmulo de tecido adiposo branco, levando ao sobrepeso (índice de massa corporal $25-30 \mathrm{~kg} / \mathrm{m}^{2}$ ) e à obesidade (índice de massa corporal $\geq 30 \mathrm{~kg} / \mathrm{m}^{2}$ ), está relacionado com condições como dislipidemia, resistência à insulina e disfunção vascular, as quais contribuem para o desenvolvimento de diabetes tipo 2 e doenças cardiovasculares ${ }^{50}$.

Quando se associa a obesidade como fator de risco para complicações vasculares, é importante considerar não apenas a magnitude da obesidade, mas também, e talvez este constitua o parâmetro mais relevante, a distribuição de gordura corporal. Há diferenças no risco atribuível à obesidade baseado na heterogeneidade de localização do tecido adiposo entre indivíduos obesos. Neste sentido, em adição à gordura corporal total, o acúmulo de gordura intra-abdominal 
ou visceral tem sido considerado como fator de risco independente para doenças cardiovasculares. Estudos epidemiológicos têm demonstrado que a adiposidade visceral, avaliada pela razão cintura-quadril ${ }^{51-52}$ ou por tomografia computadorizada 53-54, está relacionada com doenças da artéria coronária, independentemente do índice de massa corporal.

\subsection{Disfunção Endotelial na Obesidade}

A obesidade está intimamente relacionada com disfunção endotelial. Demonstrou-se de forma bastante consistente que indivíduos obesos apresentam prejuízo na função arterial caracterizado pela redução da vasodilatação dependente de endotélio ${ }^{55}$. A disfunção endotelial na obesidade constitui um dos mecanismos pelos quais esta condição leva ao desenvolvimento de doenças cardiovasculares ${ }^{56}$.

O endotélio vascular representa papel importante na manutenção da homeostase cardiovascular. Além de proporcionar uma barreira física entre o lúmen e a parede do vaso, o endotélio regula ativamente o tônus vascular basal e a reatividade vascular em condições fisiológicas, respondendo a forças mecânicas e a mediadores neurohumorais, além de liberar uma variedade de fatores contráteis e relaxantes. Frente a estímulos específicos, as células endoteliais podem liberar EDRFs, como também fatores contráteis derivados do endotélio (EDCFs) ${ }^{57}$. Os EDRFs incluem o NO, a prostaciclina $\left(\mathrm{PGI}_{2}\right)$ e o EDHF. Os EDCFs compreendem a angiotensina II (Ang II), a endotelina-1 (ET-1), as espécies reativas de oxigênio (EROs) e os prostanóides vasoconstritores ${ }^{58}$. Em condições fisiológicas, o tônus vascular é garantido pelo equilíbrio exercido por estes fatores, especialmente os produtos da ciclooxigenase (COX), em conjunto com o NO e o EDHF. O desequilíbrio na produção e/ou liberação dos fatores envolvidos no relaxamento e na contração vasculares, com aumento de EDCFs e/ou diminuição dos EDRFs, caracteriza a disfunção endotelial ${ }^{59}$.

Os mecanismos que levam ao desenvolvimento da disfunção endotelial na obesidade não estão completamente esclarecidos. A perda da função modulatória do endotélio, com alterações na geração e/ou liberação dos mediadores envolvidos no relaxamento ${ }^{60}$, especialmente o $\mathrm{NO}$, e na contração vascular em resposta a estímulo por agentes vasoconstritores ${ }^{61}$, parece ter participação crítica no desenvolvimento desta alteração. 
Estudos demonstram também o papel importante do estresse oxidativo no desenvolvimento da disfunção vascular na obesidade. Um estudo clínico demonstrou que a diminuição da resposta vasodilatadora dependente de endotélio em indivíduos obesos está relacionada, ao menos em parte, ao estresse oxidativo, tendo-se em vista que a co-infusão de vitamina $C$ melhorou, embora não tenha normalizado completamente, a resposta à acetilcolina (ACh), um agente vasodilatador dependente de endotélio ${ }^{62}$. Estudos experimentais também demonstram que a obesidade é acompanhada por diminuição da vasodilatação dependente de NO, que pode ocorrer devido ao aumento da produção de EROs, como o ânion superóxido $\left(\mathrm{O}_{2}{ }^{-}\right)$, que inativa o NO. Estudo recente em nosso laboratório demonstrou que a obesidade promove aumento da resposta contrátil e redução da resposta vasodilatadora dependente de endotélio no leito arteriolar mesentérico isolado. Essas alterações foram relacionadas com redução da produção de NO, aumento da geração de EROs e redução da razão $\mathrm{PGI}_{2} / \mathrm{TXA}_{2}$ no leito arteriolar mesentérico ${ }^{63}$.

\subsection{Modelo de Obesidade Monogenética Zucker}

Existem atualmente diversos modelos de obesidade disponíveis, os quais têm sido propostos a fim de investigar a patogênese, bem como os aspectos metabólicos e vasculares envolvidos nesta condição. Os estudos em modelos animais têm sido bastante úteis no estabelecimento das causas e conseqüências da obesidade e podem, também, ter participação importante no desenvolvimento de procedimentos mais efetivos para a prevenção e o tratamento desta condição.

Alguns dos modelos experimentais utilizados ajudaram a esclarecer características monogenéticas da obesidade ${ }^{64-65}$. Para se elucidar, por exemplo, o mecanismo de ação da leptina e a resistência à insulina conseqüente à alteração na sinalização da leptina, a primeira alteração descrita foi uma mutação no cromossomo 6, que codifica o gene de síntese da leptina, o gene ob. A ausência de leptina nos camundongos ob/ob faz com que eles sejam hiperfágicos, diabéticos e obesos ${ }^{66}$. $\mathrm{Na}$ ocasião, ganhou força a hipótese de que a hipoleptinemia pudesse ser a maior determinante da obesidade. Entretanto, estudos posteriores mostraram que mutações no gene que determina a síntese do receptor de leptina promoviam aparecimento de resistência à insulina, hiperleptinemia e obesidade. São exemplos destes animais os ratos obesos Zucker (OZRs, fa/fa). Este modelo experimental 
auxiliou no desenvolvimento do conceito de resistência à ação hipotalâmica à leptina 67-68

O rato Zucker ( $\mathrm{fa} / \mathrm{fa}$ ) é um dos mais bem conhecidos e mais amplamente utilizados modelos de obesidade genética. A mutação do gene fa que determina a síntese do receptor de leptina foi descoberta por Zucker e Zucker $(1961,1963){ }^{69-70,}$ durante os cruzamentos das matrizes conhecidas como Sherman e Merck M (linhagem 13M) ${ }^{69-70}$. Os animais eram homozigotos para o alelo fa, que determinava a síntese de receptores de leptina não funcionais ( $\mathrm{fa} / \mathrm{fa}$ ) e se tornavam notavelmente obesos por volta da terceira e da quinta semana de vida. Na décima quarta semana de idade, a composição corporal dos OZRs já era correspondente a $40 \%$ de lipídeos e com 40 semanas eles chegavam a pesar duas vezes mais do que seus respectivos controles (Lean Zucker rats - LZRs) ${ }^{71}$. A obesidade nestes animais é herdada como uma herança recessiva mendeliana. Os animais afetados são hiperlipêmicos, hipercolesterolêmicos 70,72 e hiperinsulinêmicos ${ }^{71}$, além de desenvolverem hipertrofia e hiperplasia de adipócitos ${ }^{73}$. Além das alterações em parâmetros metabólicos, demonstrou-se que OZRs na fase adulta apresentam pressão arterial maior do que os controles ${ }^{74}$. Os ratos que apresentam genótipos homozigotos dominantes $(+/+)$ ou heterozigotos $(\mathrm{fa} /+)$ permanecem magros, normoglicêmicos e normotensos.

A mais valiosa contribuição do OZR tem sido sua utilização como modelo de obesidade humana que se estabelece na fase jovem da vida. Muitos investigadores têm utilizado este modelo para estudar o desenvolvimento, a etiologia, as patologias associadas, os possíveis tratamentos e os mecanismos envolvidos neste tipo de obesidade genética considerada de grau severo.

O OZR é significantemente hiperfágico quando comparado ao LZR, já com 17 dias de vida ${ }^{75}$ e esta diferença se torna mais significativa durante períodos de rápido crescimento, por exemplo, nas 16 primeiras semanas de vida ${ }^{76}$. É importante considerar que a hiperfagia não é necessária para a expressão do fenótipo obeso que OZRs apresentam. Isto é justificado a partir de observações de que uma das primeiras alterações observadas nos OZRs é o aumento da atividade da enzima lipase lipoprotéica no tecido adiposo, a qual está significantemente correlacionada com aumento da captação de triglicerídeos pelo tecido adiposo ${ }^{77}$. A atividade desta enzima já está elevada em OZRs aos doze dias de vida, período onde ainda não é possível identificar visualmente estes animais como obesos e a hiperfagia ainda não 
é identificada ${ }^{78}$. O aumento da atividade da lipase lipoprotéica precede também outras alterações presentes na obesidade em OZRs, tais como o aumento da lipogênese hepática e a hiperinsulinemia ${ }^{79}$.

Ao contrário de seu amplo uso como modelo de obesidade, os OZRs não têm sido extensivamente utilizados como modelo de diabetes tipo 2. Isto ocorre muito provavelmente porque esses animais são relativamente normoglicêmicos, desenvolvendo pequenos aumentos na glicemia apenas ocasionalmente ${ }^{69}$. A resistência à insulina e a hiperinsulinemia ocorrem na fase jovem dos ratos Zucker, seguida pela evolução para o prejuízo na capacidade secretória de insulina. A hiperglicemia, quando ocorre, se manifesta por volta da décima segunda semana de idade ${ }^{74}$. Porém, a presença de resistência à insulina já pode ser detectada nos animais com 6-7 semanas ${ }^{80}$, indicando que OZRs, na fase jovem, representam um modelo normotenso de obesidade e resistência à insulina.

\subsection{Ativação do Sistema Endocanabinóide na Obesidade}

Diversos estudos têm relatado consistentemente que ocorre aumento da ativação do sistema endocanabinóide na obesidade. De fato, o aumento dos níveis dos canabinóides endógenos anandamida e 2-AG no plasma de indivíduos obesos foi correlacionado com adiposidade visceral, sugerindo que o aumento da ativação do sistema endocanabinóide contribui para a obesidade e as desordens relacionadas a esta condição ${ }^{81}$. Estas evidências foram acompanhadas pelo desenvolvimento clínico de antagonistas do receptor CB1 para o tratamento da obesidade ${ }^{82}$, dislipidemia ${ }^{83}$, diabetes tipo $2^{84}$ e aterosclerose ${ }^{85}$. Estudos sugeriram que a alta eficácia dos antagonistas CB1 na redução do peso corporal em animais obesos e também em humanos é devida ao aumento da atividade do sistema endocanabinóide na obesidade ${ }^{86}$. Isso ocorre por um mecanismo independente da inibição da ingestão alimentar, e não ocorre somente no sistema nervoso central ${ }^{87}$, mas também nos tecidos periféricos ${ }^{21,24,81}$.

Hormônios como a leptina, que regula a biossíntese de endocanabinóides no hipotálamo, têm sido alvos crescentes de investigação como possíveis envolvidos na perda da regulação do sistema endocanabinóide na obesidade ${ }^{88}$. Demonstrou-se que a leptina controla negativamente os níveis de endocanabinóides no tecido adiposo branco ${ }^{89}$. Adicionalmente, em outros tecidos periféricos, a insulina parece 
ter papel importante reduzindo os níveis de endocanabinóides ou aumentando sua degradação em animais que não apresentam obesidade ${ }^{24}$. Portanto, não somente a resistência à leptina, mas também a perda da sensibilidade à insulina pode resultar em elevação dos níveis de endocanabinóides. Esse fenômeno parece preceder o desenvolvimento da obesidade.

Os níveis desregulados de endocanabinóides (assim como o aumento da expressão de receptores CB1) podem afetar as ações biológicas que são exercidas por este sistema em vários órgãos. Por exemplo, estudos experimentais demonstraram que a estimulação de receptores CB1 pelos compostos canabinóides leva à inibição da liberação de neurotransmissores em neurônios centrais induzindo numerosas respostas fisiológicas, tais como ingestão alimentar ${ }^{88}$. O aumento da expressão destes receptores no hipotálamo pode não só promover ingestão alimentar e balanço energético positivo, mas também levar à obesidade e às desordens metabólicas relacionadas a esta condição.

Estudos demonstraram ainda que os compostos canabinóides estimulam a atividade da proteína quinase ativada por AMP (AMPK) no hipotálamo, o que poderia explicar seus efeitos orexigênicos. Por outro lado, eles inibem a atividade desta enzima no fígado e tecido adiposo, o que levaria ao acúmulo de gordura nestas regiões, que juntamente com o efeito central, contribuiria para o ganho de peso e o aumento da massa de tecido adiposo branco ${ }^{90}$. A AMPK pertence à família de enzimas que são ativadas em conseqüência do estresse celular resultante da depleção de trifosfato de adenosina (ATP), agindo assim como reguladora da homeostase energética celular e sistêmica. Os principais efeitos agudos provenientes da ativação da AMPK podem ser resumidos em dois componentes: supressão das vias de utilização de ATP, que incluem a síntese de ácidos graxos, glicogênio, colesterol e proteínas; e ativação de processos de geração de energia (ATP), que incluem aumento da captação de glicose, estímulo da oxidação de ácidos graxos, inibição da produção de glicose, controle da secreção de insulina e aumento da ingestão alimentar ${ }^{91}$.

Especificamente no que tange ao tecido adiposo, onde a ativação do receptor CB1 estimula a adipogênese e a lipogênese ${ }^{24}$, o aumento da atividade canabinóide pode contribuir para o acúmulo de gordura. Considerando o papel importante da gordura visceral na gênese da resistência à insulina, este fenômeno pode facilitar o desenvolvimento de diabetes tipo $2^{88}$. Uma vez que a estimulação de receptores 
CB1 inibe a expressão e a liberação de adiponectina por adipócitos ${ }^{24}$, este cenário pode ser ainda mais prejudicado na presença de hiperativação do sistema endocanabinóide. Isso ocorre, pois a adiponectina protege a musculatura esquelética contra a resistência à insulina além de inibir a liberação e os efeitos promovidos por citocinas pró-inflamatórias.

No fígado, o aumento da expressão de receptores CB1 e também dos níveis de endocabinóides facilita a produção excessiva de ácidos graxos e triglicerídeos, os quais, por sua vez, contribuem para a resistência à insulina, para a redução na razão HDL/ VLDL colesterol, e para a esteatose hepática ${ }^{21}$.

O aumento generalizado dos níveis de endocanabinóides também aumenta diretamente os níveis de triacilgliceróis por prejudicar o clearance, mediado pela apolipoproteina $\mathrm{E}$, de lipoproteínas ricas em triacilgliceróis ${ }^{92}$. No pâncreas, a conseqüência do aumento da atividade do sistema endocanabinóide inclui aumento da liberação de insulina por este tecido ${ }^{24}$. Esta alteração, combinada com a redução da sensibilidade à insulina, pode levar à hiperglicemia e, eventualmente, à hipertrofia e morte das células $\beta$, contribuindo assim para o desenvolvimento do diabetes tipo 2 88.

Alterações na atividade do sistema endocanabinóide têm sido descritas em modelos experimentais de obesidade induzida por dieta e também em modelos genéticos ${ }^{21,88}$. No que tange ao modelo experimental de obesidade utilizado no presente estudo (OZRs), alterações na atividade do sistema endocanabinóide também já foram descritas. Nesse modelo experimental, em que a sinalização mediada pela leptina está prejudicada, não foi surpresa a observação dos níveis de endocanabinóides permanentemente elevados no tecido que apresenta maiores níveis de expressão dos receptores para leptina, que é o hipotálamo, onde a leptina inibe a síntese de endocanabinóides ${ }^{87}$. Nestes animais, o tratamento crônico com o antagonista de receptores canabinóides CB1 (o composto rimonabanto) reduziu a falência renal, a disfunção da célula beta ${ }^{93}$ e a esteatose hepática ${ }^{94}$. Esses efeitos ocorreram de modo totalmente independente de seus efeitos sobre a ingestão alimentar. De fato, uma observação que merece especial menção é que o aumento do gasto energético é o principal mecanismo envolvido na perda de peso induzida pelo rimonabanto na obesidade. Esse efeito é independente de sua ação anoréxica.

Estudo recente mostrou também que os níveis do agonista canabinóide anandamida encontram-se elevados no pâncreas, no fígado e no duodeno de OZRs 
95. Esses dados, em conjunto, indicam que a hiperatividade persistente do sistema endocanabinóide em tecidos que controlam o balanço energético pode ter, então, papel central não só no desenvolvimento da obesidade como no surgimento dos fatores de risco a ela agregados em OZRs. Entretanto, o papel da obesidade sobre as respostas mediadas por agonistas canabinóides no sistema vascular não foram ainda investigados. 


\section{JUSTIFICATIVA E OBJETIVOS}

O sistema endocanabinóide, que apresenta pronunciados efeitos metabólicos e vasculares em condições fisiológicas, encontra-se ativado na obesidade, em tecidos que controlam o balanço energético, como o tecido adiposo branco. Entretanto, os efeitos da obesidade sobre as ações vasculares mediadas por este sistema não foram ainda investigados. Portanto, o objetivo do presente estudo foi avaliar o efeito da obesidade sobre o relaxamento a agonistas canabinóides em artérias mesentéricas de resistência. Considerando o papel fisiológico do sistema endocanabinóide no controle da função vascular, propomos a hipótese de que a obesidade prejudica o relaxamento mediado pela anandamida, um dos principais agonistas canabinóides. Para investigar nossa hipótese, utilizamos ratos obesos Zucker (OZRs) jovens (6-7 semanas de idade), um modelo que manifesta obesidade e disfunção vascular. 


\section{MATERIAL E MÉTODOS}

\subsection{Animais}

Foram utilizados ratos obesos e seus respectivos controles da linhagem Zucker com 6-7 semanas de idade (Harlan laboratories, Madison, WI). Todos os experimentos foram realizados de acordo com os princípios éticos na experimentação animal adotados pelo colégio brasileiro de experimentação animal (COBEA) e pelo comitê institucional para uso e cuidado de animais em experimentação do Medical College of Georgia (Augusta, GA, EUA) e foram aprovados pela Comissão de Ética em Experimentação Animal (CEEA) do ICB (Protocolo número: 007/04). Os animais foram mantidos em caixas de polipropileno, acondicionadas em ambiente com temperatura controlada de $22 \pm 2 \stackrel{\circ}{\circ} \mathrm{C}$ e ciclo claroescuro de 12 horas, com livre acesso à água e alimento.

\subsection{Caracterização da Obesidade}

A obesidade foi avaliada pela determinação do peso corporal $(\mathrm{g})$ e do peso relativo ( $\mathrm{g} / 100 \mathrm{~g}$ peso corporal) das gorduras periepididimal e retroperitonial. Durante todos os protocolos experimentais o acúmulo de gordura retroperitonial e periepididimal foi avaliado.

\subsection{Determinação da Glicemia}

Foi coletada uma gota de sangue caudal em ratos submetidos à privação alimentar de 4 horas. A glicemia foi determinada com o uso de glicosímetro e fitas (Advantage $\AA$, South San Francisco, California, USA).

\subsection{Determinação da Pressão Arterial Caudal}

A pressão arterial caudal dos ratos acordados foi determinada por método indireto, através da pletismografia de cauda. Dois dias antes da primeira medida de 
pressão arterial caudal os ratos foram submetidos a um período de adaptação que envolvia o aquecimento dos animais em estufa especial por 10 minutos a $33{ }^{\circ} \mathrm{C}$ e a contenção em cilindro de acrílico, com abertura para focinho e cauda. Após o procedimento de adaptação foram determinados os níveis pressóricos dos ratos. Um oclusor e um sensor foram ajustados à porção proximal da cauda do rato, acoplados ao esfigmomanômetro elétrico PE-399 conectado a um sistema de transdução (Kent Scientific Corporation, CT). O valor final da pressão arterial caudal de cada animal representa a média aritmética de três medidas seqüenciais.

\subsection{Estudo da Reatividade Vascular em Artérias Mesentéricas de Resistência}

Foi utilizado o método descrito por Mulvany e Halpern (1977) ${ }^{96}$. Os animais foram sacrificados em câmara de $\mathrm{CO}_{2}$. O leito mesentérico foi removido e colocado em uma placa de Petri contendo solução de Krebs-Henseleit a $4{ }^{\circ} \mathrm{C}$ (composição em mM: $\mathrm{NaCl} 118 ; \mathrm{KCl} 4,7 ; \mathrm{NaHCO}_{3} 25 ; \mathrm{CaCl}_{2} .2 \mathrm{H}_{2} \mathrm{O}$ 2,5; $\mathrm{KH}_{2} \mathrm{PO}_{4} 1,2 ; \mathrm{MgSO}_{4} .7 \mathrm{H} 2 \mathrm{O}$ 1,2; EDTA 0,01 e glicose 11). O terceiro ramo da artéria mesentérica superior foi dissecado e cortado em segmentos de 2,0 mm de comprimento com o auxílio de um microscópio de dissecação. Dois fios de tungstênio (40 $\mu \mathrm{m}$ de diâmetro) foram então inseridos no lúmen das artérias e fixados em um miógrafo para vasos de resistência (Figura 2) para o estudo da tensão isométrica. Esse miógrafo, por sua vez, foi conectado a um sistema para aquisição de dados (PowerLab / 8SP, ADinstruments, Austrália) e este a um computador. 


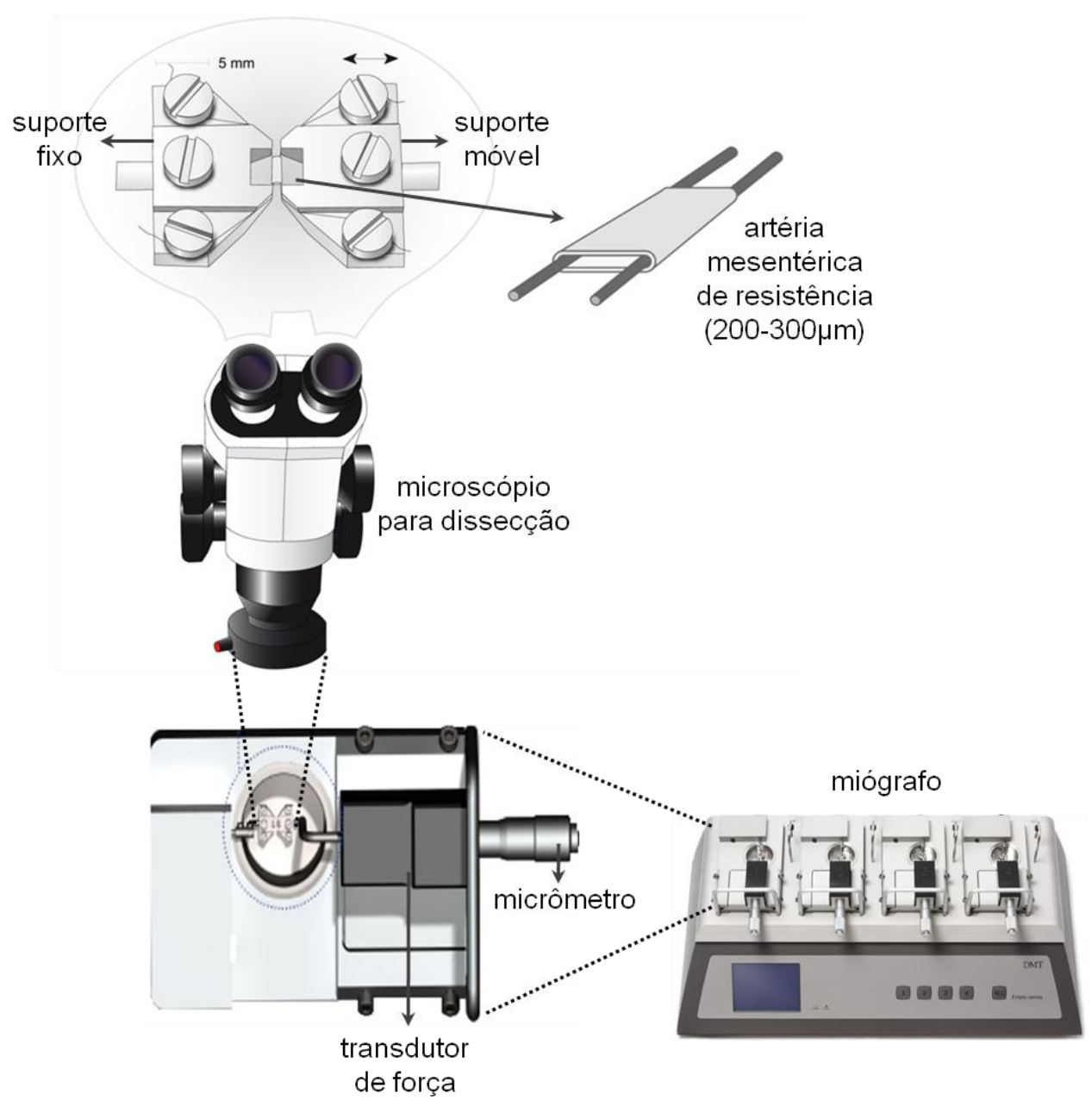

Figura 2 - Esquema da preparação em miógrafo para vasos de resistência isolados desenvolvido por Mulvany e Halpern (1977) ${ }^{96}$.

\subsubsection{Normalização das artérias de resistência}

O propósito do procedimento de normalização é distender o segmento vascular até que se atinja a chamada circunferência interna normalizada (IC1): definida como uma fração determinada da circunferência interna (IC100) que um segmento totalmente relaxado teria em uma determinada pressão transmural. Para artérias mesentéricas de resistência, a pressão transmural alvo é de $100 \mathrm{mmHg}$, que corresponde a 13,3 $\mathrm{kPa}$.

Após o período de estabilização e aquecimento dos segmentos vasculares (15 minutos) em solução de Krebs-Henseleit $\left(\mathrm{pH} 7,4\right.$ e a $\left.37^{\circ} \mathrm{C}\right)$, as artérias mesentéricas foram distendidas de forma gradativa e a leitura do micrômetro e da força aplicada foram registrados a cada ponto (Figura 3). Estes dados foram então convertidos em valores de circunferência interna $(\mu \mathrm{m})$ e de tensão na parede 
vascular $\mathrm{T}(\mathrm{mN} / \mathrm{mm})$, respectivamente. A plotagem da tensão na parede do vaso contra a circunferência interna revela uma curva exponencial. Pela aplicação da curva de isobarra correspondente a $100 \mathrm{mmHg}$, a IC100 é então calculada a partir do ponto de interseção, utilizando o software específico para normalização de artérias de resistência (DMT Normalization Module, ADInstruments, Austrália) (Figura 3). A IC1 foi calculada a partir da IC100 por meio da fórmula $I C_{1}=0,90 x$ $I C_{100}$, dando uma circunferência interna na qual a produção de força ativa bem como a sensibilidade do segmento a agonistas é máxima. O diâmetro interno normalizado foi calculado dividindo-se IC1 por $\pi$.

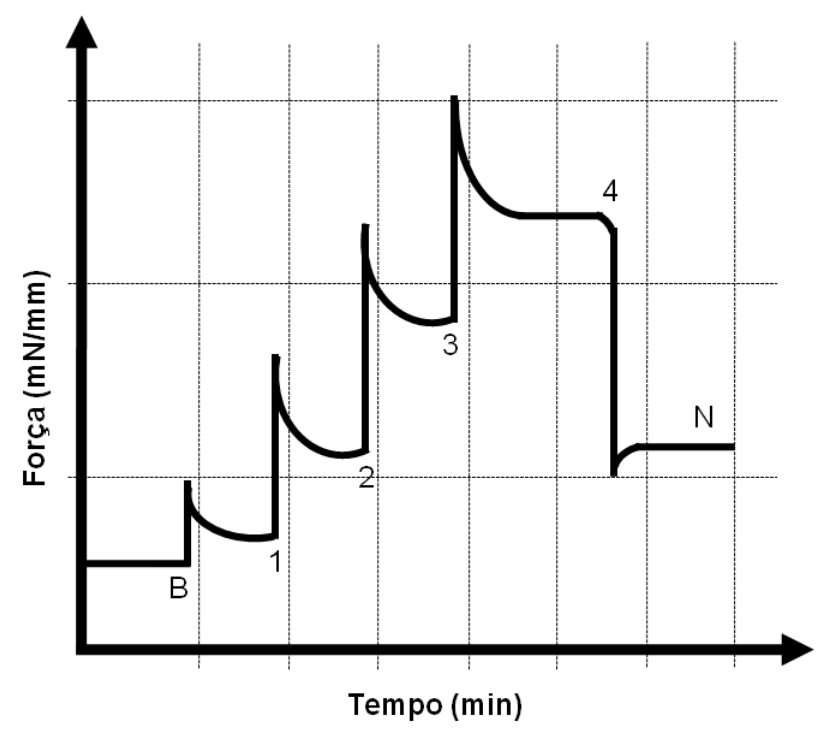

Figura 3 - llustração do procedimento de normalização.

\subsubsection{Protocolo experimental}

Após 15 minutos do processo de normalização, as artérias foram contraídas com a administração de cloreto de potássio $(\mathrm{KCl}, 120 \mathrm{mM})$, com a finalidade de se avaliar a integridade funcional. Após um período de lavagem e estabilização por mais 15 minutos, a integridade do endotélio foi testada por meio da avaliação do relaxamento à $\mathrm{ACh}$ (vasodilatador dependente de endotélio) em vasos précontraídos com fenilefrina (FE, $1 \mu \mathrm{M})$. A ausência de relaxamento à $A C h$ ou a presença de relaxamento de até $5 \%$ do valor da pré-contração em artérias mesentéricas submetidas previamente à remoção mecânica do endotélio, com o auxílio de um fio de cabelo, segundo protocolo descrito por Mulvany e Halpern $(1977){ }^{96}$, foi dada como prova da retirada do endotélio. 
Curvas concentração-resposta cumulativas para anandamida, para o agonista seletivo de receptores canabinóides CB1 (araquidonil-2-cloroetilamida, ACEA), para o agonista seletivo de receptores canabinóides CB2 (2-Metil-1-propil-1H-indol-3-il-1naftalenilmetanona, JWH-015) e para o agonista de receptores vanilóides (capsaicina) foram realizadas em artérias mesentéricas pré-contraídas com 0 composto U46619 (1 $\mu \mathrm{M})$. Para determinar o papel do endotélio no relaxamento induzido pela anandamida, as respostas foram também avaliadas em artérias mesentéricas sem endotélio. Para determinar o envolvimento dos receptores canabinóides na resposta à anandamida, artérias mesentéricas foram pré-incubadas com o antagonista específico de receptores CB1 (AM 251, $1 \mu \mathrm{M}){ }^{97}$ ou com o antagonista específico de receptores CB2 (AM 630, $1 \mu \mathrm{M}){ }^{98}$.

Para investigar o envolvimento das fibras nervosas sensoriais na resposta mediada pela anandamida, artérias mesentéricas foram incubadas com diferentes bloqueadores. A dessensibilização das fibras nervosas sensoriais do tipo $C$ foi induzida utilizando a neurotoxina capsaicina ( $1 \mu \mathrm{M}$ por 20 minutos, seguida por um período de lavagem de 40 minutos) ${ }^{99}$. A exposição aguda à capsaicina ativa fibras nervosas sensoriais, porém, após exposição prolongada, conforme realizado neste protocolo, ocorre dessensibilização do nervo. A lavagem por 40 minutos garante a remoção de qualquer neuropeptídeo residual que possa ter sido liberado ${ }^{100}$.

Considerando que os receptores vanilóides têm sido identificados como local de ligação da anandamida nas fibras nervosas do tipo $C^{101}$, investigamos o efeito do bloqueador seletivo de TRPV-1, o composto capsazepina $(3 \mu \mathrm{M}){ }^{102}$ e do bloqueador não seletivo de canais de cátions, o composto vermelho de rutênio $(30 \mu \mathrm{M}){ }^{103}$. Adicionalmente, a participação dos produtos liberados após ativação dos receptores vanilóides foi investigada pelo uso do antagonista do receptor do CGRP ( $\alpha$-CGRP (8-37), $1 \mu \mathrm{M}){ }^{13}$ ou do antagonista do receptor purinérgico P2Y1 (MRS 2179, $1 \mu \mathrm{M}$ ) 104.

Para examinar a contribuição dos EDRFs na resposta da anandamida, os vasos foram incubados com o inibidor da enzima NOS (L-NAME, $100 \mu \mathrm{M}$ ), com o inibidor da enzima COX (indometacina $10 \mu \mathrm{M}$ ) ou com os bloqueadores de canais de $\mathrm{K}^{+}$ativados por $\mathrm{Ca}^{2+}$ de baixa, média e alta condutância (apamina e caribidotoxina, $100 \mu \mathrm{M})^{63}$.

A contribuição da adenilil ciclase, da AMPK e da ERK1/2 na resposta da anandamida foi avaliada utilizando os compostos: forskolin (ativador da adenilil 
ciclase, $1 \mu \mathrm{M}$ ), SQ2256 (inibidor da adenilil ciclase, $1 \mu \mathrm{M}$ ), aminoimidazol carboxamida ribonucleotídeo (AICAR, ativador da AMPK, 1mM) ou PD98059 (inibidor da ERK1/2, $1 \mu \mathrm{M}$ ) ${ }^{105,106}$.

Quando os inibidores foram utilizados, os vasos foram incubados com os compostos por 30 minutos e permaneceram durante os ensaios de relaxamento. Os inibidores utilizados não alteraram a tensão basal das artérias de LZRs ou de OZRs. Uma vez que não detectamos diferença nas respostas à anandamida nos vasos sem endotélio, os estudos foram realizados em artérias com o endotélio intacto.

\subsection{Quantificação Protéica por Western Blotting}

\subsubsection{Extrato total}

Artérias mesentéricas isoladas de ratos do grupo LZR e OZR, incubadas ou não com anandamida ( $1 \mu \mathrm{M}, 30$ minutos), foram isoladas, congeladas em nitrogênio líquido, pulverizadas e homogeneizadas em tampão de lise gelado (coquetel inibidor de proteases ([4-\{2-aminoetil\} fluoreto de benzenosulfonil, pepstatina A, E-64, bestatina, leupeptina e aprotinina]; Sigma Aldrich) acrescido de ortovanadato de sódio (10 mM), PMSF (fluoreto de fenilmetil-sulfonil, $10 \mathrm{mM}$ ) e coquetel inibidor de protease (1\%). A pulverização dos tecidos foi realizada com o auxílio de um homogeneizador mecânico. Os extratos teciduais foram centrifugados a $10000 \mathrm{rpm}$ a $4{ }^{\circ} \mathrm{C}$ por 50 minutos para a remoção do material insolúvel. Após a centrifugação, foi quantificado o conteúdo protéico total, utilizando o método de BCA (ácido bicincônínico, Thermo Scientific). As amostras foram então tratadas com tampão de Laemmli contendo DTT (ditiotreitol, $200 \mathrm{mM}$ ) e $40 \mu \mathrm{g}$ de proteína total foram submetidos a eletroforese em gel de poliacrilamida (SDS PAGE 8\%) em aparelho para mini gel (BioRad, Hercules, USA). Em cada gel havia um marcador com peso molecular de valores estabelecidos.

\subsection{2 "Immunoblotting"}

A transferência das proteínas separadas no gel para a membrana de nitrocelulose foi feita eletricamente, por meio de aparelho da BioRad por 2 horas a 100 V. O tampão foi acrescido de SDS 0,1\% para melhorar a eluição de proteínas de 
alto peso molecular. As membranas foram incubadas com solução bloqueadora (leite desnatado 5\%) a temperatura ambiente por 2 horas, para reduzir a ligação inespecífica de proteínas na membrana.

As membranas foram incubadas individualmente com diferentes anticorpos: anti-CB1 (1:250, Sigma), anti-CB2 (1:1000, Sigma), anti-TRPV-1 (1:2000, Sigma), anti-AMPK (1:1000, Cell signaling), anti-fosfo AMPK (Thr172, 1:1000, Cell signaling), anti-acetil CoA carboxilase (1: 1000, Cell signaling), anti-fosfo acetil CoA carboxilase (Ser79, 1:1000, Cell signaling), anti-eNOs (1:500, Cell signaling), antifosfo eNOs (Ser1177, 1:1000, Cell signaling), anti-ERK1/2 (1:1000, Cell signaling), anti-fosfo ERK1/2 (Thr 202/Tyr204, 1:1000, cell signaling) e anti- $\beta$-actina (1:20000, Sigma). Essas incubações foram feitas com solução bloqueadora (leite 5\%), por 18 horas a $4{ }^{\circ} \mathrm{C}$. Em seguida as membranas foram lavadas com a solução tampão (TBS-T) por 30 minutos e incubadas com o anticorpo secundário conjugado com peroxidase, por $1 \mathrm{~h}$ em temperatura ambiente e, logo após, com a solução para detecção por quimioluminescência como descrito no protocolo do kit. A emissão de luz foi detectada e visualizada em auto-radiografias. A intensidade das bandas foi quantificada por densitometria óptica através da utilização de programa de análise de intensidade de bandas (Scion Image).

\subsection{Imunofluorescência e Microscopia Confocal}

\subsubsection{Obtenção do material}

Os animais foram sacrificados em câmara de $\mathrm{CO}_{2}$ e, após laparotomia, o mesentério foi cuidadosamente exposto. Artérias mesentéricas de segunda ordem com o endotélio intacto foram removidas e colocadas em solução fixadora de paraformaldeído 4\% (PFA) por 6 horas. Após a fixação, as artérias foram crioprotegidas em solução de sacarose $30 \%$ e em seguida emblocadas em meio para congelamento OCT (Sakura Finetek USA, Torrance, CA), e mantidas a $-80{ }^{\circ} \mathrm{C}$ até a realização dos cortes. Para garantir que os cortes utilizados abrangessem uma porção significativa da artéria mesentérica, foram feitos quinze cortes não seriados de $20 \mu \mathrm{m}$ de espessura com o auxílio de um criostato a $-25{ }^{\circ} \mathrm{C}$ e estes foram colocados em lâminas silanizadas. Após esse procedimento os cortes foram armazenados em freezer $\left(-20^{\circ} \mathrm{C}\right)$ para posterior análise. 


\subsubsection{Imunofluorescência}

As lâminas referidas no item anterior foram lavadas em tampão de fosfato salina (PBS) 0,1 M durante 5 minutos. Após lavagem em PBS, os cortes foram bloqueados com solução de albumina de soro fetal bovino (BSA, 0.1\%) por uma hora à temperatura ambiente. Os cortes foram subseqüentemente incubados com anticorpo monoclonal produzido em coelho anti-CB1 (1:100, Abcam), anticorpo policlonal produzido em coelho anti-CB2 (1:100, Abcam) ou anticorpo produzido em mouse anti-von Willebrand (1:500, Abcam), por 18 horas a $4^{\circ} \mathrm{C}$. As reações controle foram realizadas substituindo-se o anticorpo primário por PBS 0,1 M com Tween 20 a $0,3 \%$. Após o período de incubação, as lâminas foram lavadas três vezes a cada 5 minutos em PBS 0,1 M.

Após lavagem em PBS, os anticorpos secundários fluorescentes, goat antimouse IgG Alexa Fluor 488 e goat anti-rabbit Alexa Fluor 594 (1:1000, Molecular Probes) foram aplicados e incubados por 1 hora à temperatura ambiente. Após esse período, os cortes foram novamente lavados por três vezes de 5 minutos cada, em PBS 0,1 M e em seguida foram incubados com o composto 4'-6'-diamino-2-fenil-indol (DAPI, 1:200, por 5 minutos), um marcador de núcleo. Após este período realizou-se então uma nova série de lavagens de 5 minutos por 3 vezes, utilizando PBS. Os cortes foram então cobertos com meio para montagem (Gel/Mount medium; Biomeda, Foster City, CA) e protegidos da luz até que fosse realizada a aquisição das imagens, utilizando um microscópio confocal do tipo laser-scanning (Leica TCSDMRE, Germany), com objetiva de imersão em óleo (63X).

\subsection{Análise Estatística}

Os resultados estão expressos como média \pm erro padrão da média (epm). teste "t" de Student ou a análise de variância de uma via (ANOVA) seguido do teste de Bartlett para a homogeneidade das variâncias e teste de múltiplas comparações Tukey-Kramer foram utilizados quando pertinente. O nível de significância mínima aceitável foi $p<0,05$. 


\subsection{Drogas Utilizadas}

ACh, FE, L-NAME, forskolin, SQ2256, AICAR, PD98059, MRS2179 e $\alpha$ CGRP (8-37) foram obtidos da Sigma Chemical Co (St. Louis, MO). Anandamida, ACEA, JWH-015, AM251, AM630, capsazepina, capsaicina, vermelho de rutênio e AM404 foram obtidos da Tocris (Ellisville, MO). O composto URB597 foi obtido da Cayman Chemical (Ann Arbor, MI). 


\section{RESULTADOS}

\subsection{Características Gerais do Modelo de Obesidade Monogenética Zucker}

A tabela 1 mostra os dados referentes às caracterização do modelo de obesidade utilizado neste estudo. Conforme descrito na tabela, OZRs com 6-7 semanas de idade apresentam obesidade, caracterizada pelo aumento significativo do peso corpóreo e pelo acúmulo de gordura visceral (representada pelas gorduras periepididimal e retroperitonial). As concentrações de glicose sanguíneas bem como os níveis de pressão arterial são semelhantes entre LZRs e OZRs nesta fase em que foram utilizados para o presente estudo.

Tabela 1- Características gerais de ratos Zucker controles (LZRs) e obesos (OZRs) com 6-7 semanas de idade

\begin{tabular}{lcc}
\hline \hline Parâmetro & LZR & OZR \\
\hline Peso corpóreo $(\mathbf{g})$ & $193,0 \pm 11,1$ & $283,3 \pm 18,2^{*}$ \\
Gordura retroperitonial (g/100 g de peso corpóreo) & $0,46 \pm 0,03$ & $2,05 \pm 0,30^{*}$ \\
Gordura periepididimal (g/100 g de peso corpóreo) & $0,54 \pm 0,02$ & $2,3 \pm 0,45^{\star}$ \\
Glicose (mg/dL) & $130,0 \pm 0,8$ & $134,0 \pm 2,5$ \\
Pressão sanguínea (mmHg) & $110,5 \pm 3,6$ & $116,8 \pm 1,6$ \\
\hline \hline
\end{tabular}

Valores representam a média \pm epm. $n=10$ grupo. * $p<0,05$ vs. LZR. 


\subsection{Medida do Diâmetro Luminal Efetivo das Artérias Mesentéricas de Resistência}

A tabela 2 mostra os valores do diâmetro luminal efetivo, correspondente à medida da circunferência interna das artérias mesentéricas de resistência isoladas de LZRs e de OZRs. O diâmetro luminal efetivo das artérias mesentéricas isoladas de OZRs não foi estatisticamente diferente daquele observado em artérias de LZRs (Tabela 2).

Tabela 2- Diâmetro luminal efetivo das artérias mesentéricas de resistência isoladas de ratos controles Zucker (LZR) e obesos Zucker (OZR) com 6-7 semanas de idade.

\begin{tabular}{lcc}
\hline \hline Parâmetro & LZR & OZR \\
\hline Diâmetro luminar efetivo & $269,0 \pm 12,8$ & $271,3 \pm 8,9$ \\
& & \\
\hline \hline
\end{tabular}

Valores representam a média \pm epm. $n=20 /$ grupo. 


\subsection{Avaliação da Contração ao Cloreto de Potássio em Artérias Mesentéricas de Resistência}

A resposta contrátil induzida pelo $\mathrm{KCl}$ foi semelhante em artérias mesentéricas de LZRs $(9,9 \pm 0,5)$ e de OZRs $(9,9 \pm 0,6)$ (Figura 4).

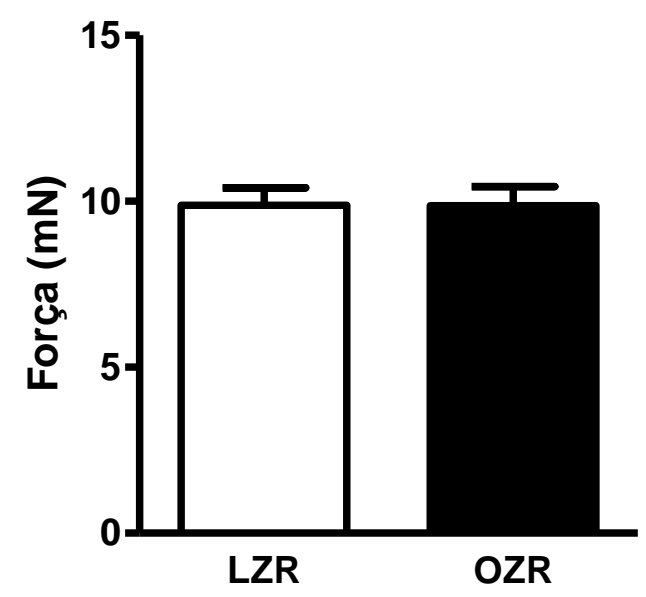

Figura 4 - Contração ao cloreto de potássio $(\mathrm{KCl})$ em artérias mesentéricas de resistência com o endotélio intacto isoladas de ratos controles Zucker (LZR) e obesos Zucker (OZR) com 6-7 semanas de idade. Cada ponto representa a média \pm epm. $n=6 / g r u p o$. 


\subsection{Avaliação do Relaxamento Dependente de Endotélio à Acetilcolina em} Artérias Mesentéricas de Resistência e o Efeito da Incubação com Anandamida

O relaxamento dependente de endotélio induzido pela ACh foi menor em OZRs quando comparado àquele observado em artérias de LZRs (Figura 5A, Tabela 3). A incubação com anandamida por 30 minutos corrigiu a redução do relaxamento dependente de endotélio à ACh em OZRs, sem afetar a resposta mediada pela ACh no grupo LZR (Figura 5B, Tabela 3).
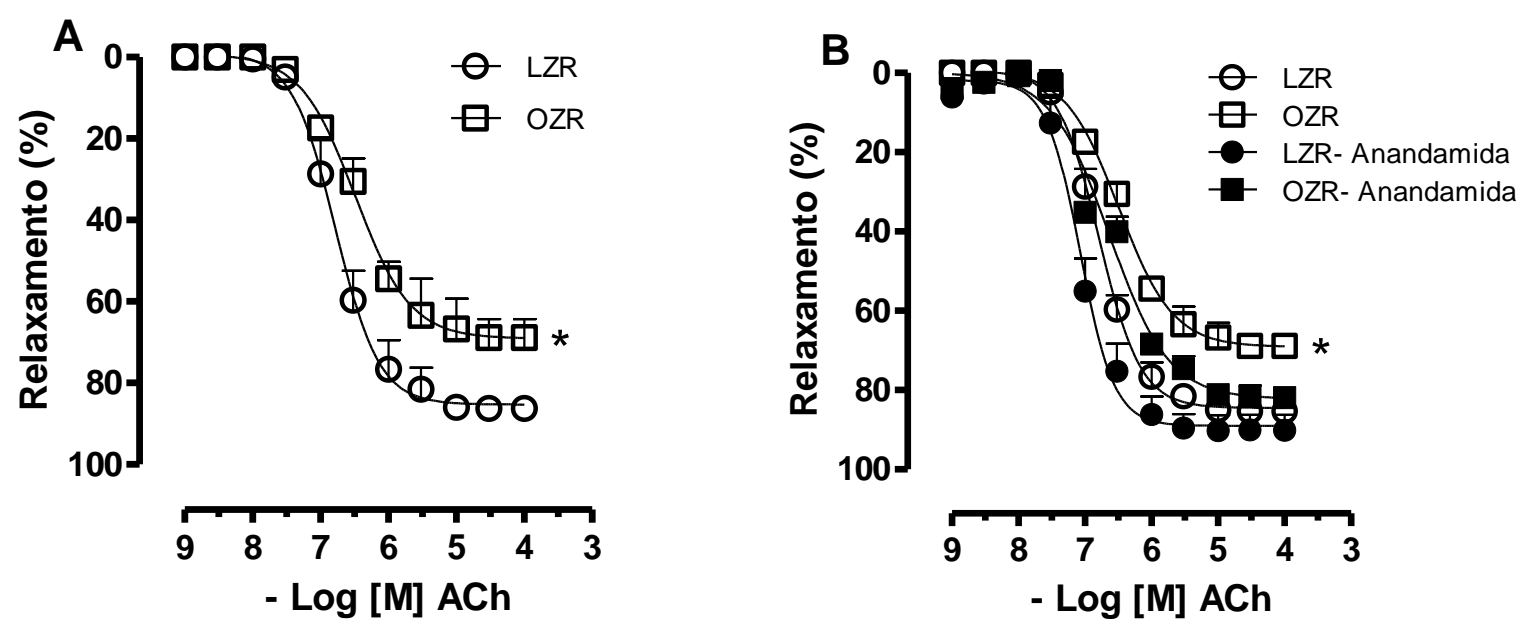

Figura 5 - Curvas concentração-efeito à acetilcolina (ACh) em artérias mesentéricas de resistência isoladas de ratos controles Zucker (LZR) e obesos Zucker (OZR) com 6-7 semanas de idade. Artérias mesentéricas com o endotélio intacto foram contraídas com o composto U46619 $(1 \mu \mathrm{M})$ e curvas concentração-efeito à $A C h$ foram realizadas na presença $(A)$ ou na ausência $(B)$ de anandamida $(1 \mu \mathrm{M}$, pré-incubada por 30 minutos). Cada ponto representa a média \pm epm. $n=6 /$ grupo. * $p<0.05$ vs. LZR. 
Tabela 3 - Efeito da incubação com anandamida sobre a resposta máxima à acetilcolina (ACh) em artérias mesentéricas de resistência isoladas de ratos controles Zucker (LZR) e obesos Zucker (OZR) com 6-7 semanas de idade.

\begin{tabular}{ccccc}
\hline & \multicolumn{2}{c}{ LZR } & \multicolumn{2}{c}{ OZR } \\
\hline & $\mathrm{R}_{\mathrm{MAX}}$ & $\mathrm{pD} \mathrm{D}_{2}$ & $\mathrm{R}_{\mathrm{MAX}}$ & $\mathrm{pD}_{2}$ \\
ACh & $85,4 \pm 1,1$ & $\mathrm{ND}$ & $69,2 \pm 1,4^{*}$ & $\mathrm{ND}$ \\
$\mathbf{A C h}+$ Anandamida & $89,1 \pm 1,4$ & $\mathrm{ND}$ & $82,3 \pm 1,9 \#$ & $\mathrm{ND}$ \\
\hline \hline
\end{tabular}

Os valores de $\mathrm{pD}_{2}$ (-log $\mathrm{EC50}$ ) e $\mathrm{R}_{\mathrm{MAX}}$ (Resposta máxima) representam a média \pm epm. $\mathrm{ND}=$ não foi determinada a pD2 por ter havido diferença significativa na resposta máxima. EC50 = concentração que promove $50 \%$ da $R_{\text {MAX. }}$. $n=5-6 /$ grupo. * $p<0,05$ vs LZR, ${ }^{\#} p<0.05$ vs. OZR na ausência de anandamida. 


\subsection{Avaliação da Resposta Contrátil à Fenilefrina em Artérias Mesentéricas de Resistência e o Efeito da Incubação com Anandamida}

A resposta contrátil à $\mathrm{FE}$ foi maior tanto em artérias mesentéricas com 0 endotélio intacto quanto em artérias mesentéricas sem endotélio de OZRs quando comparados à LZRs (Figura 6A, Tabela 4). A incubação com anandamida por 30 minutos corrigiu o aumento da contração à $\mathrm{FE}$ em artérias mesentéricas com o endotélio intacto de OZRs (Figura 6B, Tabela 4). Por outro lado, quando a incubação foi realizada em anéis sem o endotélio, a anandamida não corrigiu o aumento da contração à FE em OZRs (Figura 6C, Tabela 4).
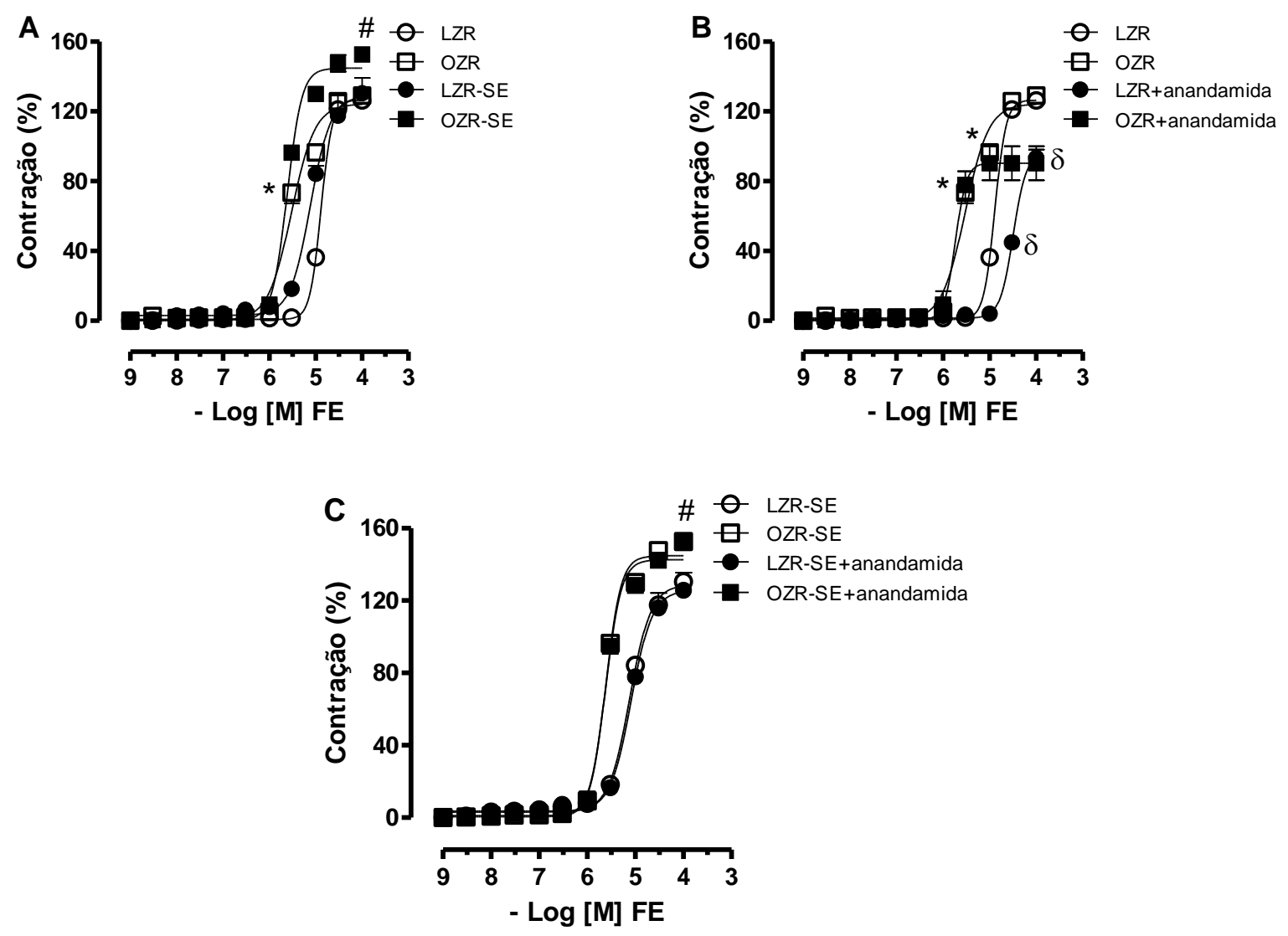

Figura 6 - Curvas concentração-efeito à fenilefrina (FE) em artérias mesentéricas de resistência isoladas de ratos controles Zucker (LZR) e obesos Zucker (OZR) com 6-7 semanas de idade. Curvas concentração-efeito à $F E$ foram realizadas em artérias mesentéricas com o endotélio intacto ou sem endotélio (A) na presença $(B)$ ou na ausência $(C)$ de anandamida $(1 \mu \mathrm{M}$, pré-incubada por 30 minutos). Cada ponto representa a média \pm epm. $n=6 /$ grupo. * $p<0.05$ vs. LZR, \# $p<0.05$ vs. LZR-SE, $\delta p<0.05$ vs. respectivo grupo na ausência de anandamida. 
Tabela 4 - Efeito da incubação com anandamida sobre a resposta máxima à fenilefrina (FE) em artérias mesentéricas de resistência isoladas de ratos controles Zucker (LZR) e obesos Zucker (OZR) com 6-7 semanas de idade.

\begin{tabular}{ccccc}
\hline \hline & \multicolumn{2}{c}{ LZR } & \multicolumn{2}{c}{ OZR } \\
\hline & $\mathrm{R}_{\mathrm{MAX}}$ & $\mathrm{pD}_{2}$ & $\mathrm{R}_{\mathrm{MAX}}$ & $\mathrm{pD}_{2}$ \\
FE & $126,5 \pm 0,8$ & $4,8 \pm 0,01$ & $124,3 \pm 3,4$ & $5,5 \pm 0,03^{*}$ \\
FE SE & $128,9 \pm 2,6$ & $\mathrm{ND}$ & $144,8 \pm 1,8 \#$ & $\mathrm{ND}$ \\
FE + Anandamida & $96,0 \pm 2,1 \delta$ & $4,5 \pm 0,01$ & $90,4 \pm 1,9 \delta$ & $5,7 \pm 1,9^{*}$ \\
FE SE + Anandamida & $125,6 \pm 1,4$ & $\mathrm{ND}$ & $142,6 \pm 1,8 \#$ & $\mathrm{ND}$ \\
\hline \hline
\end{tabular}

Os valores de $\mathrm{pD}_{2}$ (-log $\mathrm{EC50}$ ) e $\mathrm{R}_{\mathrm{MAX}}$ (Resposta máxima) representam a média \pm epm. $\mathrm{SE}=$ sem endotélio

$\mathrm{ND}=$ não foi determinada a pD2 por ter havido diferença significativa na resposta máxima. $E C 50=$ concentração que promove $50 \%$ da $R_{\text {MAX. }}$. $n=6 /$ grupo. * $p<0.05$ vs. LZR, ${ }^{\#} p<0.05$ vs. LZR-SE, $\delta p<0.05$ vs. respectivo grupo na ausência de anandamida. 


\subsection{Avaliação do Relaxamento à Anandamida em Artérias Mesentéricas de Resistência}

A anandamida induziu relaxamento dependente de concentração, que foi menor em artérias mesentéricas de resistência de OZRs quando comparado àquele observado em LZRs. Na ausência de endotélio a resposta máxima à anandamida foi semelhante entre ratos dos grupos LZR e OZR (Figura 7, Tabela 5).

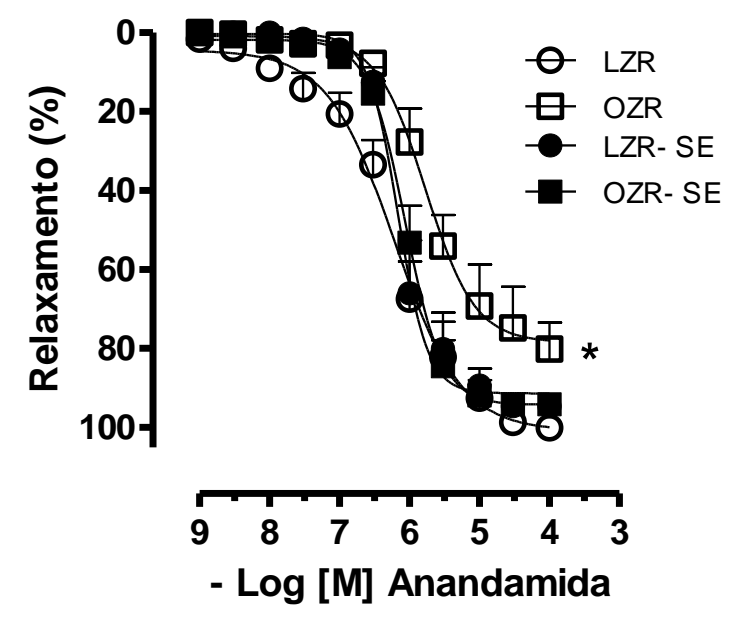

Figura 7 - Curvas concentração-efeito à anandamida em artérias mesentéricas de resistência isoladas de ratos controles Zucker (LZR) e obesos Zucker (OZR) com 6-7 semanas de idade. Artérias mesentéricas com o endotélio intacto ou removido mecanicamente (SE) foram contraídas com o composto U46619 (1 $\mu \mathrm{M})$ e curvas concentração-efeito à anandamida foram realizadas. Cada ponto representa a média \pm epm. $n=6 /$ grupo. ${ }^{*} p<0.05$ vs. LZR. 


\subsection{Avaliação do Relaxamento aos Agonistas CB1 e CB2 em Artérias Mesentéricas de Resistência}

A resposta relaxante mediada tanto pelo agonista de receptores canabinóides CB1 (ACEA, Figura 8A, Tabela 5) quanto pelo agonista CB2 (JWH-015, Figura 8B, Tabela 5), foi menor em OZRs quando comparada à observada em LZRs. A remoção do endotélio reduziu a resposta ao agonista CB1 apenas em LZRs, sem alterá-la no grupo OZR (Figura 8A, Tabela 5). Por outro lado, a resposta ao agonista CB2 (JWH-015), que já era significantemente menor no grupo OZR, não foi afetada pela remoção do endotélio em ambos os grupos experimentais (Figura 8B, Tabela5).
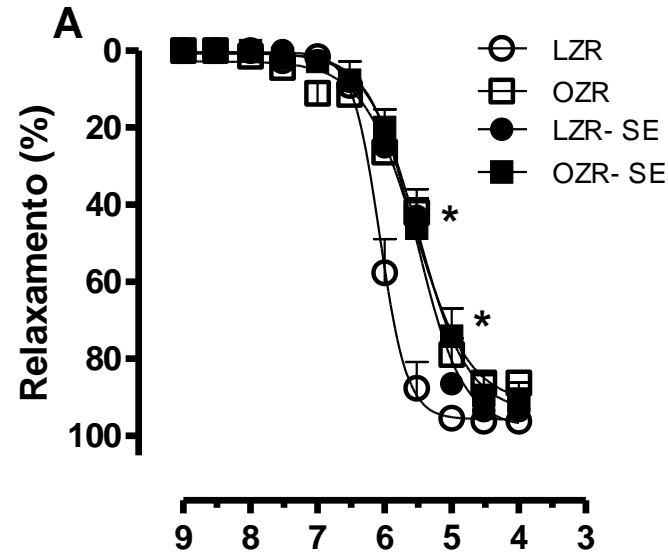

- Log [M] ACEA
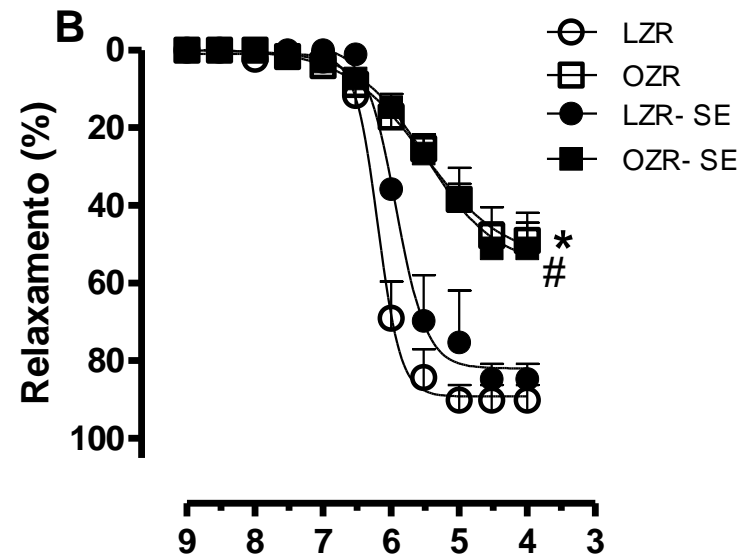

- Log [M] JWH-015

Figura 8 - Curvas concentração-efeito aos agonistas específicos de receptores canabinóides CB1 (ACEA, A) e CB2 (JWH-015, B) em artérias mesentéricas de resistência isoladas de ratos controles Zucker (LZR) e obesos Zucker (OZR) com 6-7 semanas de idade. Artérias mesentéricas com o endotélio intacto (círculos vazios) ou removido mecanicamente (círculos preenchidos, SE) foram contraídas com o composto U46619 $(1 \mu \mathrm{M})$ e curvas concentração-efeito aos agonistas canabinóides foram realizadas. Cada ponto representa a média \pm epm. $n=6 /$ grupo. * $p<0.05$ vs. LZR, ${ }^{\#} p<0.05$ vs. LZR-SE. 
Tabela 5 - Resposta à anandamida e aos agonistas canabinóides CB1 e CB2 em artérias mesentéricas de resistência isoladas de ratos controles Zucker (LZR) e obesos Zucker (OZR) com 6-7 semanas de idade.

\begin{tabular}{ccccc}
\hline \hline & \multicolumn{2}{c}{ LZR } & \multicolumn{2}{c}{ OZR } \\
\hline & $\mathrm{R}_{\mathrm{MAX}}$ & $\mathrm{pD}_{2}$ & $\mathrm{R}_{\mathrm{MAX}}$ & $\mathrm{pD}_{2}$ \\
Anandamida & $100,9 \pm 3,8$ & $\mathrm{ND}$ & $78,5 \pm 4,8^{*}$ & $\mathrm{ND}$ \\
Anandamida SE & $91,4 \pm 2,8$ & $6,2 \pm 0,05$ & $94,3 \pm 2,3$ & $6,0 \pm 0,04$ \\
ACEA & $95,7 \pm 1,8$ & $6,1 \pm 0,03$ & $91,5 \pm 3,7$ & $5,5 \pm 0,06^{*}$ \\
ACEA SE & $97,9 \pm 4,0$ & $5,5 \pm 0,06$ & $93,7 \pm 4,0$ & $5,5 \pm 0,07$ \\
JWH-015 & $89,3 \pm 2,1$ & $\mathrm{ND}$ & $54,2 \pm 6,9^{*}$ & $\mathrm{ND}$ \\
JWH-015 SE & $82,0 \pm 3,0$ & $\mathrm{ND}$ & $55,5 \pm 4,9 \#$ & $\mathrm{ND}$ \\
\hline \hline
\end{tabular}

Os valores de $\mathrm{pD}_{2}$ (-log $\mathrm{EC50}$ ) e $\mathrm{R}_{\mathrm{MAX}}$ (Resposta máxima) representam a média \pm epm. $\mathrm{ND}=$ não foi determinada a pD2 por ter havido diferença significativa na resposta máxima. $E C 50=$ concentração que promove $50 \%$ da $R_{\text {MAX }}$.

$n=6 /$ grupo. * $p<0,05$ vs. LZR, ${ }^{\#} p<0.05$ vs. LZR-SE.

$\mathrm{SE}=$ sem endotélio

$\mathrm{ACEA}=$ agonista $\mathrm{CB} 1$

JWH-015= agonista CB2 


\subsection{Papel dos Receptores Canabinóides CB1 e CB2 no Relaxamento Promovido pela Anandamida}

O bloqueio de receptores canabinóides CB1 (Figura 9A, Tabela 6) ou CB2 (Figura 9B, Tabela 6) reduziu a resposta máxima à anandamida em artérias mesentéricas de LZRs. A incubação com estes agentes também promoveu redução do relaxamento à anadamida em OZRs, porém, esta redução parece ter sido mais pronunciada neste grupo (Figuras 9A e B, Tabela 6).
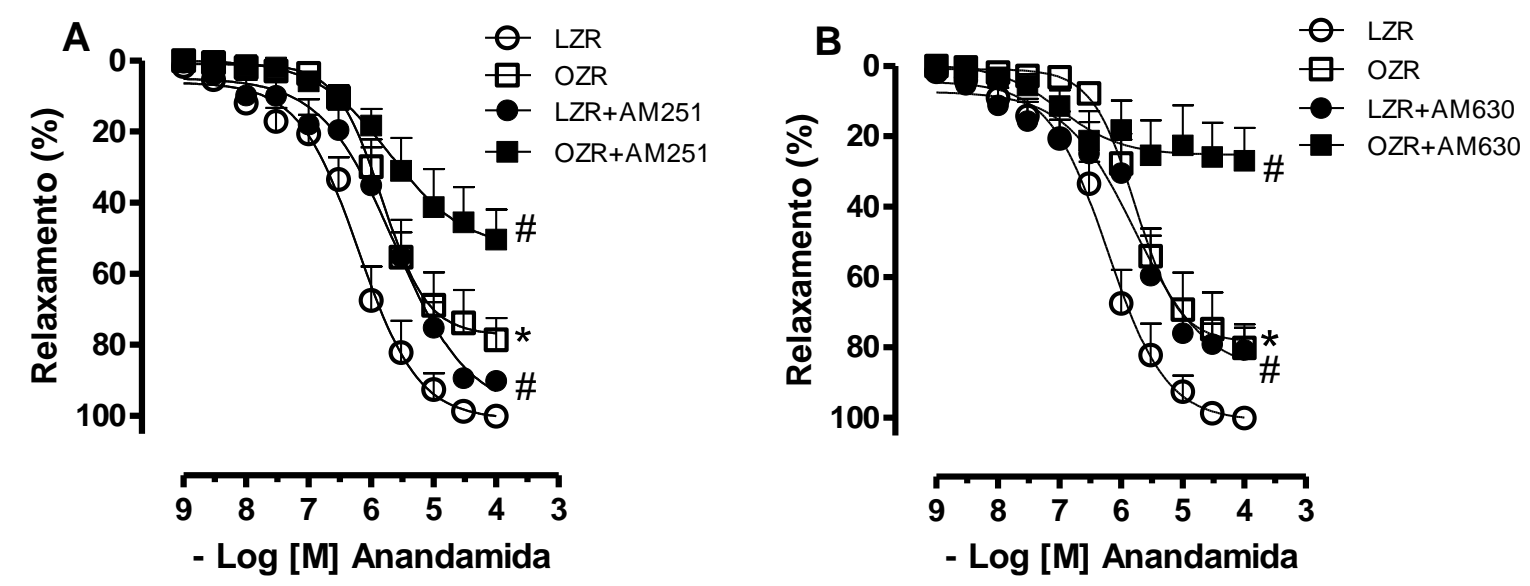

Figura 9 - Curvas concentração-efeito à anandamida na presença e na ausência de antagonistas específicos dos receptores canabinóides CB1 (AM251, A) ou CB2 (AM630, B) em artérias mesentéricas de resistência isoladas de ratos controles Zucker (LZR) e obesos Zucker (OZR) com 6-7 semanas de idade. Artérias mesentéricas com o endotélio intacto foram contraídas com o composto U46619 $(1 \mu \mathrm{M})$ e curvas concentração-efeito à anandamida foram realizadas. Cada ponto representa a média \pm epm. $n=6$ /grupo. * $p<0.05$ vs. LZR, ${ }^{*} p<0.05$ vs. respectivo grupo na ausência do antagonista. 


\subsection{Papel dos Receptores Vanilóides (TRPV-1) na Resposta à Anandamida}

A incubação de artérias mesentéricas de resistência com a capsaicina, que inicialmente ativa, mas logo promove dessensibilização de receptores vanilóides, reduziu significantemente a resposta à anandamida em LZRs e em OZRs (Figura10A, Tabela 6). Resposta similar foi observada quando as artérias foram incubadas com o bloqueador de receptores vanilóides, o composto vermelho de rutênio (Figura 10B, Tabela 6). Porém, o bloqueador específico de receptores vanilóides do tipo TRPV-1, o composto capsazepina, reduziu a resposta à anandamida em LZRs, embora de modo bem discreto, mas não afetou essa resposta no grupo OZR (Figura 10C, Tabela 6).
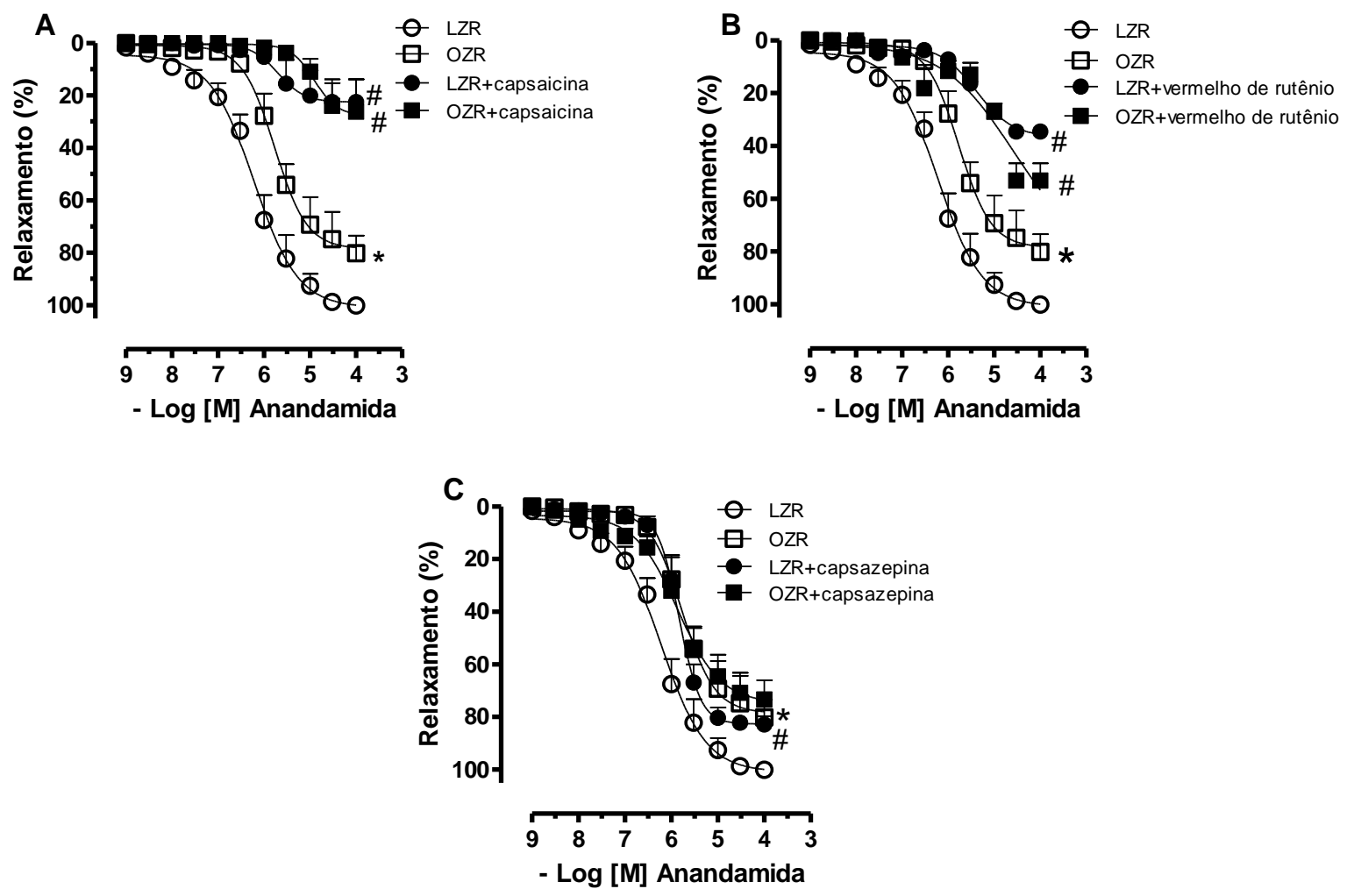

Figura 10 - Curvas concentração-efeito para anandamida em artérias mesentéricas de resistência com endotélio, isoladas de ratos controles Zucker (LZR) e obesos Zucker (OZR) com 6-7 semanas de idade. A- Curvas concentração-efeito à anandamida na presença de capsaicina, neurotoxina que dessensibiliza fibras nervosas sensoriais do tipo C; B- Curvas concentração-efeito à anandamida na presença de vermelho de rutênio, bloqueador de receptores vanilóides; CCurvas concentração-efeito à anandamida na presença de capsazepina, bloqueador de receptores vanilóides do tipo TRPV-1. Artérias mesentéricas com o endotélio intacto foram contraídas com o composto U46619 $(1 \mu \mathrm{M})$ e curvas concentração-efeito à anandamida foram realizadas. Cada ponto representa a média \pm epm. $n=6 /$ grupo. ${ }^{*} p<0.05$ vs. LZR, ${ }^{\#} p<0.05$ vs. respectivo grupo na ausência do antagonista. 
Tabela 6 - Participação dos receptores canabinóides (CB1 e CB2) e do receptor vanilóide (TRPV-1) na resposta à anandamida em artérias mesentéricas de resistência isoladas de ratos controles Zucker (LZR) e obesos Zucker (OZR) com 6-7 semanas de idade.

\begin{tabular}{ccccc}
\hline \hline & \multicolumn{2}{c}{ LZR } & \multicolumn{2}{c}{ OZR } \\
\hline Anandamida & $\mathrm{R}_{\mathrm{MAX}}$ & $\mathrm{pD}_{2}$ & $\mathrm{R}_{\mathrm{MAX}}$ & $\mathrm{pD}_{2}$ \\
& & & & \\
Anandamida + AM251 & $101,0 \pm 3,9$ & $6,2 \pm 0,09$ & $77,3 \pm 4,3^{*}$ & $5,8 \pm 0,1$ \\
Anandamida + AM630 & $98,6 \pm 9,3$ & $5,6 \pm 0,17 \#$ & $52,9 \pm 8,8 \#$ & $5,7 \pm 0,3$ \\
Anandamida + capsaicina & $85.5 \pm 8,3$ & $5,3 \pm 0,15 \#$ & $25,3 \pm 4,2 \#$ & $7,0 \pm 0,4$ \\
Anandamida + vermelho de rutênio & $22,6 \pm 3,9 \#$ & $\mathrm{ND}$ & $27,7 \pm 5,6 \#$ & $\mathrm{ND}$ \\
Anandamida + capsazepina & $82,3 \pm 1,8 \#$ & $\mathrm{ND}$ & $46,5 \pm 5,6 \#$ & $\mathrm{ND}$ \\
\hline \hline
\end{tabular}

Os valores de $\mathrm{pD}_{2}$ (-log $\mathrm{EC50}$ ) e $\mathrm{R}_{\mathrm{MAX}}$ (Resposta máxima) representam a média \pm epm. $\mathrm{ND}=$ não foi determinada a pD2 por ter havido diferença significativa na resposta máxima. $E C 50=$ concentração que promove $50 \%$ da $R_{\text {MAX. }}$.

AM 251 = antagonista de receptores canabinóides CB1

AM 630 = antagonista de receptores canabinóides CB2

Capsaicina $=$ neurotoxina que dessensibiliza receptores TRPV-1

Vermelho de rutênio= bloqueador de receptores vanilóides

Capsazepina $=$ bloqueador de receptores TRPV-1

$n=6 /$ grupo. * $p<0.05$ vs. LZR, ${ }^{\#} p<0.05$ vs. respectivo grupo na ausência do antagonista. 


\subsection{Participação do Receptor do Peptídeo Relacionado ao Gene da Calcitonina (CGRP) e do Receptor da Substância P na Resposta à Anandamida}

O bloqueio dos receptores do CGRP diminuiu drasticamente a resposta à anandamida nos dois grupos experimentais estudados, porém, essa redução parece ter sido bem mais pronunciada em LZRs do que em OZRs (Figura 11A, Tabela 7). Por outro lado, a incubação de artérias mesentéricas com MRS 2179, que bloqueia receptores da substância $P$, não afetou significativamente a resposta à anandamida em LZRs ou em OZRs (Figura 11B, Tabela 7).
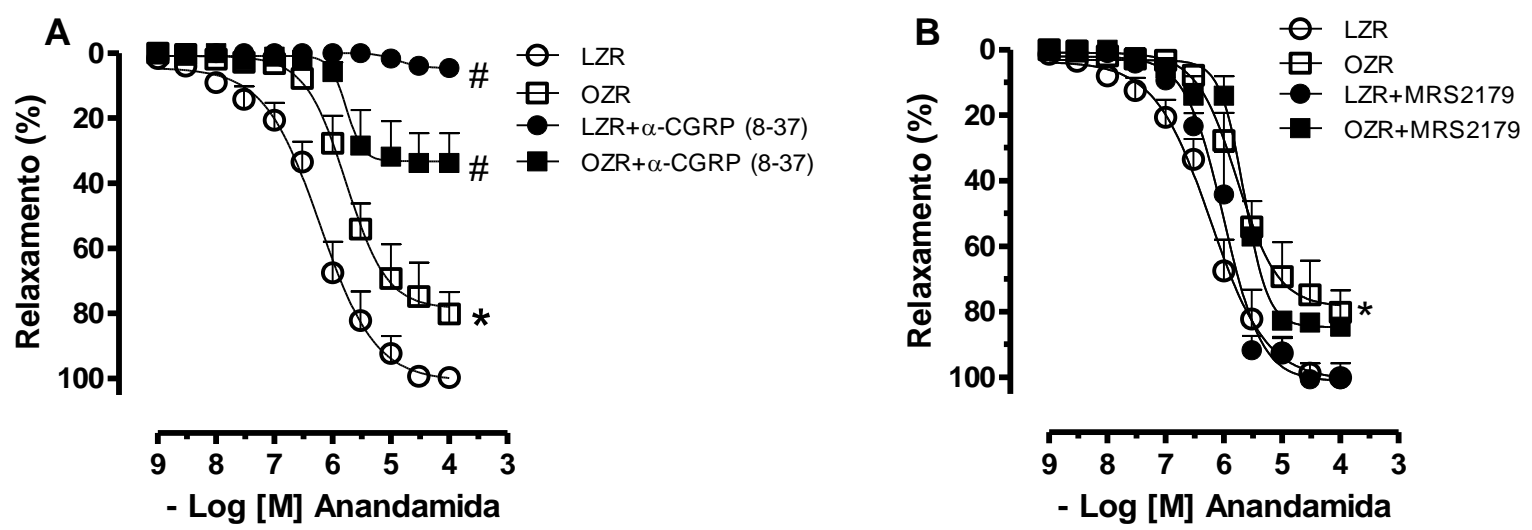

Figura 11 - Curvas concentração-efeito para anandamida em artérias mesentéricas de resistência com endotélio, isoladas de ratos controles Zucker (LZR) e obesos Zucker (OZR) com 6-7 semanas de idade. A- Curvas concentração-efeito na presença de $\alpha$-CGRP (8-37), antagonista do receptor do peptídeo relacionado ao gene da calcitonina (CGRP). B- Curvas concentração-efeito na presença de MRS-2179, antagonista do receptor da substância P. Artérias mesentéricas com o endotélio intacto foram contraídas com U46619 (1 $\mu \mathrm{M})$ e curvas concentração-efeito à anandamida foram realizadas. Cada ponto representa a média \pm epm. $n=6$ /grupo. * $p<0.05$ vs. LZR, ${ }^{\#} p<0.05$ vs. o respectivo grupo na ausência do antagonista. 
Tabela 7 - Participação do receptor do peptídeo relacionado ao gene da calcitonina (CGRP) e do receptor da substância $P$ na resposta à anandamida em artérias mesentéricas de resistência isoladas de ratos controles Zucker (LZR) e obesos Zucker (OZR) com 6-7 semanas de idade.

\begin{tabular}{ccccc}
\hline \hline & \multicolumn{2}{c}{ LZR } & \multicolumn{2}{c}{ OZR } \\
\hline & $\mathrm{R}_{\mathrm{MAX}}$ & $\mathrm{pD} 2$ & $\mathrm{R}_{\mathrm{MAX}}$ & $\mathrm{pD}_{2}$ \\
Anandamida & $100,8 \pm 4,1$ & $\mathrm{ND}$ & $78,5 \pm 4,7^{*}$ & $\mathrm{ND}$ \\
Anandamida+a-CGRP (8-37) & $4,6 \pm 0,3 \#$ & $\mathrm{ND}$ & $33,3 \pm 3,2 \#$ & $\mathrm{ND}$ \\
Anandamida+MRS 2179 & $101,2 \pm 3,6$ & $\mathrm{ND}$ & $84,7 \pm 2,1$ & $\mathrm{ND}$ \\
\hline \hline
\end{tabular}

Os valores de $\mathrm{pD}_{2}$ (-log $\mathrm{EC50}$ ) e $\mathrm{R}_{\operatorname{MAX}}$ (Resposta máxima) representam a média \pm epm. $\mathrm{ND}=$ não foi determinada a pD2 por ter havido diferença significativa na resposta máxima. EC50 = concentração que promove $50 \%$ da $\mathrm{R}_{\mathrm{MAX}}$. a-CGRP (8-37)= antagonista do receptor do peptídeo relacionado ao gene da calcitonina MRS 2179= antagonista do receptor da substância $P$ $n=6 /$ grupo. ${ }^{*} p<0.05$ vs. LZR, ${ }^{\#} p<0.05$ vs. o respectivo grupo na ausência do antagonista. 


\subsection{Avaliação da Resposta Vasodilatadora à Capsaicina}

O relaxamento máximo induzido pela capsaicina foi reduzido em OZRs quando comparados ao grupo LZR (Figura 12, Tabela 8).

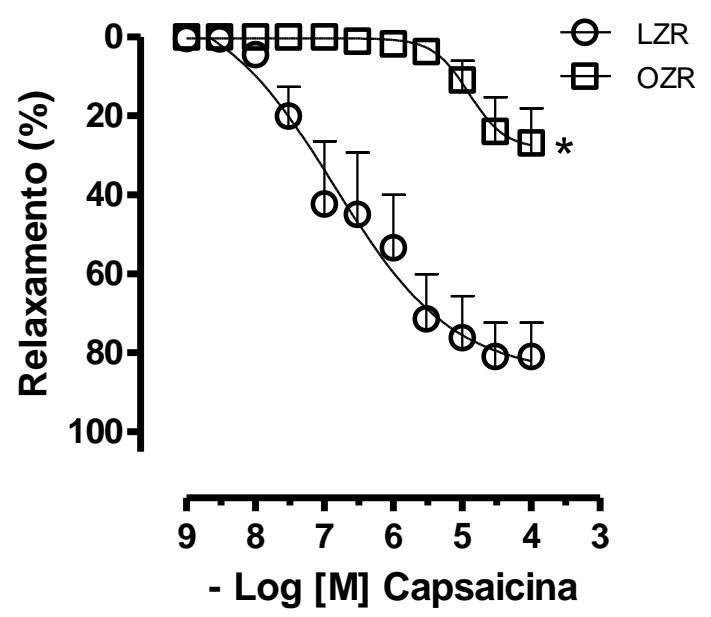

Figura 12 - Curvas concentração-efeito à capsaicina em artérias mesentéricas de resistência isoladas de ratos controles Zucker (LZR) e obesos Zucker (OZR) com 6-7 semanas de idade. Artérias mesentéricas com o endotélio intacto foram contraídas com o composto U46619 (1 $\mu \mathrm{M})$ e curvas concentraçãoefeito à capsaicina foram realizadas. Cada ponto representa a média \pm epm. $n=5 /$ grupo. ${ }^{*} p<0.05$ vs. LZR. 
Tabela 8 - Resposta à capsaicina em artérias mesentéricas de resistência isoladas de ratos controles Zucker (LZR) e obesos Zucker (OZR) com 6-7 semanas de idade.

\begin{tabular}{ccccc}
\hline & \multicolumn{2}{c}{ LZR } & \multicolumn{2}{c}{ OZR } \\
\hline & $\mathrm{R}_{\mathrm{MAX}}$ & $\mathrm{pD}_{2}$ & $\mathrm{R}_{\mathrm{MAX}}$ & $\mathrm{pD}_{2}$ \\
Capsaicina & $85,4 \pm 12,2$ & $\mathrm{ND}$ & $28,3 \pm 5,1^{*}$ & $\mathrm{ND}$ \\
\hline \hline
\end{tabular}

Os valores de $\mathrm{pD}_{2}$ (-log $\mathrm{EC50}$ ) e $\mathrm{R}_{\mathrm{MAX}}$ (Resposta máxima) representam a média \pm epm. $\mathrm{ND}=$ não foi determinada a pD2 por ter havido diferença significativa na resposta máxima. $E C 50=$ concentração que promove $50 \%$ da $R_{\text {MAX }}$. $n=5 /$ grupo. * $p<0.05$ vs. LZR. 


\subsection{Participação dos Fatores Relaxantes Derivados do Endotélio na Resposta} à Anandamida

A incubação com L-NAME, inibidor da NOS, ou indometacina, inibidor inespecífico da COX, reduziu a vasodilatação à anandamida em LZRs. No grupo OZR a resposta à anandamida não foi alterada pela incubação com estes agentes (Figuras 13A e B, Tabela 9). De modo similar, a incubação simultânea com apamina e caribidotoxina, bloqueadores de canais de $\mathrm{K}^{+}$, resultou na redução da sensibilidade à anandamida no grupo LZR, sem alteração da resposta a este agonista no grupo OZR (Figura 13C, Tabela 9).
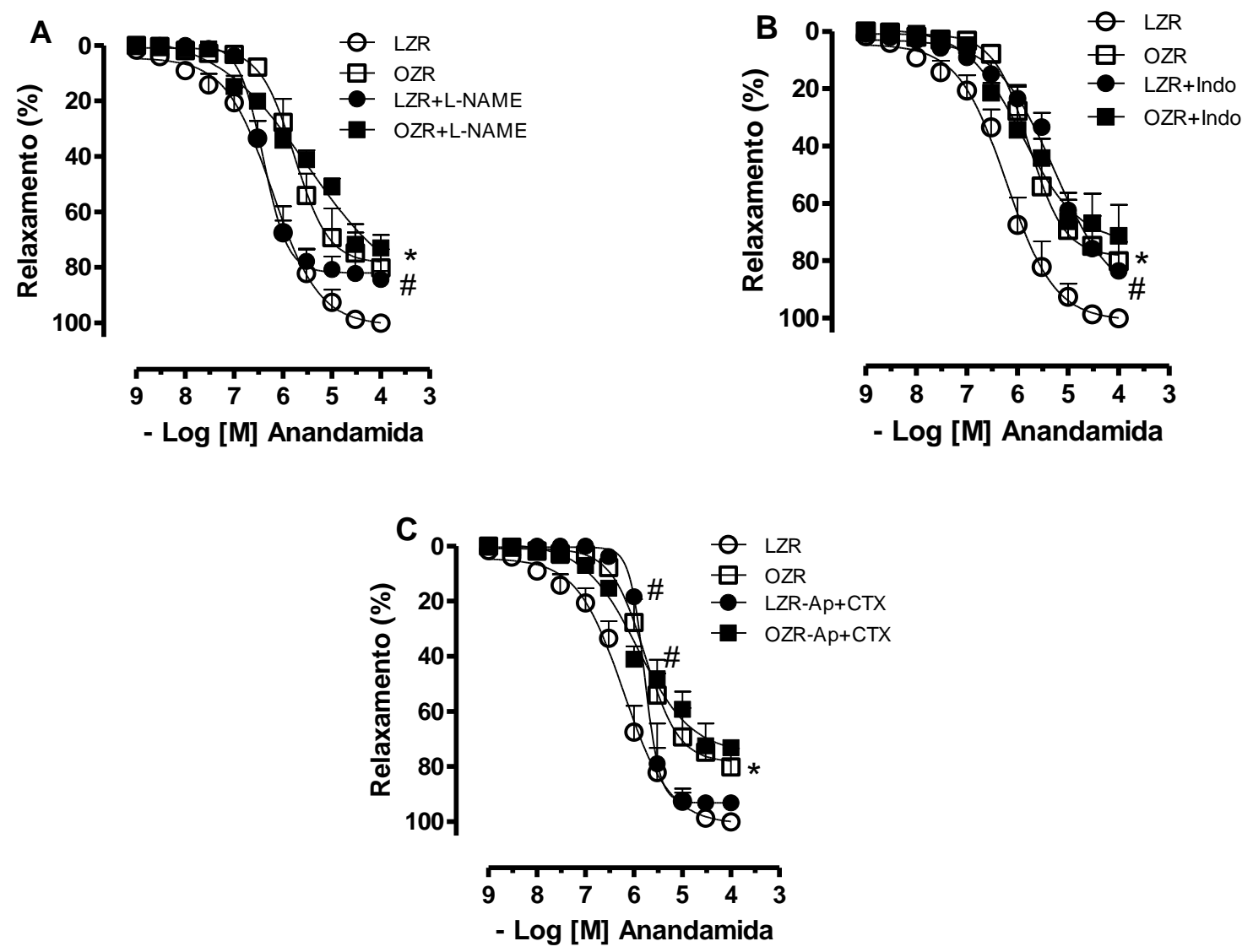

Figura 13 - Curvas concentração-efeito à anandamida em artérias mesentéricas de resistência isoladas de ratos controles Zucker (LZR) e obesos Zucker (OZR) com 6-7 semanas de idade. Artérias mesentéricas com o endotélio intacto foram contraídas com o composto U46619 (1 $\mu \mathrm{M})$ e curvas concentraçãoefeito à anandamida foram realizadas. A- curvas concentração-efeito na presença de L-NAME, inibidor da NOS; B- curvas concentração-resposta na presença de indometacina (Indo), inibidor da enzima COX; C- curvas concentração-resposta na presença de apamina (Ap) e caribidotoxina (CTX), bloqueadores de canais de $\mathrm{K}^{+}$. Cada ponto representa a média \pm epm. $n=6 /$ grupo. * $p<0.05$ vs. LZR, ${ }^{\#} p<0.05$ vs. LZR na ausência de bloqueio. 
Tabela 9 - Participação dos fatores relaxantes derivados do endotélio na resposta à anandamida em artérias mesentéricas de resistência isoladas de ratos controles Zucker (LZR) e obesos Zucker (OZR) com 6-7 semanas de idade.

\begin{tabular}{ccccc}
\hline \hline & \multicolumn{2}{c}{ LZR } & \multicolumn{2}{c}{ OZR } \\
\hline & $\mathrm{R}_{\mathrm{MAX}}$ & $\mathrm{pD}_{2}$ & $\mathrm{R}_{\mathrm{MAX}}$ & $\mathrm{pD}_{2}$ \\
Anandamida & $100,7 \pm 3,6$ & $6,3 \pm 0,1$ & $75,2 \pm 4,0^{*}$ & $5,8 \pm 0,09$ \\
Anandamida + L-NAME & $82,0 \pm 1,6 \#$ & $\mathrm{ND}$ & $73,0 \pm 2,0^{*}$ & $\mathrm{ND}$ \\
Anandamida + Indo & $83,5 \pm 3,2 \#$ & $\mathrm{ND}$ & $74,1 \pm 3,7^{*}$ & $\mathrm{ND}$ \\
Anandamida + Ap + CTX & $93,2 \pm 2,2$ & $5,7 \pm 0,03 \#$ & $75,3 \pm 3,8^{*}$ & $5,9 \pm 0,1$ \\
\hline \hline
\end{tabular}

Os valores de $\mathrm{pD}_{2}$ (-log $\mathrm{EC50}$ ) e $\mathrm{R}_{\mathrm{MAX}}$ (Resposta máxima) representam a média \pm epm. $\mathrm{ND}=$ não foi determinada a pD2 por ter havido diferença significativa na resposta máxima. EC50- concentração que promove $50 \%$ da $R_{\text {MAX. }}$.

L-NAME = inibidor da enzima óxido nítrico sintase (NOS)

Indometacina (Indo)= inibidor da enzima COX

Apamina $(\mathrm{Ap})=$ bloqueador de canais de $\mathrm{K}^{+}$.

Caribidotoxina $(\mathrm{CTX})=$ bloqueador de canais de $\mathrm{K}^{+}$.

* $p<0.05$ vs. LZR, " $p<0.05$ vs. LZR na ausência de bloqueio. 


\subsection{Participação dos Mecanismos de Transporte e de Metabolização da Anandamida em LZRs e OZRs}

A inibição do transporte de anandamida com o composto AM404 reduziu significantemente a resposta a este agonista no grupo LZR sem afetá-la em OZRs (Figura 14A, Tabela 10). Por outro lado, a redução da resposta à anandamida observada em OZRs foi corrigida pela incubação com o inibidor da enzima FAAH, o composto URB597. A resposta à anandamida não foi alterada em LZRs na presença deste inibidor (Figura 14B, Tabela 10).
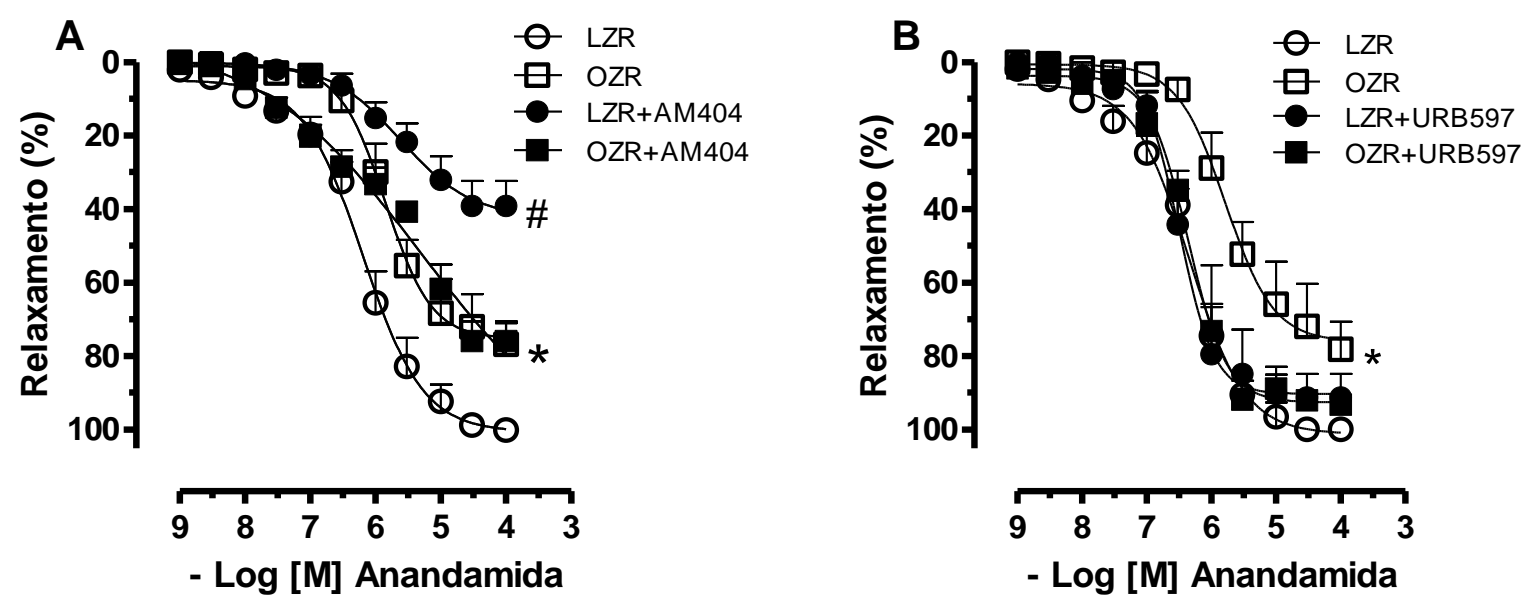

Figura 14 - Curvas concentração-efeito à anandamida na presença de AM404 (A), inibidor do transporte de anandamida ou URB 597, inibidor da enzima FAAH (B), em artérias mesentéricas de resistência isoladas de ratos controles Zucker (LZR) e obesos Zucker (OZR) com 6-7 semanas de idade. Artérias mesentéricas com o endotélio intacto foram contraídas com o composto U46619 $(1 \mu \mathrm{M})$ e curvas concentração-efeito à anandamida foram realizadas. Cada ponto representa a média \pm epm. $n=5-6$ /grupo. * $p<0.05$ vs. LZR, ${ }^{\#} p<0.05$ vs. LZR na ausência de bloqueio. 
Tabela 10 - Participação dos mecanismos de transporte e de metabolização da anandamida em artérias mesentéricas de resistência isoladas de ratos controles Zucker (LZR) e obesos Zucker (OZR) com 6-7 semanas de idade.

\begin{tabular}{ccccc}
\hline \hline & \multicolumn{2}{c}{ LZR } & \multicolumn{2}{c}{ OZR } \\
\hline & $\mathrm{R}_{\mathrm{MAX}}$ & $\mathrm{pD} \mathrm{R}_{\mathrm{MAX}}$ & $\mathrm{pD}_{2}$ \\
Anandamida & $101,2 \pm 2,8$ & $\mathrm{ND}$ & $76,04 \pm 5,4^{*}$ & $\mathrm{ND}$ \\
Anandamida + AM404 & $42,3 \pm 5,5 \#$ & $\mathrm{ND}$ & $75,85 \pm 4,2$ & $\mathrm{ND}$ \\
Anandamida + URB597 & $90,3 \pm 3,6$ & $\mathrm{ND}$ & $92,6 \pm 2,8 \#$ & $\mathrm{ND}$ \\
\hline \hline
\end{tabular}

Os valores de $\mathrm{pD}_{2}$ (-log $\mathrm{EC50}$ ) e $\mathrm{R}_{\mathrm{MAX}}$ (Resposta máxima) representam a média \pm epm. $\mathrm{ND}=$ não foi determinada a pD2 por ter havido diferença significativa na resposta máxima. $E C 50=$ concentração que promove $50 \%$ da $R_{\text {MAX }}$.

AM404= inibidor do transporte de anandamida

URB 597= inibidor da enzima hidrosilase de amida de ácido graxo (FAAH)

$n=5-6 /$ grupo. * $p<0.05$ vs. LZR, ${ }^{\#} p<0.05$ vs. o respectivo grupo na ausência de bloqueio. 


\subsection{Participação da Via do cAMP e da AMPK na Resposta à Anandamida}

A incubação com forskolin, ativador da adenilil ciclase, corrigiu a redução da resposta à anandamida em OZRs sem afetar essa resposta em LZRs (Figura 15A, Tabela 11). Adicionalmente, a incubação com o inibidor da adenilil ciclase (SQ2256) reduziu significantemente a resposta à anandamida em LZRs, sem afetar essa resposta em OZRs (Figura 15B, Tabela 11). Do mesmo modo, a ativação da enzima AMPK pelo uso do composto AICAR corrigiu a redução da vasodilatação mediada pela anandamida em OZRs (Figura 15C, Tabela 11).
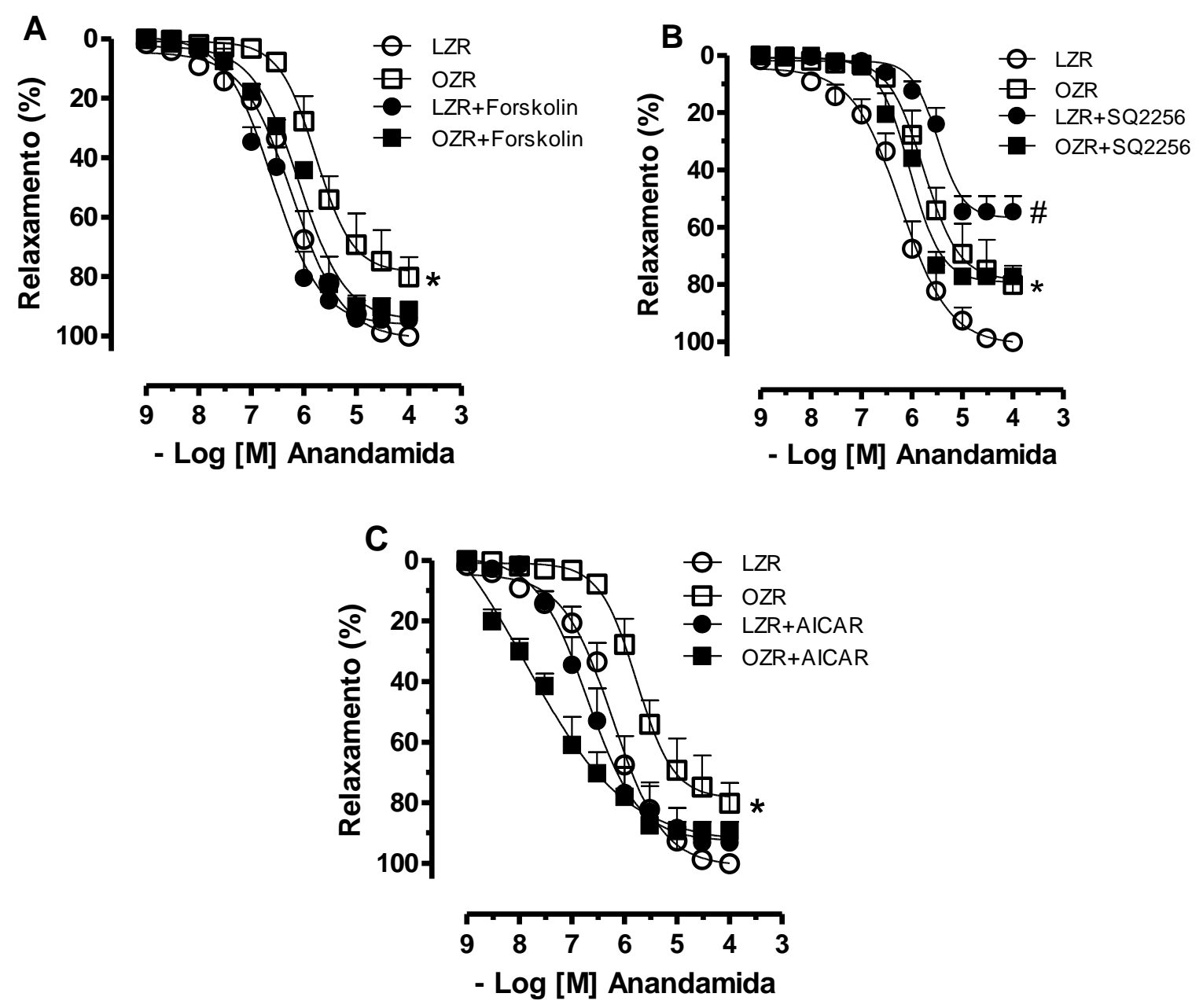

Figura 15 - Curvas concentração-efeito à anandamida na presença de forskolin, ativador da adenilil ciclase (A), SQ2256, inibidor da adenilil ciclase (B) e AICAR, ativador da enzima AMPK (C), em artérias mesentéricas de resistência isoladas de ratos controles Zucker (LZR) e obesos Zucker (OZR) com 6-7 semanas de idade. Artérias mesentéricas com 0 endotélio intacto foram contraídas com 0 composto U46619 $(1 \mu \mathrm{M})$ e curvas concentração-efeito à anandamida foram realizadas. Cada ponto representa a média \pm epm. $n=6 /$ grupo. ${ }^{*} p<0.05$ vs. LZR. 


\subsection{Participação da ERK1/2 na Resposta à Anandamida}

A incubação de artérias mesentéricas de OZRs com o composto Pd 98059, inibidor da ERK1/2, corrigiu a redução da resposta à anandamida. A resposta do grupo LZR não foi significantemente afetada na presença deste inibidor (Figura 16, Tabela 11).

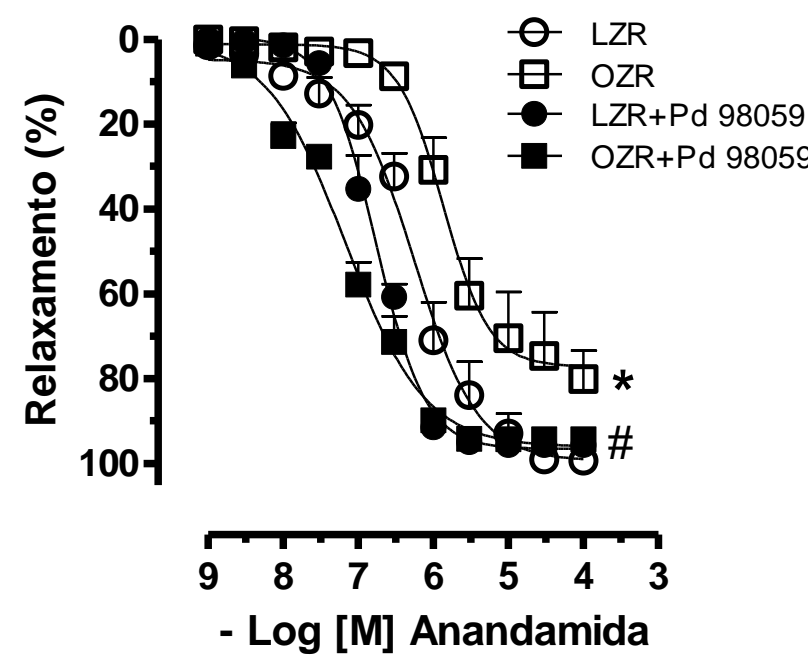

Figura 16 - Curvas concentração-efeito à anandamida na presença de Pd98059, inibidor da ERK 1/2, em artérias mesentéricas de resistência isoladas de ratos controles Zucker (LZR) e obesos Zucker (OZR) com 6-7 semanas de idade. Artérias mesentéricas com o endotélio intacto foram contraídas com o composto U46619 $(1 \mu \mathrm{M})$ e curvas concentração-efeito à anandamida foram realizadas. Cada ponto representa a média \pm epm. $n=6 /$ grupo. ${ }^{*} p<0.05$ vs. LZR, ${ }^{\#} p<0.05$ vs. LZR na ausência de bloqueio. 
Tabela 11 - Participação de vias de sinalização intracelulares na resposta à anandamida em artérias mesentéricas de resistência isoladas de ratos controles Zucker (LZR) e obesos Zucker (OZR) com 6-7 semanas de idade.

\begin{tabular}{ccccc}
\hline \hline & \multicolumn{2}{c}{ LZR } & \multicolumn{2}{c}{ OZR } \\
\hline & $\mathrm{R}_{\mathrm{MAX}}$ & $\mathrm{pD} 2$ & $\mathrm{R}_{\mathrm{MAX}}$ & $\mathrm{pD}_{2}$ \\
Anandamida & $99,4 \pm 3,3$ & $6,2 \pm 0,1$ & $77,16 \pm 4,1^{*}$ & $5,9 \pm 0,1$ \\
Anandamida + forskolin & $96,3 \pm 3,1$ & $\mathrm{ND}$ & $94,7 \pm 2,7$ & $\mathrm{ND}$ \\
Anandamida + SQ2256 & $56,7 \pm 2,8 \#$ & $\mathrm{ND}$ & $79,2 \pm 2,6$ & $\mathrm{ND}$ \\
Anandamida + AICAR & $92,7 \pm 3,9$ & $\mathrm{ND}$ & $93,4 \pm 5,2$ & $\mathrm{ND}$ \\
Anandamida + Pd 98059 & $96,6 \pm 1,3$ & $6,8 \pm 0,03 \#$ & $96,1 \pm 1,8$ & $7,1 \pm 0,1$ \\
\hline \hline
\end{tabular}

Os valores de $\mathrm{pD}_{2}$ (-log $\left.\mathrm{EC} 50\right)$ e $\mathrm{R}_{\mathrm{MAX}}$ (Resposta máxima) representam a média \pm epm. $\mathrm{ND}=$ não foi determinada a pD2 por ter havido diferença significativa na resposta máxima. $E C 50=$ concentração que promove $50 \%$ da $R_{\text {MAX }}$.

Forskolin= ativador da adenilil ciclase

SQ2256= inibidor da adenilil ciclase

AICAR = ativador da enzima AMPK

Pd98059= inibidor da ERK1/2

$n=6 /$ grupo. * $p<0.05$ vs. LZR, ${ }^{\#} p<0.05$ vs. LZR na ausência de bloqueio. 


\subsection{Análise da Expressão Protéica dos Receptores Canabinóides (CB1 e CB2) e do Receptor Vanilóide (TRPV-1)}

A expressão dos receptores canabinóides CB1 e CB2 foi menor em artérias mesentéricas de OZRs quando comparada àquela observada no grupo LZR (Figuras 17A e B). A expressão protéica do receptor TRPV-1 foi semelhante entre artérias mesentéricas dos grupos OZR e LZR (Figura 17C).
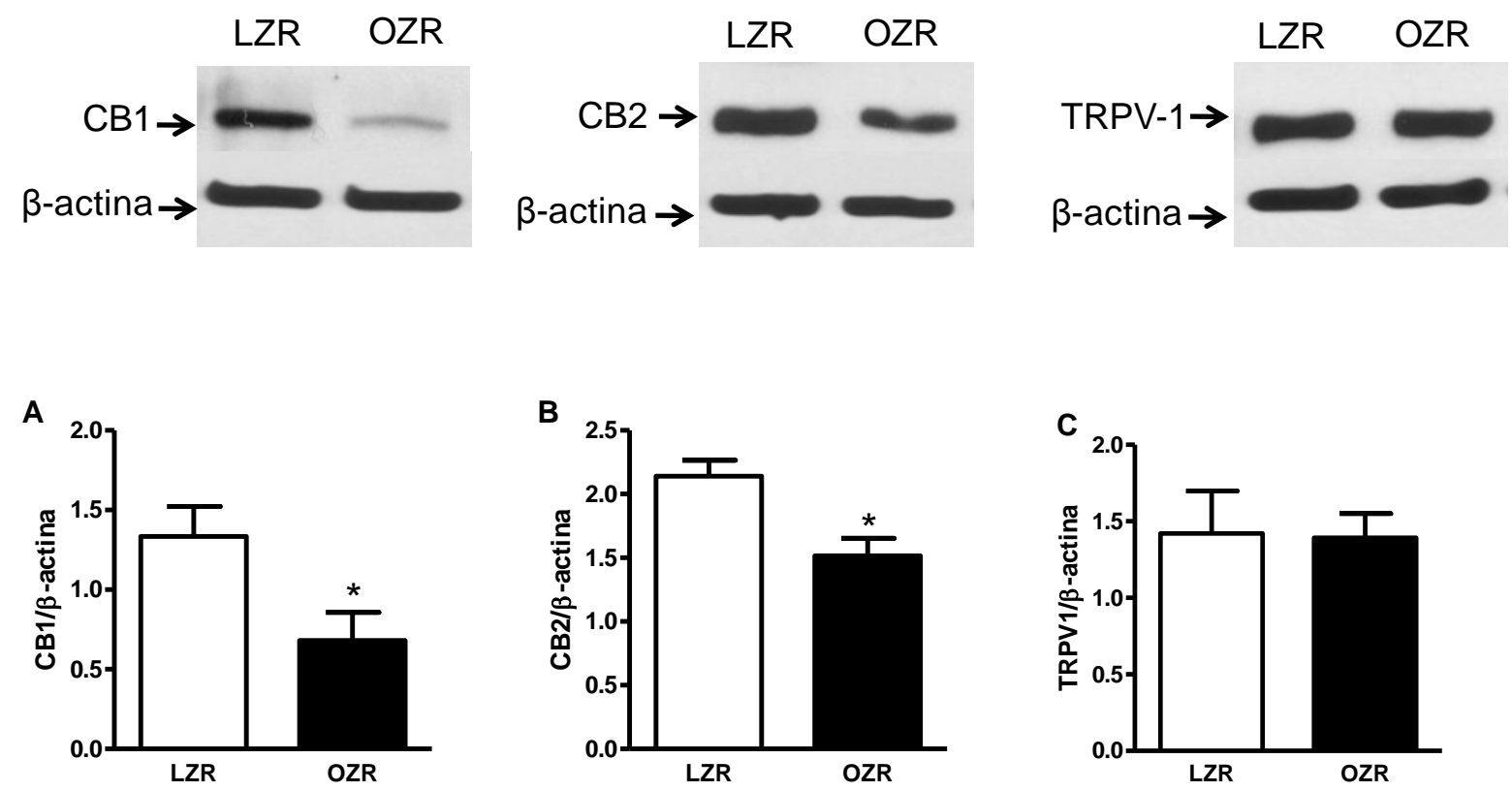

Figura 17 - Western blot para os receptores canabinóides CB1 (A, peso molecular aproximado: $60 \mathrm{kDa}$ ) e $\mathrm{CB} 2$ (B, peso molecular aproximado: $52 \mathrm{kDa}$ ), e para o receptor vanilóide TRPV-1 (C, peso molecular aproximado: 90kDa) em artérias mesentéricas com o endotélio isoladas de ratos controles Zucker (LZR) e obesos Zucker (OZR) com 6-7 semanas de idade. Os gráficos mostram a análise densitométrica da expressão dos receptores. Valores normalizados pela expressão de $\beta$-actina. Os dados são representados como média \pm epm. $n=5 /$ grupo. * $p<0.05$ vs. LZR. 


\subsection{Efeito da Anandamida sobre a Fosforilação da AMPK e da ACC}

A expressão das formas total e fosforilada das proteínas AMPK e acetil coA carboxilase (ACC) foi semelhante em artérias mesentéricas de ratos dos grupos LZR e OZR. A razão das duas formas das proteínas AMPK e ACC (fosforilada/total) foi calculada e não foi diferente entre os grupos (Figura 18A). A incubação com anandamida não alterou a expressão protéica da forma total da AMPK e da ACC nos vasos de LZRs ou de OZRs. Porém, a expressão da forma fosforilada da AMPK e da ACC está aumentada após estímulo por 30 minutos com anandamida em vasos do grupo LZR (Figuras 18A e B). Em OZRs, a incubação com anandamida diminuiu a razão das formas fosforilada/total da AMPK e da ACC, indicando menor fosforilação destas proteínas (Figura 18A e B).
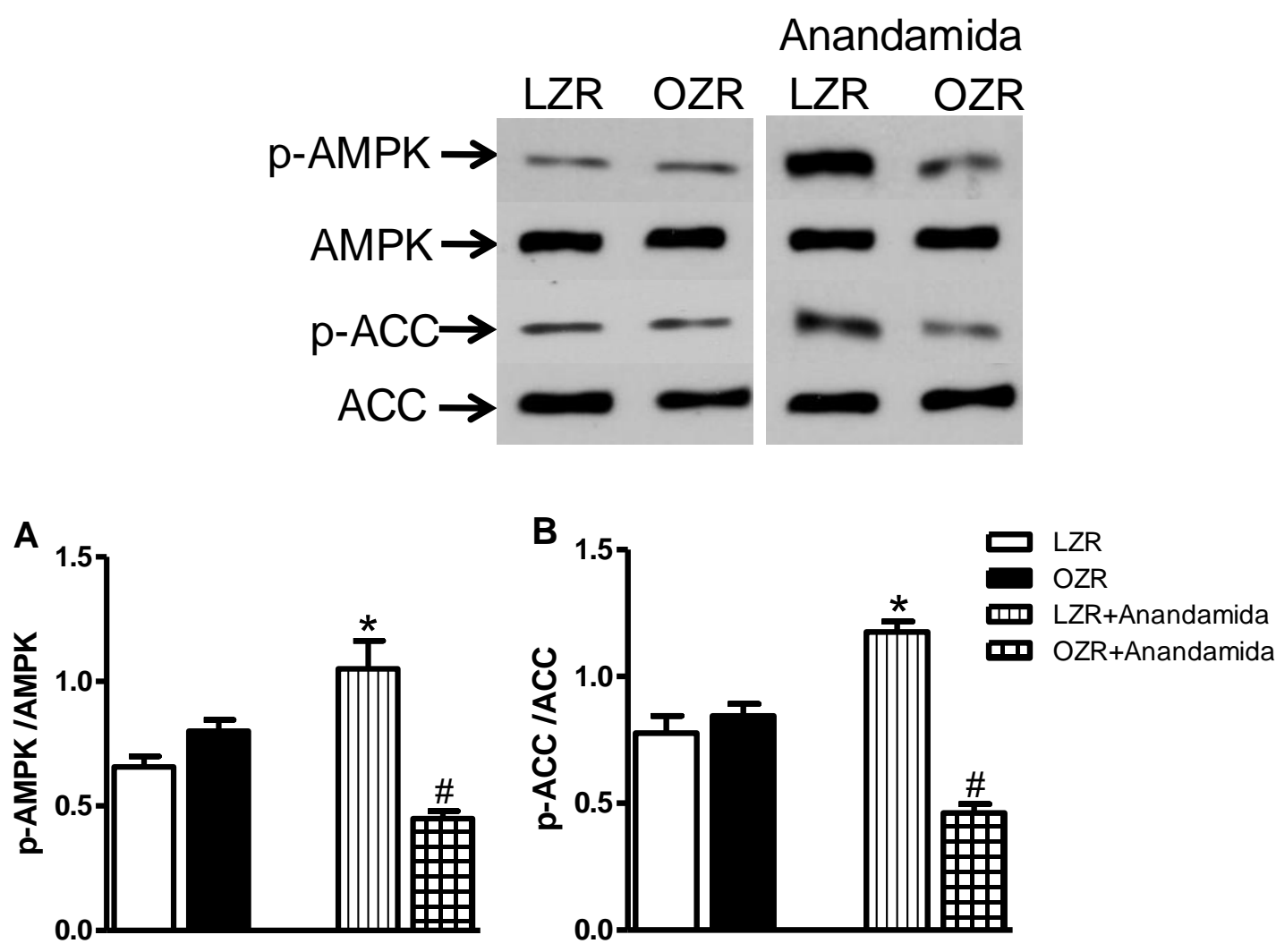

Figura 18 - Imagens representativas do Western blot para a proteína quinase ativada por AMP (AMPK, peso molecular aproximado: 63kDa) e para a acetil coA carboxilase (ACC, peso molecular aproximado: $250 \mathrm{kDa}$ ), nas formas total e fosforilada ( $p$ ) em artérias mesentéricas com endotélio isoladas de ratos controles Zucker (LZR) e obesos Zucker (OZR) com 6-7 semanas de idade, submetidas ou não à incubação com anandamida (1 $\mu \mathrm{M}, 30$ minutos). Os gráficos mostram a razão das formas total e fosforilada das proteínas AMPK (A) e ACC (B). Os dados são representados como média \pm epm. $n=5 / g r u p o$. ${ }^{*} p<0.05$ vs. LZR, ${ }^{\#} p<0.05$ vs. OZR. 


\subsection{Efeito da Anandamida sobre a Fosforilação da ERK1/2}

A expressão da forma total da proteína ERK1/2 foi semelhante em artérias mesentéricas de ratos dos grupos LZR e OZR. Porém, a forma fosforilada dessa proteína apresentou expressão aumentada em vasos do grupo OZR quando comparado ao grupo LZR. De fato, a razão das duas formas da proteína ERK1/2 (fosforilada/total) é maior no grupo OZR, indicando ativação aumentada desta MAPK no grupo OZR (Figura 19). A incubação com anandamida não alterou a expressão protéica da forma total da ERK1/2 nos vasos dos dois grupos experimentais estudados. Porém, a forma fosforilada dessa proteína apresentou expressão aumentada após estímulo por 30 minutos com anandamida em vasos do grupo LZR. Em OZRs, a fosforilação da ERK1/2 foi potencializada após a incubação com anandamida, o que pode ser evidenciado pelo aumento da razão fosforilada/total desta proteína neste grupo (Figura 19).

\section{Anandamida}
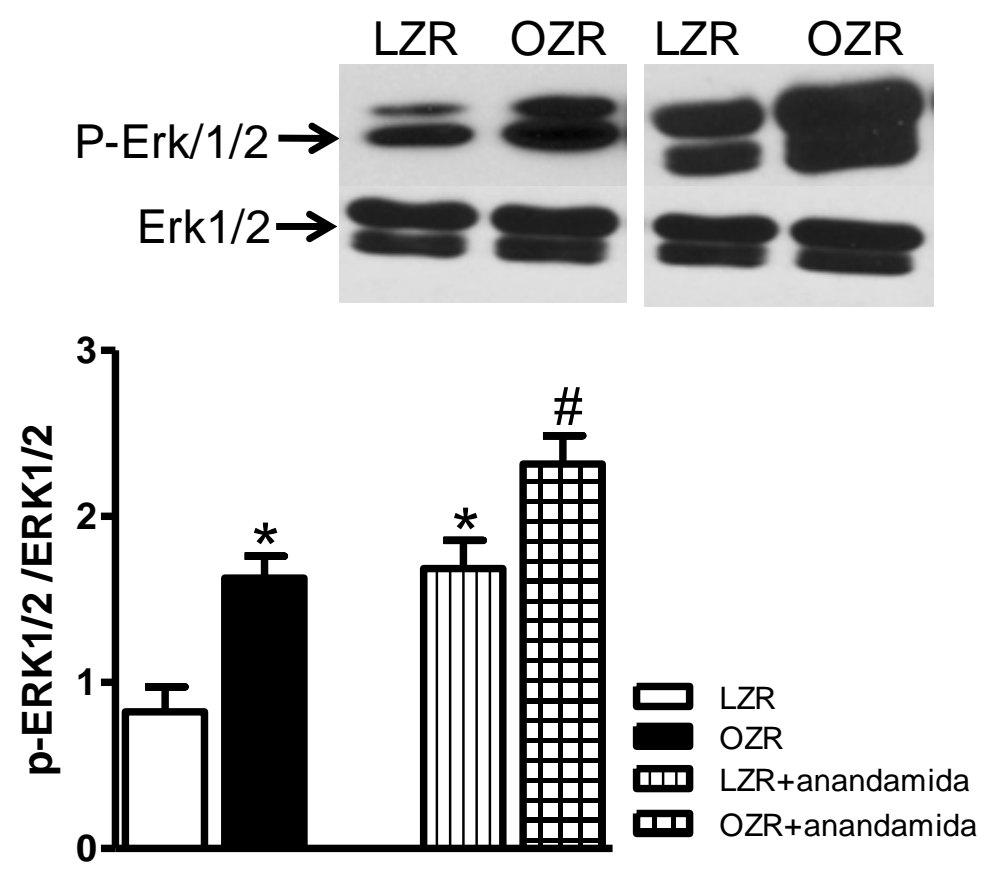

Figura 19 - Imagens representativas do Western blot para a proteína ERK1/2 (peso molecular aproximado: $42 / 44 \mathrm{kDa}$ ), nas formas total e fosforilada (p) em artérias mesentéricas com endotélio isoladas de ratos controles Zucker (LZR) e obesos Zucker (OZR) com 6-7 semanas de idade, submetidas ou não à incubação com anandamida ( $1 \mu \mathrm{M}, 30$ minutos). $\mathrm{O}$ gráfico mostra a razão das formas total e fosforilada da proteína ERK1/2. Os dados são representados como média \pm epm. $n=5 /$ grupo. * $p<0.05$ vs. LZR, ${ }^{\#} p<0.05$ vs. OZR. 


\subsection{Efeito da Anandamida sobre a Fosforilação da eNOS}

A expressão da enzima óxido nítrico sintase endotelial (eNOS) foi semelhante em artérias mesentéricas de ratos dos grupos LZR e OZR tanto na forma total quanto na forma fosforilada. A incubação com anandamida não alterou a expressão protéica de eNOS nos vasos dos dois grupos experimentais estudados. Porém, a forma fosforilada dessa proteína apresentou expressão aumentada após estímulo por 30 minutos com anandamida em vasos do grupo LZR. Em OZRs, a fosforilação da eNOS diminuiu após incubação com anandamida (Figura 20).

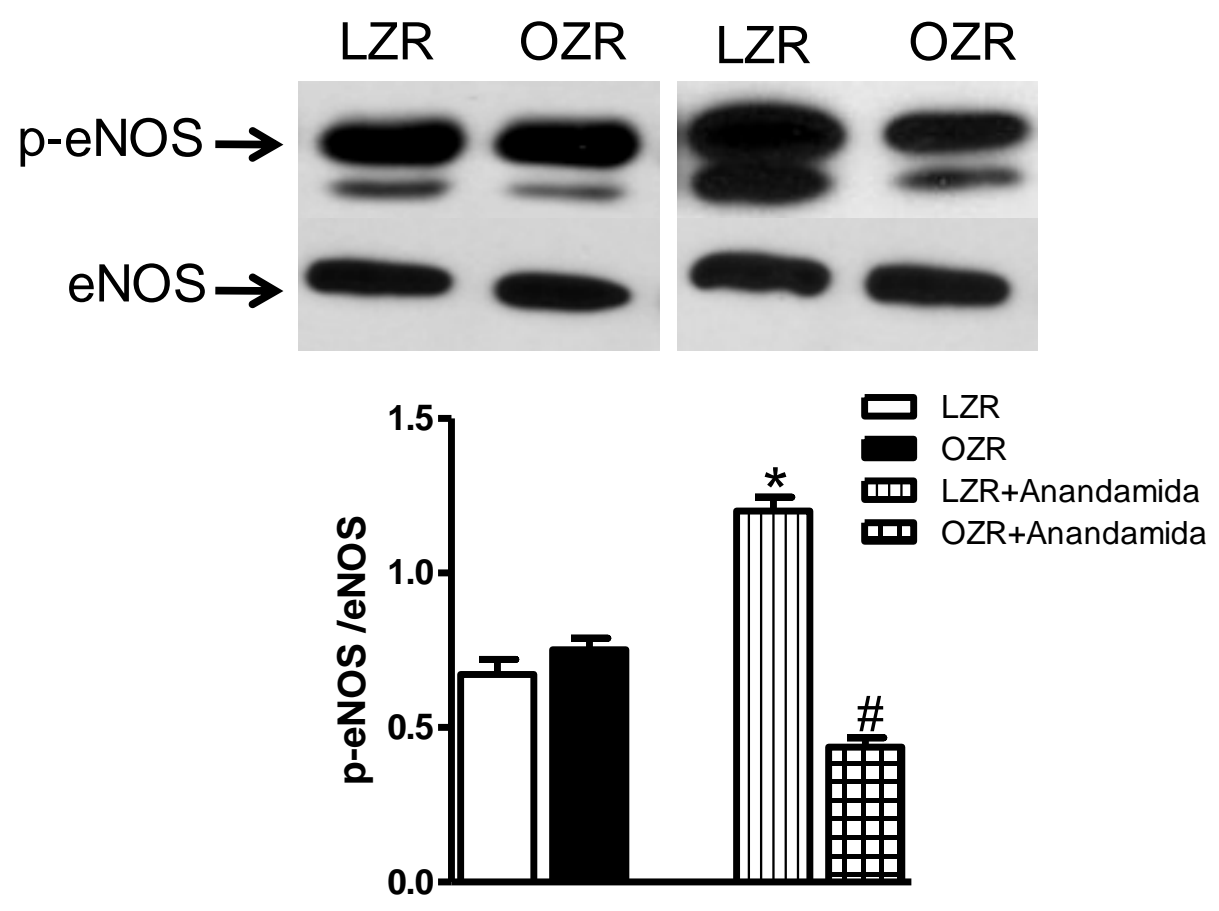

Figura 20 - Imagens representativas do Western blot para a enzima óxido nítrico sintase endotelial (eNOS, peso molecular aproximado: $130 \mathrm{kDa}$ ), nas formas total e fosforilada em artérias mesentéricas isoladas de ratos controles Zucker (LZR) e obesos Zucker (OZR) com 6-7 semanas de idade. O gráfico mostra a análise densitométrica da expressão dos receptores. Os dados são representados como média \pm epm. $n=5$ /grupo. ${ }^{*} p<0.05$ vs. LZR, ${ }^{\#} p<0.05$ vs. OZR. 


\subsection{Localização dos Receptores Canabinóides CB1 e CB2}

A localização dos receptores CB1 e CB2 juntamente com o fator de Von Willebrand foi demonstrada pela imunofluorescência em segmentos de artéria mesentérica com o endotélio intacto. A imunofluorescência para receptores CB1 (Figura 21A) e CB2 (Figura 21B) foi encontrada em artérias mesentéricas de LZRs. Para determinar se os receptores CB1 e CB2 estavam localizados nas células endoteliais, utilizamos a marcação dupla das artérias mesentéricas para receptores CB1 ou CB2 juntamente com a marcação para o fator de Willebrand, um marcador de célula endotelial amplamente utilizado. $O$ fator de Von Willebrand foi visualizado utilizando um anticorpo secundário para von Willebrand vermelho fluorescente, ao passo que os receptores $\mathrm{CB} 1$ e $\mathrm{CB} 2$ foram visualizados com anticorpos secundários fluorescentes de coloração verde. A co-localização de CB1 ou CB2 com o fator de Von Willebrand, conforme observado pela cor amarela resultante da sobreposição das imagens de CB1, CB2 e Von Willebrand foi encontrada nas células endoteliais de LZRs e de OZRs. Artérias mesentéricas de OZRs exibiram diminuída imunofluorescência para CB1 (Figura 21C) e CB2 (Figura 21D) tanto no endotélio quanto em células do músculo liso vascular, indicando redução da expressão desses receptores tanto no endotélio quanto no músculo liso vascular de OZRs. 


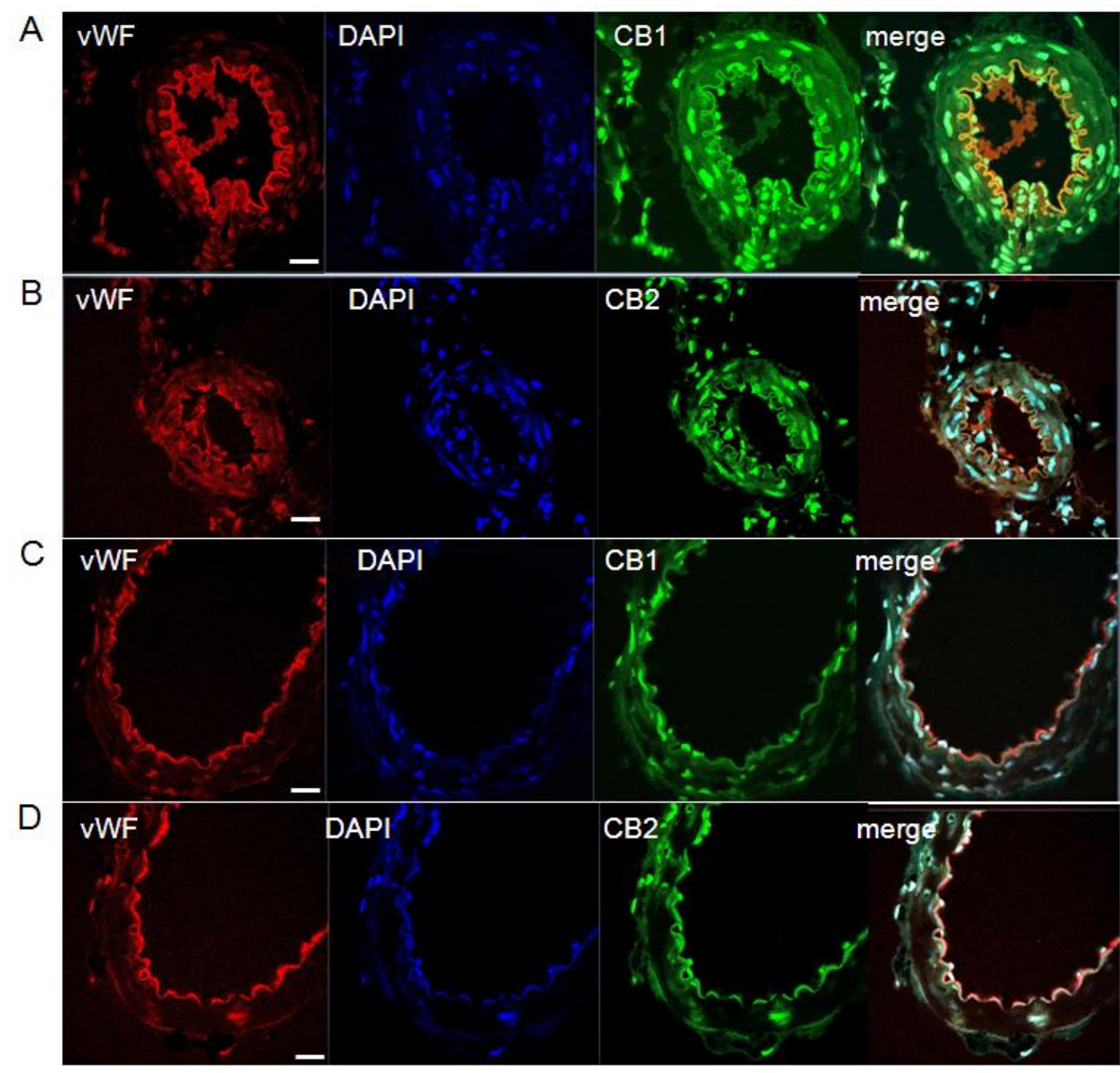

Figura 21 - Imagens de microscopia confocal do fator de Von Willebrand (vWF, em vermelho), do DAPI (em azul) e dos receptores CB1 e CB2 (em verde) em artérias mesentéricas de ratos controles Zucker (LZR) e obesos Zucker (OZR) com 6-7 semanas de idade. Segmentos de artérias mesentéricas com 0 endotélio intacto foram marcados com anticorpos contra CB1, CB2 e fator de Von Willebrand. O núcleo foi contra marcado com DAPI. Uma sobreposição das imagens do vWF, DAPI e CB1 ou CB2 está representada (merge). A localização endotelial de receptores CB1 e CB2 está demonstrada nas imagens sobrepostas em alaranjado (merge). As imagens são representativas de 4 experimentos separados. $n=4 / g r u p o$. Barra de escalas $=40 \mu \mathrm{m}$. 


\section{DISCUSSÃO}

Os estudos desenvolvidos no sentido de avaliar as funções que podem ser afetadas pelos compostos canabinóides têm enfocado a regulação da homeostase energética ${ }^{1}$ 20,107. Entretanto, as respostas aos agonistas canabinóides não são restritas apenas aos tecidos que controlam os parâmetros metabólicos. Os canabinóides endógenos também contribuem para a regulação do tônus vascular em condições fisiológicas, promovendo relaxamento em diversos territórios vasculares, principalmente em vasos de resistência ${ }^{28-30,36}$. Considerando que na obesidade ocorre prejuízo da função vascular ${ }^{60-63}$, o propósito do presente estudo foi investigar os efeitos da obesidade sobre a resposta de artérias mesentéricas de resistência a agonistas canabinóides.

Para a realização deste estudo, utilizamos OZRs jovens (6-7 semanas de idade). Os OZRs têm sido amplamente utilizados para investigar os efeitos metabólicos e cardiovasculares promovidos pela obesidade e pela resistência à insulina ${ }^{80,108-113}$. É importante considerar que, embora a causa da obesidade em OZRs não seja comum à de humanos, o fenótipo desse modelo experimental se assemelha muito à obesidade humana em diversas características. Esses ratos apresentam hiperfagia, hipertrigliceridemia, hiperinsulinemia e, eventualmente, desenvolvem diabetes tipo $2^{64-66}$. Além dessas alterações, demonstrou-se que OZRs podem desenvolver aumento significante dos níveis pressóricos ${ }^{74}$.

Observamos no presente estudo que entre 6 e 7 semanas de idade os níveis sanguíneos de glicose, assim como os níveis pressóricos, não estão elevados em OZRs. Estes resultados estão de acordo com aqueles observados por estudo recente onde se verificou que OZRs apresentam aumento da pressão arterial apenas na fase adulta (14 a 16 semanas) ${ }^{80}$. A elevação dos níveis glicêmicos é observada apenas eventualmente em OZRs. De fato, o estudo realizado por Osmond e colaboradores (2009) ${ }^{80}$ demonstrou que nem mesmo na fase adulta, os OZRs desenvolveram alterações no perfil glicêmico. Porém, a presença de resistência à insulina já foi detectada nos animais com 6-7 semanas de idade ${ }^{80}$, indicando que OZRs jovens representam um modelo normotenso de obesidade resistência à insulina. Estas observações justificam a utilização deste modelo em 
nosso estudo na idade de 6-7 semanas, uma vez que aumento dos níveis pressóricos bem como hiperglicemia são fatores que podem contribuir para alterações na atividade do sistema endocanabinóide ${ }^{24,29}$ e poderiam, portanto, interferir na interpretação dos dados.

No presente estudo, demonstramos que OZRs ainda na fase jovem, já apresentam disfunção vascular em artérias mesentéricas de resistência, demonstrada pela redução do relaxamento dependente de endotélio mediado pela ACh e pelo aumento da resposta vasoconstritora mediada pela FE. O aumento da contração vascular em OZRs parece estar relacionado com prejuízo em vias de sinalização presentes tanto no endotélio quanto no músculo liso vascular, uma vez que esta alteração foi observada tanto em anéis com o endotélio intacto quanto naqueles onde o endotélio foi removido mecanicamente. Alterações vasculares já foram bem descritas em OZRs. Estudos prévios realizados por diversos grupos de pesquisa têm demonstrado alterações estruturais ${ }^{108-109}$, bem como prejuízo no relaxamento e aumento na contração vascular em OZRs quando estes animais se encontram na fase adulta ${ }^{110-113}$. No presente estudo demonstramos que a disfunção vascular em OZRs já se estabelece na fase jovem deste modelo de obesidade, período no qual a hiperglicemia ou o aumento da pressão arterial ainda não estão presentes, indicando efeito específico da obesidade sobre o prejuízo da função vascular neste modelo.

O papel de vias de sinalização ativadas pelo sistema canabinóide na disfunção vascular de OZRs pode ser sugerido em nosso estudo uma vez que a incubação com o agonista canabinóide anandamida foi capaz de corrigir a redução do relaxamento à $A C h$ em OZRs sem afetar essa resposta no grupo LZR. O fato por nós observado, de que a incubação com anandamida não corrigiu o aumento da resposta vasoconstritora em artérias mesentéricas sem endotélio de OZRs, leva-nos a sugerir que vias endoteliais envolvidas na liberação de fatores relaxantes participam do efeito da anandamida.

Com o objetivo de investigar se a obesidade prejudica a resposta mediada pelo sistema canabinóide no vaso sanguíneo, afetando com isto, a resposta a agentes vasoativos, o presente estudo avaliou o relaxamento de artérias mesentéricas de resistência à anandamida, considerada um dos principais agonistas do sistema endocanabinóide ${ }^{28}$. O presente estudo foi o primeiro a demonstrar que na obesidade há prejuízo do relaxamento vascular mediado pela anandamida. 
Adicionalmente, um importante achado do presente estudo foi que, embora o relaxamento promovido pela anandamida seja independente da presença do endotélio, o prejuízo no relaxamento mediado por este agonista em artérias mesentéricas de resistência de OZRs envolve alterações endoteliais, uma vez que a resposta induzida pela anandamida em OZRs não difere daquela observada em LZRs após a remoção do endotélio. Este dado, em conjunto com a observação da resposta dependente de endotélio à $A C h$, reduzida em OZRs, confirma a existência de redução na geração e/ou liberação de fatores relaxantes pelo endotélio vascular deste modelo experimental.

Alguns estudos têm demonstrado que a anandamida regula a função cardiovascular por promover relaxamento ou por prevenir aumento nos níveis pressóricos através da ligação a receptores canabinóides CB1 ${ }^{30,114-116}$, embora as vias de sinalização intracelulares relacionadas com seu efeito vasodilatador não tenham sido ainda identificadas. Em nosso estudo, confirmamos o papel dos receptores $\mathrm{CB} 1$ mediando o relaxamento à anandamida em artérias mesentéricas de LZRs e de OZRs, uma vez que o bloqueio deste receptor pelo uso do composto AM 251 reduziu significantemente a resposta à anandamida nos dois grupos experimentais estudados. Entretanto, é importante considerar que o efeito da inibição de receptores CB1 parece ter sido mais pronunciado em OZRs, sugerindo maior participação deste receptor na resposta à anandamida neste grupo experimental. Uma condição que pode ser sugerida como envolvida nesta resposta diferenciada frente ao bloqueio de receptores canabinóides em OZRs é a redução da densidade de receptores. De fato, verificamos que OZRs apresentam redução da expressão de receptores CB1 nas artérias mesentéricas quando comparados ao grupo LZR, a qual pode ter contribuído para a redução mais pronunciada da resposta relaxante à anandamida neste grupo experimental.

Não há dados na literatura demonstrando os efeitos da obesidade sobre a expressão de receptores CB1 no sistema vascular. Entretanto, em tecidos envolvidos no controle do metabolismo lipídico e glicêmico, demonstrou-se aumento da expressão desse receptor. Essa diferença nos resultados observados pode ser explicada com base nas funções mediadas pelos agonistas canabinóides em cada um destes tecidos. No tecido adiposo, por exemplo, onde se demonstrou aumento da expressão de receptores CB1, a ativação deste sistema contribui para processos relacionados com o acúmulo de gordura ${ }^{2,22}$. No hipotálamo, o aumento da 
expressão desses receptores justifica o aumento da ingestão alimentar observado nesta condição 2, 22 . Porém, no sistema cardiovascular, os agonistas endocanabinóides contribuem para a regulação do tônus vascular, mediando a vasodilatação e a redução dos níveis pressóricos ${ }^{30,114-116}$. Considerando que a obesidade está associada com prejuízo no relaxamento vascular, é plausível sugerir que exista comprometimento na resposta mediada por agonistas deste sistema. De fato, em nosso estudo demonstramos que este comprometimento parece ocorrer em virtude de redução na expressão de receptores CB1 em artérias mesentéricas.

Além de receptores CB1, a anandamida pode também se ligar a receptores CB2, embora com menor eficácia quando comparada àquela observada com 0 receptor $\mathrm{CB} 1^{2,4,6-7}$. A expressão dos receptores $\mathrm{CB} 2$, inicialmente descrita apenas em células hematopoiéticas e em células do sistema imune, foi recentemente identificada em células endoteliais de artérias coronárias e em células de músculo liso ${ }^{117-118}$. Entretanto, o papel deste receptor no efeito vasodilatador e hipotensor da anandamida não foi ainda descrito. No presente estudo, demonstramos que 0 receptor CB2, assim como o receptor $\mathrm{CB1}$, contribui para o relaxamento mediado pela anandamida em LZRs e em OZRs, uma vez que o antagonismo deste receptor (com o composto AM630) reduziu significantemente a resposta à anandamida nos dois grupos experimentais. De modo similar ao observado com o receptor CB1, o antagonismo de receptores CB2 promoveu aparentemente um efeito mais pronunciado em OZRs do que em LZRs, o qual pode também ser explicado pela observação de que a expressão protéica desses receptores está reduzida em OZRs. Portanto, esses dados indicam que os receptores CB2, assim como os receptores CB1, estão envolvidos na redução da resposta à anandamida na obesidade.

Com o objetivo de confirmar o prejuízo no relaxamento mediado por pelos receptores CB1 e CB2 em OZRs, realizamos curvas concentração-efeito a agonistas específicos para estes receptores, os compostos ACEA e JWH-015, respectivamente. Nossos dados confirmaram a hipótese proposta anteriormente, uma vez que a resposta vascular aos agonistas específicos dos dois receptores canabinóides também foi menor em OZRs quando comparada àquela de LZRs. $A$ localização dos receptores CB1 e CB2, avaliada em nosso estudo pela técnica da imunofluorescência, confirmou a presença destes receptores tanto no endotélio quanto no músculo liso vascular de LZRs e de OZRs. Adicionalmente, a análise das imagens nos indicou redução na expressão destes receptores tanto no endotélio 
quanto no músculo liso vascular de OZRs. Com base nestas observações, os resultados do presente estudo permitem-nos concluir que a obesidade prejudica o controle da função vascular exercido por agonistas canabinóides por reduzir as respostas mediadas pela ativação de receptores $C B 1$ e CB2, como conseqüência da redução na expressão dos mesmos na vasculatura.

Considerando que o prejuízo no relaxamento induzido pela anandamida em artérias mesentéricas de OZRs está relacionado com alterações no endotélio, avaliamos a participação das diferentes vias endoteliais envolvidas no relaxamento vascular, na redução da resposta relaxante à anandamida em OZRs. Embora diversos estudos tenham descrito as cascatas de sinalização que podem ser reguladas pela ativação de receptores canabinóides em células neuronais ${ }^{28}$, muito pouco é conhecido sobre as vias de sinalização ativadas por agonistas canabinóides na vasculatura. Há evidências de que em vasos de resistência o relaxamento induzido pela anandamida depende da liberação de EDRFs ${ }^{116}$. As células endoteliais vasculares participam do controle do tônus vascular basal e da reatividade vascular por liberar uma variedade de fatores contráteis e relaxantes ${ }^{57}$. Os EDRFs incluem o NO, a PGI2 e o EDHF. O desequilíbrio na produção e/ou liberação dos fatores envolvidos no relaxamento e na contração vasculares, caracteriza a disfunção endotelial ${ }^{61}$.

$A P \mathrm{Pl}_{2}$ é um EDRF formado a partir do AA, que é metabolizado pela ação da COX ${ }^{119}$. Em 1995, Ellis e colaboradores relataram pela primeira vez que a vasodilatação promovida pela anandamida em artérias cerebrais é dependente da ativação da ciclooxigenase ${ }^{120}$. Alguns estudos adicionais confirmaram este achado em artérias coronárias ${ }^{33,121}$, porém, outros estudos têm revelado que a geração de AA e seu subseqüente metabolismo pela $\operatorname{COX}$ não é o principal mecanismo envolvido nos efeitos vasodilatadores dos compostos canabinóides. Nossos dados indicam que os produtos gerados a partir do metabolismo do AA participam do relaxamento à anandamida em LZRs, uma vez que a incubação de artérias mesentéricas desses animais com o inibidor da COX (indometacina) reduziu a resposta à anandamida, embora a magnitude desta redução tenha sido aparentemente pequena. Por outro lado, estes fatores parecem não estar envolvidos no relaxamento à anandamida em OZRs, uma vez que a inibição da COX não alterou a resposta a este agonista no grupo OZR. 
Embora a anandamida possa atuar através dos produtos formados pela via da COX, na maior parte dos territórios vasculares este agonista tem sido descrito atuar diretamente no músculo liso vascular, como, por exemplo, na vasculatura mesentérica ${ }^{122}$. As ações vasodilatadoras diretas dos endocanabinóides ganharam grande interesse após a publicação do trabalho de Randall e colaboradores (1996), sugerindo que a anandamida poderia ser um EDHF ${ }^{122}$. Embora não tenha ainda sido identificado, sabe-se que após sua formação nas células endoteliais e difusão para as células do músculo liso vascular, o EDHF promove hiperpolarização e conseqüente relaxamento. Esse mecanismo parece acontecer principalmente através da ativação de canais de $\mathrm{K}^{+} \mathrm{e}$ inibição de canais de $\mathrm{Ca}^{2+}$ dependentes de voltagem $^{123}$.

O papel do EDHF foi investigado em nosso estudo pelo uso simultâneo dos compostos apamina e caribidotoxina, que permitem avaliar a participação de canais de $\mathrm{K}^{+}$ativados por $\mathrm{Ca}^{2+}$ de baixa, média e alta condutância no relaxamento vascular 124. Nossos resultados mostraram que, semelhantemente ao observado com os prostanóides, a hiperpolarização de membrana participa do relaxamento promovido pela anandamida apenas em LZRs, sem participação no grupo OZR. Adicionalmente, assim como verificado com a indometacina, a magnitude de redução da resposta à anandamida foi aparentemente baixa em LZRs, indicando que o EDHF não é o principal componente envolvido no relaxamento promovido pela anandamida neste modelo experimental. De fato, alguns estudos não conseguiram confirmar o papel crucial da hiperpolarização de membrana na vasodilatação promovida pela anandamida ${ }^{33,125-126}$. Estas diferenças podem ser explicadas considerando-se que os mecanismos envolvidos nos efeitos vasodilatadores diretos dos canabinóides parecem ser dependentes do território vascular e das condições experimentais empregadas, provavelmente refletindo o envolvimento de diferentes receptores vasculares e diferentes vias de sinalização que são acopladas à ativação destes receptores, dependendo do território vascular estudado. Cada território vascular pode ter uma regulação local particular do tônus vascular que poderia, por sua vez, contribuir diferencialmente para os efeitos hemodinâmicos globais dos canabinóides.

Dentre os EDRFs, o NO tem papel crucial na regulação do tônus vascular ${ }^{57}$. O NO é formado a partir do metabolismo do aminoácido L-arginina através da enzima NOS. A isoforma eNOS produz NO constantemente para manter o tônus 
vascular e também pode ser estimulada por alguns agonistas. Uma vez produzido, o NO é liberado pelo endotélio e difunde-se para as células do músculo liso vascular, ativando a guanilato ciclase solúvel, resultando em redução da concentração de $\mathrm{Ca}^{2+}$ intracelular e conseqüente vasodilatação ${ }^{127}$. Com relação ao efeito vasodilatador promovido pela anandamida, há estudos descrevendo que o relaxamento mediado por este agonista depende da produção de $\mathrm{NO}^{128}$, enquanto outros estudos demonstraram que este efeito independe da liberação de NO ${ }^{30,129-}$ 130

No presente estudo, observamos que o NO participa do relaxamento à anandamida em LZRs, uma vez que a incubação de artérias mesentéricas desses animais com o inibidor da síntese de NO, o composto L-NAME, reduziu a resposta a este agonista canabinóide. Por outro lado, este fator parece não estar envolvido no relaxamento à anandamida em OZRs, uma vez que a inibição da síntese da NOS não alterou a resposta a este agonista no grupo OZR. A ausência de participação do NO como conseqüência de prejuízo prévio na ativação da enzima eNOS pela anandamida em OZRs, pode ser sugerida em nosso estudo com base nos experimentos de análise de expressão protéica desta enzima em sua forma total e fosforilada (Western blotting). Em artérias mesentéricas de LZRs, a eNOS sofreu fosforilação em Ser1177, após estímulo com anandamida ( $1 \mu \mathrm{M}, 30$ minutos), mas teve sua fosforilação reduzida no grupo OZR após este estímulo. Esse dado, em conjunto com as observações obtidas nos experimentos de reatividade vascular, permitem-nos concluir que a ativação da eNOS, pela anandamida, participa de seu efeito vascular em LZRs e está também envolvida no prejuízo do relaxamento a este agonista na obesidade.

A fosforilação da eNOS possui papel crítico na regulação da produção de NO ${ }^{131}$. Diversas proteínas quinases, incluindo a $A M P K{ }^{132}$, a proteína quinase $A(P K A)$ ${ }^{133}$ e as MAPKs ${ }^{134}$, podem promover a fosforilação da eNOS. O complexo AMPK é um heterodímero $\alpha \beta y$ que atua como um sensor da condição energética da célula. Ela é ativada por qualquer estresse que promova depleção dos níveis de ATP celular, com concomitante aumento de AMP, causando fosforilação do resíduo de treonina 172 (Thr172), localizado no sítio de ativação do domínio catalítico da subunidade $a{ }^{135-136}$. Assim como reguladora do balanço energético no nível da célula, a AMPK regula a ingestão e o gasto energético ${ }^{137-138}$. Uma vez ativada, a AMPK inativa a enzima ACC, também por fosforilação, o que contribui para seus 
efeitos sobre o gasto energético celular ${ }^{139}$. Além de fosforilar a ACC e uma série de outras enzimas envolvidas na metabolismo energético celular, a AMPK também fosforila a eNOS em Ser 1177 e em Ser 1179, promovendo a produção de NO em células endoteliais ${ }^{139}$.

Estudos recentes mostraram que a enzima AMPK não só medeia os efeitos orexigênicos dos endocanabinóides no hipotálamo ${ }^{90}$, mas também seus efeitos sobre o metabolismo glicêmico e lipídico nos tecidos periféricos, como no fígado, no músculo esquelético e no tecido adiposo ${ }^{135}$. Entretanto, o papel da AMPK nas ações vasculares promovidas pelos compostos canabinóides não foi ainda descrito na literatura.

No presente estudo avaliamos a participação da enzima AMPK na ação vascular promovida pela anandamida, bem como na redução do relaxamento a este agonista na obesidade. Demonstramos de forma inédita neste estudo que a AMPK é ativada pela anandamida em artérias mesentéricas de LZRs, uma vez que a incubação com este agonista ( $1 \mu \mathrm{M}, 30$ minutos) promoveu significante aumento na fosforilação da AMPK e também da ACC em LZRs. Demonstramos ainda que a obesidade está associada com prejuízo na ativação da AMPK, uma vez que a fosforilação desta enzima e da ACC foi reduzida no grupo OZR após o período de incubação com anandamida. O papel da AMPK na redução do relaxamento à anandamida em OZRs foi confirmado em nosso estudo, por meio da observação de que a incubação de artérias mesentéricas com o ativador da AMPK, o composto AICAR, corrigiu a resposta reduzida a este agonista em OZRs.

Um alvo de ação descrito para os compostos canabinóides em diversos tecidos é a enzima adenilil ciclase ${ }^{26}$. Estes compostos podem ativar ou inibir esta enzima, dependendo do tecido onde atuam. Em células neuronais a inibição da adenilil ciclase foi descrita como envolvida na ação dos canabinóides ${ }^{26}$. Porém, no sistema vascular, a forma como essa proteína é afetada após estímulo por agonistas canabinóides não foi ainda descrita. Entretanto, sabe-se que a ativação desta enzima por outros agonistas vasodilatadores leva ao aumento nos níveis de cAMP no interior da célula vascular, com conseqüente ativação da enzima eNOS ${ }^{140}$.

Considerando que o principal estímulo para a ativação da AMPK é o aumento dos níveis de AMP no interior da célula, nós propomos que a ativação desta enzima também possa estar prejudicada em OZRs, de modo similar à AMPK. De fato, nossos dados mostraram que a ativação da adenilil ciclase, pelo uso do composto 
forskolin, foi capaz de corrigir a redução do relaxamento à anandamida em OZRs (Figura 15A). Adicionalmente, a inibição desta enzima reduziu significantemente o relaxamento à anandamida em LZRs sem afetar essa resposta em OZRs (Figura 15B). Esses dados indicam não somente o papel da via de sinalização ativada pelo cAMP na vasodilatação promovida pela anandamida em LZRs, como também o papel desta via na redução da resposta à anandamida na obesidade.

A ERK1/2 constitui outra enzima cuja atividade pode ser regulada por compostos canabinóides em tecidos neuronais e também em tecidos que controlam o metabolismo energético ${ }^{141}$. O papel da ERK1/2 nos efeitos vasculares promovidos pelos compostos canabinóides não foi ainda demonstrado. Entretanto, diversos trabalhos já demonstraram que a ativação desta enzima está relacionada com redução ou aumento da atividade da enzima eNOS 133, 142-143. Os mecanismos envolvidos nesta inter-relação da eNOS e da ERK1/2 não foram ainda esclarecidos.

Com base nestas observações, investigamos no presente estudo o papel desta MAPK nos efeitos vasculares promovidos pela anandamida e na redução do relaxamento a este agonista na obesidade. Nossos resultados mostraram que a ativação desta MAPK modula negativamente a resposta à anandamida em LZRs e em OZRs, uma vez que a incubação com inibidor da ERK1/2, o composto Pd 98059, aumentou a resposta à anandamida nos dois grupos experimentais. Adicionalmente, demonstramos que o aumento da ativação desta enzima em artérias mesentéricas de OZRs participa da redução do relaxamento à anandamida, uma vez que a incubação com Pd 98059 corrigiu a redução da resposta à anandamida nestes animais.

De fato, verificamos um efeito ativador da anandamida sobre a atividade da ERK1/2 tanto em LZRs quanto em OZRs através dos experimentos de Western blotting. Entretanto, cabe ressaltar que a ativação da ERK1/2 já se encontrava previamente aumentada em OZRs em condições basais. A incubação com anandamida potencializou a fosforilação desta enzima neste grupo. Esta ativação aumentada da ERK1/2 já em condições basais pode ter contribuído para o prejuízo na via de sinalização dependente de NO, ativada pela anandamida em OZRs. Em resumo, de modo similar ao observado com a AMPK, demonstramos que a ERK1/2 é ativada pela anandamida em artérias mesentéricas de resistência de LZRs, e está envolvida nas alterações promovidas pela obesidade sobre a resposta à agonistas canabinóides. 
Estudos têm demonstrado que a ativação da ERK1/2 leva à fosforilação de enzimas envolvidas não apenas no relaxamento, mas também na contração vascular 144-145. O mecanismo pelo qual a ativação da ERK1/2 leva à contração vascular não foi ainda investigado. Porém, podemos sugerir no presente estudo que a estimulação exacerbada da ERK1/2 em condições basais em OZRs contribui para a ativação de outras proteínas intracelulares que não são ativadas quando esta proteína se encontra em níveis mais baixos de atividade. A maior fosforilação desta enzima em OZRs pode assim, indicar ativação de vias envolvidas não só na produção de NO, mas também de fatores contráteis. De fato, estudos recentes mostraram que a ERK1/2 participa da resposta mediada por agonistas contráteis em condições fisiológicas e que o aumento da ativação desta enzima contribui para o aumento da contração observada em doenças vasculares, como no diabetes tipo 2 ${ }^{146}$ e na hipertensão arterial ${ }^{147}$.

Em relação ao papel da ERK1/2 na redução da resposta à anandamida, sugerido por nós, é importante relatar um estudo publicado por Kim e colaboradores (2001), que demonstrou a interação da AMPK e das MAPKs ${ }^{148}$. Estes autores mostraram que a ativação da AMPK inibe a ativação da ERK1/2. Considerando nossa hipótese de que o aumento da ativação da ERK1/2 em OZRs pode ter contribuído para o prejuízo na via de sinalização dependente de NO, podemos sugerir que o aumento da atividade desta MAPK ocorre como conseqüência da reduzida ativação da AMPK pela anandamida nestes animais.

Além de ativar os receptores canabinóides CB1 e CB2, a anandamida pode também ativar receptores vanilóides localizados em nervos sensoriais perivasculares, os quais são sensíveis à neurotoxina capsaicina. Demonstrou-se que esta interação resulta na liberação do CGRP, promovendo relaxamento vascular ${ }^{13}$, 38. Resultado semelhante foi observado em nosso estudo. Nós observamos que o tratamento com capsaicina, in vitro, resultando na dessensibilização de fibras C, suprimiu as respostas à anandamida tanto em LZRs quanto em OZRs. Esse resultado indica que o silenciamento de fibras nervosas sensoriais vasculares do tipo C evita que o vaso sanguíneo responda adequadamente à anandamida. Adicionalmente, nós observamos que a diminuição da resposta vascular à anandamida em OZRs também envolve diminuição da ativação dessas fibras sensoriais uma vez que o grau de inibição da resposta à andandamida em OZRs foi menor do que aquele observado em LZRs. 
Os efeitos promovidos pela ativação das fibras nervosas do tipo $\mathrm{C}$ no sistema vascular já foram demonstrados em diversos estudos ${ }^{149}$. Entretanto, o papel desses nervos na regulação fisiológica do tônus vascular permanece a ser esclarecido. $O$ receptor TRPV-1 tem surgido recentemente como sendo o principal local para a ativação de fibras sensoriais do tipo $C$ na periferia ${ }^{150}$. A presença desses receptores foi demonstrada previamente em nervos que penetram na parede de artérias mesentéricas de resistência ${ }^{100}$. Apesar da expressão protéica de TRPV-1 não estar alterada em OZRs, nós demonstramos dependência da ativação desses receptores para o relaxamento da anandamida nos dois grupos experimentais. $O$ uso de agentes que interferem seletivamente com a atividade desses receptores, a capsazepina e o composto vermelho de rutênio dão suporte a essa conclusão ${ }^{102}$. Este achado foi confirmado pelo uso do antagonista do receptor do CGRP, o composto $\alpha$-CGRP, que diminuiu consideravelmente a resposta à anandamida nos dois grupos experimentais. Entretanto, a redução ocorreu aparentemente em magnitude muito maior em OZRs. Em conjunto, esses resultados indicam que, além de redução na participação de vias de sinalização ativadas por receptores canabinóides CB1 e CB2, o prejuízo na resposta mediada pela ativação de receptores vanilóides contribui para a diminuição do relaxamento à anandamida em OZRs.

Estudos recentes demonstraram que os compostos canabinóides, além de se ligarem a receptores, podem se difundir através da membrana celular a atuarem intracelularmente. Este processo seria também uma etapa essencial no processo de metabolização destes compostos ${ }^{36}$. Sugere-se que o transporte dos compostos canabinóides seja mediado por um transportador protéico de anandamida, localizado ao longo da membrana plasmática, ou ainda que a anandamida simplesmente se difunda passivamente pela membrana plasmática em um processo que não é mediado por proteínas transmembrana ${ }^{151}$. Moore e colaboradores (2005) ${ }^{152}$ identificaram um sítio de ligação da anandamida, saturável e de alta afinidade. Estes autores sugeriram ser esse um transportador de anandamida.

Portanto, nós propomos em nosso estudo que a diminuição do relaxamento à anandamida em OZRs poderia ocorrer devido à diminuição da captação deste agonista para o meio intracelular. Utilizando o inibidor do transporte de anandamida, o composto AM404, demonstramos que, de fato, o transporte da anandamida para o interior da célula é um passo importante no relaxamento mediado por este agonista 
em LZRs, uma vez que a resposta à anandamida foi significantemente reduzida na presença desse composto. Adicionalmente, o fato de a resposta à anandamida não ter sido alterada na presença do composto AM404 em OZRs, indica que este mecanismo já se encontra prejudicado nas artérias mesentéricas desses animais.

As ações dos compostos canabinóides são finalizadas pela reação de hidrólise enzimática intracelular. Em particular, a anandamida, é rapidamente metabolizada pela enzima FAAH para produzir AA e etanolamina ${ }^{36}$. O aumento da degradação de anandamida em artérias mesentéricas de OZRs pode ser sugerido em nosso estudo como um mecanismo envolvido na diminuição da resposta à anandamida em OZRs, uma vez que o tratamento prévio de artérias mesentéricas de OZRs com o inibidor seletivo da FAAH, o composto URB 597, corrigiu a redução do relaxamento à anandamida em OZRs.

Em resumo, no presente estudo demonstramos que 0 relaxamento ao agonista canabinóide anandamida está prejudicado em OZRs. A redução da expressão dos receptores canabinóides CB1 e CB2 e as alterações em vias de sinalização que são ativadas por esses receptores e também por receptores vanilóides foram também demonstradas. Adicionalmente, a diminuição da atividade do transportador de anandamida e o aumento da degradação dela também podem estar envolvidos na redução da vasodilatação mediada pela anandamida na obesidade. Nosso estudo é o primeiro a avaliar o envolvimento das proteínas AMPK e ERK1/2 na resposta vascular promovida pela anandamida bem como o envolvimento delas na redução do relaxamento à anandamida na obesidade. Nosso estudo proporciona novas evidências com relação à relevância dos efeitos vasculares do sistema endocanabinóide e do seu papel na disfunção vascular presente na obesidade. 


\section{CONCLUSÃO}

Os resultados apresentados neste estudo permitem-nos concluir que:

$\checkmark \quad$ A obesidade diminui o relaxamento de artérias mesentéricas de resistência a agonistas canabinóides;

$\checkmark \quad$ A redução da expressão dos receptores canabinóides CB1 e CB2 em artérias mesentéricas de OZRs contribui para a redução do relaxamento à anandamida em OZRs;

$\checkmark \quad$ Embora a expressão de receptores vanilóides (TRPV-1) não esteja alterada em OZRs, há prejuízo nas vias de sinalização mediadas pela ativação destes receptores, uma vez que a resposta ao agonista deste receptor (capsaicina) está reduzida;

$\checkmark \quad$ Redução da captação e aumento da degradação de anandamida estão presentes em artérias mesentéricas de resistência de OZRs e podem ter contribuído para a redução do relaxamento à anandamida;

$\checkmark \quad$ A fosforilação da eNOS, com conseqüente produção de NO pelas células endoteliais, possui papel importante no relaxamento à anandamida em LZRs e participa do prejuízo no relaxamento a este agonista em OZRs, por ter sua ativação reduzida após estímulo com anandamida;

$\checkmark \quad$ A AMPK é um alvo da anandamida em artérias mesentéricas de resistência de LZRs e, assim como a eNOS, medeia o prejuízo no relaxamento a este agonista em OZRs, por ter sua ativação reduzida após estímulo com anandamida;

$\checkmark$ A ERK1/2, embora sofra fosforilação frente a estímulo com anandamida, não parece mediar o relaxamento à anandamida em LZRs, porém sua ativação aumentada em OZRs contribui para a redução do relaxamento à anandamida em OZRs. 


\section{REFERÊNCIAS*}

1 Osei-Hyiaman D, Harvey-White J, Batkai S, Kunos G. The role of the endocannabinoid system in the control of energy homeostasis. Int $\mathrm{J}$ Obes (Lond). 2006;30 Suppl 1:S33-8.

2 Pacher P, Batkai S, Kunos G. The endocannabinoid system as an emerging target of pharmacotherapy. Pharmacol Rev. 2006;58(3):389-462.

3 Mechoulam R, Gaoni Y. A Total Synthesis of DI-Delta-1Tetrahydrocannabinol, the Active Constituent of Hashish. J Am Chem Soc. 1965;87:3273-5.

4 Devane WA, Dysarz FA, 3rd, Johnson MR, Melvin LS, Howlett AC. Determination and characterization of a cannabinoid receptor in rat brain. Mol Pharmacol. 1988;34(5):605-13.

5 Matsuda LA, Lolait SJ, Brownstein MJ, Young AC, Bonner TI. Structure of a cannabinoid receptor and functional expression of the cloned cDNA. Nature. 1990;346(6284):561-4.

6 Munro S, Thomas KL, Abu-Shaar M. Molecular characterization of a peripheral receptor for cannabinoids. Nature. 1993;365(6441):61-5.

7 Devane WA, Hanus L, Breuer A, Pertwee RG, Stevenson LA, Griffin G, et al. Isolation and structure of a brain constituent that binds to the cannabinoid receptor. Science. 1992;258(5090):1946-9.

8 Mechoulam R, Ben-Shabat S, Hanus L, Ligumsky M, Kaminski NE, Schatz $\mathrm{AR}$, et al. Identification of an endogenous 2-monoglyceride, present in canine gut, that binds to cannabinoid receptors. Biochem Pharmacol. 1995;50(1):8390 .

9. Cravatt BF, Giang DK, Mayfield SP, Boger DL, Lerner RA, Gilula NB. Molecular characterization of an enzyme that degrades neuromodulatory fattyacid amides. Nature. 1996;384(6604):83-7.

*De acordo com: International Committee of Medical Journal Editors. Uniform requirements for manuscripts submitted to Biomedical Journal: sample references. Avaiable from: http://www.icmje.org [2007 may 22]. 
10 Karlsson M, Contreras JA, Hellman U, Tornqvist H, Holm C. cDNA cloning, tissue distribution, and identification of the catalytic triad of monoglyceride lipase. Evolutionary relationship to esterases, lysophospholipases, and haloperoxidases. J Biol Chem. 1997;272(43):27218-23.

11 Dinh TP, Carpenter D, Leslie FM, Freund TF, Katona I, Sensi SL, et al. Brain monoglyceride lipase participating in endocannabinoid inactivation. Proc Natl Acad Sci U S A. 2002;99(16):10819-24.

12 Beltramo M, Stella N, Calignano A, Lin SY, Makriyannis A, Piomelli D. Functional role of high-affinity anandamide transport, as revealed by selective inhibition. Science. 1997;277(5329):1094-7.

13 Zygmunt PM, Petersson J, Andersson DA, Chuang H, Sorgard M, Di Marzo V, et al. Vanilloid receptors on sensory nerves mediate the vasodilator action of anandamide. Nature. 1999;400(6743):452-7.

14 Herkenham M, Lynn AB, Johnson MR, Melvin LS, de Costa BR, Rice KC. Characterization and localization of cannabinoid receptors in rat brain: a quantitative in vitro autoradiographic study. J Neurosci. 1991;11(2):563-83.

15 Mailleux $\mathrm{P}$, Parmentier $\mathrm{M}$, Vanderhaeghen JJ. Distribution of cannabinoid receptor messenger RNA in the human brain: an in situ hybridization histochemistry with oligonucleotides. Neurosci Lett. 1992;143(1-2):200-4.

16 Matsuda LA, Bonner TI, Lolait SJ. Localization of cannabinoid receptor mRNA in rat brain. J Comp Neurol. 1993;327(4):535-50.

17 Howlett AC. The cannabinoid receptors. Prostaglandins Other Lipid Mediat. 2002;68-69:619-31.

18 Pertwee RG. Pharmacology of cannabinoid CB1 and CB2 receptors. Pharmacol Ther. 1997;74(2):129-80.

19 Coutts AA, Izzo AA. The gastrointestinal pharmacology of cannabinoids: an update. Curr Opin Pharmacol. 2004;4(6):572-9.

20 Cota D, Marsicano G, Tschop M, Grubler Y, Flachskamm C, Schubert M, et al. The endogenous cannabinoid system affects energy balance via central orexigenic drive and peripheral lipogenesis. J Clin Invest. 2003;112(3):423-31. 
21 Osei-Hyiaman D, DePetrillo M, Pacher P, Liu J, Radaeva S, Batkai S, et al. Endocannabinoid activation at hepatic CB1 receptors stimulates fatty acid synthesis and contributes to diet-induced obesity. J Clin Invest. 2005;115(5):1298-305.

22 Liu YL, Connoley IP, Wilson CA, Stock MJ. Effects of the cannabinoid CB1 receptor antagonist SR141716 on oxygen consumption and soleus muscle glucose uptake in Lep(ob)/Lep(ob) mice. Int J Obes (Lond). 2005;29(2):183-7.

23 Pagotto U, Marsicano G, Cota D, Lutz B, Pasquali R. The emerging role of the endocannabinoid system in endocrine regulation and energy balance. Endocr Rev. 2006;27(1):73-100.

24 Matias I, Gonthier MP, Orlando P, Martiadis V, De Petrocellis L, Cervino C, et al. Regulation, function, and dysregulation of endocannabinoids in models of adipose and beta-pancreatic cells and in obesity and hyperglycemia. J Clin Endocrinol Metab. 2006;91(8):3171-80.

25 Piomelli D. The molecular logic of endocannabinoid signalling. Nat Rev Neurosci. 2003;4(11):873-84.

26 Alexander SP, Kendall DA. The complications of promiscuity: endocannabinoid action and metabolism. Br J Pharmacol. 2007;152(5):60223.

27 Varga K, Lake K, Martin BR, Kunos G. Novel antagonist implicates the CB1 cannabinoid receptor in the hypotensive action of anandamide. Eur $\mathrm{J}$ Pharmacol. 1995;278(3):279-83.

28 Varga K, Lake KD, Huangfu D, Guyenet PG, Kunos G. Mechanism of the hypotensive action of anandamide in anesthetized rats. Hypertension. 1996;28(4):682-6.

29 Batkai S, Pacher P, Osei-Hyiaman D, Radaeva S, Liu J, Harvey-White J, et al. Endocannabinoids acting at cannabinoid-1 receptors regulate cardiovascular function in hypertension. Circulation. 2004;110(14):1996-2002.

30 Randall MD, Harris D, Kendall DA, Ralevic V. Cardiovascular effects of cannabinoids. Pharmacol Ther. 2002;95(2):191-202.

31 Plane F, Holland M, Waldron GJ, Garland CJ, Boyle JP. Evidence that anandamide and EDHF act via different mechanisms in rat isolated mesenteric arteries. Br J Pharmacol. 1997;121(8):1509-11. 
32 Randall MD, Kendall DA. Anandamide and endothelium-derived hyperpolarizing factor act via a common vasorelaxant mechanism in rat mesentery. Eur J Pharmacol. 1998;346(1):51-3.

33 Pratt PF, Hillard CJ, Edgemond WS, Campbell WB. Narachidonylethanolamide relaxation of bovine coronary artery is not mediated by CB1 cannabinoid receptor. Am J Physiol. 1998;274(1 Pt 2):H375-81.

34 Chaytor AT, Martin PE, Evans WH, Randall MD, Griffith TM. The endothelial component of cannabinoid-induced relaxation in rabbit mesenteric artery depends on gap junctional communication. J Physiol. 1999;520(Pt 2):539-50.

35 Harris D, McCulloch Al, Kendall DA, Randall MD. Characterization of vasorelaxant responses to anandamide in the rat mesenteric arterial bed. $J$ Physiol. 2002;539(Pt 3):893-902.

36 Randall MD, Kendall DA, O'Sullivan S. The complexities of the cardiovascular actions of cannabinoids. Br J Pharmacol. 2004;142(1):20-6.

37 Harris D, Kendall DA, Randall MD. Characterization of cannabinoid receptors coupled to vasorelaxation by endothelium-derived hyperpolarizing factor. Naunyn Schmiedebergs Arch Pharmacol. 1999;359(1):48-52.

38 Jarai Z, Wagner JA, Varga K, Lake KD, Compton DR, Martin BR, et al. Cannabinoid-induced mesenteric vasodilation through an endothelial site distinct from CB1 or CB2 receptors. Proc Natl Acad Sci U S A. 1999;96(24):14136-41.

39 Zygmunt PM, Hogestatt ED, Waldeck K, Edwards G, Kirkup AJ, Weston AH. Studies on the effects of anandamide in rat hepatic artery. $\mathrm{Br} \mathrm{J}$ Pharmacol. 1997;122(8):1679-86.

40 Gebremedhin D, Lange AR, Campbell WB, Hillard CJ, Harder DR. Cannabinoid CB1 receptor of cat cerebral arterial muscle functions to inhibit Ltype Ca2+ channel current. Am J Physiol. 1999;276(6 Pt 2):H2085-93.

41 Mukhopadhyay S, Chapnick BM, Howlett AC. Anandamide-induced vasorelaxation in rabbit aortic rings has two components: $G$ protein dependent and independent. Am J Physiol Heart Circ Physiol. 2002;282(6):H2046-54.

42 Edwards RM, Stack EJ, Trizna W. Calcitonin gene-related peptide stimulates adenylate cyclase and relaxes intracerebral arterioles. J Pharmacol Exp Ther. 1991;257(3):1020-4. 
43 Brayden JE, Quayle JM, Standen NB, Nelson MT. Role of potassium channels in the vascular response to endogenous and pharmacological vasodilators. Blood Vessels. 1991;28(1-3):147-53.

44 Smart D, Gunthorpe MJ, Jerman JC, Nasir S, Gray J, Muir Al, et al. The endogenous lipid anandamide is a full agonist at the human vanilloid receptor (hVR1). Br J Pharmacol. 2000;129(2):227-30.

45 Wagner JA, Varga K, Ellis EF, Rzigalinski BA, Martin BR, Kunos G. Activation of peripheral CB1 cannabinoid receptors in haemorrhagic shock. Nature. 1997;390(6659):518-21.

46 Varga K, Wagner JA, Bridgen DT, Kunos G. Platelet- and macrophagederived endogenous cannabinoids are involved in endotoxin-induced hypotension. FASEB J. 1998;12(11):1035-44.

47 Wild S, Roglic G, Green A, Sicree R, King H. Global prevalence of diabetes: estimates for the year 2000 and projections for 2030. Diabetes Care. 2004;27(5):1047-53.

48 Hill JO. Understanding and addressing the epidemic of obesity: an energy balance perspective. Endocr Rev. 2006;27(7):750-61.

49 Strauss RS, Pollack HA. Epidemic increase in childhood overweight, 19861998. JAMA. $2001 ; 286(22): 2845-8$.

50 Hubert HB, Feinleib M, McNamara PM, Castelli WP. Obesity as an independent risk factor for cardiovascular disease: a 26-year follow-up of participants in the Framingham Heart Study. Circulation. 1983;67(5):968-77.

51 Larsson B, Svardsudd K, Welin L, Wilhelmsen L, Bjorntorp P, Tibblin G. Abdominal adipose tissue distribution, obesity, and risk of cardiovascular disease and death: 13 year follow up of participants in the study of men born in 1913. Br Med J (Clin Res Ed). 1984;288(6428):1401-4.

52 Rueda-Clausen CF, Silva FA, Lopez-Jaramillo P. Epidemic of overweight and obesity in Latin America and the Caribbean. Int J Cardiol. 2008;125(1):111-2.

53 Nakamura T, Kobayashi H, Yanagi K, Nakagawa T, Nishida M, Kihara S, et al. Importance of intra-abdominal visceral fat accumulation to coronary atherosclerosis in heterozygous familial hypercholesterolaemia. Int $\mathrm{J}$ Obes Relat Metab Disord. 1997;21(7):580-6. 
54 Poirier P, Giles TD, Bray GA, Hong Y, Stern JS, Pi-Sunyer FX, et al. Obesity and cardiovascular disease: pathophysiology, evaluation, and effect of weight loss: an update of the 1997 American Heart Association Scientific Statement on Obesity and Heart Disease from the Obesity Committee of the Council on Nutrition, Physical Activity, and Metabolism. Circulation. 2006;113(6):898-918.

55 Stapleton PA, James ME, Goodwill AG, Frisbee JC. Obesity and vascular dysfunction. Pathophysiology. 2008;15(2):79-89.

56 Fruhbeck $\mathrm{G}$. The adipose tissue as a source of vasoactive factors. Curr Med Chem Cardiovasc Hematol Agents. 2004;2(3):197-208.

57 Furchgott RF, Vanhoutte PM. Endothelium-derived relaxing and contracting factors. FASEB J. 1989;3(9):2007-18.

58 Feletou M, Vanhoutte PM. The third pathway: endothelium-dependent hyperpolarization. J Physiol Pharmacol. 1999;50(4):525-34.

59 Feletou M, Vanhoutte PM. Endothelial dysfunction: a multifaceted disorder (The Wiggers Award Lecture). Am J Physiol Heart Circ Physiol. 2006;291(3):H985-1002.

60 Steinberg HO, Chaker H, Leaming R, Johnson A, Brechtel G, Baron AD. Obesity/insulin resistance is associated with endothelial dysfunction. Implications for the syndrome of insulin resistance. $\mathrm{J}$ Clin Invest. 1996;97(11):2601-10.

61 Mather KJ, Mirzamohammadi B, Lteif A, Steinberg HO, Baron AD. Endothelin contributes to basal vascular tone and endothelial dysfunction in human obesity and type 2 diabetes. Diabetes. 2002;51(12):3517-23.

62 Perticone F, Ceravolo R, Candigliota M, Ventura G, lacopino S, Sinopoli F, et al. Obesity and body fat distribution induce endothelial dysfunction by oxidative stress: protective effect of vitamin C. Diabetes. 2001;50(1):159-65.

63 Lobato NS, Filgueira FP, Akamine EH, Davel AP, Rossoni LV, Tostes RC, et al. Obesity induced by neonatal treatment with monosodium glutamate impairs microvascular reactivity in adult rats: Role of $\mathrm{NO}$ and prostanoids. Nutr Metab Cardiovasc Dis. 2010. In press.

64 Plum L, Wunderlich FT, Baudler S, Krone W, Bruning JC. Transgenic and knockout mice in diabetes research: novel insights into pathophysiology, limitations, and perspectives. Physiology (Bethesda). 2005;20:152-61. 
65 Cesareti MLR, Kohlmann JrO. Modelos Experimentais de Resistência à Insulina e Obesidade: Lições Aprendidas. Arq Bras Endocrinol Metab. 2006;50(2):190-7.

66 Marques-Lopesl, Martí A, Moreno-Aliaga MJ, Martínez A. Aspectos genéticos da obesidade. Rev Nutr. 2004;17(3):327-38.

67 Campfield LA, Smith FJ, Burn P. The OB protein (leptin) pathway--a link between adipose tissue mass and central neural networks. Horm Metab Res. 1996;28(12):619-32.

68 Munzberg $\mathrm{H}$, Myers MG, Jr. Molecular and anatomical determinants of central leptin resistance. Nat Neurosci. 2005;8(5):566-70.

69 Zucker LM, Zucker TF. Fatty, a new mutation in the rat. J Hered. 1961;52:2758.

70 Zucker TF, Zucker LM. Fat accretion and growth in the rat. J Nutr. 1963;80:619.

71 Zucker LM, Antoniades HN. Insulin and obesity in the Zucker genetically obese rat "fatty". Endocrinology. 1972;90(5):1320-30.

72 Zucker TF, Zucker LM. Hereditary obesity in the rat associated with high serum fat and cholesterol. Proc Soc Exp Biol Med. 1962;110:165-71.

73 Johnson PR, Zucker LM, Cruce JA, Hirsch J. Cellularity of adipose depots in the genetically obese Zucker rat. J Lipid Res. 1971;12(6):706-14.

74 Kurtz TW, Morris RC, Pershadsingh HA. The Zucker fatty rat as a genetic model of obesity and hypertension. Hypertension. 1989;13(6 Pt 2):896-901.

75 Stern JS, Johnson PR. Spontaneous activity and adipose cellularity in the genetically obese Zucker rat (fafa). Metabolism. 1977;26(4):371-80.

76 Vasselli JR, Cleary MP, Jen KL, Greenwood MR. Development of food motivated behavior in free feeding and food restricted Zucker fatty (fa/fa) rats. Physiol Behav. 1980;25(4):565-73.

77 Maggio CA, Greenwood MR. Adipose tissue lipoprotein lipase (LPL) and triglyceride uptake in zucker rats. Physiol Behav. 1982;29(6):1147-52. 
78 Gruen R, Hietanen E, Greenwood MR. Increased adipose tissue lipoprotein lipase activity during the development of the genetically obese rat $(\mathrm{fa} / \mathrm{fa}$ ). Metabolism. 1978;27(12 Suppl 2):1955-66.

79 Turkenkopf IJ, Olsen JL, Moray L, Greenwood MR, Johnson PR. Hepatic lipogenesis in the preobese Zucker rat. Proc Soc Exp Biol Med. 1980;164(4):530-3.

80 Osmond JM, Mintz JD, Dalton B, Stepp DW. Obesity increases blood pressure, cerebral vascular remodeling, and severity of stroke in the Zucker rat. Hypertension. 2009;53(2):381-6.

81 Engeli S, Bohnke J, Feldpausch M, Gorzelniak K, Janke J, Batkai S, et al. Activation of the peripheral endocannabinoid system in human obesity. Diabetes. 2005;54(10):2838-43.

82 Van Gaal LF, Rissanen AM, Scheen AJ, Ziegler O, Rossner S. Effects of the cannabinoid-1 receptor blocker rimonabant on weight reduction and cardiovascular risk factors in overweight patients: 1-year experience from the RIO-Europe study. Lancet. 2005;365(9468):1389-97.

83 Despres JP, Golay A, Sjostrom L. Effects of rimonabant on metabolic risk factors in overweight patients with dyslipidemia. $\mathrm{N}$ Engl $\mathrm{J}$ Med. 2005;353(20):2121-34.

84 Scheen AJ, Finer N, Hollander P, Jensen MD, Van Gaal LF. Efficacy and tolerability of rimonabant in overweight or obese patients with type 2 diabetes: a randomised controlled study. Lancet. 2006;368(9548):1660-72.

85 Nissen SE, Nicholls SJ, Wolski K, Rodes-Cabau J, Cannon CP, Deanfield JE, et al. Effect of rimonabant on progression of atherosclerosis in patients with abdominal obesity and coronary artery disease: the STRADIVARIUS randomized controlled trial. JAMA. 2008;299(13):1547-60.

86 Di Marzo V, Matias I. Endocannabinoid control of food intake and energy balance. Nat Neurosci. 2005;8(5):585-9.

87 Di Marzo V, Goparaju SK, Wang L, Liu J, Batkai S, Jarai Z, et al. Leptinregulated endocannabinoids are involved in maintaining food intake. Nature. 2001;410(6830):822-5.

88 Di Marzo V. The endocannabinoid system in obesity and type 2 diabetes. Diabetologia. 2008;51(8):1356-67. 
89 Buettner C, Muse ED, Cheng A, Chen L, Scherer T, Pocai A, et al. Leptin controls adipose tissue lipogenesis via central, STAT3-independent mechanisms. Nat Med. 2008;14(6):667-75.

90 Kola B, Hubina E, Tucci SA, Kirkham TC, Garcia EA, Mitchell SE, et al. Cannabinoids and ghrelin have both central and peripheral metabolic and cardiac effects via AMP-activated protein kinase. J Biol Chem. 2005;280(26):25196-201.

91 Schimmack G, Defronzo RA, Musi N. AMP-activated protein kinase: Role in metabolism and therapeutic implications. Diabetes Obes Metab. 2006;8(6):591-602.

92 Ruby MA, Nomura DK, Hudak CS, Mangravite LM, Chiu S, Casida JE, et al. Overactive endocannabinoid signaling impairs apolipoprotein E-mediated clearance of triglyceride-rich lipoproteins. Proc Natl Acad Sci U S A. 2008;105(38):14561-6.

93 Janiak P, Poirier B, Bidouard JP, Cadrouvele C, Pierre F, Gouraud L, et al. Blockade of cannabinoid CB1 receptors improves renal function, metabolic profile, and increased survival of obese Zucker rats. Kidney Int. 2007;72(11):1345-57.

94 Gary-Bobo M, Elachouri G, Gallas JF, Janiak P, Marini P, Ravinet-Trillou C, et al. Rimonabant reduces obesity-associated hepatic steatosis and features of metabolic syndrome in obese Zucker fa/fa rats. Hepatology. 2007;46(1):122-9.

95 Izzo AA, Piscitelli F, Capasso R, Aviello G, Romano B, Borrelli F, et al. Peripheral endocannabinoid dysregulation in obesity: relation to intestinal motility and energy processing induced by food deprivation and re-feeding. $\mathrm{Br}$ J Pharmacol. 2009;158(2):451-61.

96 Mulvany MJ, Halpern W. Contractile properties of small arterial resistance vessels in spontaneously hypertensive and normotensive rats. Circ Res. 1977;41(1):19-26.

97 O'Sullivan SE, Kendall DA, Randall MD. Heterogeneity in the mechanisms of vasorelaxation to anandamide in resistance and conduit rat mesenteric arteries. Br J Pharmacol. 2004;142(3):435-42.

98 Jiang S, Fu Y, Williams J, Wood J, Pandarinathan L, Avraham S, et al. Expression and function of cannabinoid receptors CB1 and CB2 and their cognate cannabinoid ligands in murine embryonic stem cells. PLoS One. 2007;2(7):e641. 
99 Holzer P. Capsaicin: cellular targets, mechanisms of action, and selectivity for thin sensory neurons. Pharmacol Rev. 1991;43(2):143-201.

100 Scotland RS, Chauhan S, Davis C, De Felipe C, Hunt S, Kabir J, et al. Vanilloid receptor TRPV1, sensory C-fibers, and vascular autoregulation: a novel mechanism involved in myogenic constriction. Circ Res. 2004;95(10):1027-34.

101 Caterina MJ, Schumacher MA, Tominaga M, Rosen TA, Levine JD, Julius D. The capsaicin receptor: a heat-activated ion channel in the pain pathway. Nature. 1997;389(6653):816-24.

102 Bevan S, Hothi S, Hughes G, James IF, Rang HP, Shah K, et al. Capsazepine: a competitive antagonist of the sensory neurone excitant capsaicin. Br J Pharmacol. 1992;107(2):544-52.

103 Dray A, Forbes CA, Burgess GM. Ruthenium red blocks the capsaicininduced increase in intracellular calcium and activation of membrane currents in sensory neurones as well as the activation of peripheral nociceptors in vitro. Neurosci Lett. 1990;110(1-2):52-9.

104 Rayment SJ, Ralevic V, Barrett DA, Cordell R, Alexander SP. A novel mechanism of vasoregulation: ADP-induced relaxation of the porcine isolated coronary artery is mediated via adenosine release. FASEB J. 2007;21(2):57785.

105 Goirand F, Solar M, Athea Y, Viollet B, Mateo P, Fortin D, et al. Activation of AMP kinase alpha1 subunit induces aortic vasorelaxation in mice. J Physiol. 2007;581(Pt 3):1163-71.

106 Dudley DT, Pang L, Decker SJ, Bridges AJ, Saltiel AR. A synthetic inhibitor of the mitogen-activated protein kinase cascade. Proc Natl Acad Sci U S A. 1995;92(17):7686-9.

107 Di Marzo V, Fontana A, Cadas H, Schinelli S, Cimino G, Schwartz JC, et al. Formation and inactivation of endogenous cannabinoid anandamide in central neurons. Nature. 1994;372(6507):686-91.

108 Sista AK, O'Connell MK, Hinohara T, Oommen SS, Fenster BE, Glassford AJ, et al. Increased aortic stiffness in the insulin-resistant Zucker fa/fa rat. Am J Physiol Heart Circ Physiol. 2005;289(2):H845-51. 
109 Bouvet C, Belin de Chantemele E, Guihot AL, Vessieres E, Bocquet A, Dumont $\mathrm{O}$, et al. Flow-induced remodeling in resistance arteries from obese Zucker rats is associated with endothelial dysfunction. Hypertension. 2007;50(1):248-54.

110 Stepp DW, Frisbee JC. Augmented adrenergic vasoconstriction in hypertensive diabetic obese Zucker rats. Am J Physiol Heart Circ Physiol. 2002;282(3):H816-20.

111 Naik JS, Xiang L, Hester RL. Enhanced role for RhoA-associated kinase in adrenergic-mediated vasoconstriction in gracilis arteries from obese Zucker rats. Am J Physiol Regul Integr Comp Physiol. 2006;290(1):R154-61.

112 Lesniewski LA, Donato AJ, Behnke BJ, Woodman CR, Laughlin MH, Ray CA, et al. Decreased NO signaling leads to enhanced vasoconstrictor responsiveness in skeletal muscle arterioles of the ZDF rat prior to overt diabetes and hypertension. Am $J$ Physiol Heart Circ Physiol. 2008;294(4):H1840-50.

113 Xiang L, Dearman J, Abram SR, Carter C, Hester RL. Insulin resistance and impaired functional vasodilation in obese Zucker rats. Am J Physiol Heart Circ Physiol. 2008;294(4):H1658-66.

114 Wagner JA, Varga K, Jarai Z, Kunos G. Mesenteric vasodilation mediated by endothelial anandamide receptors. Hypertension. 1999;33(1 Pt 2):429-34.

115 Hillard CJ. Endocannabinoids and vascular function. J Pharmacol Exp Ther. 2000;294(1):27-32.

116 Kunos G, Jarai Z, Batkai S, Goparaju SK, Ishac EJ, Liu J, et al. Endocannabinoids as cardiovascular modulators. Chem Phys Lipids. 2000;108(1-2):159-68.

117 Rajesh M, Mukhopadhyay P, Batkai S, Hasko G, Liaudet L, Huffman JW, et al. CB2-receptor stimulation attenuates TNF-alpha-induced human endothelial cell activation, transendothelial migration of monocytes, and monocyteendothelial adhesion. Am J Physiol Heart Circ Physiol. 2007;293(4):H2210-8.

118 Rajesh M, Mukhopadhyay P, Hasko G, Huffman JW, Mackie K, Pacher P. CB2 cannabinoid receptor agonists attenuate TNF-alpha-induced human vascular smooth muscle cell proliferation and migration. $\mathrm{Br} \mathrm{J}$ Pharmacol. 2008;153(2):347-57. 
119 McGiff JC, Carroll MA, Escalante B. Arachidonate metabolites and kinins in blood pressure regulation. Hypertension. 1991;18(5 Suppl):III150-7.

120 Ellis EF, Moore SF, Willoughby KA. Anandamide and delta 9-THC dilation of cerebral arterioles is blocked by indomethacin. Am J Physiol. 1995;269(6 Pt 2):H1859-64.

121 Grainger J, Boachie-Ansah G. Anandamide-induced relaxation of sheep coronary arteries: the role of the vascular endothelium, arachidonic acid metabolites and potassium channels. Br J Pharmacol. 2001;134(5):1003-12.

122 Randall MD, Alexander SP, Bennett T, Boyd EA, Fry JR, Gardiner SM, et al. An endogenous cannabinoid as an endothelium-derived vasorelaxant. Biochem Biophys Res Commun. 1996;229(1):114-20.

123 Cohen RA, Vanhoutte PM. Endothelium-dependent hyperpolarization. Beyond nitric oxide and cyclic GMP. Circulation. 1995;92(11):3337-49.

124 Burnham MP, Bychkov R, Feletou M, Richards GR, Vanhoutte PM, Weston $\mathrm{AH}$, et al. Characterization of an apamin-sensitive small-conductance $\mathrm{Ca}(2+)$ activated $\mathrm{K}(+)$ channel in porcine coronary artery endothelium: relevance to EDHF. Br J Pharmacol. 2002;135(5):1133-43.

125 Chataigneau T, Feletou M, Thollon C, Villeneuve N, Vilaine JP, Duhault J, et al. Cannabinoid CB1 receptor and endothelium-dependent hyperpolarization in guinea-pig carotid, rat mesenteric and porcine coronary arteries. $\mathrm{Br} J$ Pharmacol. 1998;123(5):968-74.

126 Fulton D, Quilley J. Evidence against anandamide as the hyperpolarizing factor mediating the nitric oxide-independent coronary vasodilator effect of bradykinin in the rat. J Pharmacol Exp Ther. 1998;286(3):1146-51.

127 Moncada S, Higgs EA. The discovery of nitric oxide and its role in vascular biology. Br J Pharmacol. 2006;147 Suppl 1:S193-201.

128 Mendizabal VE, Orliac ML, Adler-Graschinsky E. Long-term inhibition of nitric oxide synthase potentiates effects of anandamide in the rat mesenteric bed. Eur J Pharmacol. 2001;427(3):251-62.

129 Begg M, Pacher P, Batkai S, Osei-Hyiaman D, Offertaler L, Mo FM, et al. Evidence for novel cannabinoid receptors. Pharmacol Ther. 2005;106(2):13345. 
130 Mendizabal VE, Adler-Graschinsky E. Cannabinoids as therapeutic agents in cardiovascular disease: a tale of passions and illusions. $\mathrm{Br} \mathrm{J}$ Pharmacol. 2007;151(4):427-40.

131 Shaul PW. Regulation of endothelial nitric oxide synthase: location, location, location. Annu Rev Physiol. 2002;64:749-74.

132 Chen Z, Peng IC, Sun W, Su MI, Hsu PH, Fu Y, et al. AMP-activated protein kinase functionally phosphorylates endothelial nitric oxide synthase Ser633. Circ Res. 2009;104(4):496-505.

133 Cale JM, Bird IM. Inhibition of MEK/ERK1/2 signalling alters endothelial nitric oxide synthase activity in an agonist-dependent manner. Biochem $\mathrm{J}$. 2006;398(2):279-88.

134 Anter E, Chen K, Shapira OM, Karas RH, Keaney JF, Jr. p38 mitogenactivated protein kinase activates eNOS in endothelial cells by an estrogen receptor alpha-dependent pathway in response to black tea polyphenols. Circ Res. 2005;96(10):1072-8.

135 Carling D. The AMP-activated protein kinase cascade--a unifying system for energy control. Trends Biochem Sci. 2004;29(1):18-24.

136 Lim CT, Kola B, Korbonits M. AMPK as a mediator of hormonal signalling. J Mol Endocrinol. 2010;44(2):87-97.

137 Minokoshi Y, Kim YB, Peroni OD, Fryer LG, Muller C, Carling D, et al. Leptin stimulates fatty-acid oxidation by activating AMP-activated protein kinase. Nature. 2002;415(6869):339-43.

138 Yamauchi T, Kamon J, Minokoshi Y, Ito $\mathrm{Y}$, Waki H, Uchida S, et al. Adiponectin stimulates glucose utilization and fatty-acid oxidation by activating AMP-activated protein kinase. Nat Med. 2002;8(11):1288-95.

139 Chen ZP, Mitchelhill KI, Michell BJ, Stapleton D, Rodriguez-Crespo I, Witters $\mathrm{LA}$, et al. AMP-activated protein kinase phosphorylation of endothelial NO synthase. FEBS Lett. 1999;443(3):285-9.

140 Zhang XP, Hintze TH. cAMP signal transduction induces eNOS activation by promoting PKB phosphorylation. Am J Physiol Heart Circ Physiol. 2006;290(6):H2376-84. 
141 Lipina C, Stretton C, Hastings S, Hundal JS, Mackie K, Irving AJ, et al. Regulation of MAP kinase-directed mitogenic and protein kinase B-mediated signaling by cannabinoid receptor type 1 in skeletal muscle cells. Diabetes. 2010;59(2):375-85.

142 Li DY, Tao L, Liu H, Christopher TA, Lopez BL, Ma XL. Role of ERK1/2 in the anti-apoptotic and cardioprotective effects of nitric oxide after myocardial ischemia and reperfusion. Apoptosis. 2006;11(6):923-30.

$143 \mathrm{Xu} \mathrm{Z}$, Ji X, Boysen PG. Exogenous nitric oxide generates ROS and induces cardioprotection: involvement of PKG, mitochondrial KATP channels, and ERK. Am J Physiol Heart Circ Physiol. 2004;286(4):H1433-40.

144 Touyz RM, He G, Deng LY, Schiffrin EL. Role of extracellular signal-regulated kinases in angiotensin II-stimulated contraction of smooth muscle cells from human resistance arteries. Circulation. 1999;99(3):392-9.

145 Xiao D, Zhang L. ERK MAP kinases regulate smooth muscle contraction in ovine uterine artery: effect of pregnancy. Am J Physiol Heart Circ Physiol. 2002;282(1):H292-300.

146 Matsumoto T, Ishida K, Nakayama N, Kobayashi T, Kamata K. Involvement of $\mathrm{NO}$ and MEK/ERK pathway in enhancement of endothelin-1-induced mesenteric artery contraction in later-stage type 2 diabetic Goto-Kakizaki rat. Am J Physiol Heart Circ Physiol. 2009;296(5):H1388-97.

147 Ding L, Chapman A, Boyd R, Wang HD. ERK activation contributes to regulation of spontaneous contractile tone via superoxide anion in isolated rat aorta of angiotensin II-induced hypertension. Am J Physiol Heart Circ Physiol. 2007;292(6):H2997-3005.

148 Kim J, Yoon MY, Choi SL, Kang I, Kim SS, Kim YS, et al. Effects of stimulation of AMP-activated protein kinase on insulin-like growth factor 1-and epidermal growth factor-dependent extracellular signal-regulated kinase pathway. J Biol Chem. 2001;276(22):19102-10.

149 Kawasaki H, Takasaki K, Saito A, Goto K. Calcitonin gene-related peptide acts as a novel vasodilator neurotransmitter in mesenteric resistance vessels of the rat. Nature. 1988;335(6186):164-7.

150 Gunthorpe MJ, Benham CD, Randall A, Davis JB. The diversity in the vanilloid (TRPV) receptor family of ion channels. Trends Pharmacol Sci. 2002;23(4):183-91. 
151 Glaser ST, Kaczocha M, Deutsch DG. Anandamide transport: a critical review. Life Sci. 2005;77(14):1584-604.

152 Moore SA, Nomikos GG, Dickason-Chesterfield AK, Schober DA, Schaus JM, Ying $\mathrm{BP}$, et al. Identification of a high-affinity binding site involved in the transport of endocannabinoids. Proc Natl Acad Sci $U S A$. 2005;102(49):17852-7. 
ANEXO A - Lobato NS, Filgueira FP, Prakash R, Giachini FR, Ergul A, Carvalho MHC, Webb RC, Tostes RC, Fortes ZB. Obesity decreases the vascular relaxation to anandamide, a cannabinoid agonist. 


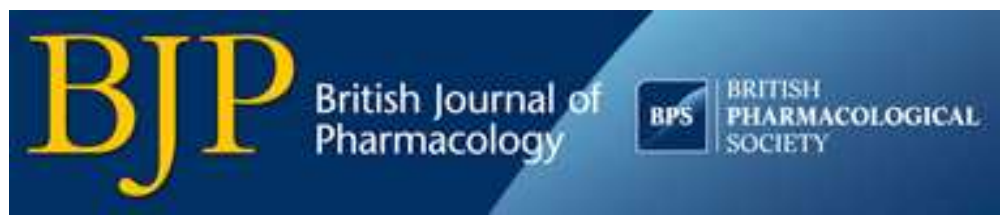

\section{Obesity decreases the vascular relaxation to anandamide, a cannabinoid agonist}

\begin{tabular}{|c|c|}
\hline Journal: & British Journal of Pharmacology \\
\hline Manuscript ID: & Draft \\
\hline Manuscript Type: & Research Paper \\
\hline $\begin{array}{r}\text { Date Submitted by the } \\
\text { Author: }\end{array}$ & $\mathrm{n} / \mathrm{a}$ \\
\hline Complete List of Authors: & $\begin{array}{l}\text { Lobato, Nubia; University of Sao Paulo, Pharmacology; Medical } \\
\text { College of Georgia, Physiology } \\
\text { Filgueira, Fernando; University of Sao Paulo, Pharmacology; } \\
\text { Medical College of Georgia, Physiology } \\
\text { Prakash, roshyni; Medical College of Georgia, Physiology } \\
\text { Ergul, Advye; Medical College of Georgia, Physiology } \\
\text { Giachini, Fernanda; University of Sao Paulo, Pharmacology; Medical } \\
\text { College of Georgia, Physiology } \\
\text { Carvalho, Maria Helena; University of Sao Paulo, Pharmacology } \\
\text { Webb, Clinton; Medical college of georgia, Physiology } \\
\text { Tostes, Rita; University of Sao Paulo, Pharmacology; Medical } \\
\text { College of Georgia, Physiology } \\
\text { Fortes, Zuleica; University of Sao Paulo, Pharmacology }\end{array}$ \\
\hline \multirow[t]{2}{*}{ Publication category: } & Cardiovascular pharmacology \\
\hline & $\begin{array}{l}\text { Cardiovascular pharmacology }<\text { A. General fields, Cannabinoids }< \\
\text { B. Mediators, Receptors, Transporters, Channels \& Ligands, Drug } \\
\text { receptor mechanisms }<\text { A. General fields, CGRP }<\text { B. Mediators, } \\
\text { Receptors, Transporters, Channels \& Ligands, Nitric oxide }<\text { B. } \\
\text { Mediators, Receptors, Transporters, Channels \& Ligands, Transient } \\
\text { receptor potential channels (TRP) }<\text { B. Mediators, Receptors, } \\
\text { Transporters, Channels \& Ligands }\end{array}$ \\
\hline
\end{tabular}

\section{SCHOLARONE ${ }^{m}$ Manuscripts}



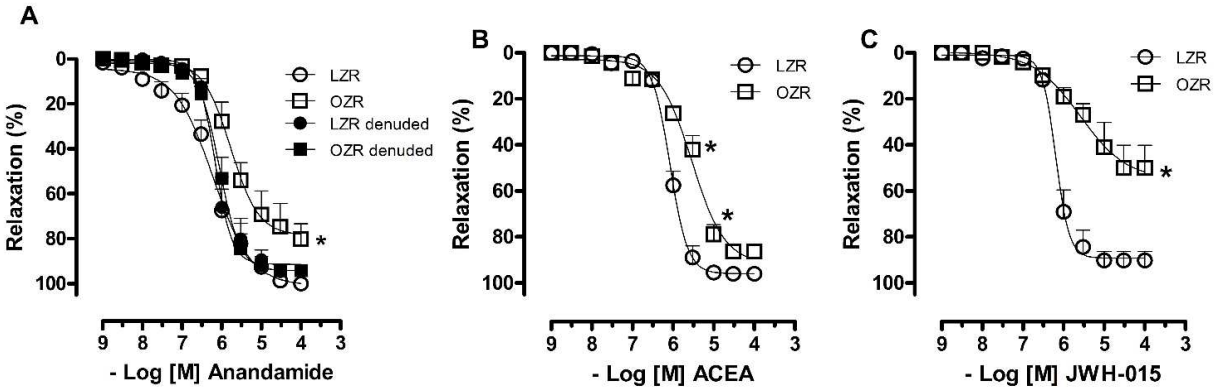

Figure 1- Effect of obesity on vascular relaxation to cannabinoid agonists. Cumulative concentrationresponse curves for anandamide (A), ACEA (CB1 receptor-selective agonist, B) and JWH-015 (CB2 receptor-selective agonist, $C$ ) in U46619-precontracted mesenteric arteries from lean Zucker rats (LZRs) and obese Zucker rats (OZRs). Each point represents the mean \pm SEM. ${ }^{*} \mathrm{P}<0.05$ vs. LZR. N $=6 /$ group. $239 \times 84 \mathrm{~mm}(500 \times 500$ DPI $)$ 

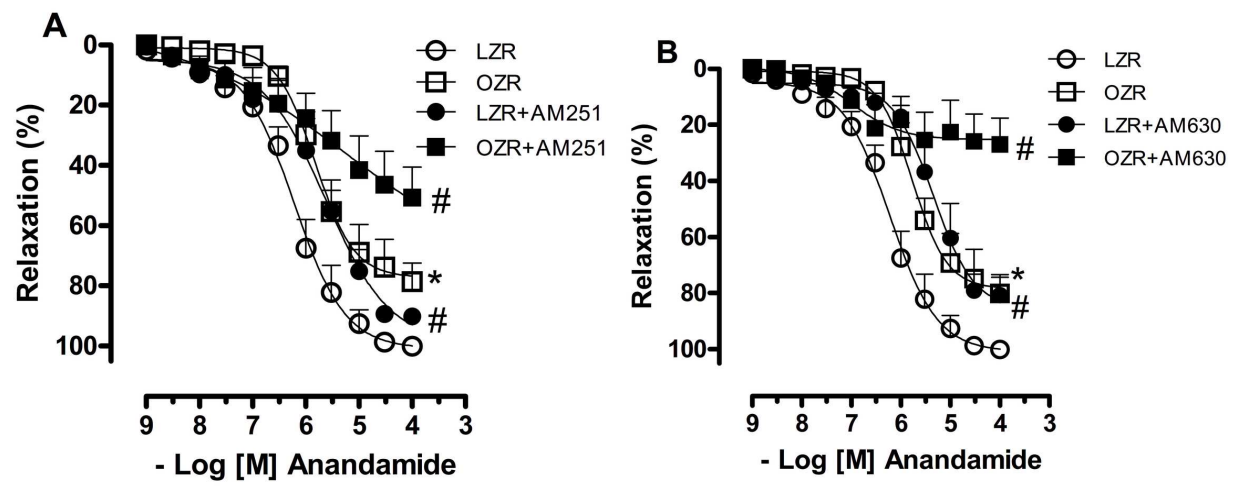

Figure 2- Contribution of $\mathrm{CB} 1$ and $\mathrm{CB} 2$ receptors to the vascular effects of anandamide in mesenteric arteries from lean Zucker rats (LZRs) and obese Zucker rats (OZRs). In A, the vessels were pretreated with a CB1 antagonist (AM 251, $1 \mu \mathrm{M}$ ) and in B with a CB2 antagonist (AM 630, 1 $\mu \mathrm{M}$ ) for 30 minutes. In $C$ and $D$, representative western blots for CB1 and CB2 receptors, respectively, in mesenteric arteries from lean Zucker rats (LZRs) and obese Zucker rats (OZRs). Results were normalised to $\beta$-actin expression and expressed as units of change from the control. Data are expressed as mean $\pm \mathrm{SEM}$. $* \mathrm{P}<0.05$ vs. LZR. $\# \mathrm{P}<0.05$ vs. respective group in the absence of blockade. $\mathrm{N}=5$ or $6 /$ group. $104 \times 45 \mathrm{~mm}(600 \times 600 \mathrm{DPI})$ 

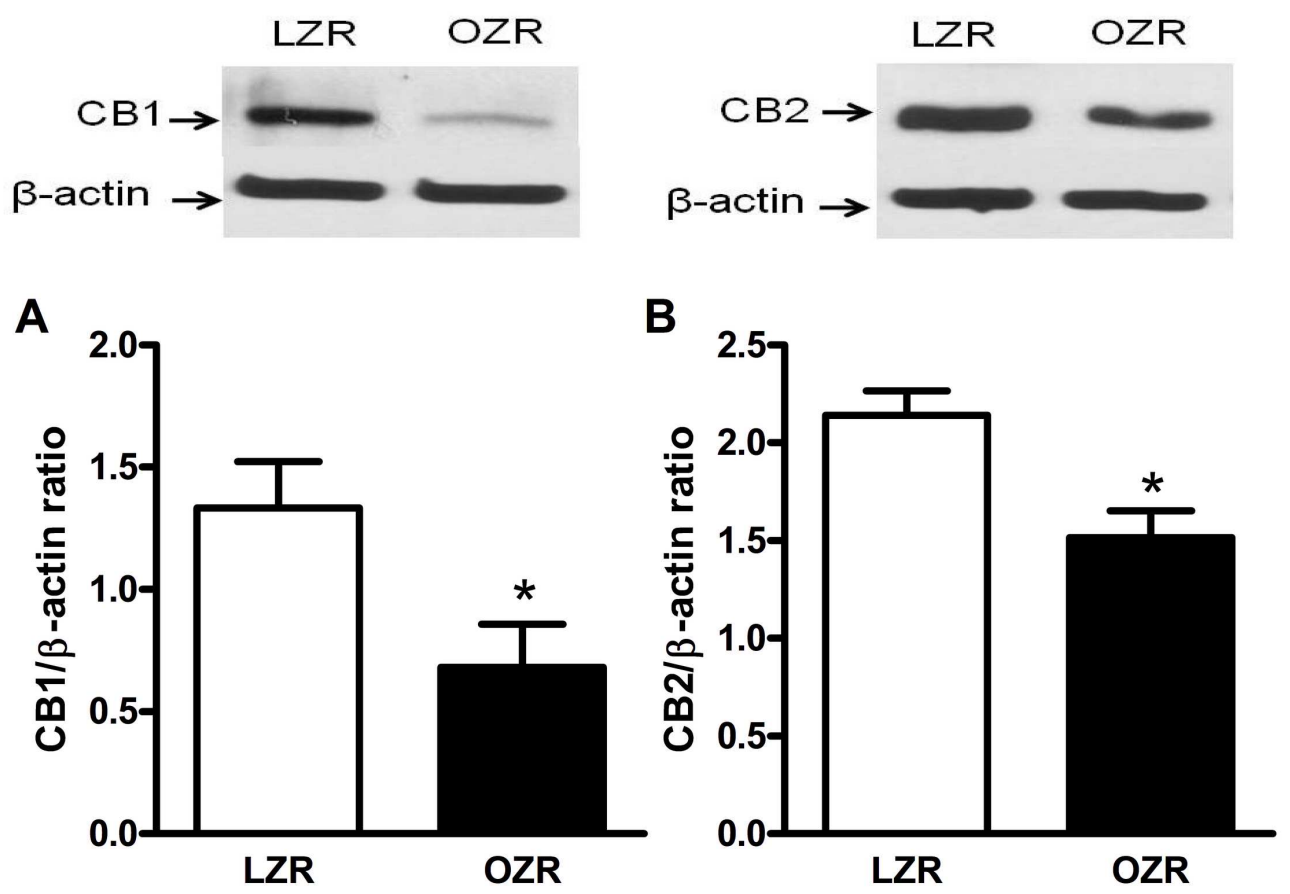

Figure 3- Effect of obesity on the protein expression of cannabinoid receptors. In $A$ and $B$, western blots for $C B 1(A)$ and $C B 2$ receptors (B) in mesenteric arteries from lean Zucker rats (LZRs) and obese Zucker rats (OZRs). Results were normalised to $\beta$-actin expression and expressed as units of change from the control. Data are expressed as mean \pm SEM. ${ }^{*} P<0.05$ vs. LZR. $N=5 / g r o u p$. $95 \times 67 \mathrm{~mm}(600 \times 600 \mathrm{DPI})$ 


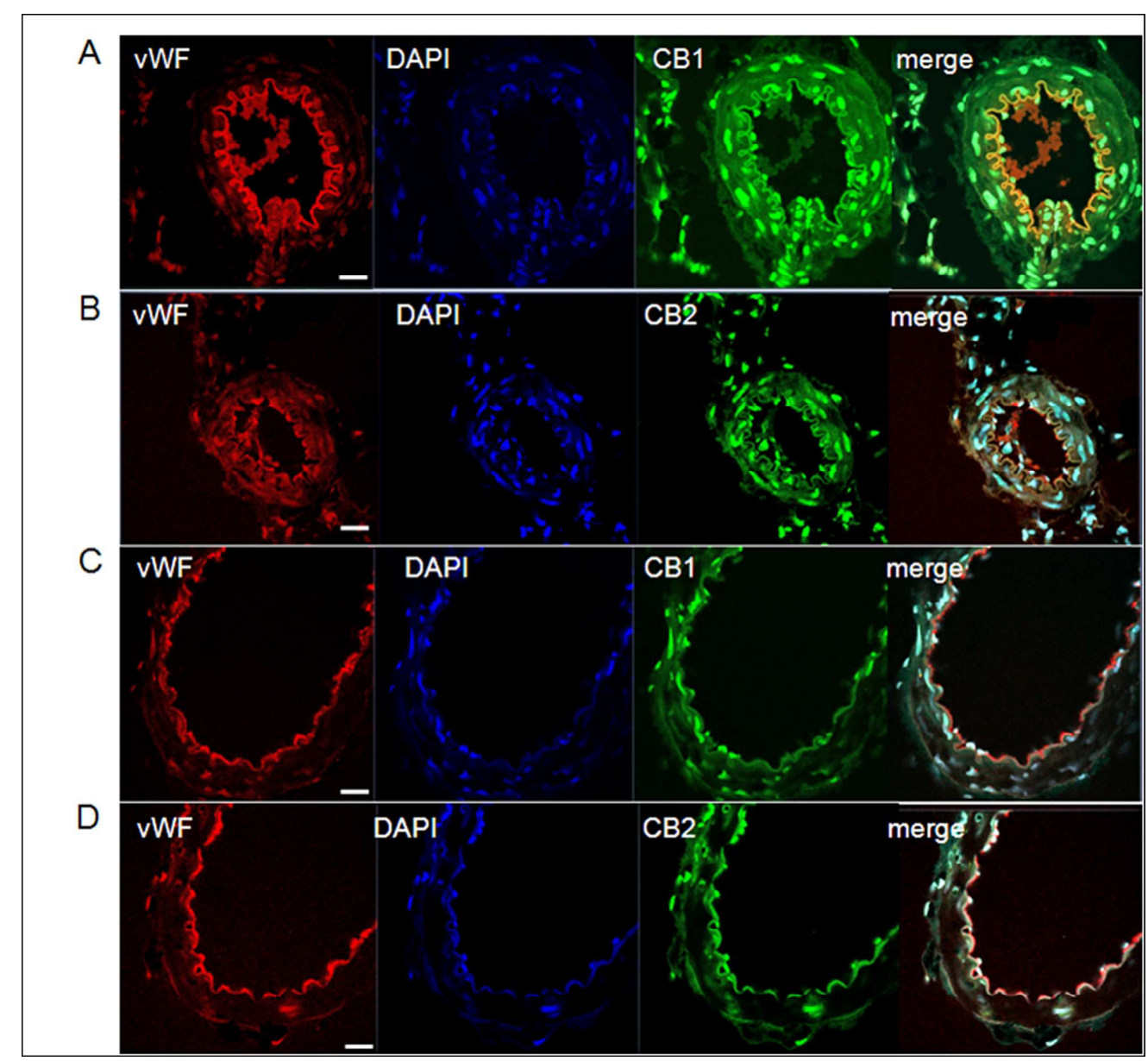

Figure 4- Confocal microscopic images of von Willebrand factor (vWF, red), DAPI (blue), CB1 receptors (green) and CB2 receptors (green) in mesenteric arteries from lean Zucker rats (LZRs, $A$ and $B$ ) and obese Zucker rats (OZRs, C and D). Endothelium-intact mesenteric sections were immunolabeled with antibodies against CB1, CB2 and von Willebrand factor. The nuclei were counterstained with DAPI. An overlay of the VWF, DAPI and CB1 or CB2 images is presented (merge). Endothelial localisation of CB1 and CB2 receptors is shown in the merged images (yellow). The images are representative of three separated experiments. $N=5 /$ group. Scale bar $=40 \mu \mathrm{m}$. $174 \times 161 \mathrm{~mm}(600 \times 600 \mathrm{DPI})$ 

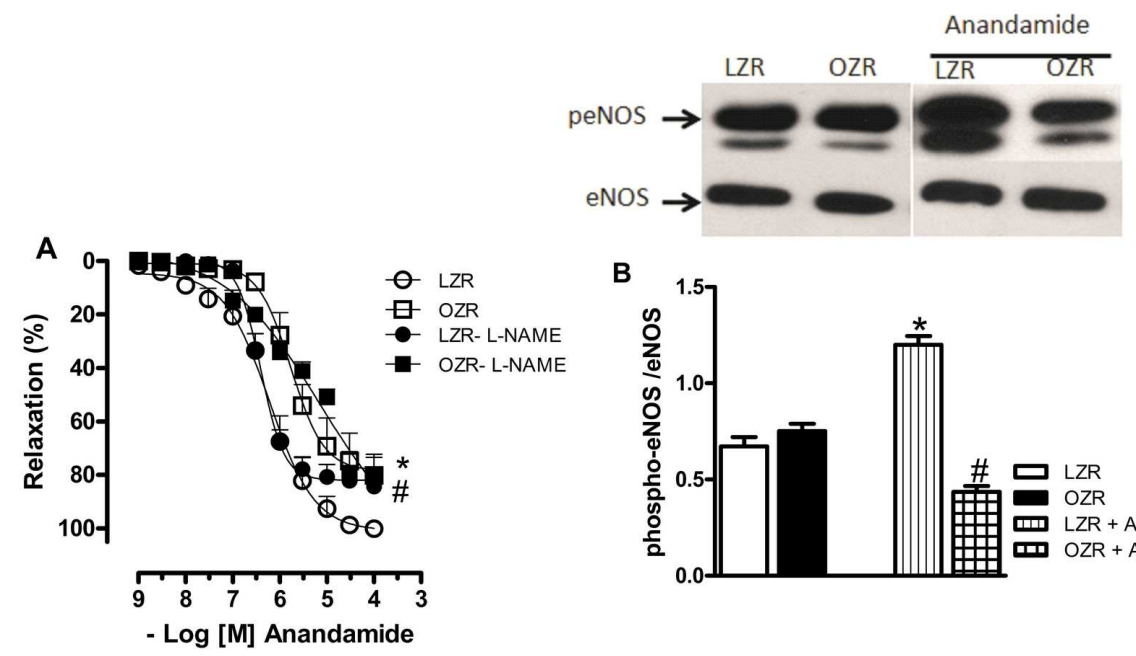

B

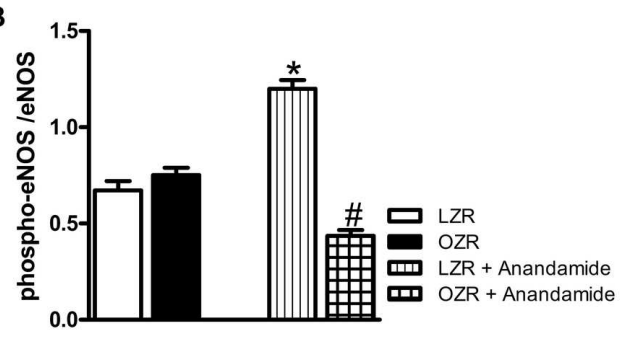

Figure 5- Contribution of the nitric oxide (NO) to the vascular effects of anandamide in mesenteric arteries from lean Zucker rats (LZRs) and obese Zucker rats (OZRs). In A, the vessels were pretreated with an NO synthase inhibitor (L-NAME, $100 \mu \mathrm{M}$, for 30 minutes) and the vascular relaxation to anandamide was evaluated in U46619-precontracted mesenteric arteries. In $B$, the phosphorylation of eNOS was evaluated by western in mesenteric arteries from blot LZRs and OZRs. Panel shows densitometric analysis of the western blot for eNOS protein expression. Total eNOS levels are shown as loading controls. Data are expressed as mean \pm SEM. $* P<0.05$ vs. LZR. $\# P<0.05$ vs. OZR. $N=5 /$ group. $76 \times 41 \mathrm{~mm}(600 \times 600 \mathrm{DPI})$ 


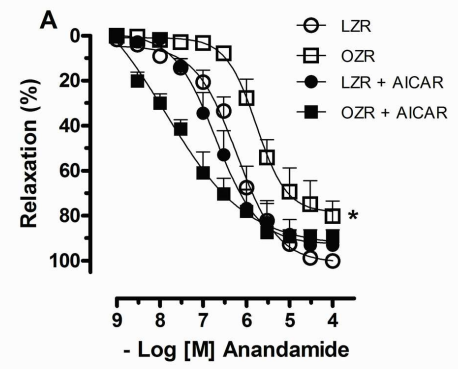

C

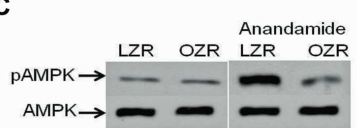

\section{。}
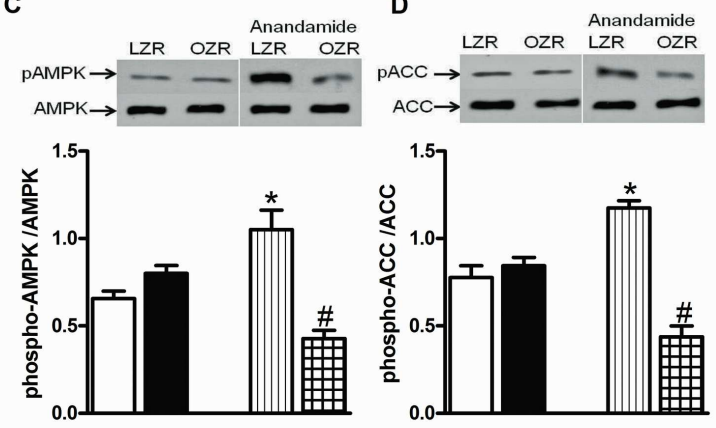

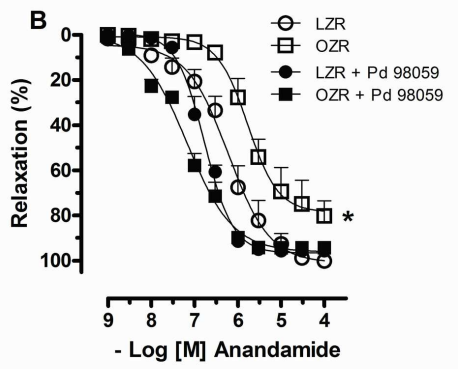

E
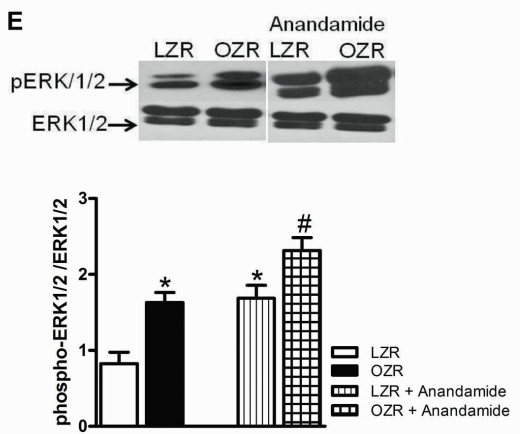

Figure 6- Contribution of cyclic AMP-dependent protein kinase (AMPK) and extracellular signalregulated kinases 1 and 2 (ERK1/2) pathways to anandamide responses in mesenteric arteries from lean Zucker rats (LZRs) and obese Zucker rats (OZRs). In A and B, the vessels were incubated with AICAR (an AMPK activator, $1 \mathrm{mM}$ ) or PD98059 (ERK1/2 inhibitor, $1 \mu \mathrm{M}$ ), respectively, for 30 minutes and the vascular relaxation to anandamide was evaluated in U46619-precontracted mesenteric arteries. In C, D and E representative western blots for phosphorylation of AMPK, acetylCoA carboxylase (ACC) and ERK1/2 in mesenteric arteries from LZRs and OZRs are shown. Panels show densitometric analysis of the western blots for AMPK, ACC and ERK1/2 protein expression. Total protein levels are shown as loading controls. Data are expressed as mean $\pm \mathrm{SEM}$. ${ }^{*} \mathrm{P}<0.05$ vs. LZR, \#P<0.05 vs. OZR. $N=5$ or $6 /$ group. $112 \times 75 \mathrm{~mm}(600 \times 600 \mathrm{DPI})$ 

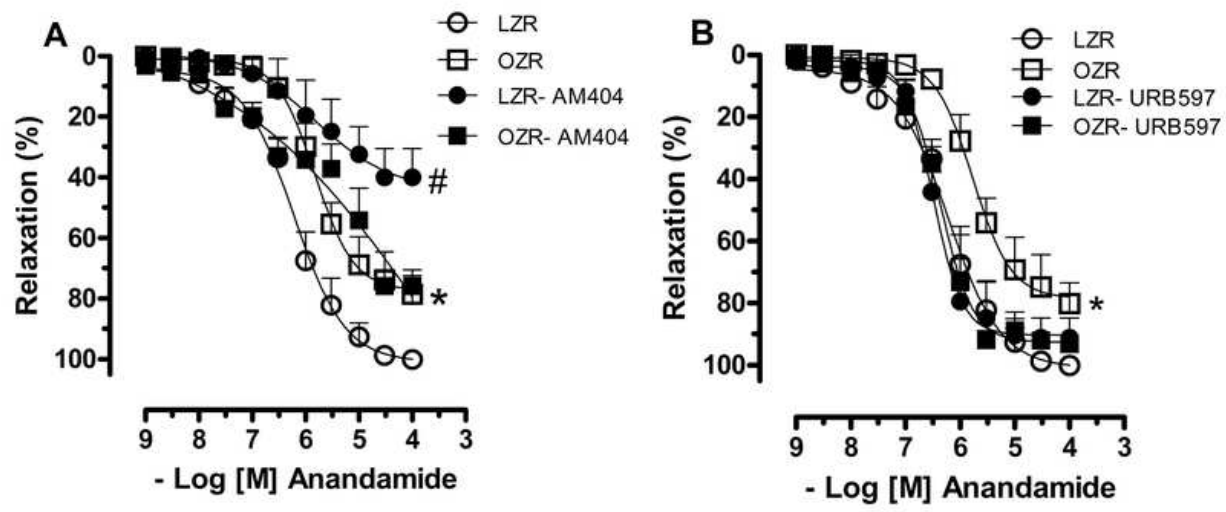

Figure 7- Contribution of uptake and degradation of anandamide in mesenteric arteries from lean Zucker rats (LZRs) and obese Zucker rats (OZRs). Vessels were pretreated with the anandamide transport blocker AM $404(1 \mu \mathrm{M}, \mathrm{A})$ or the fatty acid amide hydrolase (FAAH) inhibitor URB 597 (1 $\mu \mathrm{M}, \mathrm{B})$ for 30 minutes and the vascular relaxation to anandamide was evaluated in U46619precontracted mesenteric arteries. Each point represents the mean \pm SEM. ${ }^{*} P<0.05$ vs. LZR. $\# P<0.05$ vs. LZR in the absence of blockade. $N=6 /$ group. $36 \times 16 \mathrm{~mm}(600 \times 600 \mathrm{DPI})$ 

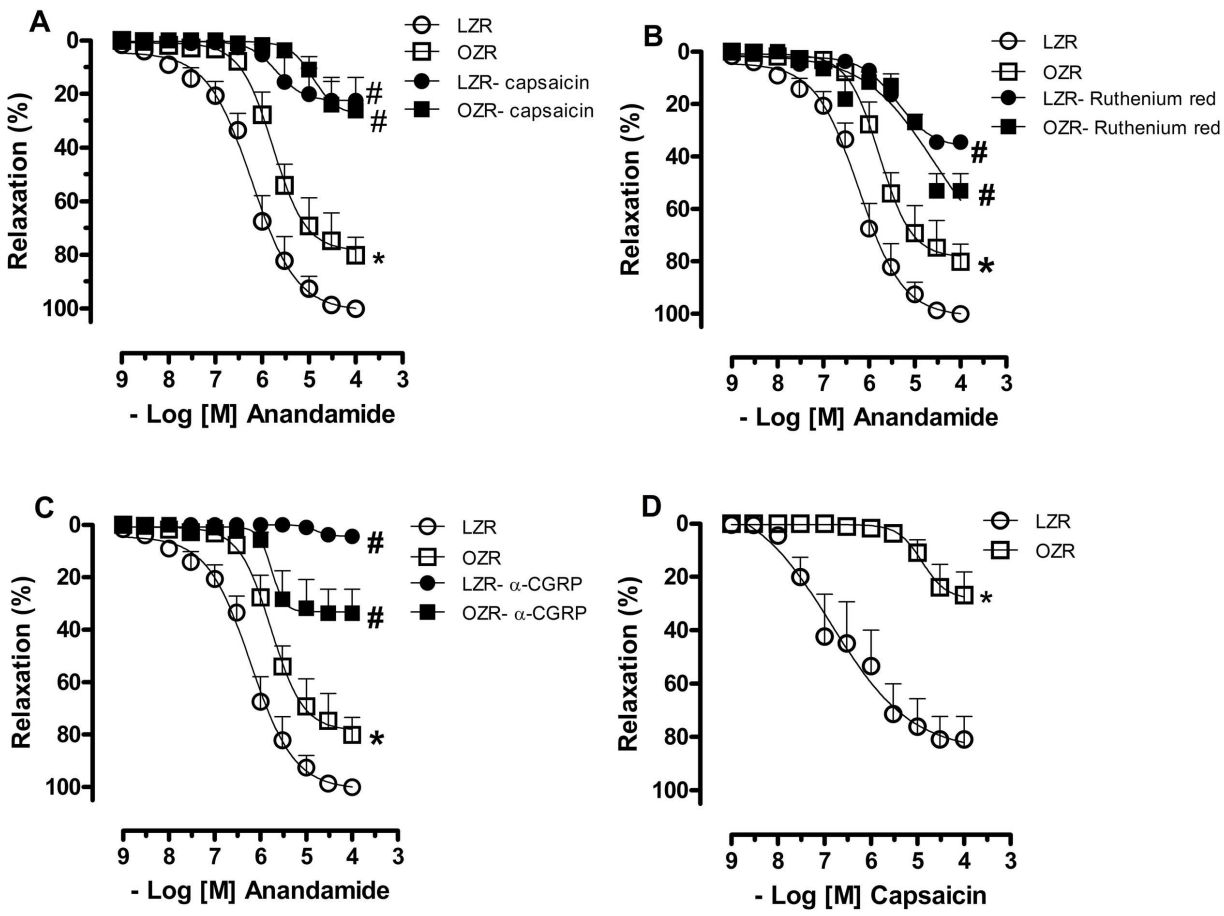

Figure 8- Involvement of TRPV1 receptors on sensory C-fibres in anandamide responses of mesenteric arteries from lean Zucker rats (LZRs) and obese Zucker rats (OZRs). In A, in vitro Cfibre desensitisation was induced using the selective neurotoxin capsaicin $(1 \mu \mathrm{M})$. In $B$, vessels were pretreated with the TRPV1 blocker, ruthenium red $(30 \mu \mathrm{M}, 30$ minutes). In $\mathrm{C}$, vessels were pretreated with the calcitonin gene-related peptide (CGRP) receptor antagonist a-CGRP (8-37) (10 $\mu \mathrm{M}, 30$ minutes). In $\mathrm{D}$, concentration-response curves for capsaicin in U46619-precontracted mesenteric arteries. Each point represents the mean \pm SEM. $* P<0.05$ vs. LZR, $\# P<0.05$ vs. respective group in the absence of blockade. $N=6 /$ group.

\section{$114 \times 86 \mathrm{~mm}(600 \times 600 \mathrm{DPI})$}


Obesity decreases the vascular relaxation to anandamide, a cannabinoid agonist

\section{Running title: Endocannabinoid system in obesity}

NS Lobato ${ }^{1,2}$, FP Filgueira ${ }^{1,2}, \mathrm{R}$ Prakash $^{2}$, FR Giachini ${ }^{1,2}$, A Ergul $^{2}, \mathrm{MHC}$ Carvalho ${ }^{1}, \mathrm{RC}$ Webb $^{2}, \mathrm{RC}$ Tostes $^{1,2}$, ZB Fortes $^{1 *}$

${ }^{1}$ Department of Pharmacology, Institute of Biomedical Sciences, University of Sao Paulo, Sao Paulo, Brazil, and ${ }^{2}$ Department of Physiology, Medical College of Georgia, Augusta, Georgia, USA.

* Corresponding author: Dr. Zuleica Bruno Fortes.

Department of Pharmacology, Institute of Biomedical Sciences, University of Sao Paulo, Sao Paulo, 05508-900 - Brazil.

Tel/Fax: +55-11-3091-7317

e-mail: zbfortes@icb.usp.br

Number of words: 6368 


\section{Obesity decreases the vascular relaxation to anandamide, a cannabinoid agonist}

NS Lobato, FP Filgueira, R Prakash, FR Giachini, A Ergul, MHC Carvalho, RC Webb, RC Tostes, ZB Fortes

Background and purpose: Considering the role of the endocannabinoid system in the control of the vascular tone, we hypothesised that obesity impairs the vasorelaxation to cannabinoid agonists.

Experimental approach: Young obese Zucker rats (OZRs) and their lean counterparts (LZRs) were used. The vascular reactivity was evaluated in a small vessel myograph for isometric tension recording. The protein expression and localisation were performed by western blotting and immunofluorescence, respectively.

Key results: The vasorelaxation induced by anandamide as well as by CB1, CB2 and TRPV1 agonists was impaired in mesenteric arteries with intact endothelium from OZRs. Incubation with an AMP-dependent protein kinase (AMPK) activator, an extracellular signal-regulated kinases 1 and 2 (ERK1/2) inhibitor or a fatty acid amide hydrolase (FAAH) inhibitor restored anandamide-induced relaxation in arteries from OZRs. The protein expression of CB1 and CB2 receptors was decreased in mesenteric arteries from OZRs. Incubation of mesenteric arteries with anandamide evoked endothelial nitric oxide synthase, AMPK and acetyl CoA carboxylase phosphorylation in LZRs, whereas it decreased the phosphorylation of these proteins in OZRs. Basal ERK1/2 phosphorylation was increased in vessels from OZRs, and this effect was potentiated by anandamide.

Conclusions and implications: Obesity decreases the endothelium-dependent relaxation to anandamide in resistance mesenteric arteries. Reductions in cannabinoid receptors expression, decreased transport and increased degradation of anandamide as well as decreased AMPK/eNOS activity and increased ERK1/2 activity are involved in this alteration. These data provide new evidence for a role of the endocannabinoid system in the vascular dysfunction present in obesity.

Keywords: obesity; endocannabinoid system; anandamide; resistance mesenteric arteries 


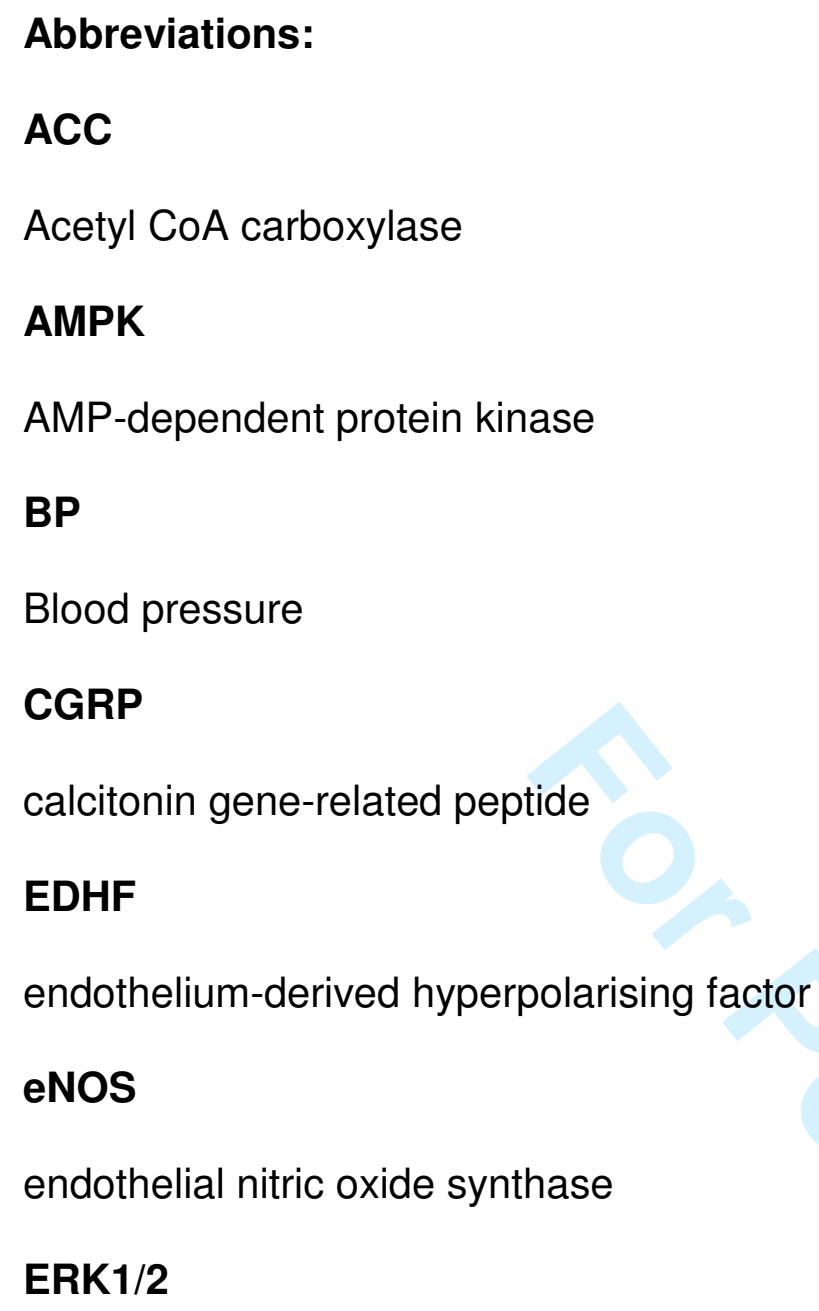

Abbreviations:

ACC

Acetyl CoA carboxylase

\section{AMPK}

AMP-dependent protein kinase

BP

Blood pressure

CGRP

calcitonin gene-related peptide

EDHF

endothelium-derived hyperpolarising factor

eNOS

endothelial nitric oxide synthase

ERK1/2

extracellular signal-regulated kinases 1 and 2

FAAH

fatty acid amide hydrolase

\section{LZR}

lean Zucker rat

MAPK

mitogen-activated protein kinase

NOS

nitric oxide synthase

OZR

obese Zucker rat 


\section{INTRODUCTION}

Obesity is a major public health problem in worldwide (Flegal et al., 2002; Hill, 2006). This condition is considered one of the main risk factors for the increased morbidity and mortality from hypertension, dyslipidemia, type 2 diabetes, heart failure, stroke, and coronary artery disease (Echahidi et al., 2007). Obesity is strongly linked to endothelial dysfunction (Stapleton et al., 2008), which can be considered the first step in the progression of cardiovascular diseases (Gokce et al., 2003; Lerman et al., 2005). In obese individuals, a substantial amount of evidence consistently demonstrates impaired arterial function manifested by reduced endothelium-dependent vasodilation. In the largest study that examined this issue, the Framingham Heart Study, an independent relationship between body mass index and blunted brachial artery flow-mediated dilation was reported (Mitchell et al., 2004).

An increased release of endocannabinoid agonists has been reported in obesity. In addition, higher levels of the endogenous cannabinoids anandamide (arachidonylethanolamide) and 2arachidonoylglycerol in the plasma of obese subjects correlated with visceral adiposity (Engeli et al., 2005; Matias et al., 2008; Szmitko et al., 2008). The endocannabinoid system is an endogenous system that plays an important role in the central and peripheral regulation of energy homeostasis, lipid metabolism, and fat accumulation (Cota et al., 2003). This system comprises the endocannabinoids, the enzymes involved in their biosynthesis and degradation and the G proteincoupled receptors that mediate their effects (CB1 and CB2) (Cravatt et al., 1996; Di Marzo, 2008; Liu et al., 2008; Mackie et al., 2006). The expression of CB receptors in various tissues explains the evergrowing list of functions attributed to the endocannabinoid system.

Endogenous cannabinoids such as anandamide also contribute to the regulation of vascular tone, evoking the release of prostanoids, nitric oxide (NO) and endothelium-derived hyperpolarising factor (EDHF) (Grainger et al., 2001; Hillard, 2000; Randall et al., 2004). Nevertheless, the relevance of the vascular actions of the endocannabinoid system in the vascular dysfunction associated with 
obesity is still unknown. In the present study, we investigated the implications of obesity for the response to anandamide in resistance mesenteric arteries. Considering the role of the endocannabinoid system in the control of the vascular tone, we hypothesised that the vascular relaxation induced by anandamide, a cannabinoid agonist, is impaired in obesity through reductions in cannabinoid receptor expression or in the signalling pathways downstream of cannabinoid receptors. To test our hypothesis, we used young (six- to seven-week-old) obese Zucker rats (OZRs), which display vascular dysfunction, providing a suitable model to investigate the response of resistance vessels to cannabinoids in obesity.

Our results showed that the arterial relaxation induced by the cannabinoid agonist anandamide is impaired in OZRs. Reductions in cannabinoid receptors expression, decreased transport and increased degradation of anandamide as well as decreased AMPK/eNOS activity and increased ERK $1 / 2$ activity are involved in this alteration. 


\section{METHODS}

\section{Animals}

All animal procedures were performed in accordance with the Guide for the Care and Use of Laboratory Animals published by the US National Institutes of Health (NIH Publication No. 85-23, revised 1996) and approved by the Institutional Animal Care and Use Committees at the Medical College of Georgia. Male lean Zucker rats (LZRs) and OZRs (six- to seven-week-old) were purchased from Harlan Laboratories and were maintained on a 12-hour light/dark cycle under controlled temperature $\left(22 \pm 1^{\circ} \mathrm{C}\right)$ with access to food and water ad libitum. On the day of the experiment, after food deprivation (5 h), LZRs and OZRs were weighed, and tail blood samples were taken. Blood glucose levels were analysed using a glucometer (Roche, Mannheim, Germany). After sacrifice, the white adipose tissue (epididymal and retroperitoneal) was dissected and weighed. Blood pressure (BP) was measured in conscious rats by an indirect tail-cuff method (Kent Scientific Corporation, CT) after a training period of three days. Rats were maintained at $37{ }^{\circ} \mathrm{C}$ for $10 \mathrm{~min}$, and then three consecutive stable BP measurements were averaged.

\section{Vascular function studies}

Force development in response to a specific experimental protocol was evaluated in mesenteric arteries from both groups as previously described (Mulvany et al., 1977). The mesenteric vascular bed was removed and placed in Krebs solution (see below for composition). Segments (2 $\mathrm{mm}$ in length) of the mesenteric arteries were mounted on $40-\mu \mathrm{m}$ wires in a small vessel myograph for isometric tension recording. The vessels were allowed to equilibrate for about 30 min in Krebs solution of the following composition (in $\mathrm{mM}$ ): $130 \mathrm{NaCl}, 14.9 \mathrm{NaHCO}_{3}, 4.7 \mathrm{KCl}, 1.18 \mathrm{KH}_{2} \mathrm{PO}_{4}, 1.17$ $\mathrm{MgSO}_{4} \cdot 7 \mathrm{H}_{2} \mathrm{O}, 5.5$ glucose, $1.56 \mathrm{CaCl}_{2} \cdot 2 \mathrm{H}_{2} \mathrm{O}$, and 0.026 EDTA. The solution was gassed with $5 \%$ $\mathrm{CO}_{2}$ in $\mathrm{O}_{2}$ to maintain a $\mathrm{pH}$ of 7.4 . The relationship between resting wall tension and internal circumference was determined, and the internal circumference, L100, corresponding to a transmural 
pressure of $100 \mathrm{mmHg}$ for a relaxed vessel in situ, was calculated. The vessels were set to the internal circumference $L 1$, given by $L 1=0.9 \times L 100$. The effective internal lumen diameter was determined as $L 1=L 1 / \pi$, and was between 200 and $300 \mu \mathrm{m}$. After stabilisation, arterial integrity was assessed by stimulation of vessels with $120 \mathrm{mM} \mathrm{KCl}$. Endothelial function was assessed by testing the relaxant effect of acetylcholine $(\mathrm{ACh}, 1 \mu \mathrm{M})$ on vessels precontracted with phenylephrine $(1 \mu \mathrm{M})$. The failure of ACh to elicit relaxation of mesenteric arteries previously subjected to rubbing of the intimal surface with a human hair was taken as proof of endothelium removal.

\section{Vascular responses to anandamide, CB1 and CB2 agonists}

Cumulative concentration-response curves for anandamide, ACEA (a CB1 receptor-selective agonist), JWH-015 (a CB2 receptor-selective agonist) and capsaicin were performed in U46619precontracted mesenteric arteries. Each preparation was tested with a single agent. To determine whether anandamide-induced relaxation was dependent on the endothelium, responses were also measured using endothelium-denuded arteries. To investigate the involvement of cannabinoid receptors in anandamide responses, mesenteric arteries were preincubated for 30 min with either the CB1 receptor antagonist (AM251, $1 \mu \mathrm{M}$ ) (O'Sullivan et al., 2004) or the CB2 receptor antagonist (AM630, $1 \mu \mathrm{M})$ (Jiang et al., 2007).

To determine whether prior cellular uptake or metabolic conversion of anandamide was required for its vascular effects, mesenteric arteries were pretreated for $30 \mathrm{~min}$ with the endocannabinoid transport inhibitor AM404 $(10 \mu \mathrm{M})$ (Beltramo et al., 1997) or the fatty acid amide hydrolase (FAAH) inhibitor URB597 (100 nM) (Kaczocha et al., 2009), respectively.

To investigate the contribution of the cyclic AMP-dependent protein kinase (AMPK) and extracellular signal-regulated kinases 1 and 2 (ERK1/2) pathways to anandamide responses, the AMPK activator aminoimidazole carboxamide ribonucleotide (AICAR, $1 \mathrm{mM}$ ) (Goirand et al., 2007) and the ERK1/2 inhibitor PD98059 (1 $\mu \mathrm{M}, 30 \mathrm{~min}$ ) (Dudley et al., 1995) were used, respectively. To 
examine the contribution of $\mathrm{NO}$ in the vascular effects of anandamide, mesenteric arteries were pretreated with the nitric oxide synthase inhibitor N $\omega$-nitro-L-arginine methyl ester (L-NAME, $100 \mu \mathrm{M}$, for $30 \mathrm{~min}$ ) (Lobato et al., 2010).

To investigate the involvement of sensory C-fibres in anandamide responses, mesenteric arteries were pretreated with different blockers. Desensitisation of C-fibres in vitro was induced using the selective neurotoxin capsaicin ( $1 \mu \mathrm{M}$ for 20 minutes, followed by a 40 -minute washout period) (Holzer, 1991). Acute exposure to capsaicin promotes activation of sensory C-fibres; however, after prolonged exposure, as in the current protocol, a desensitisation of the nerve ending occurs. A 40minute washout period ensures removal of any residual neuropeptide that may have been released, as previously described (Scotland et al., 2004).

Considering that transient receptor potential vanilloid-1 (TRPV-1) channels have been identified as the major activation site on C-fibre nerve endings (Caterina et al., 1997), we investigated the effects of the selective TRPV1 blocker capsazepine ( $3 \mu \mathrm{M}, 30 \mathrm{~min})$ (Bevan et al., 1992) and the nonselective cation channel blocker ruthenium red (30 $\mu \mathrm{M}, 30 \mathrm{~min}$ ) (Dray et al., 1990) on anandamide responses. In addition, the participation of the products released after activation of vanilloid receptors was investigated using the calcitonin gene-related peptide (CGRP) receptor antagonist $\alpha$-CGRP (837) $(10 \mu \mathrm{M}, 30 \mathrm{~min})$ (Zygmunt et al., 2002) or the P2Y1 receptor antagonist MRS2179 (1 $\mu \mathrm{M}, 30 \mathrm{~min})$ (Rayment et al., 2007).

Because we did not observe any difference in the responses to anandamide of denuded arteries from LZRs and OZRs, the studies were carried out with intact arteries.

\section{Western Blotting}

Mesenteric arteries from LZRs and OZRs were isolated, cleaned of fat, dissected and frozen in liquid nitrogen. Extracted proteins $(50 \mu \mathrm{g})$ were separated by electrophoresis on $8 \%$ polyacrylamide gels and transferred to nitrocellulose membranes. Nonspecific binding sites were blocked with $5 \%$ 
skim milk in Tris-buffered saline solution with Tween $(0.1 \%)$ for 1 hour at $24^{\circ} \mathrm{C}$. Membranes were incubated with antibodies (at the indicated dilutions) overnight at $4{ }^{\circ} \mathrm{C}$. Antibodies were as follows: anti-CB1 (1:250, Sigma), anti-CB2 (1:1000, Sigma), anti-eNOs (1:500, Cell Signaling), anti-phospho eNOs (1:1000, Cell Signaling), anti-AMPK (1:1000, Cell Signaling), anti-phospho AMPK (1:1000, Cell Signaling), anti-acetyl CoA carboxylase (ACC, 1:1000, Cell Signaling), anti-phospho ACC (1:1000, Cell Signaling), anti-ERK1/2 (1:1000, Cell Signaling), anti-phospho ERK1/2 (1:1000, Cell Signaling) and anti- $\beta$-actin (1:20000, Sigma). After incubation with secondary antibodies, signals were revealed by chemiluminescence, visualised by autoradiography and quantified densitometrically. Results were normalised to $\beta$-actin expression and expressed as units relative to the control.

\section{Immunofluorescence and confocal microscopy}

After fixation of the endothelium-intact mesenteric segments, the samples were frozen in OCT compound (Sakura Finetek USA, Torrance, CA), and serial cryosections (20 $\mu \mathrm{m})$ were prepared and mounted on slides. After washing in phosphate-buffered saline (PBS), slides containing samples were blocked with bovine serum albumin (BSA, $0.1 \%$ ) for 1 hour at room temperature. The sections were subsequently incubated (at the indicated dilutions) with rabbit monoclonal anti-CB1 (1:100, Abcam), rabbit polyclonal anti-CB2 (1:100, Abcam), or mouse anti-von Willebrand (1:500, Abcam) overnight at $4^{\circ} \mathrm{C}$. After washing in PBS, the fluorescent secondary antibodies (at a 1:1000 dilution) goat antimouse IgG Alexa Fluor 488 and goat anti-rabbit Alexa Fluor 594 (Molecular Probes) were applied and incubated for $1 \mathrm{~h}$ at room temperature. After washing in PBS, the slides were coverslipped with antifading mounting medium (Gel/Mount medium; Biomeda, Foster City, CA). Fluorescent photomicrographs were obtained using a laser scanning confocal microscope (Leica TCS-DMRE, Germany). The nuclear stain 4',6-diamidino-2-phenylindole (DAPI) was used to label all cells. No significant fluorescence was observed when the primary antibodies were omitted. 


\section{Data analysis and statistical procedures}

Vasodilatation is represented as a percentage of the maximal response to U46619. The maximum response was calculated by non-linear regression analysis. Data are presented as mean \pm SEM, and intergroup comparisons were performed using Student's t-test or one-way ANOVA when appropriate. $\mathrm{P}$ values less than 0.05 were considered significant.

\section{Drugs}

Phenylephrine, acetylcholine, capsaicin, L-NAME, AICAR, PD98059, MRS2179 and a-CGRP (8-37) were purchased from Sigma Chemical Co (St. Louis, MO). Anandamide, ACEA, JWH-015, AM251, AM630, capsazepine, ruthenium red and AM404 were purchased from Tocris (Ellisville, MO), and URB597 was obtained from Cayman Chemical (Ann Arbor, MI). 


\section{RESULTS}

\section{General characteristics of OZRs}

Table 1 summarised comparisons of general parameters between young LZRs and OZRs. BP and glucose levels were similar between LZRs and OZRs. However, OZRs displayed higher body weight and fat mass compared with age-matched LZRs. This indicates that young OZRs represent a normotensive and normoglycemic model of obesity.

\section{Effect of obesity on vascular relaxation to cannabinoid agonists}

Anandamide induced dose-dependent relaxation in mesenteric arteries from both LZRs and OZRs. However, this response was impaired in arteries from OZRs. In endothelium-denuded preparations, similar relaxation responses to anandamide were observed in samples from OZRs and LZRs (Figure 1A). Endothelium-intact arteries from OZRs also displayed a marked decrease in the vascular relaxation mediated by $\mathrm{CB} 1$ and $\mathrm{CB} 2$ cannabinoid receptor agonists compared with vessels from LZRs (Figures 1B and 1C). Blockade of CB1 and CB2 receptors with AM251 or AM630, respectively, slightly decreased the relaxation responses to anandamide in arteries from LZRs. On the other hand, anandamide responses were almost blunted in samples from OZRs after incubation with $\mathrm{CB} 1$ and $\mathrm{CB} 2$ antagonists (Figures $2 \mathrm{~A}$ and $\mathrm{B}$ ).

Inhibition of NO synthase with L-NAME significantly decreased the anandamide-induced relaxation of vessels from LZRs, whereas it did not alter this response in samples from OZRs (Figure 5A). Incubation of mesenteric arteries from OZRs with either the AMPK activator (AICAR) or the ERK1/2 inhibitor (PD98059) corrected the reduced relaxation response to anandamide (Figures 6A and $B)$.

The cannabinoid transport inhibitor AM404 did not alter the anandamide-induced relaxation of vessels from OZRs, whereas it significantly decreased this response in arteries from LZRs (Figure 
7A). Incubation with the FAAH inhibitor URB597 corrected the reduced anandamide-induced relaxation of samples from OZRs (Figure 7B).

In vitro C-fibre desensitisation with capsaicin markedly reduced the anandamide-induced relaxation of arteries from both LZRs and OZRs (Figure 8A). Blockade of TRPV1 with ruthenium red also decreased anandamide-induced vessel relaxation in samples from both LZRs and OZRs (Figure 8B). Purinergic receptors antagonism with MRS2179 did not change anandamide-induced arterial relaxation in vessels from both experimental groups (data not shown). However, the blockade of CGRP receptors with $\alpha$-CGRP (8-37) almost completely inhibited the anandamide-induced relaxation in LZRs, and it decreased this response to a lesser extent in OZRs (Figure 8C). Capsaicin-induced relaxation was markedly decreased in OZRs compared with LZRs (Figure 8D).

\section{Effect of obesity on the protein expression of cannabinoid receptors}

The protein expression of $\mathrm{CB} 1$ and $\mathrm{CB} 2$ receptors was decreased in mesenteric arteries from OZRs as compared with LZRs (Figures $3 \mathrm{C}$ and D). The protein expression of TRPV1 receptors was similar in mesenteric arteries from LZRs and OZRs (data not shown).

\section{Effect of anandamide on the phosphorylation of eNOS, AMPK and ERK1/2 in LZRs and OZRs}

We tested whether anandamide altered the activity of eNOS, AMPK and ERK1/2 in mesenteric arteries. Vessels were incubated with $1 \mu \mathrm{M}$ anandamide for $30 \mathrm{~min}$, and the activation these proteins was examined. The phosphorylation of eNOS at Ser-1177 was not altered in vessels from OZRs. However, after incubation with anandamide, eNOS phosphorylation was decreased in mesenteric arteries from OZRs. In contrast, a robust increase in eNOS phosphorylation was observed in LZRs (Figure 5B). Similarly, anandamide treatment decreased AMPK Thr-172 phosphorylation in arteries from OZRs and increased AMPK phosphorylation in vessels from LZRs (Figure 6C). To confirm that AMPK activation by anandamide results in typical AMPK-mediated downstream responses, we 
evaluated the phosphorylation of ACC, a primary target of activated AMPK. We found that anandamide treatment decreased ACC phosphorylation in arteries from OZRs. Phosphorylation of ACC was increased in vessels from LZRs after incubation with anandamide (Figure 6D). Phosphorylation of ERK1/2 was increased in vessels from OZRs. Incubation with anandamide increased ERK1/2 phosphorylation in arteries from LZRs, and it potentiated the activation of this mitogen-activated protein kinase (MAPK) in vessels from OZRs (Figure 6E).

\section{Localisation of CB1 and CB2 receptors in mesenteric arteries}

Localisation of CB1 and CB2 receptors with von Willebrand factor is shown by confocal immunofluorescence microscopy in endothelium-intact mesenteric sections. Immunofluorescence for CB1 (Figure 4A) and CB2 (Figure 4B) receptors was visualised in mesenteric arteries of LZRs. To determine whether $\mathrm{CB} 1$ and $\mathrm{CB} 2$ receptors were localised in endothelial cells, we used double immunolabeling of rat mesenteric arteries for CB1, CB2 and von Willebrand factor, a widely used marker for endothelial cells. Von Willebrand factor was visualised using a red fluorescent secondary antibody, whereas CB1 and CB2 were visualised with green fluorescent secondary antibodies. Colocalisation of $\mathrm{CB} 1$ or $\mathrm{CB} 2$ and von Willebrand factor, as observed by the yellow colour of the overlay of CB1 or CB2 and von Willebrand staining, was observed in endothelial cells. Mesenteric arteries from OZRs displayed decreased CB1 (Figure 4C) and CB2 (Figure 4D) immunofluorescence in both smooth muscle cells and endothelium when compared with the representative images from LZRs. 


\section{DISCUSSION}

Studies investigating the physiological effects of cannabinoids have focused on the regulation of the metabolic homeostasis (Cota et al., 2003; Engeli et al., 2005; Matias et al., 2008). However, the effects of cannabinoid agonists are not restricted to tissues that control metabolic homeostasis. Endogenous cannabinoids also contribute to the regulation of vascular tone in physiological conditions (Grainger et al., 2001; Hillard, 2000). In this regard, the goal of the current study was to test the hypothesis that the vascular response to anandamide, an endocannabinoid agonist, is impaired in obesity. Herein, we present the novel finding that resistance mesenteric arteries from young OZRs display decreased endothelium-dependent relaxation to anandamide.

The OZR model has been widely used to investigate the cardiovascular effects of obesity and insulin resistance. It is important to consider that although the cause of obesity in OZRs is not common among humans, the phenotype parallels human obesity in many ways. These rats display increased triglycerides, cholesterol and insulin levels, and eventually develop type 2 diabetes (Zucker et al., 1972). It must be noted, however, that at the age the OZRs were used in the current study, they did not display increased BP or hyperglycemia, which are factors that can contribute to changes in the endocannabinoid system (Subramanian et al., 2003).

One important finding in the current study was that the impairment of anandamide-induced relaxation of mesenteric arteries from OZRs involves changes at the level of the endothelium because the reduced responses to anandamide were only observed in preparations with intact endothelium. Furthermore, we demonstrated that the reduction of anandamide response in OZRs is mediated by $\mathrm{CB} 1$ and $\mathrm{CB} 2$ receptors because the vascular responses to specific agonists of these receptors were also impaired in these rats. The role of $\mathrm{CB} 1$ and $\mathrm{CB} 2$ receptors in the reduced relaxation response to anandamide in arteries from OZRs was further confirmed in our study by western blotting and immunofluorescence analysis. We observed that the protein expression of CB1 and CB2 receptors is decreased in both smooth muscle and endothelial cells of mesenteric arteries 
from OZRs. Previous studies have demonstrated that the tonic activation of CB1 receptors regulates cardiovascular function, either promoting vasodilation or preventing increases in BP (Grainger et al., 2001; Hillard, 2000; Randall et al., 2004). Based on this, the impairment of CB1- and CB2-mediated responses in OZRs observed in the present study supports the role of the endocannabinoid system in the vascular dysfunction in obesity.

Considering that the impairment of anandamide-induced relaxation in mesenteric arteries from OZRs is endothelium-dependent, a more detailed investigation of the role of different endothelial relaxant pathways was carried out. Although much is known about the downstream signalling cascades regulated by cannabinoid receptor activation in neuronal cells, very little is known about the signalling cascades that are activated by cannabinoid agonists in the vasculature. There are evidences in resistance vessels that anandamide-induced relaxation is dependent on NO (Deutsch et al., 1997; Randall et al., 2004). Because mesenteric arteries from OZRs were insensitive to inhibition of NO synthesis, the involvement of a dysfunctional eNOS on the reduced response to anandamide is proposed. In fact, we demonstrated that, in contrast with what we observed in vessels from LZRs, anandamide-induced phosphorylation of eNOS was decreased in arteries from OZRs.

Phosphorylation of eNOS plays a critical role in the regulation of NO production (Shaul, 2002). Multiple protein kinases, including AMPK (Chen et al., 2009) and MAPKs (Anter et al., 2005), have been implicated in eNOS phosphorylation. Recent studies indicate that cannabinoid compounds activate AMPK and ERK1/2 pathways in tissues that control energy homeostasis (Kola et al., 2005). Using agents shown to selectively interfere with AMPK and ERK1/2 activity, i.e., AICAR (AMPK activator) (Goirand et al., 2007) and PD98059 (ERK1/2 inhibitor) (Dudley et al., 1995), we demonstrated a dependence of these intracellular proteins on the decreased relaxation response of vessels to anandamide in obesity. The activation of these proteins by anandamide was shown in mesenteric arteries from LZRs. Incubation of mesenteric arteries with anandamide resulted in a robust increase in phosphorylation of AMPK, ACC (the primary target of activated AMPK), and 
ERK1/2 in vessels from LZRs, whereas they were decreased in vessels from OZRs. To date, no study has assessed the involvement of the AMPK and ERK1/2 pathways on the vascular responses to anandamide and the participation of these pathways in alterations of cannabinoid responses in obesity.

There are studies showing that in addition to acting on their cognate receptors, endocannabinoids can also diffuse passively through lipid membranes. This process has been reported to be mediated by the so-called anandamide transmembrane transporter (Beltramo et al., 1997). We therefore postulated that the decreased relaxation response of arteries from OZRs to anandamide might be due to the decreased uptake of anandamide. Thus, using a selective inhibitor of the cannabinoid transporter (AM404) (Beltramo et al., 1997), we showed that the transport of anandamide into the cell, important for anandamide-induced vessel relaxation in LZRs, is impaired in arteries from OZRs.

The actions of cannabinoid compounds are terminated through intracellular enzymatic hydrolysis (Kaczocha et al., 2009). In particular; anandamide is rapidly metabolised by the FAAH to yield arachidonic acid and ethanolamine (Cravatt et al., 1996). Increased degradation of anandamide in mesenteric arteries from OZRs might explain the decreased response to this agonist in obesity since the pretreatment of mesenteric arteries from OZRs with the selective FAAH inhibitor (URB597) corrected the deficit in anandamide-induced vessel relaxation.

Besides interacting with its cognate receptors $\mathrm{CB} 1$ and $\mathrm{CB} 2$, anandamide can also activate vanilloid receptors on capsaicin-sensitive perivascular sensory nerves, and this interaction was shown to result in the release of the potent vasodilator peptide CGRP, evoking vasorelaxation (Zygmunt et al., 1999). In fact, our results corroborate these studies. In vitro treatment with capsaicin, which induces desensitisation of C-fibres, profoundly suppressed anandamide responses of vessels from both LZRs and OZRs. Thus, it appears that effective silencing of vascular sensory C-fibres prevents blood vessels from responding normally to anandamide. Additionally, because the inhibition 
of anandamide responses of vessels from OZRs was lower than that observed in samples from LZRs, we suggest that the impaired vascular response to anandamide in arteries from OZRs also involves decreased activation of C-fibre nerve endings. The functional implications of vascular C-fibre activation was previously demonstrated by Kawasaki in 1988 (Kawasaki et al., 1988). In addition, many other groups have demonstrated the vascular effects of C-fibre activation in different vascular preparations, including the rat mesenteric vascular bed (Holzer, 1991). However, the role of these nerves in the physiological regulation of vascular tone has remained uncertain. Recently, TRPV1 has emerged as a major site for activation of C-fibres in the periphery (Gunthorpe et al., 2002), and the presence of these receptors was previously demonstrated in nerves penetrating the walls of resistance mesenteric arteries. Although the protein expression of TRPV-1 was not altered in vessels from OZRs compared with samples from LZRs, we demonstrated the dependence of TRPV1 activation on anandamide-induced vessel relaxation using agents that interfere with vanilloid receptor activity, namely capsazepine (Bevan et al., 1992) and ruthenium red (Dray et al., 1990). This finding was confirmed using a CGRP receptor antagonist, which promoted a considerable decrease in anandamide responses of vessels from both LZRs and OZRs. However, the inhibition observed with all of these blockers was lower in OZRs. These findings, coupled with the observation of the decreased relaxation to capsaicin in OZRs, indicate that impairment of the anandamide responses mediated by vanilloid receptors activation is also present in OZRs and might contribute to the vascular dysfunction present in this model.

In summary, the present study demonstrated that the endothelium-dependent arterial relaxation induced by the cannabinoid agonist anandamide is impaired in OZRs. Reductions in cannabinoid receptors expression, decreased activity of AMPK and eNOS as well as increased activation of ERK1/2 pathway are involved in the decreased anandamide-mediated relaxation in vessels from OZRs. Decreased transport and increased degradation of anandamide are also present in mesenteric arteries from OZRs. This study also shows that although anandamide-induced 
relaxation involves vanilloid receptors in both LZRs and in OZRs, the response mediated by TRPV1 activation is impaired in vessels from OZRs.

Our findings further underscore the relationship between obesity and vascular dysfunction. Furthermore, our study provides new evidence of the vascular effects of the endocannabinoid system and its role in the vascular dysfunction present in obesity. 


\section{ACKNOWLEDGEMENTS}

This work was supported by grants from the National Institutes of Health (HL71138 and HL74167), Fundacao de Amparo a Pesquisa do Estado de Sao Paulo (FAPESP), INCT Obesity and Diabetes and Conselho Nacional de Desenvolvimento Cientifico e Tecnologico (CNPq) Brazil.

The authors are grateful to Zidonia N Carneiro for excellent technical assistance.

\section{CONFLICT OF INTEREST}

The authors state no conflict of interest. 


\section{REFERENCES}

Anter E, Chen K, Shapira OM, Karas RH, Keaney JFJr (2005). p38 mitogen-activated protein kinase activates eNOS in endothelial cells by an estrogen receptor alpha-dependent pathway in response to black tea polyphenols. Circ Res 96(10): 1072-1078.

Beltramo M, Stella N, Calignano A, Lin SY, Makriyannis A, Piomelli D (1997). Functional role of highaffinity anandamide transport, as revealed by selective inhibition. Science 277(5329): 1094-1097.

Bevan S, Hothi S, Hughes G, James IF, Rang HP, Shah K, et al. (1992). Capsazepine: a competitive antagonist of the sensory neurone excitant capsaicin. Br J Pharmacol 107(2): 544-552.

Caterina MJ, Schumacher MA, Tominaga M, Rosen TA, Levine JD, Julius D (1997). The capsaicin receptor: a heat-activated ion channel in the pain pathway. Nature 389(6653): 816-824.

Chen Z, Peng IC, Sun W, Su MI, Hsu PH, Fu Y, et al. (2009). AMP-activated protein kinase functionally phosphorylates endothelial nitric oxide synthase Ser633. Circ Res 104(4): 496-505.

Cota D, Marsicano G, Tschop M, Grubler Y, Flachskamm C, Schubert M, et al. (2003). The endogenous cannabinoid system affects energy balance via central orexigenic drive and peripheral lipogenesis. J Clin Invest 112(3): 423-431.

Cravatt BF, Giang DK, Mayfield SP, Boger DL, Lerner RA, Gilula NB (1996). Molecular characterization of an enzyme that degrades neuromodulatory fatty-acid amides. Nature 384(6604): 83-87.

Deutsch DG, Goligorsky MS, Schmid PC, Krebsbach RJ, Schmid HH, Das SK, et al. (1997). Production and physiological actions of anandamide in the vasculature of the rat kidney. $\mathrm{J}$ Clin Invest 100(6): 1538-1546.

Di Marzo V (2008). Targeting the endocannabinoid system: to enhance or reduce? Nat Rev Drug Discov 7(5): 438-455. 
Dray A, Forbes CA, Burgess GM (1990). Ruthenium red blocks the capsaicin-induced increase in intracellular calcium and activation of membrane currents in sensory neurones as well as the activation of peripheral nociceptors in vitro. Neurosci Lett 110(1-2): 52-59.

Dudley DT, Pang L, Decker SJ, Bridges AJ, Saltiel AR (1995). A synthetic inhibitor of the mitogenactivated protein kinase cascade. Proc Natl Acad Sci U S A 92(17): 7686-7689.

Echahidi N, Mohty D, Pibarot P, Despres JP, O'Hara G, Champagne J, et al. (2007). Obesity and metabolic syndrome are independent risk factors for atrial fibrillation after coronary artery bypass graft surgery. Circulation 116(11 Suppl): I213-219.

Engeli S, Bohnke J, Feldpausch M, Gorzelniak K, Janke J, Batkai S, et al. (2005). Activation of the peripheral endocannabinoid system in human obesity. Diabetes 54(10): 2838-2843.

Flegal KM, Carroll MD, Ogden CL, Johnson CL (2002). Prevalence and trends in obesity among US adults, 1999-2000. JAMA 288(14): 1723-1727.

Goirand F, Solar M, Athea Y, Viollet B, Mateo P, Fortin D, et al. (2007). Activation of AMP kinase alpha1 subunit induces aortic vasorelaxation in mice. J Physiol 581(Pt 3): 1163-1171.

Gokce N, Keaney JF, Jr., Hunter LM, Watkins MT, Nedeljkovic ZS, Menzoian JO, et al. (2003). Predictive value of noninvasively determined endothelial dysfunction for long-term cardiovascular events in patients with peripheral vascular disease. J Am Coll Cardiol 41(10): 1769-1775.

Grainger J, Boachie-Ansah G (2001). Anandamide-induced relaxation of sheep coronary arteries: the role of the vascular endothelium, arachidonic acid metabolites and potassium channels. $\mathrm{Br} \mathrm{J}$ Pharmacol 134(5): 1003-1012.

Gunthorpe MJ, Benham CD, Randall A, Davis JB (2002). The diversity in the vanilloid (TRPV) receptor family of ion channels. Trends Pharmacol Sci 23(4): 183-191.

Hill JO (2006). Understanding and addressing the epidemic of obesity: an energy balance perspective. Endocr Rev 27(7): 750-761.

Hillard CJ (2000). Endocannabinoids and vascular function. J Pharmacol Exp Ther 294(1): 27-32. 
Holzer P (1991). Capsaicin: cellular targets, mechanisms of action, and selectivity for thin sensory neurons. Pharmacol Rev 43(2): 143-201.

Jiang S, Fu Y, Williams J, Wood J, Pandarinathan L, Avraham S, et al. (2007). Expression and function of cannabinoid receptors CB1 and CB2 and their cognate cannabinoid ligands in murine embryonic stem cells. PLoS One 2(7): e641.

Kaczocha M, Glaser ST, Deutsch DG (2009). Identification of intracellular carriers for the endocannabinoid anandamide. Proc Natl Acad Sci U S A 106(15): 6375-6380.

Kawasaki H, Takasaki K, Saito A, Goto K (1988). Calcitonin gene-related peptide acts as a novel vasodilator neurotransmitter in mesenteric resistance vessels of the rat. Nature 335(6186): 164-167.

Kola B, Hubina E, Tucci SA, Kirkham TC, Garcia EA, Mitchell SE, et al. (2005). Cannabinoids and ghrelin have both central and peripheral metabolic and cardiac effects via AMP-activated protein kinase. J Biol Chem 280(26): 25196-25201.

Lerman A, Zeiher AM (2005). Endothelial function: cardiac events. Circulation 111(3): 363-368.

Liu J, Wang L, Harvey-White J, Huang BX, Kim HY, Luquet S, et al. (2008). Multiple pathways involved in the biosynthesis of anandamide. Neuropharmacology 54(1): 1-7.

Lobato NS, Filgueira FP, Akamine EH, Davel AP, Rossoni LV, Tostes RC, et al. (2010). Obesity induced by neonatal treatment with monosodium glutamate impairs microvascular reactivity in adult rats: Role of NO and prostanoids. Nutr Metab Cardiovasc Dis. in press.

Mackie K, Stella N (2006). Cannabinoid receptors and endocannabinoids: evidence for new players. AAPS J 8(2): E298-306.

Matias I, Petrosino S, Racioppi A, Capasso R, Izzo AA, Di Marzo V (2008). Dysregulation of peripheral endocannabinoid levels in hyperglycemia and obesity: Effect of high fat diets. Mol Cell Endocrinol 286(1-2 Suppl 1): S66-78. 
Mitchell GF, Parise H, Vita JA, Larson MG, Warner E, Keaney JF, Jr., et al. (2004). Local shear stress and brachial artery flow-mediated dilation: the Framingham Heart Study. Hypertension 44(2): 134-139.

Mulvany MJ, Halpern W (1977). Contractile properties of small arterial resistance vessels in spontaneously hypertensive and normotensive rats. Circ Res 41(1): 19-26.

O'Sullivan SE, Kendall DA, Randall MD (2004). Heterogeneity in the mechanisms of vasorelaxation to anandamide in resistance and conduit rat mesenteric arteries. Br J Pharmacol 142(3): 435-442.

Randall MD, Kendall DA, O'Sullivan S (2004). The complexities of the cardiovascular actions of cannabinoids. Br J Pharmacol 142(1): 20-26.

Rayment SJ, Ralevic V, Barrett DA, Cordell R, Alexander SP (2007). A novel mechanism of vasoregulation: ADP-induced relaxation of the porcine isolated coronary artery is mediated via adenosine release. FASEB J 21(2): 577-585.

Scotland RS, Chauhan S, Davis C, De Felipe C, Hunt S, Kabir J, et al. (2004). Vanilloid receptor TRPV1, sensory C-fibers, and vascular autoregulation: a novel mechanism involved in myogenic constriction. Circ Res 95(10): 1027-1034.

Shaul PW (2002). Regulation of endothelial nitric oxide synthase: location, location, location. Annu Rev Physiol 64: 749-774.

Stapleton PA, James ME, Goodwill AG, Frisbee JC (2008). Obesity and vascular dysfunction. Pathophysiology 15(2): 79-89.

Subramanian R, MacLeod KM (2003). Age-dependent changes in blood pressure and arterial reactivity in obese Zucker rats. Eur J Pharmacol 477(2): 143-152.

Szmitko PE, Verma S (2008). The endocannabinoid system and cardiometabolic risk. Atherosclerosis 199(2): 248-256.

Zucker LM, Antoniades HN (1972). Insulin and obesity in the Zucker genetically obese rat "fatty". Endocrinology 90(5): 1320-1330. 
Zygmunt PM, Andersson DA, Hogestatt ED (2002). Delta 9-tetrahydrocannabinol and cannabinol activate capsaicin-sensitive sensory nerves via a CB1 and CB2 cannabinoid receptor-independent mechanism. J Neurosci 22(11): 4720-4727.

Zygmunt PM, Petersson J, Andersson DA, Chuang H, Sorgard M, Di Marzo V, et al. (1999). Vanilloid receptors on sensory nerves mediate the vasodilator action of anandamide. Nature 400(6743): 452457. 


\section{FIGURE LEGENDS}

Figure 1- Effect of obesity on vascular relaxation to cannabinoid agonists. Cumulative concentrationresponse curves for anandamide $(\mathbf{A})$, ACEA (CB1 receptor-selective agonist, $\mathbf{B})$ and JWH-015 (CB2 receptor-selective agonist, C) in U46619-precontracted mesenteric arteries from lean Zucker rats (LZRs) and obese Zucker rats (OZRs). Each point represents the mean \pm SEM. ${ }^{\star} P<0.05$ vs. LZR. $N=$ 6/group.

Figure 2- Contribution of CB1 and CB2 receptors to the vascular effects of anandamide in mesenteric arteries from lean Zucker rats (LZRs) and obese Zucker rats (OZRs). In A, the vessels were pretreated with a CB1 antagonist $(A M 251,1 \mu \mathrm{M})$ and in B with a CB2 antagonist $(A M 630,1 \mu M)$ for 30 minutes. In $\mathbf{C}$ and $\mathbf{D}$, representative western blots for CB1 and CB2 receptors, respectively, in mesenteric arteries from lean Zucker rats (LZRs) and obese Zucker rats (OZRs). Results were normalised to $\beta$-actin expression and expressed as units of change from the control. Data are expressed as mean \pm SEM. ${ }^{*} \mathrm{P}<0.05$ vs. LZR. \#P<0.05 vs. respective group in the absence of blockade. $\mathrm{N}=5$ or 6/group.

Figure 3- Effect of obesity on the protein expression of cannabinoid receptors. In $\mathbf{A}$ and $\mathbf{B}$, western blots for CB1 $(\mathbf{A})$ and CB2 receptors $(\mathbf{B})$ in mesenteric arteries from lean Zucker rats (LZRs) and obese Zucker rats (OZRs). Results were normalised to $\beta$-actin expression and expressed as units of change from the control. Data are expressed as mean \pm SEM. ${ }^{*} \mathrm{P}<0.05$ vs. LZR. $N=5 /$ group.

Figure 4- Confocal microscopic images of von Willebrand factor (vWF, red), DAPI (blue), CB1 receptors (green) and CB2 receptors (green) in mesenteric arteries from lean Zucker rats (LZRs, A and $\mathbf{B}$ ) and obese Zucker rats (OZRs, C and D). Endothelium-intact mesenteric sections were immunolabeled with antibodies against CB1, CB2 and von Willebrand factor. The nuclei were 
counterstained with DAPI. An overlay of the vWF, DAPI and CB1 or CB2 images is presented (merge). Endothelial localisation of CB1 and CB2 receptors is shown in the merged images (yellow). The images are representative of three separated experiments. $N=5 /$ group. Scale bar $=40 \mu \mathrm{m}$.

Figure 5- Contribution of the nitric oxide (NO) to the vascular effects of anandamide in mesenteric arteries from lean Zucker rats (LZRs) and obese Zucker rats (OZRs). In A, the vessels were pretreated with an NO synthase inhibitor (L-NAME, $100 \mu \mathrm{M}$, for 30 minutes) and the vascular relaxation to anandamide was evaluated in U46619-precontracted mesenteric arteries. In $\mathbf{B}$, the phosphorylation of eNOS was evaluated by western in mesenteric arteries from blot LZRs and OZRs. Panel shows densitometric analysis of the western blot for eNOS protein expression. Total eNOS levels are shown as loading controls. Data are expressed as mean \pm SEM. ${ }^{*} P<0.05$ vs. LZR. \#P<0.05 vs. OZR. $N=5$ /group.

Figure 6- Contribution of cyclic AMP-dependent protein kinase (AMPK) and extracellular signalregulated kinases 1 and $2(E R K 1 / 2)$ pathways to anandamide responses in mesenteric arteries from lean Zucker rats (LZRs) and obese Zucker rats (OZRs). In A and $\mathbf{B}$, the vessels were incubated with AICAR (an AMPK activator, $1 \mathrm{mM}$ ) or PD98059 (ERK1/2 inhibitor, 1 $\mu \mathrm{M}$ ), respectively, for 30 minutes and the vascular relaxation to anandamide was evaluated in U46619-precontracted mesenteric arteries. In C, D and E representative western blots for phosphorylation of AMPK, acetyl-CoA carboxylase (ACC) and ERK1/2 in mesenteric arteries from LZRs and OZRs are shown. Panels show densitometric analysis of the western blots for AMPK, ACC and ERK1/2 protein expression. Total protein levels are shown as loading controls. Data are expressed as mean $\pm \mathrm{SEM}$. ${ }^{*} \mathrm{P}<0.05$ vs. LZR, ${ }^{\#} \mathrm{P}<0.05$ vs. OZR. $\mathrm{N}=5$ or $6 /$ group. 
Figure 7- Contribution of uptake and degradation of anandamide in mesenteric arteries from lean Zucker rats (LZRs) and obese Zucker rats (OZRs). Vessels were pretreated with the anandamide transport blocker AM $404(1 \mu \mathrm{M}, \mathrm{A})$ or the fatty acid amide hydrolase (FAAH) inhibitor URB 597 (1 $\mu \mathrm{M}$, B) for 30 minutes and the vascular relaxation to anandamide was evaluated in U46619precontracted mesenteric arteries. Each point represents the mean \pm SEM. ${ }^{*} P<0.05$ vs. LZR. $\# P<0.05$ vs. LZR in the absence of blockade. $N=6 /$ group.

Figure 8- Involvement of TRPV1 receptors on sensory C-fibres in anandamide responses of mesenteric arteries from lean Zucker rats (LZRs) and obese Zucker rats (OZRs). In A, in vitro C-fibre desensitisation was induced using the selective neurotoxin capsaicin $(1 \mu \mathrm{M})$. In $\mathbf{B}$, vessels were pretreated with the TRPV1 blocker, ruthenium red ( $30 \mu \mathrm{M}, 30$ minutes). In $\mathbf{C}$, vessels were pretreated with the calcitonin gene-related peptide (CGRP) receptor antagonist $\alpha$-CGRP (8-37) $(10 \mu \mathrm{M}, 30$ minutes). In D, concentration-response curves for capsaicin in U46619-precontracted mesenteric arteries. Each point represents the mean \pm SEM. ${ }^{*} \mathrm{P}<0.05$ vs. $L Z R,{ }^{\#} \mathrm{P}<0.05$ vs. respective group in the absence of blockade. $N=6 /$ group. 
Table 1. Basic physiological parameters of young LZRs and OZRs

\begin{tabular}{|l|l|l|}
\hline Parameter & Lean Zucker & Fatty Zucker \\
\hline Body weight $(\mathrm{g})$ & $193.0 \pm 11.1$ & $283.3 \pm 18.2^{*}$ \\
\hline Retroperitoneal fat mass, $(\mathrm{g} / 100 \mathrm{~g})$ & $0.46 \pm 0.03$ & $2.05 \pm 0.30^{*}$ \\
\hline Perigonadal fat mass, $(\mathrm{g} / 100 \mathrm{~g})$ & $0.54 \pm 0.02$ & $2.3 \pm 0.45^{\star}$ \\
\hline Glycemia, $(\mathrm{mg} / \mathrm{dL})$ & $122 \pm 0.8$ & $124 \pm 2.5$ \\
\hline Blood pressure, $(\mathrm{mmHg})$ & $110.5 \pm 3.6$ & $116.8 \pm 1.6$ \\
\hline Mean \pm sem; ${ }^{*}<0,05 \mathrm{vs}$. Control group; $\mathrm{n}=8 /$ group. \\
\hline
\end{tabular}




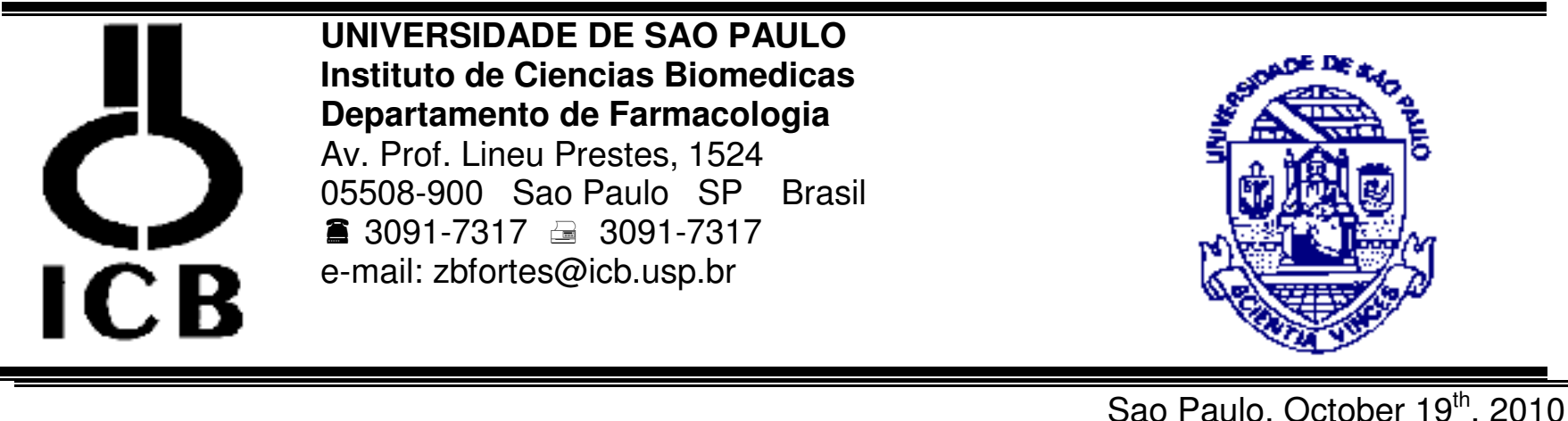

Sao Paulo, October $19^{\text {th }}, 2010$

\section{Professor J C McGrath}

Editor-in-Chief

British Journal of Pharmacology

\section{Obesity decreases the vascular relaxation to anandamide, a cannabinoid agonist}

Department of Pharmacology, University of Sao Paulo, Sao Paulo, Brazil

Dear Mr. McGrath,

We are submitting the above-mentioned manuscript for publication. In this manuscript we used pharmacological and molecular approaches to investigate the impact of obesity on the vascular response to cannabinoid agonists. Our data may constitute an additional approach to the understanding of the mechanisms involved on vascular dysfunction in obesity. The manuscript has neither been published (only in form of abstract) nor is currently under consideration for publication by any other journal. The authors have read the manuscript and approved its submission to British Journal of Pharmacology. None of the authors have financial or other relations that could lead to a conflict of interest.

\section{Yours Sincerely,}

Dr. Zuleica B. Fortes

Dept. Pharmacology

Institute of Biomedical Sciences

University of Sao Paulo

E-mail: zbfortes@icb.usp.br 
ANEXO B - Curriculum Vitae 
Núbia de Souza Lobato

Curriculum Vitae 


\section{I- DADOS PESSOAIS}

Nome

Filiação

Nascimento

Carteira de Identidade CPF

Endereço residencial

Endereço profissional

Universidade Federal de Goiás, Campus de Jataí Unidade Jatobá

Rodovia BR 364, Km 192, no 3800, Setor Parque Industrial

75801-615 - Jataí, GO - Brasil

Telefone: 6436068290

Endereço eletrônico e-mail: nubialobato@yahoo.com.br 


\section{II- FORMAC̄̃̃O ACADÊMICA/TITULACÃO}

2008 - atual Doutorado em Ciências Biológicas, área de Farmacologia, Conceito CAPES 6.

Universidade de São Paulo, USP, São Paulo, Brasil.

Título: A Obesidade Diminui a Resposta de Artérias Mesentéricas de Resistência a Agonistas Canabinóides.

Orientadora: $\mathrm{Dr}^{\mathrm{a}}$ Zuleica Bruno Fortes.

Bolsista da Fundação de Amparo à Pesquisa do Estado de São Paulo - FAPESP.

2006 - 2008 Mestrado em Ciências Biológicas, área de Farmacologia, Conceito CAPES 6.

Universidade de São Paulo, USP, São Paulo, Brasil.

Título: Efeito do Tratamento com Metformina sobre Alterações Vasculares em Modelo de Resistência à Insulina (Obesidade em Ratos).

Orientadora: $\mathrm{Dr}^{\mathrm{a}}$ Zuleica Bruno Fortes.

Bolsista da Fundação de Amparo à Pesquisa do Estado de São Paulo - FAPESP.

2002 - 2006 Graduação em Farmácia.

Universidade Federal de Mato Grosso, UFMT, Barra do Garças, Brasil.

Título: Análise Química Preliminar e Avaliação da Atividade Farmacológica das folhas de Strychnos pseudoquina ST. HILL (Quina do Cerrado).

Orientadora: $\mathrm{Dr}^{\mathrm{a}}$ Eliane Augusto Ndiaye.

Bolsista do Conselho Nacional de Desenvolvimento Científico e Tecnológico - CNPq. 


\title{
III- ATUACÃO PROFISSIONAL
}

1. Universidade Federal de Goiás - UFG

Vínculo institucional

2010 - atual Vínculo: Funcionário Público, Enquadramento funcional: Professor Assistente Nível I, Regime: Dedicação Exclusiva

\author{
Atividades \\ 8/2010 - Atual Curso: Psicologia. \\ Disciplina: Fisiologia do Sistema Nervoso \\ 8/2010 - Atual Curso: Zootecnia. \\ Disciplina: Fisiologia Animal \\ 8/2010 - Atual Curso: Fisioterapia. \\ Disciplina: Histologia de Órgãos e Sistemas
}

2. Universidade de São Paulo - USP

Vínculo institucional

2008 - atual Vínculo: Aluno, Enquadramento funcional: Doutoranda

2006-2008 Vínculo: Aluno bolsista, Enquadramento funcional: Mestranda

\begin{abstract}
Atividades
2008 - Atual Projeto de pesquisa, Universidade de São Paulo Instituto de Ciências Biomédicas.

Participação do tecido adiposo nas alterações da reatividade vascular em aorta de ratos obesos com resistência à insulina: efeito das citocinas, do sistema endocanabinóide e da AMPK.

2007 - Atual Projeto de pesquisa, Universidade de São Paulo Instituto de Ciências Biomédicas.

Estudo do tratamento com metformina nas alterações da reatividade vascular em modelo de resistência à insulina (obesidade): possíveis mecanismos envolvidos.

2006 - Atual Grupo de pesquisa, Universidade de São Paulo - Instituto de Ciências Biomédicas.

Resistência à insulina: diabetes, obesidade e alterações
\end{abstract}


vasculares. Reversão farmacológica das alterações e seu mecanismo.

2006-2008 Projeto de pesquisa, Universidade de São Paulo Instituto de Ciências Biomédicas.

Efeito do tratamento com metformina sobre alterações vasculares em modelo de resistência à insulina (obesidade em ratos).

\section{Universidade Federal de Mato Grosso - UFMT}

\begin{tabular}{llll}
\hline Vínculo institucional & Vínculo: Aluno bolsista, Enquadramento funcional: \\
2004 - 2005 & Estudante de Graduação
\end{tabular}

\begin{tabular}{ll}
\hline Atividades & \\
2004 - 2005 & $\begin{array}{l}\text { Projetos de pesquisa, Instituto de Ciências e Letras do } \\
\text { Médio Araguaia }\end{array}$ \\
& Análise Química Preliminar e Avaliação da Atividade \\
Farmacológica das Folhas de Strychnos pseudoquina \\
(Quina) e Duguetia furfuracea (Sofre do Rim Quem Quer).
\end{tabular}




\section{PROJETOS DE PESQUISA}

2008 - Atual Participação do tecido adiposo nas alterações da reatividade vascular em aorta de ratos obesos com resistência à insulina: efeito das citocinas, do sistema endocanabinóide e da AMPK

Situação: Em Andamento Natureza: Pesquisa

Integrantes: Núbia de Souza Lobato; Zuleica Bruno Fortes (Responsável)

Financiadores: Conselho Nacional de Desenvolvimento Científico e Tecnológico-CNPq, Fundação de Amparo à Pesquisa do Estado de São Paulo-FAPESP

2007 - Atual Estudo do tratamento com metformina nas alterações da reatividade vascular em modelo de resistência à insulina (obesidade): possíveis mecanismos envolvidos.

Situação: Em Andamento Natureza: Pesquisa

Integrantes: Núbia de Souza Lobato; Zuleica Bruno Fortes (Responsável)

Financiadores: Fundação de Amparo à Pesquisa do Estado de São Paulo-FAPESP

2006 - Atual Resistência à insulina, diabetes, obesidade e alterações vasculares. Reversão farmacológica das alterações e seus mecanismos.

Situação: Em Andamento Natureza: Pesquisa Integrantes: Pesquisadores: Eliana Hiromi Akamine, Maristella de Almeida Vitta Landgraf,Maria Aparecida de Oliveira, Roberto Kenji Nakamura Cuman, Maria do Carmo Pinho Franco, Stephen Fernandes de Paula Rodrigues, Maria Helena Catelli de Carvalho Zuleica Bruno Fortes (responsável), Núbia de Souza Lobato, Eveline Aparecida Isquierdo Fonseca, Graziela Neves Hagihara, Simone Marcieli Sartoretto.

2006 - 2008 Efeito do tratamento com metformina sobre alterações vasculares em modelo de resistência à insulina (obesidade em ratos).

Situação: Concluído Natureza: Pesquisa Integrantes: Núbia de Souza Lobato; Zuleica Bruno Fortes (Responsável)

Financiador: Fundação de Amparo à Pesquisa do Estado de São Paulo-FAPESP

2004 - 2005 Projetos de pesquisa, Instituto de Ciências e Letras do Médio Araguaia

Análise Química Preliminar e Avaliação da Atividade Farmacológica das Folhas de Strychnos pseudoquina (Quina) e Duguetia furfuracea (Sofre do Rim Quem Quer)

Situação: Concluído Natureza: Pesquisa

Integrantes: Núbia de Souza Lobato (Bolsista); Eliane Augusto Ndiaye (Responsável)

Financiador: $\mathrm{CNPq}$ 


\section{ATIVIDADES DE EXTENSÃO}

\section{PARTICIPAÇÃO EM PROJETOS DE EXTENSÃO}

2005 - 2005 Participação como monitora voluntária no projeto de extensão: PROCEDIMENTOS PREVENTIVOS E REALIZAÇÃO DE EXAMES SOBRE ANEMIA E ENTEROPARASITOSES NAS CRIANÇAS DA CRECHE SÃO JUDAS TADEU, promovido pelo Departamento de Ciências Biológicas e da Saúde (DCBS) / Instituto de Ciências e Letras do Médio Araguaia (ICLMA), realizado de agosto a dezembro de 2004.

Integrantes: Núbia de Souza Lobato (voluntário); Fernando Paranaiba Filgueira (bolsista); Frederico dos Santos Faria (voluntário); Janaina da Silva Carvalho (voluntário); Olegário Rosa Toledo (Responsável)

Financiador: Universidade Federal do Mato Grosso

2004 - 2004 Participação como monitora voluntária no projeto de extensão: PROCEDIMENTOS PREVENTIVOS E REALIZAÇÃO DE EXAMES SOBRE ANEMIA E ENTEROPARASITOSES NAS CRIANÇAS DA CRECHE SÃO JUDAS TADEU, promovido pelo Departamento de Ciências Biológicas e da Saúde (DCBS) / Instituto de Ciências e Letras do Médio Araguaia (ICLMA), realizado de agosto a dezembro de 2004.

Integrantes: Núbia de Souza Lobato (voluntário); Fernando Paranaiba Filgueira (bolsista); Frederico dos Santos Faria (voluntário); Janaina da Silva Carvalho (voluntário); Olegário Rosa Toledo (Responsável)

Financiador: Universidade Federal do Mato Grosso

2003 - 2003 Participação como monitora voluntária do projeto de extensão universitária PLANTAS MEDICINAIS: EDUCAÇÃO E SAÚDE, realizado de maio a dezembro de 2003, promovido pelo Departamento de Ciências Biológicas e da Saúde (DCBS) / Instituto de Ciências e Letras do Médio Araguaia (ICLMA), realizado de agosto a dezembro de 2003.

Integrantes: Núbia de Souza Lobato (voluntário); Fernando Paranaiba Filgueira (voluntário); Fausto Guimarães Costa (bolsista); Francismeire A. da Silva (bolsista); Devanir Mistuyuki Murakami (Responsável)

Financiador: Universidade Federal do Mato Grosso

\section{CURSOS DE EXTENSÃO}

2009-2009 Cursos de treinamento: "Biological Safety Refresher Course", "Library Ergonomic Training", "Computer Workstation Ergonomic 
Training", "Bloodborne Pathogens Training", "Hazardous Waste Awareness Training", "Right-To-Know Chemical Specific Training", "Right-To-Know Basic Awareness Training", oferecidos na instituição Medical College of Georgia, Augusta-GA, Estados Unidos da América.

2008 - 2008 Monitoria do CURSO DE DIFUSÃO CULTURAL intitulado "ICB aberto à escola", oferecido de 22 a 30 de abril de 2008 Universidade de São Paulo, Instituto de Ciências Biomédicas, São Paulo, Brasil.

2008 - 2008 CURSO DE BIOESTATÍSTICA (Workshop) - Universidade de São Paulo, Instituto de Ciências Biomédicas, São Paulo, Brasil, 25 a 27 de agosto de 2008. Carga horária: 8 horas.

2007 - 2007 CURSO DE PROTEÇÃO RADIOLÓGICA, promovido pelo Núcleo de Radioproteção do Instituto de Ciências Biomédicas da Universidade de São Paulo, São Paulo, Brasil, 10 a 12 de dezembro de 2007. Carga horária: 15 horas.

2006-2006 CURSO DE TREINAMENTO NO USO DE ANIMAIS DE EXPERIMENTAÇÃO, organizado pelas Comissões de Biotério e de Ética em Experimentação Animal do Instituto de Ciências Biomédicas da Universidade de São Paulo, São Paulo, Brasil, 18 de setembro de 2006. Carga horária: 03 horas.

2006 - 2006 Curso FUNDAMENTOS TEÓRICOS dos MÉTODOS de BIOLOGIA MOLECULAR APLICADOS à PESQUISA e ao DIAGNÓSTICO CLÍNICO- Universidade de São Paulo, USP-oficina, São Paulo, Brasil, 10 a 14 de julho de 2006.

2006 - 2006 PLANEJANDO e OTIMIZANDO a REAÇÃO de PCR - Universidade de São Paulo, USP-oficina, São Paulo, Brasil, 17 a 20 de julho de 2006.

2004-2005 Extensão universitária em PROGRAMA DE PREVENÇÃO A DST/AIDS. DCBS, ICLMA, Universidade Federal de Mato Grosso, UFMT, Cuiabá, Brasil. Carga horária: 40 horas.

2004 - 2004 Curso de curta duração em HEMOGRAMA E COAGULOPATIAS, Sociedade Brasileira de Análises Clínicas, SBAC, Cuiabá-MT, Brasil. Carga horária: 08 horas. 
2004-2004 Curso de curta duração em I SEMANA DE FARMACOLOGIA. Universidade Federal de Mato Grosso, UFMT, Pontal do Araguaia, Brasil. Carga horária: 40 horas.

2004 - 2004 Curso de extensão em PRIMEIROS SOCORROS. Universidade Federal de Mato Grosso, Pontal do Araguaia, Brasil. Carga horária: 80 horas.

2004 - 2004 Participação como monitora no projeto de extensão universitária FARMÁCIA NA PRAIA. DCBS/ICLMA, Universidade Federal de Mato Grosso, UFMT, Cuiabá, Brasil. Carga horária: 40 horas.

2004 - 2004 Participação como membro da Comissão de Divulgação/Recepção na II MOSTRA DE EXTENSÃO UNIVERSITÁRIA DO ICLMA/UFMT. Câmara de Extensão - NUPEX - ICLMA, Universidade Federal de Mato Grosso, UFMT, Pontal do Araguaia-MT, Brasil, Carga horária: 20 horas.

2003 - 2003 Curso de Treinamento LEVANDO SAÚDE ATRAVÉS DA ÁGUA. DCBS/ICLMA, Universidade Federal de Mato Grosso, UFMT, Cuiabá, Brasil. Carga horária: 40 horas.

\section{PALESTRANTE EM EVENTO CIENTÍFICO}

Conferencista no XVII Congresso da Sociedade Brasileira de Diabetes, 2009. Obesidade e Resistência à Insulina.

Conferencista no $9^{\circ}$ Congresso Paulista de Diabetes e Metabolismo, 2010. Metformina, obesidade e reatividade vascular. 
IV- PRODUCÃO BIBLIOGRÁFICA

\section{PRÊMIOS CIENTífICOS}

2009

2009

2008

2008

PRÊMIO QUALIDADE CIENTÍFICA PROF. DR. JOÃO GARCIA LEME, Instituto de Ciências Biomédicas - Universidade de São Paulo.

MELHOR TRABALHO - II SIMFARMA, Simpósio de Farmácia do Médio Araguaia.

MENÇÃO HONROSA, INSTITUTO DE CIÊNCIAS BIOMÉDICAS Universidade de São Paulo.

PRÊMIO AMIL - SBH DE INCENTIVO À PESQUISA, XVI Congresso Brasileiro de Hipertensão.

\section{ARTIGOS COMPLETOS PUBLICADOS EM PERIÓDICOS}

2.1. lobato, N. S., AKamine, E. H., tostes, R. C., CARVAlho, M.H.C., FORTES, Z.B. Obesidade e hipertensão arterial.

Hipertensão (ISSN 1809-4260), v.12, n.1, p.4-12, 2009.

2.2. LOBATO, N. S., FilgueiRA, F. P., AKAMine, E. H., DAVEL, A. P. C., ROSSONI, L. V., TOSTES, R. C., CARVALHO, M.H.C., FORTES, Z.B.

Obesity Induced by Neonatal Treatment with Monosodium Glutamate Impairs Microvascular Reactivity in Adult Rats: Role of $\mathrm{NO}$ and Prostanoids.

(D.O.I.: 10.1016/j.numecd.2010.02.006).

Nutrition, Metabolism and Cardiovascular Diseases (ISSN 0939-4753), no prelo, 2010.

\section{APRESENTAÇÃO ORAL DE TRABALHO EM CONGRESSO CIENTÍFICO}

3.1. LobAto, N. S., FILGUeIRA, F. P., GIACHINI, F. R., CARVALHO, M.H.C., WEBB, R. C., TOSTES, R. C., FORTES, Z.B.

A atividade do sistema endocanabinóide vascular está diminuída na obesidade: participação da eNOS, da AMPK e da ERK.

V Simpósio de Farmacologia "Qualidade Científica Prof. Dr. João Garcia Leme", 2009.

3.2. LOBATO, N. S., TOSTES, R. C., CARVALHO, M.H.C., FORTES, Z.B.

Alterações da contração vascular em ratos obesos e o efeito da metformina: possíveis mecanismos envolvidos. 
XVI Congresso Brasileiro de Hipertensão, Rio de Janeiro-RJ, 2008.

3.3. LOBATO, N. S., TOSTES, R. C., CARVALHO, M.H.C., FORTES, Z.B.

Efeito benéfico da metformina nas alterações vasculares de ratos obesos: Papel das EROs e da hiperpolarização de membrana.

XXIII Reunião Anual da Federação de Sociedades de Biologia Experimental FeSBE, Águas de Lindóia, 2008.

3.4. LOBATO, N. S., TOSTES, R. C., CARVALHO, M.H.C., FORTES, Z.B.

Metformina Corrige Alterações da Reatividade Vascular no Leito Arteriolar Mesentérico de Ratos Obesos Com Resistência à Insulina.

IV Simpósio de Farmacologia "Qualidade Científica Prof. Dr. João Garcia Leme", 2007.

\section{RESUMOS COMPLETOS PUBLICADOS EM ANAIS DE EVENTOS}

4.1. LOBATO, N. S., TOSTES, R. C., CARVALHO, M.H.C., FORTES, Z.B.

Alterações da contração vascular em ratos obesos e o efeito da metformina: possíveis mecanismos envolvidos.

Hipertensão (ISSN 1519-7522), v. 11, n.4, p.156-156, 2008.

In: XVII Congresso Brasileiro de Hipertensão, Rio de Janeiro, RJ, Brasil, 2008.

\section{RESUMOS PUBLICADOS EM ANAIS DE EVENTOS}

5.1. LOBATO, N. S., FILGUEIRA, F. P., GIACHINI, F., CARVALHO. M. H., WEBB, R. C., TOSTES, R. C., FORTES, Z. B.

A obesidade diminui a atividade do sistema endocanabinóide vascular: participação da eNOS, da AMPK e da ERK.

Arquivos Brasileiros de Endocrinologia e Metabologia (ISSN 0004-2730), v.54, suplemento 2, p.133-133, 2010.

In: 9o Congresso Paulista de Diabetes e Metabolismo, Águas de São Pedro, SP, Brasil, 2010.

5.2. LOBATO, N. S., FILGUEIRA, F. P., GIACHINI, F., CARVALHO. M. H., WEBB, R. C., TOSTES, R. C., FORTES, Z. B.

Obesity decreases the activity of the endocannabinoid system: role of $\mathrm{NO}$ and AMPK.

Faseb Journal (ISSN 0892-6638), v.24, abstract n.570.7, 2010.

In: Experimental Biology, Anaheim, Califórnia, EUA, 2010.

5.3. FilgueiRA, F. P., Lobato, N. S., CERAVolo, G. S., DANTAS, A. P. V., FORTES, Z. B., WEBB, R. C., TOSTES, R. C., CARVALHO, M. H. C.

Characterization of the relaxant response to equilin in rat mesenteric arteries.

Faseb Journal (ISSN 0892-6638), v.24, abstract n.575.7, 2010.

In: Experimental Biology, Anaheim, Califórnia, EUA, 2010. 
5.4. LOBATO, N. S., FILGUEIRA, F. P., GIACHINI, F., CARVALHO. M. H., WEBB, R. C., TOSTES, R. C., FORTES, Z. B.

A obesidade diminui a atividade do sistema endocanabinóide vascular: participação da eNOS, da AMPK e da ERK.

FeSBE, resumo n.16.049, 2010.

In: XXV Reunião Anual da Federação de Sociedades de Biologia Experimental FeSBE, Águas de Lindóia, SP, Brasil, 2010.

5.5. FILGUeIRA, F. P., LOBATO, N. S., CERAVOLO, G. S., DANTAS, A. P. V., FORTES, Z. B., WEBB, R. C., TOSTES, R. C., CARVALHO, M. H. C.

Vascular actions of equilin in resistance mesenteric arteries of hypertensive rats.

FeSBE, resumo n.16.040, 2010.

In: XXV Reunião Anual da Federação de Sociedades de Biologia Experimental FeSBE, Águas de Lindóia, SP, Brasil, 2010.

5.6. PEREIRA, M. L. L., FILGUEIRA, F. P., LOBATO, N. S., CERAVOLO, G. S., DANTAS, A. P. V., TOSTES, R. C., FORTES, Z. B., CARVALHO, M. H. C.

Premarin melhora a função vascular em ratas geneticamente hipertensas.

FeSBE, resumo n.16.018, 2010.

In: XXV Reunião Anual da Federação de Sociedades de Biologia Experimental FeSBE, Águas de Lindóia, SP, Brasil, 2010.

5.7. LOBAto, N. S., AKAMine, E. H., FILGUeiRA, F. P., tOSTeS, R. C., CARVALHO, M.H.C., FORTES, Z.B.

Metformin improves endothelial function in obese rats.

Faseb Journal (ISSN 0892-6638), v. 23, abstract n. 578.1, 2009.

In: Experimental Biology, New Orleans, Louisiana, EUA, 2009.

5.8. FILGUeIRA, F. P., LOBATO, N. S., SANTOS, R. A., OliVEIRA, M. A., FORTES, Z.B., TOSTES, R. C., CARVALHO, M.H.C.

Influence of endogenous testosterone on vascular endothelium-leukocyte interaction in spontaneously hypertensive rats (SHRs).

Faseb Journal (ISSN 0892-6638), v.23, abstract n. 934.5, 2009.

In: Experimental Biology, New Orleans, Louisiana, EUA, 2009.

5.9. FILGUEIRA, F. P., CERAVOLO, G., LOBATO, N. S., FORTES, Z.B., TOSTES, R. C., DANTAS, A. P., CARVALHO, M.H.C.

Conjugated equine estrogen improves vascular reactivity and metabolic parameters in ovariectomized SHR.

Hypertension (ISSN 0194911X), v.54, n. 4, e79 -e79, 2009.

In: 63rd Annual High Blood Pressure Research Conference, Chicago, Illinois, EUA, 2009.

5.10. KLAJMAN, A. B., LOBATO, N. S., OIGMAN, W., FORTES, Z.B., NEVES, M. F. Beneficial effects of metformin on the cardiac and vascular fibrosis in the monosodium glutatamate- induced obesity.

Hipertensão (ISSN 1809-4260 e CD-ROM), v.12, p. 7-7, abstract n. 915, 2009.

In: Inter-American Society of Hypertension XVIlth Scientific Sessions. XVII Congresso da Sociedade Brasileira de Hipertensão, Belo Horizonte, MG, Brasil, 2009. 
5.11. HAGIHARA, G. N., AKAMINE, E. H., LOBATO, N. S., TOSTES, R. C., CARVALHO, M.H.C., FORTES, Z.B.

Vascular reactivity in female obese rats.

Hipertensão (ISSN 1809-4260 e CD-ROM), v.12, p.7-7, abstract n.937, 2009.

In: Inter-American Society of Hypertension XVIIth Scientific Sessions. XVII Congresso da Sociedade Brasileira de Hipertensão, Belo Horizonte, MG, Brasil, 2009.

5.12. CERAVOLO, G., FILGUEIRA, F. P., LOBATO, N. S., FORTES, Z.B., TOSTES, R. C., DANTAS, A. P., CARVALHO, M. H. C.

Conjugated equine estrogen improves vascular reactivity and metabolic parameters in ovariectomized SHR.

Hipertensão (ISSN 1809-4260 e CD-ROM), v.12, p.7-7, abstract n.940, 2009.

In: Inter-American Society of Hypertension XVIIth Scientific Sessions. XVII Congresso da Sociedade Brasileira de Hipertensão, Belo Horizonte, MG, Brasil, 2009.

5.13. LOBATO, N. S., tOSTES, R. C., CARVALHO, M. H. C., FORTES, Z. B.

Metformina corrige alterações na função vascular em ratos obesos: estudo dos mecanismos envolvidos.

In: V Congresso do Instituto de Ciências Biomédicas, Universidade de São Paulo, São Paulo, SP, Brasil, 2008.

5.14. CASTRO, D. B., NDIAYE, E. A., LOBATO, N. S., FIlGUEIRA, F. P., CARVALHO, M.H.C.

Avaliação do efeito do extrato etanólico e subextrato das raízes de Croton antisyphiliticus MART. (pé de perdiz) em macrovasos de ratos geneticamente hipertensos (SHR).

In: II Congresso de Fitoterápicos do Mercosul e VI Reunião da Sociedade Latino Americana de Fitoquímica, Belo Horizonte, MG, Brasil, 2008.

5.15. LOBATO, N. S., TOSTES, R. C., CARVALHO, M.H.C., FORTES, Z.B. Efeito benéfico da metformina nas alterações vasculares de ratos obesos: papel das EROs e da hiperpolarização de membrana.

FeSBE, p. 75-75, 2008.

In: XXIII Reunião Anual da Federação de Sociedades de Biologia Experimental FeSBE, Águas de Lindóia, SP, Brasil, 2008.

5.16. LOBATO, N. S., PARIZ, J. R., TOSTES, R. C. A., CARVALHO. M. H. C., FORTES, Z. B.

Metformina modula a resposta contrátil e vasodilatadora via NO, prostanóides e hiperpolarização do músculo liso do leito arteriolar mesentérico de ratos obesos com resistência à insulina.

Arquivos Brasileiros de Endocrinologia e Metabologia (ISSN 0004-2730), v.52, supl. 2, S209 - S209, 2008.

In: 8ํㅡㄹ Congresso Paulista de Diabetes e Metabolismo, Águas de Lindóia, SP, Brasil, 2008.

5.17. KLAJMAN, A. B., LOBATO, N. S., OIGMAN, W., FORTES, Z.B., NEVES, M. F. Morfologia de arteríolas intramiocárdicas em modelo experimental de obesidade: 
alterações independentes da variação da pressão arterial.

Hipertensão (ISSN 1519-7522), v. 11, n.4, p.36-36, 2008.

In: XVII Congresso Brasileiro de Hipertensão, Rio de Janeiro, RJ, Brasil, 2008.

5.18. LOBATO, N. S., TOSTES, R. C., CARVALHO, M.H.C., FORTES, Z.B.

Papel do endotélio nas alterações da resposta vasodilatora em ratos obesos e 0 efeito da metformina: possíveis mecanismos envolvidos.

Hipertensão (ISSN 1519-7522), v. 11, n.4, p.80-80, 2008.

In: XVII Congresso Brasileiro de Hipertensão, Rio de Janeiro, RJ, Brasil, 2008.

5.19. LOBATO, N. S., TOSTES, R. C., CARVALHO, M.H.C., FORTES, Z.B.

Alterações da contração vascular em ratos obesos e o efeito da metformina: possíveis mecanismos envolvidos.

Hipertensão (ISSN 1519-7522), v. 11, n.4, p.80-80, 2008.

In: XVII Congresso Brasileiro de Hipertensão, Rio de Janeiro, RJ, Brasil, 2008.

5.20. LOBATO, N. S., TOSTES, R. C., CARVALHO, M.H.C., FORTES, Z.B.

Reatividade vascular em ratos wistar obesos com resistência à insulina induzida por glutamato monossódico (MSG).

Arquivos Brasileiros de Endocrinologia e Metabologia (ISSN 0004-2730), 2007, v.51, n.3, supl. 1, p.S126-S126.

In: $7^{\circ}$ Congresso Paulista de Endocrinologia e Metabolismo, São Paulo, SP, Brasil, 2007.

5.21. LOBATO, N. S., TOSTES, R. C., CARVALHO, M.H.C., FORTES, Z.B.

Alterações na Reatividade Vascular em Modelo de Resistência à Insulina Induzida por Glutamato Monossódico (Obesidade em Ratos).

Hipertensão (ISSN 1519-7522), v. 10, p.55-55, 2007.

In: XVI Congresso Brasileiro de Hipertensão, Recife, PE, Brasil, 2007.

5.22. FILGUEIRA, F. P., LOBATO, N. S., TOSTES, R. C., CARVALHO, M.H.C., FORTES, Z.B.

Castração aumenta a resposta vasoconstritora induzida pela angiotensina II em ratos SHR.

Hipertensão (ISSN 1519-7522), v. 10, p.56-56, 2007.

In: XVI Congresso Brasileiro de Hipertensão, Recife, PE, Brasil, 2007.

5.23. PARIZ, J. R., Lobato, N. S., tOStes, R. C. A., CARVAlHO. M. H. C., FORTES, Z. B.

Efeito da metformina nas alterações da resposta vasoconstritora da aorta de ratos obesos: papel do endotélio.

In: IV Simpósio de Farmacologia "Qualidade Científica Prof. Dr. João Garcia Leme", São Paulo, SP, Brasil, 2007.

5.24. FILGUEIRA, F. P., CARVALHO J. S., LOBATO N. S., LIMA V. V., COSTA F. G., SILVA P. J., NDIAYE E. A.

Análise química preliminar do extrato lipofílico da Strychnos pseudoquina ST. Hill (Quina do Cerrado).

In: Congresso Farmacêutico do Pantanal, Cuiabá, MT, Brasil, p.12-2, 2005. 
5.25. CARVALHO J. S., LOBATO N. S., LIMA V. V., COSTA F. G., FILGUEIRA, F. P., NDIAYE E. A., SILVA P. J.

Avaliação do potencial citotóxido do extrato hexânico de Duguetia furfuracea (sofre do rim quem quer).

In: Congresso Farmacêutico do Pantanal, Cuiabá, MT, Brasil, p.12-13, 2005.

5.26. COSTA F. G., LIMA V. V., FILGUEIRA, F. P., CARVALHO J. S., LOBATO N. S., NDIAYE E. A.

Avaliação da atividade antimicrobiana do extrato hexânico de Duguetia furfuracea ST. Hill (sofre do rim quem quer).

In: Congresso Farmacêutico do Pantanal, Cuiabá, MT, Brasil, p.13-13, 2005.

5.27. COSTA F. G., FILGUEIRA, F. P., CARVALHO J. S., LOBATO N. S., LIMA V. V., NDIAYE E. A.

Avaliação da atividade antimicrobiana do extrato hexânico de Strychnos pseudoquina ST. Hill (quina do cerrado).

In: Congresso Farmacêutico do Pantanal, Cuiabá, MT, Brasil, p.19-19, 2005.

5.28. LOBATO, N. S., FILGUEIRA, F. P., COSTA, F. G., LIMA, V. V., CARVALHO, J. S., NDIAYE, E. A., SILVA, P. J., SOUTO, P. C. S.

Avaliação da atividade antimicrobiana do extrato metanólico de Strychnos pseudoquina st. hill (quina do cerrado) frente a bactérias gram +, gram - e fungo.

In: VII Congresso Regional de Análises Clínicas do Centro-Oeste, Campo Grande, MS, Brasil, 2005.

5.29. LOBATO, N. S., FILGUEIRA, F. P., LIMA, V. V., TOLEDO, O. R.

Avaliação do uso de contraceptivos hormonais por alunas matriculadas no ensino médio de Barra do Garças - MT.

In: VII Congresso Regional de Análises Clínicas do Centro-Oeste, Campo Grande, MS, Brasil, 2005.

5.30. FILGUEIRA, F. P., CARVALHO, J. S., LOBATO, N. S., LIMA, V. V., COSTA, F. G., NDIAYE, E. A., SOUTO, P. C. S., SILVA, P. J.

Avaliação da atividade antimicrobiana do extrato metanólico de Duguetia furfuracea (St. Hill) Benth \& Hook (sofre do rim quem quer).

In: VII Congresso Regional de Análises Clínicas do Centro-Oeste, Campo Grande, MS, Brasil, 2005.

5.31. FILGUEIRA, F. P., CARVALHO, J. S., LOBATO, N. S., BERNARDES, A. P. V. Estudo da prevalência de enteroparasitoses no centro de educação infantil são judas tadeu, na Cidade de Aragarças - GO.

In: VII Congresso Regional de Análises Clínicas do Centro-Oeste, Campo Grande, MS, Brasil, 2005.

5.32. COSTA, F. G., DAVID, F. L., FILGUEIRA, F. P., LIMA, V. V., LOBATO, N. S., MELO, L. V. L.

Avaliação do conhecimento dos freqüentadores da praia de Aragarças - GO, com relação aos riscos da exposição ao sol.

In: VI Congresso Regional de Análises Clínicas do Centro-Oeste, Cuiabá, MT, Brasil, p.33-33, 2004. 
5.33. ANDRADE, L. C. M., CARVALHO, J. S., FARIA, F. S., FILGUEIRA, F. P., LOBATO, N. S., TOLEDO, O. R.

Determinação da relação entre eosinofilia, giardíase e amebíase.

In: VI Congresso Regional de Análises Clínicas do Centro-Oeste, Cuiabá, MT, Brasil, p.31-31, 2004.

5.34. ANDRADE, L. C. M., CARVALHO, J. S., FARIA, F. S., FILGUEIRA, F. P., LOBATO, N. S., TOLEDO, O. R.

Determinação de giardíase e amebíase em uma creche de Aragarças - GO.

In: VI Congresso Regional de Análises Clínicas do Centro-Oeste, Cuiabá, MT, Brasil, p.29-29, 2004.

5.35. ANDRADE, L. C. M., CARVALHO, J. S., FARIA, F. S., FILGUEIRA, F. P., LOBATO, N. S., TOLEDO, O. R.

Prevalência de anemia em pré-escolares de uma creche da cidade de Aragarças GO.

In: VI Congresso Regional de Análises Clínicas do Centro-Oeste, Cuiabá, MT, Brasil, p.17-17, 2004.

5.36. LOBATO, N. S., FILGUEIRA, F. P., CARVALHO, J. S., COSTA, F. G., LIMA, V. V., PEIXOTO, R. F., DAVID, F. L.

Farmácia na praia - temporada da Praia Quarto Crescente

In: Il Mostra de Extensão Universitária - UFMT, Barra do Garças, MT, Brasil, p.19-19, 2004.

5.37. LOBATO, N. S., FIlgueIRA, F. P., CARVALHO, J. S., FARIA, F. S., TOLEDO, O.R.

Procedimentos preventivos e realização de exames sobre anemia e enteroparasitoses nas crianças da Creche São Judas Tadeu.

In: II Mostra de Extensão Universitária - UFMT, Barra do Garças, MT, Brasil, p.27-27, 2004.

5.38. LOBATO, N. S., FILGUEIRA, F. P., CARVALHO, J. S., COSTA, F. G., LIMA, V. V., PEIXOTO, R. F., DAVID, F. L.

Programa de prevenção DST/AIDS.

In: II Mostra de Extensão Universitária - UFMT, Barra do Garças, MT, Brasil, p.28-28, 2004.

5.39. LOBATO, N. S., FILGUEIRA, F. P., COSTA, F. G., LIMA, V. V., SILVA, F., SILVA, E. S., MURAKAMI, D. M. Plantas medicinais - educação e saúde.

In: I Mostra de Extensão Universitária - UFMT, Barra do Garças, MT, Brasil, p.27-27, 2003.

\section{APRESENTAÇÃO DE TRABALHO EM FORMATO DE PAINEL EM CONGRESSO CIENTÍFICO}

6.1. LOBATO, N. S., FILGUEIRA, F. P., GIACHINI, F., CARVALHO. M. H., WEBB, 
R. C., TOSTES, R. C., FORTES, Z. B.

A obesidade diminui a atividade do sistema endocanabinóide vascular: participação da eNOS, da AMPK e da ERK.

Arquivos Brasileiros de Endocrinologia e Metabologia (ISSN 0004-2730), v.54, suplemento 2, p.133-133, 2010.

In: 9ํㅡㄹ Congresso Paulista de Diabetes e Metabolismo, Águas de São Pedro, SP, Brasil, 2010.

6.2. LOBATO, N. S., FILGUEIRA, F. P., GIACHINI, F., CARVALHO. M. H., WEBB, R. C., TOSTES, R. C., FORTES, Z. B.

Obesity decreases the activity of the endocannabinoid system: role of $\mathrm{NO}$ and AMPK.

Faseb Journal (ISSN 0892-6638), v.24, abstract n.570.7, 2010.

In: Experimental Biology, Anaheim, Califórnia, EUA, 2010.

6.3. LOBATO, N. S., FILGUEIRA, F. P., GIACHINI, F., CARVALHO. M. H., WEBB, R. C., TOSTES, R. C., FORTES, Z. B.

A obesidade diminui a atividade do sistema endocanabinóide vascular: participação da eNOS, da AMPK e da ERK.

FeSBE, resumo n.16.049, 2010.

In: XXV Reunião Anual da Federação de Sociedades de Biologia Experimental FeSBE, Águas de Lindóia, SP, Brasil, 2010.

6.4. LOBATO, N. S., FILGUEIRA, F. P., GIACHINI, F. R., WEBB, R. C., TOSTES, R. C., FORTES, Z.B.

Hyperactivation of ERK pathway and decreased activity of AMPK contribute to the decreased relaxation to anandamide in obese Zucker rats.

In: $20^{\text {th }}$ Annual Vascular Biology and Hypertension Symposium, Birmingham, Alabama, EUA, 2009.

6.5. LOBATO, N. S., AKAMINE, E. H., FILGUEIRA, F. P., TOSTES, R. C., CARVALHO, M.H.C., FORTES, Z.B.

Metformin improves endothelial function in obese rats.

Faseb Journal (ISSN 0892-6638), v. 23, abstract n. 578.1, 2009.

In: Experimental Biology, New Orleans, Louisiana, EUA, 2009.

6.6. Lobato, N. S., tostes, R. C., CARVAlHO, M. H. C., FORTES, Z. B.

Metformina corrige alterações na função vascular em ratos obesos: estudo dos mecanismos envolvidos.

In: V Congresso do Instituto de Ciências Biomédicas, Universidade de São Paulo, São Paulo, SP, Brasil, 2008.

6.7. LOBATO, N. S., PARIZ, J. R., tOSteS, R. C. A., CARVAlHO. M. H. C., FORTES, Z. B.

Metformina modula a resposta contrátil e vasodilatadora via NO, prostanóides e hiperpolarização do músculo liso do leito arteriolar mesentérico de ratos obesos com resistência à insulina.

Arquivos Brasileiros de Endocrinologia e Metabologia (ISSN 0004-2730), v.52, supl. 2, S209 - S209, 2008.

In: 8ํㅡㄹ Congresso Paulista de Diabetes e Metabolismo, Águas de Lindóia, SP, Brasil, 
2008.

6.8. LOBATO, N. S., tOSTES, R. C., CARVALHO, M.H.C., FORTES, Z.B. Efeito benéfico da metformina nas alterações vasculares de ratos obesos: papel das EROs e da hiperpolarização de membrana.

FeSBE, p. 75-75, 2008.

In: XXIII Reunião Anual da Federação de Sociedades de Biologia Experimental FeSBE, Águas de Lindóia, SP, Brasil, 2008.

6.9. LOBATO, N. S., PARIZ, J. R., TOSTES, R. C., CARVALHO, M.H.C., FORTES, Z.B.

Efeito da metformina nas alterações da resposta vasoconstritora da aorta de ratos obesos: papel do endotélio.

In: XXIII Reunião Anual da Federação de Sociedades de Biologia Experimental FeSBE, Águas de Lindóia- SP, 2008.

6.10. LOBATO, N. S., TOSTES, R. C., CARVALHO, M.H.C., FORTES, Z.B.

Papel do endotélio nas alterações da resposta vasodilatora em ratos obesos e o efeito da metformina: possíveis mecanismos envolvidos.

Hipertensão (ISSN 1519-7522), v. 11, n.4, p.80-80, 2008.

In: XVII Congresso Brasileiro de Hipertensão, Rio de Janeiro, RJ, Brasil, 2008.

6.11. LOBATO, N. S., TOSTES, R. C., CARVALHO, M.H.C., FORTES, Z.B.

Alterações da contração vascular em ratos obesos e o efeito da metformina: possíveis mecanismos envolvidos.

Hipertensão (ISSN 1519-7522), v. 11, n.4, p.80-80, 2008.

In: XVII Congresso Brasileiro de Hipertensão, Rio de Janeiro, RJ, Brasil, 2008.

6.12. LOBATO, N. S., TOSTES, R. C., CARVALHO, M.H.C., FORTES, Z.B.

Reatividade vascular em ratos wistar obesos com resistência à insulina induzida por glutamato monossódico (MSG).

Arquivos Brasileiros de Endocrinologia e Metabologia (ISSN 0004-2730), 2007, v.51, n.3, supl. 1, p.S126-S126.

In: $7^{\circ}$ Congresso Paulista de Endocrinologia e Metabolismo, São Paulo, SP, Brasil, 2007.

6.13. LOBATO, N. S., TOSTES, R. C., CARVALHO, M.H.C., FORTES, Z.B.

Alterações na Reatividade Vascular em Modelo de Resistência à Insulina Induzida por Glutamato Monossódico (Obesidade em Ratos).

Hipertensão (ISSN 1519-7522), v. 10, p.55-55, 2007.

In: XVI Congresso Brasileiro de Hipertensão, Recife, PE, Brasil, 2007.

\section{OUTRAS PUBLICAÇÕES}

7.1. Dissertação de mestrado defendida e aprovada

LOBATO, N. S. Efeito do tratamento com metformina sobre alterações vasculares em modelo de resistência à insulina. $128 \mathrm{f}$. Dissertação (Mestrado em Farmacologia). 
Instituto de Ciências Biomédicas, Universidade de São Paulo, São Paulo, 2008. 


\section{V- $\quad$ ATIVIDADES DE QUALIFICACÃO}

\section{PARTICIPAÇÃO EM EVENTOS CIENTÍFICOS}

1.1. XXV Reunião Anual da Federação de Sociedades de Biologia Experimental FeSBE, Águas de Lindóia - SP, 2010. (Congresso)

1.2. $9^{\circ}$ Congresso Paulista de Diabetes e Metabolismo, Águas de São Pedro - SP, 2010. (Congresso)

1.3. Experimental Biology, Anaheim - CA, EUA, 2010. (Congresso)

1.4. 63rd High Blood Pressure Research Conference, Chicago - IL, EUA, 2009. (Congresso)

1.5. $20^{\text {th }}$ Annual Vascular Biology and Hypertension Symposium, Birmingham - AL, EUA, 2009. (Simpósio)

1.6. Experimental Biology, New Orleans - LA, EUA, 2009. (Congresso)

1.7. V Simpósio de Farmacologia "Prêmio Qualidade Científica Prof. Dr. João Garcia Leme", São Paulo - SP, 2009.(Simpósio)

1.8. V Congresso do Instituto de Ciências Biomédicas, Instituto de Ciências Biomédicas, Universidade de São Paulo, São Paulo - SP, 2008. (Congresso)

1.9. XXIII Reunião Anual da Federação de Sociedades de Biologia Experimental FeSBE, Águas de Lindóia - SP, 2008. (Congresso)

1.10. XVI Congresso Brasileiro de Hipertensão, Rio de Janeiro - RJ, 2008. (Congresso)

1.11. III Simpósio Temático do Departamento de Fisiologia e Biofísica "Sinalização Celular", Instituto de Ciências Biomédicas, Universidade de São Paulo, São Paulo SP, 2008. (Simpósio)

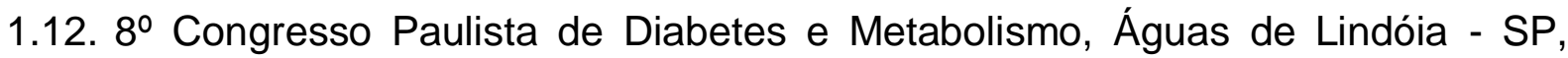
2008. (Congresso)

1.13. IV Simpósio "Ácidos Graxos e Saúde", Instituto de Ciências Biomédicas, Universidade de São Paulo, São Paulo - SP, 2008. (Simpósio)

1.14. XV Congresso da Sociedade Brasileira de Hipertensão, Recife - PE, 2007. (Congresso)

1.15. IV Simpósio de Farmacologia "Prêmio Qualidade Científica Prof. Dr. João Garcia Leme", São Paulo - SP, 2007. (Simpósio)

1.16. $7^{\circ}$ Congresso Paulista de Endocrinologia e Metabolismo, São Paulo - SP, 
2007. (Congresso)

1.17. VII Congresso Regional de Análises Clínicas do Centro-Oeste, Cuiabá - MT, 2005. (Congresso)

1.18. VI Congresso Regional de Análises Clínicas do Centro-Oeste, Cuiabá - MT, 2004. (Congresso)

1.19. II Mostra de Extensão Universitária - UFMT, 2004.

1.20. I Mostra de Extensão Universitária - UFMT, 2003.

\section{CURSOS DE APERFEIÇOAMENTO}

Realização de estágio no Programa de Aperfeiçoamento de Ensino (PAE) da Universidade de são Paulo, na área de Farmacologia, do Instituto de Ciências Biomédicas, com carga horária semanal de 06 horas, durante o primeiro semestre de 2007 (total de horas: 144). Foram desenvolvidas atividades didáticas junto à disciplina BMF-220 - Farmacologia, com os alunos de graduação do curso de Medicina, sob supervisão da Prof. Dra Maria Helena Catelli de Carvalho. 


\section{VI- $\quad$ ATIVIDADES DE ENSINO}

\section{CO-ORIENTAÇÕES CONCLUÍDAS}

\section{INICIAÇÃO CIENTÍFICA}

1.1 Graziela Neves Hagihara.

Estudo do tratamento com metformina nas alterações da reatividade vascular em modelo de resistência à insulina (obesidade):possíveis mecanismos envolvidos. 2008-2009.

Iniciação científica (Bolsa de Treinamento Técnico para Estudantes de Graduação) Universidade de São Paulo.

1.2 Juliana Pariz Risso.

Influência do tratamento com metformina nas alterações vasculares induzidas por obesidade: estudo em ratos. 2007-2007.

Iniciação científica (Programa de Iniciação Científica - PIBIC) - Universidade de São Paulo.

\section{CO-ORIENTAÇÕES EM ANDAMENTO}

\section{MESTRADO}

\subsection{Graziela Neves Hagihara.}

Resposta a angiotensina II em artérias mesentéricas de resistência na obesidade: papel das MAPKs. 2010-atual.

Bolsista da Fundação de Amparo à Pesquisa do Estado de São Paulo - FAPESP, Universidade de São Paulo.

\section{OUTRAS ATIVIDADES DESENVOLVIDAS}

ESTÁGIO no Departamento de Fisiologia do "MEDICAL COLLEGE OF GEORGIA", Augusta-GA, USA. Período: de fevereiro a outubro de 2009, sob a co-orientação da Prof. Dra. Rita de Cássia Tostes e do Prof. Dr. Clinton Webb. 
Núbia de Souza Lobato

Curriculum Vitae 


\section{I- DADOS PESSOAIS}

Nome

Filiação

Nascimento

Carteira de Identidade CPF

Endereço residencial

Endereço profissional

Universidade Federal de Goiás, Campus de Jataí Unidade Jatobá

Rodovia BR 364, Km 192, no 3800, Setor Parque Industrial

75801-615 - Jataí, GO - Brasil

Telefone: 6436068290

Endereço eletrônico e-mail: nubialobato@yahoo.com.br 


\section{II- FORMAC̄̃̃O ACADÊMICA/TITULACÃO}

2008 - atual Doutorado em Ciências Biológicas, área de Farmacologia, Conceito CAPES 6.

Universidade de São Paulo, USP, São Paulo, Brasil.

Título: A Obesidade Diminui a Resposta de Artérias Mesentéricas de Resistência a Agonistas Canabinóides.

Orientadora: $\mathrm{Dr}^{\mathrm{a}}$ Zuleica Bruno Fortes.

Bolsista da Fundação de Amparo à Pesquisa do Estado de São Paulo - FAPESP.

2006 - 2008 Mestrado em Ciências Biológicas, área de Farmacologia, Conceito CAPES 6.

Universidade de São Paulo, USP, São Paulo, Brasil.

Título: Efeito do Tratamento com Metformina sobre Alterações Vasculares em Modelo de Resistência à Insulina (Obesidade em Ratos).

Orientadora: $\mathrm{Dr}^{\mathrm{a}}$ Zuleica Bruno Fortes.

Bolsista da Fundação de Amparo à Pesquisa do Estado de São Paulo - FAPESP.

2002 - 2006 Graduação em Farmácia.

Universidade Federal de Mato Grosso, UFMT, Barra do Garças, Brasil.

Título: Análise Química Preliminar e Avaliação da Atividade Farmacológica das folhas de Strychnos pseudoquina ST. HILL (Quina do Cerrado).

Orientadora: $\mathrm{Dr}^{\mathrm{a}}$ Eliane Augusto Ndiaye.

Bolsista do Conselho Nacional de Desenvolvimento Científico e Tecnológico - CNPq. 


\title{
III- ATUACÃO PROFISSIONAL
}

1. Universidade Federal de Goiás - UFG

Vínculo institucional

2010 - atual Vínculo: Funcionário Público, Enquadramento funcional: Professor Assistente Nível I, Regime: Dedicação Exclusiva

\author{
Atividades \\ 8/2010 - Atual Curso: Psicologia. \\ Disciplina: Fisiologia do Sistema Nervoso \\ 8/2010 - Atual Curso: Zootecnia. \\ Disciplina: Fisiologia Animal \\ 8/2010 - Atual Curso: Fisioterapia. \\ Disciplina: Histologia de Órgãos e Sistemas
}

2. Universidade de São Paulo - USP

Vínculo institucional

2008 - atual Vínculo: Aluno, Enquadramento funcional: Doutoranda

2006-2008 Vínculo: Aluno bolsista, Enquadramento funcional: Mestranda

\begin{abstract}
Atividades
2008 - Atual Projeto de pesquisa, Universidade de São Paulo Instituto de Ciências Biomédicas.

Participação do tecido adiposo nas alterações da reatividade vascular em aorta de ratos obesos com resistência à insulina: efeito das citocinas, do sistema endocanabinóide e da AMPK.

2007 - Atual Projeto de pesquisa, Universidade de São Paulo Instituto de Ciências Biomédicas.

Estudo do tratamento com metformina nas alterações da reatividade vascular em modelo de resistência à insulina (obesidade): possíveis mecanismos envolvidos.

2006 - Atual Grupo de pesquisa, Universidade de São Paulo - Instituto de Ciências Biomédicas.

Resistência à insulina: diabetes, obesidade e alterações
\end{abstract}


vasculares. Reversão farmacológica das alterações e seu mecanismo.

2006-2008 Projeto de pesquisa, Universidade de São Paulo Instituto de Ciências Biomédicas.

Efeito do tratamento com metformina sobre alterações vasculares em modelo de resistência à insulina (obesidade em ratos).

\section{Universidade Federal de Mato Grosso - UFMT}

\begin{tabular}{llll}
\hline Vínculo institucional & Vínculo: Aluno bolsista, Enquadramento funcional: \\
2004 - 2005 & Estudante de Graduação
\end{tabular}

\begin{tabular}{ll}
\hline Atividades & \\
2004 - 2005 & $\begin{array}{l}\text { Projetos de pesquisa, Instituto de Ciências e Letras do } \\
\text { Médio Araguaia }\end{array}$ \\
& Análise Química Preliminar e Avaliação da Atividade \\
Farmacológica das Folhas de Strychnos pseudoquina \\
(Quina) e Duguetia furfuracea (Sofre do Rim Quem Quer).
\end{tabular}




\section{PROJETOS DE PESQUISA}

2008 - Atual Participação do tecido adiposo nas alterações da reatividade vascular em aorta de ratos obesos com resistência à insulina: efeito das citocinas, do sistema endocanabinóide e da AMPK

Situação: Em Andamento Natureza: Pesquisa

Integrantes: Núbia de Souza Lobato; Zuleica Bruno Fortes (Responsável)

Financiadores: Conselho Nacional de Desenvolvimento Científico e Tecnológico-CNPq, Fundação de Amparo à Pesquisa do Estado de São Paulo-FAPESP

2007 - Atual Estudo do tratamento com metformina nas alterações da reatividade vascular em modelo de resistência à insulina (obesidade): possíveis mecanismos envolvidos.

Situação: Em Andamento Natureza: Pesquisa

Integrantes: Núbia de Souza Lobato; Zuleica Bruno Fortes (Responsável)

Financiadores: Fundação de Amparo à Pesquisa do Estado de São Paulo-FAPESP

2006 - Atual Resistência à insulina, diabetes, obesidade e alterações vasculares. Reversão farmacológica das alterações e seus mecanismos.

Situação: Em Andamento Natureza: Pesquisa Integrantes: Pesquisadores: Eliana Hiromi Akamine, Maristella de Almeida Vitta Landgraf,Maria Aparecida de Oliveira, Roberto Kenji Nakamura Cuman, Maria do Carmo Pinho Franco, Stephen Fernandes de Paula Rodrigues, Maria Helena Catelli de Carvalho Zuleica Bruno Fortes (responsável), Núbia de Souza Lobato, Eveline Aparecida Isquierdo Fonseca, Graziela Neves Hagihara, Simone Marcieli Sartoretto.

2006 - 2008 Efeito do tratamento com metformina sobre alterações vasculares em modelo de resistência à insulina (obesidade em ratos).

Situação: Concluído Natureza: Pesquisa Integrantes: Núbia de Souza Lobato; Zuleica Bruno Fortes (Responsável)

Financiador: Fundação de Amparo à Pesquisa do Estado de São Paulo-FAPESP

2004 - 2005 Projetos de pesquisa, Instituto de Ciências e Letras do Médio Araguaia

Análise Química Preliminar e Avaliação da Atividade Farmacológica das Folhas de Strychnos pseudoquina (Quina) e Duguetia furfuracea (Sofre do Rim Quem Quer)

Situação: Concluído Natureza: Pesquisa

Integrantes: Núbia de Souza Lobato (Bolsista); Eliane Augusto Ndiaye (Responsável)

Financiador: $\mathrm{CNPq}$ 


\section{ATIVIDADES DE EXTENSÃO}

\section{PARTICIPAÇÃO EM PROJETOS DE EXTENSÃO}

2005 - 2005 Participação como monitora voluntária no projeto de extensão: PROCEDIMENTOS PREVENTIVOS E REALIZAÇÃO DE EXAMES SOBRE ANEMIA E ENTEROPARASITOSES NAS CRIANÇAS DA CRECHE SÃO JUDAS TADEU, promovido pelo Departamento de Ciências Biológicas e da Saúde (DCBS) / Instituto de Ciências e Letras do Médio Araguaia (ICLMA), realizado de agosto a dezembro de 2004.

Integrantes: Núbia de Souza Lobato (voluntário); Fernando Paranaiba Filgueira (bolsista); Frederico dos Santos Faria (voluntário); Janaina da Silva Carvalho (voluntário); Olegário Rosa Toledo (Responsável)

Financiador: Universidade Federal do Mato Grosso

2004 - 2004 Participação como monitora voluntária no projeto de extensão: PROCEDIMENTOS PREVENTIVOS E REALIZAÇÃO DE EXAMES SOBRE ANEMIA E ENTEROPARASITOSES NAS CRIANÇAS DA CRECHE SÃO JUDAS TADEU, promovido pelo Departamento de Ciências Biológicas e da Saúde (DCBS) / Instituto de Ciências e Letras do Médio Araguaia (ICLMA), realizado de agosto a dezembro de 2004.

Integrantes: Núbia de Souza Lobato (voluntário); Fernando Paranaiba Filgueira (bolsista); Frederico dos Santos Faria (voluntário); Janaina da Silva Carvalho (voluntário); Olegário Rosa Toledo (Responsável)

Financiador: Universidade Federal do Mato Grosso

2003 - 2003 Participação como monitora voluntária do projeto de extensão universitária PLANTAS MEDICINAIS: EDUCAÇÃO E SAÚDE, realizado de maio a dezembro de 2003, promovido pelo Departamento de Ciências Biológicas e da Saúde (DCBS) / Instituto de Ciências e Letras do Médio Araguaia (ICLMA), realizado de agosto a dezembro de 2003.

Integrantes: Núbia de Souza Lobato (voluntário); Fernando Paranaiba Filgueira (voluntário); Fausto Guimarães Costa (bolsista); Francismeire A. da Silva (bolsista); Devanir Mistuyuki Murakami (Responsável)

Financiador: Universidade Federal do Mato Grosso

\section{CURSOS DE EXTENSÃO}

2009-2009 Cursos de treinamento: "Biological Safety Refresher Course", "Library Ergonomic Training", "Computer Workstation Ergonomic 
Training", "Bloodborne Pathogens Training", "Hazardous Waste Awareness Training", "Right-To-Know Chemical Specific Training", "Right-To-Know Basic Awareness Training", oferecidos na instituição Medical College of Georgia, Augusta-GA, Estados Unidos da América.

2008 - 2008 Monitoria do CURSO DE DIFUSÃO CULTURAL intitulado "ICB aberto à escola", oferecido de 22 a 30 de abril de 2008 Universidade de São Paulo, Instituto de Ciências Biomédicas, São Paulo, Brasil.

2008 - 2008 CURSO DE BIOESTATÍSTICA (Workshop) - Universidade de São Paulo, Instituto de Ciências Biomédicas, São Paulo, Brasil, 25 a 27 de agosto de 2008. Carga horária: 8 horas.

2007 - 2007 CURSO DE PROTEÇÃO RADIOLÓGICA, promovido pelo Núcleo de Radioproteção do Instituto de Ciências Biomédicas da Universidade de São Paulo, São Paulo, Brasil, 10 a 12 de dezembro de 2007. Carga horária: 15 horas.

2006-2006 CURSO DE TREINAMENTO NO USO DE ANIMAIS DE EXPERIMENTAÇÃO, organizado pelas Comissões de Biotério e de Ética em Experimentação Animal do Instituto de Ciências Biomédicas da Universidade de São Paulo, São Paulo, Brasil, 18 de setembro de 2006. Carga horária: 03 horas.

2006 - 2006 Curso FUNDAMENTOS TEÓRICOS dos MÉTODOS de BIOLOGIA MOLECULAR APLICADOS à PESQUISA e ao DIAGNÓSTICO CLÍNICO- Universidade de São Paulo, USP-oficina, São Paulo, Brasil, 10 a 14 de julho de 2006.

2006 - 2006 PLANEJANDO e OTIMIZANDO a REAÇÃO de PCR - Universidade de São Paulo, USP-oficina, São Paulo, Brasil, 17 a 20 de julho de 2006.

2004-2005 Extensão universitária em PROGRAMA DE PREVENÇÃO A DST/AIDS. DCBS, ICLMA, Universidade Federal de Mato Grosso, UFMT, Cuiabá, Brasil. Carga horária: 40 horas.

2004 - 2004 Curso de curta duração em HEMOGRAMA E COAGULOPATIAS, Sociedade Brasileira de Análises Clínicas, SBAC, Cuiabá-MT, Brasil. Carga horária: 08 horas. 
2004-2004 Curso de curta duração em I SEMANA DE FARMACOLOGIA. Universidade Federal de Mato Grosso, UFMT, Pontal do Araguaia, Brasil. Carga horária: 40 horas.

2004 - 2004 Curso de extensão em PRIMEIROS SOCORROS. Universidade Federal de Mato Grosso, Pontal do Araguaia, Brasil. Carga horária: 80 horas.

2004 - 2004 Participação como monitora no projeto de extensão universitária FARMÁCIA NA PRAIA. DCBS/ICLMA, Universidade Federal de Mato Grosso, UFMT, Cuiabá, Brasil. Carga horária: 40 horas.

2004 - 2004 Participação como membro da Comissão de Divulgação/Recepção na II MOSTRA DE EXTENSÃO UNIVERSITÁRIA DO ICLMA/UFMT. Câmara de Extensão - NUPEX - ICLMA, Universidade Federal de Mato Grosso, UFMT, Pontal do Araguaia-MT, Brasil, Carga horária: 20 horas.

2003 - 2003 Curso de Treinamento LEVANDO SAÚDE ATRAVÉS DA ÁGUA. DCBS/ICLMA, Universidade Federal de Mato Grosso, UFMT, Cuiabá, Brasil. Carga horária: 40 horas.

\section{PALESTRANTE EM EVENTO CIENTÍFICO}

Conferencista no XVII Congresso da Sociedade Brasileira de Diabetes, 2009. Obesidade e Resistência à Insulina.

Conferencista no $9^{\circ}$ Congresso Paulista de Diabetes e Metabolismo, 2010. Metformina, obesidade e reatividade vascular. 
IV- PRODUCÃO BIBLIOGRÁFICA

\section{PRÊMIOS CIENTífICOS}

2009

2009

2008

2008

PRÊMIO QUALIDADE CIENTÍFICA PROF. DR. JOÃO GARCIA LEME, Instituto de Ciências Biomédicas - Universidade de São Paulo.

MELHOR TRABALHO - II SIMFARMA, Simpósio de Farmácia do Médio Araguaia.

MENÇÃO HONROSA, INSTITUTO DE CIÊNCIAS BIOMÉDICAS Universidade de São Paulo.

PRÊMIO AMIL - SBH DE INCENTIVO À PESQUISA, XVI Congresso Brasileiro de Hipertensão.

\section{ARTIGOS COMPLETOS PUBLICADOS EM PERIÓDICOS}

2.1. lobato, N. S., AKamine, E. H., tostes, R. C., CARVAlho, M.H.C., FORTES, Z.B. Obesidade e hipertensão arterial.

Hipertensão (ISSN 1809-4260), v.12, n.1, p.4-12, 2009.

2.2. LOBATO, N. S., FilgueiRA, F. P., AKAMine, E. H., DAVEL, A. P. C., ROSSONI, L. V., TOSTES, R. C., CARVALHO, M.H.C., FORTES, Z.B.

Obesity Induced by Neonatal Treatment with Monosodium Glutamate Impairs Microvascular Reactivity in Adult Rats: Role of $\mathrm{NO}$ and Prostanoids.

(D.O.I.: 10.1016/j.numecd.2010.02.006).

Nutrition, Metabolism and Cardiovascular Diseases (ISSN 0939-4753), no prelo, 2010.

\section{APRESENTAÇÃO ORAL DE TRABALHO EM CONGRESSO CIENTÍFICO}

3.1. LobAto, N. S., FILGUeIRA, F. P., GIACHINI, F. R., CARVALHO, M.H.C., WEBB, R. C., TOSTES, R. C., FORTES, Z.B.

A atividade do sistema endocanabinóide vascular está diminuída na obesidade: participação da eNOS, da AMPK e da ERK.

V Simpósio de Farmacologia "Qualidade Científica Prof. Dr. João Garcia Leme", 2009.

3.2. LOBATO, N. S., TOSTES, R. C., CARVALHO, M.H.C., FORTES, Z.B.

Alterações da contração vascular em ratos obesos e o efeito da metformina: possíveis mecanismos envolvidos. 
XVI Congresso Brasileiro de Hipertensão, Rio de Janeiro-RJ, 2008.

3.3. LOBATO, N. S., TOSTES, R. C., CARVALHO, M.H.C., FORTES, Z.B.

Efeito benéfico da metformina nas alterações vasculares de ratos obesos: Papel das EROs e da hiperpolarização de membrana.

XXIII Reunião Anual da Federação de Sociedades de Biologia Experimental FeSBE, Águas de Lindóia, 2008.

3.4. LOBATO, N. S., TOSTES, R. C., CARVALHO, M.H.C., FORTES, Z.B.

Metformina Corrige Alterações da Reatividade Vascular no Leito Arteriolar Mesentérico de Ratos Obesos Com Resistência à Insulina.

IV Simpósio de Farmacologia "Qualidade Científica Prof. Dr. João Garcia Leme", 2007.

\section{RESUMOS COMPLETOS PUBLICADOS EM ANAIS DE EVENTOS}

4.1. LOBATO, N. S., TOSTES, R. C., CARVALHO, M.H.C., FORTES, Z.B.

Alterações da contração vascular em ratos obesos e o efeito da metformina: possíveis mecanismos envolvidos.

Hipertensão (ISSN 1519-7522), v. 11, n.4, p.156-156, 2008.

In: XVII Congresso Brasileiro de Hipertensão, Rio de Janeiro, RJ, Brasil, 2008.

\section{RESUMOS PUBLICADOS EM ANAIS DE EVENTOS}

5.1. LOBATO, N. S., FILGUEIRA, F. P., GIACHINI, F., CARVALHO. M. H., WEBB, R. C., TOSTES, R. C., FORTES, Z. B.

A obesidade diminui a atividade do sistema endocanabinóide vascular: participação da eNOS, da AMPK e da ERK.

Arquivos Brasileiros de Endocrinologia e Metabologia (ISSN 0004-2730), v.54, suplemento 2, p.133-133, 2010.

In: 9o Congresso Paulista de Diabetes e Metabolismo, Águas de São Pedro, SP, Brasil, 2010.

5.2. LOBATO, N. S., FILGUEIRA, F. P., GIACHINI, F., CARVALHO. M. H., WEBB, R. C., TOSTES, R. C., FORTES, Z. B.

Obesity decreases the activity of the endocannabinoid system: role of $\mathrm{NO}$ and AMPK.

Faseb Journal (ISSN 0892-6638), v.24, abstract n.570.7, 2010.

In: Experimental Biology, Anaheim, Califórnia, EUA, 2010.

5.3. FilgueiRA, F. P., Lobato, N. S., CERAVolo, G. S., DANTAS, A. P. V., FORTES, Z. B., WEBB, R. C., TOSTES, R. C., CARVALHO, M. H. C.

Characterization of the relaxant response to equilin in rat mesenteric arteries.

Faseb Journal (ISSN 0892-6638), v.24, abstract n.575.7, 2010.

In: Experimental Biology, Anaheim, Califórnia, EUA, 2010. 
5.4. LOBATO, N. S., FILGUEIRA, F. P., GIACHINI, F., CARVALHO. M. H., WEBB, R. C., TOSTES, R. C., FORTES, Z. B.

A obesidade diminui a atividade do sistema endocanabinóide vascular: participação da eNOS, da AMPK e da ERK.

FeSBE, resumo n.16.049, 2010.

In: XXV Reunião Anual da Federação de Sociedades de Biologia Experimental FeSBE, Águas de Lindóia, SP, Brasil, 2010.

5.5. FILGUeIRA, F. P., LOBATO, N. S., CERAVOLO, G. S., DANTAS, A. P. V., FORTES, Z. B., WEBB, R. C., TOSTES, R. C., CARVALHO, M. H. C.

Vascular actions of equilin in resistance mesenteric arteries of hypertensive rats.

FeSBE, resumo n.16.040, 2010.

In: XXV Reunião Anual da Federação de Sociedades de Biologia Experimental FeSBE, Águas de Lindóia, SP, Brasil, 2010.

5.6. PEREIRA, M. L. L., FILGUEIRA, F. P., LOBATO, N. S., CERAVOLO, G. S., DANTAS, A. P. V., TOSTES, R. C., FORTES, Z. B., CARVALHO, M. H. C.

Premarin melhora a função vascular em ratas geneticamente hipertensas.

FeSBE, resumo n.16.018, 2010.

In: XXV Reunião Anual da Federação de Sociedades de Biologia Experimental FeSBE, Águas de Lindóia, SP, Brasil, 2010.

5.7. LOBAto, N. S., AKAMine, E. H., FILGUeiRA, F. P., tOSTeS, R. C., CARVALHO, M.H.C., FORTES, Z.B.

Metformin improves endothelial function in obese rats.

Faseb Journal (ISSN 0892-6638), v. 23, abstract n. 578.1, 2009.

In: Experimental Biology, New Orleans, Louisiana, EUA, 2009.

5.8. FILGUeIRA, F. P., LOBATO, N. S., SANTOS, R. A., OliVEIRA, M. A., FORTES, Z.B., TOSTES, R. C., CARVALHO, M.H.C.

Influence of endogenous testosterone on vascular endothelium-leukocyte interaction in spontaneously hypertensive rats (SHRs).

Faseb Journal (ISSN 0892-6638), v.23, abstract n. 934.5, 2009.

In: Experimental Biology, New Orleans, Louisiana, EUA, 2009.

5.9. FILGUEIRA, F. P., CERAVOLO, G., LOBATO, N. S., FORTES, Z.B., TOSTES, R. C., DANTAS, A. P., CARVALHO, M.H.C.

Conjugated equine estrogen improves vascular reactivity and metabolic parameters in ovariectomized SHR.

Hypertension (ISSN 0194911X), v.54, n. 4, e79 -e79, 2009.

In: 63rd Annual High Blood Pressure Research Conference, Chicago, Illinois, EUA, 2009.

5.10. KLAJMAN, A. B., LOBATO, N. S., OIGMAN, W., FORTES, Z.B., NEVES, M. F. Beneficial effects of metformin on the cardiac and vascular fibrosis in the monosodium glutatamate- induced obesity.

Hipertensão (ISSN 1809-4260 e CD-ROM), v.12, p. 7-7, abstract n. 915, 2009.

In: Inter-American Society of Hypertension XVIlth Scientific Sessions. XVII Congresso da Sociedade Brasileira de Hipertensão, Belo Horizonte, MG, Brasil, 2009. 
5.11. HAGIHARA, G. N., AKAMINE, E. H., LOBATO, N. S., TOSTES, R. C., CARVALHO, M.H.C., FORTES, Z.B.

Vascular reactivity in female obese rats.

Hipertensão (ISSN 1809-4260 e CD-ROM), v.12, p.7-7, abstract n.937, 2009.

In: Inter-American Society of Hypertension XVIIth Scientific Sessions. XVII Congresso da Sociedade Brasileira de Hipertensão, Belo Horizonte, MG, Brasil, 2009.

5.12. CERAVOLO, G., FILGUEIRA, F. P., LOBATO, N. S., FORTES, Z.B., TOSTES, R. C., DANTAS, A. P., CARVALHO, M. H. C.

Conjugated equine estrogen improves vascular reactivity and metabolic parameters in ovariectomized SHR.

Hipertensão (ISSN 1809-4260 e CD-ROM), v.12, p.7-7, abstract n.940, 2009.

In: Inter-American Society of Hypertension XVIIth Scientific Sessions. XVII Congresso da Sociedade Brasileira de Hipertensão, Belo Horizonte, MG, Brasil, 2009.

5.13. LOBATO, N. S., tOSTES, R. C., CARVALHO, M. H. C., FORTES, Z. B.

Metformina corrige alterações na função vascular em ratos obesos: estudo dos mecanismos envolvidos.

In: V Congresso do Instituto de Ciências Biomédicas, Universidade de São Paulo, São Paulo, SP, Brasil, 2008.

5.14. CASTRO, D. B., NDIAYE, E. A., LOBATO, N. S., FIlGUEIRA, F. P., CARVALHO, M.H.C.

Avaliação do efeito do extrato etanólico e subextrato das raízes de Croton antisyphiliticus MART. (pé de perdiz) em macrovasos de ratos geneticamente hipertensos (SHR).

In: II Congresso de Fitoterápicos do Mercosul e VI Reunião da Sociedade Latino Americana de Fitoquímica, Belo Horizonte, MG, Brasil, 2008.

5.15. LOBATO, N. S., TOSTES, R. C., CARVALHO, M.H.C., FORTES, Z.B. Efeito benéfico da metformina nas alterações vasculares de ratos obesos: papel das EROs e da hiperpolarização de membrana.

FeSBE, p. 75-75, 2008.

In: XXIII Reunião Anual da Federação de Sociedades de Biologia Experimental FeSBE, Águas de Lindóia, SP, Brasil, 2008.

5.16. LOBATO, N. S., PARIZ, J. R., TOSTES, R. C. A., CARVALHO. M. H. C., FORTES, Z. B.

Metformina modula a resposta contrátil e vasodilatadora via NO, prostanóides e hiperpolarização do músculo liso do leito arteriolar mesentérico de ratos obesos com resistência à insulina.

Arquivos Brasileiros de Endocrinologia e Metabologia (ISSN 0004-2730), v.52, supl. 2, S209 - S209, 2008.

In: 8ํㅡㄹ Congresso Paulista de Diabetes e Metabolismo, Águas de Lindóia, SP, Brasil, 2008.

5.17. KLAJMAN, A. B., LOBATO, N. S., OIGMAN, W., FORTES, Z.B., NEVES, M. F. Morfologia de arteríolas intramiocárdicas em modelo experimental de obesidade: 
alterações independentes da variação da pressão arterial.

Hipertensão (ISSN 1519-7522), v. 11, n.4, p.36-36, 2008.

In: XVII Congresso Brasileiro de Hipertensão, Rio de Janeiro, RJ, Brasil, 2008.

5.18. LOBATO, N. S., TOSTES, R. C., CARVALHO, M.H.C., FORTES, Z.B.

Papel do endotélio nas alterações da resposta vasodilatora em ratos obesos e 0 efeito da metformina: possíveis mecanismos envolvidos.

Hipertensão (ISSN 1519-7522), v. 11, n.4, p.80-80, 2008.

In: XVII Congresso Brasileiro de Hipertensão, Rio de Janeiro, RJ, Brasil, 2008.

5.19. LOBATO, N. S., TOSTES, R. C., CARVALHO, M.H.C., FORTES, Z.B.

Alterações da contração vascular em ratos obesos e o efeito da metformina: possíveis mecanismos envolvidos.

Hipertensão (ISSN 1519-7522), v. 11, n.4, p.80-80, 2008.

In: XVII Congresso Brasileiro de Hipertensão, Rio de Janeiro, RJ, Brasil, 2008.

5.20. LOBATO, N. S., TOSTES, R. C., CARVALHO, M.H.C., FORTES, Z.B.

Reatividade vascular em ratos wistar obesos com resistência à insulina induzida por glutamato monossódico (MSG).

Arquivos Brasileiros de Endocrinologia e Metabologia (ISSN 0004-2730), 2007, v.51, n.3, supl. 1, p.S126-S126.

In: $7^{\circ}$ Congresso Paulista de Endocrinologia e Metabolismo, São Paulo, SP, Brasil, 2007.

5.21. LOBATO, N. S., TOSTES, R. C., CARVALHO, M.H.C., FORTES, Z.B.

Alterações na Reatividade Vascular em Modelo de Resistência à Insulina Induzida por Glutamato Monossódico (Obesidade em Ratos).

Hipertensão (ISSN 1519-7522), v. 10, p.55-55, 2007.

In: XVI Congresso Brasileiro de Hipertensão, Recife, PE, Brasil, 2007.

5.22. FILGUEIRA, F. P., LOBATO, N. S., TOSTES, R. C., CARVALHO, M.H.C., FORTES, Z.B.

Castração aumenta a resposta vasoconstritora induzida pela angiotensina II em ratos SHR.

Hipertensão (ISSN 1519-7522), v. 10, p.56-56, 2007.

In: XVI Congresso Brasileiro de Hipertensão, Recife, PE, Brasil, 2007.

5.23. PARIZ, J. R., Lobato, N. S., tOStes, R. C. A., CARVAlHO. M. H. C., FORTES, Z. B.

Efeito da metformina nas alterações da resposta vasoconstritora da aorta de ratos obesos: papel do endotélio.

In: IV Simpósio de Farmacologia "Qualidade Científica Prof. Dr. João Garcia Leme", São Paulo, SP, Brasil, 2007.

5.24. FILGUEIRA, F. P., CARVALHO J. S., LOBATO N. S., LIMA V. V., COSTA F. G., SILVA P. J., NDIAYE E. A.

Análise química preliminar do extrato lipofílico da Strychnos pseudoquina ST. Hill (Quina do Cerrado).

In: Congresso Farmacêutico do Pantanal, Cuiabá, MT, Brasil, p.12-2, 2005. 
5.25. CARVALHO J. S., LOBATO N. S., LIMA V. V., COSTA F. G., FILGUEIRA, F. P., NDIAYE E. A., SILVA P. J.

Avaliação do potencial citotóxido do extrato hexânico de Duguetia furfuracea (sofre do rim quem quer).

In: Congresso Farmacêutico do Pantanal, Cuiabá, MT, Brasil, p.12-13, 2005.

5.26. COSTA F. G., LIMA V. V., FILGUEIRA, F. P., CARVALHO J. S., LOBATO N. S., NDIAYE E. A.

Avaliação da atividade antimicrobiana do extrato hexânico de Duguetia furfuracea ST. Hill (sofre do rim quem quer).

In: Congresso Farmacêutico do Pantanal, Cuiabá, MT, Brasil, p.13-13, 2005.

5.27. COSTA F. G., FILGUEIRA, F. P., CARVALHO J. S., LOBATO N. S., LIMA V. V., NDIAYE E. A.

Avaliação da atividade antimicrobiana do extrato hexânico de Strychnos pseudoquina ST. Hill (quina do cerrado).

In: Congresso Farmacêutico do Pantanal, Cuiabá, MT, Brasil, p.19-19, 2005.

5.28. LOBATO, N. S., FILGUEIRA, F. P., COSTA, F. G., LIMA, V. V., CARVALHO, J. S., NDIAYE, E. A., SILVA, P. J., SOUTO, P. C. S.

Avaliação da atividade antimicrobiana do extrato metanólico de Strychnos pseudoquina st. hill (quina do cerrado) frente a bactérias gram +, gram - e fungo.

In: VII Congresso Regional de Análises Clínicas do Centro-Oeste, Campo Grande, MS, Brasil, 2005.

5.29. LOBATO, N. S., FILGUEIRA, F. P., LIMA, V. V., TOLEDO, O. R.

Avaliação do uso de contraceptivos hormonais por alunas matriculadas no ensino médio de Barra do Garças - MT.

In: VII Congresso Regional de Análises Clínicas do Centro-Oeste, Campo Grande, MS, Brasil, 2005.

5.30. FILGUEIRA, F. P., CARVALHO, J. S., LOBATO, N. S., LIMA, V. V., COSTA, F. G., NDIAYE, E. A., SOUTO, P. C. S., SILVA, P. J.

Avaliação da atividade antimicrobiana do extrato metanólico de Duguetia furfuracea (St. Hill) Benth \& Hook (sofre do rim quem quer).

In: VII Congresso Regional de Análises Clínicas do Centro-Oeste, Campo Grande, MS, Brasil, 2005.

5.31. FILGUEIRA, F. P., CARVALHO, J. S., LOBATO, N. S., BERNARDES, A. P. V. Estudo da prevalência de enteroparasitoses no centro de educação infantil são judas tadeu, na Cidade de Aragarças - GO.

In: VII Congresso Regional de Análises Clínicas do Centro-Oeste, Campo Grande, MS, Brasil, 2005.

5.32. COSTA, F. G., DAVID, F. L., FILGUEIRA, F. P., LIMA, V. V., LOBATO, N. S., MELO, L. V. L.

Avaliação do conhecimento dos freqüentadores da praia de Aragarças - GO, com relação aos riscos da exposição ao sol.

In: VI Congresso Regional de Análises Clínicas do Centro-Oeste, Cuiabá, MT, Brasil, p.33-33, 2004. 
5.33. ANDRADE, L. C. M., CARVALHO, J. S., FARIA, F. S., FILGUEIRA, F. P., LOBATO, N. S., TOLEDO, O. R.

Determinação da relação entre eosinofilia, giardíase e amebíase.

In: VI Congresso Regional de Análises Clínicas do Centro-Oeste, Cuiabá, MT, Brasil, p.31-31, 2004.

5.34. ANDRADE, L. C. M., CARVALHO, J. S., FARIA, F. S., FILGUEIRA, F. P., LOBATO, N. S., TOLEDO, O. R.

Determinação de giardíase e amebíase em uma creche de Aragarças - GO.

In: VI Congresso Regional de Análises Clínicas do Centro-Oeste, Cuiabá, MT, Brasil, p.29-29, 2004.

5.35. ANDRADE, L. C. M., CARVALHO, J. S., FARIA, F. S., FILGUEIRA, F. P., LOBATO, N. S., TOLEDO, O. R.

Prevalência de anemia em pré-escolares de uma creche da cidade de Aragarças GO.

In: VI Congresso Regional de Análises Clínicas do Centro-Oeste, Cuiabá, MT, Brasil, p.17-17, 2004.

5.36. LOBATO, N. S., FILGUEIRA, F. P., CARVALHO, J. S., COSTA, F. G., LIMA, V. V., PEIXOTO, R. F., DAVID, F. L.

Farmácia na praia - temporada da Praia Quarto Crescente

In: Il Mostra de Extensão Universitária - UFMT, Barra do Garças, MT, Brasil, p.19-19, 2004.

5.37. LOBATO, N. S., FIlgueIRA, F. P., CARVALHO, J. S., FARIA, F. S., TOLEDO, O.R.

Procedimentos preventivos e realização de exames sobre anemia e enteroparasitoses nas crianças da Creche São Judas Tadeu.

In: II Mostra de Extensão Universitária - UFMT, Barra do Garças, MT, Brasil, p.27-27, 2004.

5.38. LOBATO, N. S., FILGUEIRA, F. P., CARVALHO, J. S., COSTA, F. G., LIMA, V. V., PEIXOTO, R. F., DAVID, F. L.

Programa de prevenção DST/AIDS.

In: II Mostra de Extensão Universitária - UFMT, Barra do Garças, MT, Brasil, p.28-28, 2004.

5.39. LOBATO, N. S., FILGUEIRA, F. P., COSTA, F. G., LIMA, V. V., SILVA, F., SILVA, E. S., MURAKAMI, D. M. Plantas medicinais - educação e saúde.

In: I Mostra de Extensão Universitária - UFMT, Barra do Garças, MT, Brasil, p.27-27, 2003.

\section{APRESENTAÇÃO DE TRABALHO EM FORMATO DE PAINEL EM CONGRESSO CIENTÍFICO}

6.1. LOBATO, N. S., FILGUEIRA, F. P., GIACHINI, F., CARVALHO. M. H., WEBB, 
R. C., TOSTES, R. C., FORTES, Z. B.

A obesidade diminui a atividade do sistema endocanabinóide vascular: participação da eNOS, da AMPK e da ERK.

Arquivos Brasileiros de Endocrinologia e Metabologia (ISSN 0004-2730), v.54, suplemento 2, p.133-133, 2010.

In: 9ํㅡㄹ Congresso Paulista de Diabetes e Metabolismo, Águas de São Pedro, SP, Brasil, 2010.

6.2. LOBATO, N. S., FILGUEIRA, F. P., GIACHINI, F., CARVALHO. M. H., WEBB, R. C., TOSTES, R. C., FORTES, Z. B.

Obesity decreases the activity of the endocannabinoid system: role of $\mathrm{NO}$ and AMPK.

Faseb Journal (ISSN 0892-6638), v.24, abstract n.570.7, 2010.

In: Experimental Biology, Anaheim, Califórnia, EUA, 2010.

6.3. LOBATO, N. S., FILGUEIRA, F. P., GIACHINI, F., CARVALHO. M. H., WEBB, R. C., TOSTES, R. C., FORTES, Z. B.

A obesidade diminui a atividade do sistema endocanabinóide vascular: participação da eNOS, da AMPK e da ERK.

FeSBE, resumo n.16.049, 2010.

In: XXV Reunião Anual da Federação de Sociedades de Biologia Experimental FeSBE, Águas de Lindóia, SP, Brasil, 2010.

6.4. LOBATO, N. S., FILGUEIRA, F. P., GIACHINI, F. R., WEBB, R. C., TOSTES, R. C., FORTES, Z.B.

Hyperactivation of ERK pathway and decreased activity of AMPK contribute to the decreased relaxation to anandamide in obese Zucker rats.

In: $20^{\text {th }}$ Annual Vascular Biology and Hypertension Symposium, Birmingham, Alabama, EUA, 2009.

6.5. LOBATO, N. S., AKAMINE, E. H., FILGUEIRA, F. P., TOSTES, R. C., CARVALHO, M.H.C., FORTES, Z.B.

Metformin improves endothelial function in obese rats.

Faseb Journal (ISSN 0892-6638), v. 23, abstract n. 578.1, 2009.

In: Experimental Biology, New Orleans, Louisiana, EUA, 2009.

6.6. Lobato, N. S., tostes, R. C., CARVAlHO, M. H. C., FORTES, Z. B.

Metformina corrige alterações na função vascular em ratos obesos: estudo dos mecanismos envolvidos.

In: V Congresso do Instituto de Ciências Biomédicas, Universidade de São Paulo, São Paulo, SP, Brasil, 2008.

6.7. LOBATO, N. S., PARIZ, J. R., tOSteS, R. C. A., CARVAlHO. M. H. C., FORTES, Z. B.

Metformina modula a resposta contrátil e vasodilatadora via NO, prostanóides e hiperpolarização do músculo liso do leito arteriolar mesentérico de ratos obesos com resistência à insulina.

Arquivos Brasileiros de Endocrinologia e Metabologia (ISSN 0004-2730), v.52, supl. 2, S209 - S209, 2008.

In: 8ํㅡㄹ Congresso Paulista de Diabetes e Metabolismo, Águas de Lindóia, SP, Brasil, 
2008.

6.8. LOBATO, N. S., tOSTES, R. C., CARVALHO, M.H.C., FORTES, Z.B. Efeito benéfico da metformina nas alterações vasculares de ratos obesos: papel das EROs e da hiperpolarização de membrana.

FeSBE, p. 75-75, 2008.

In: XXIII Reunião Anual da Federação de Sociedades de Biologia Experimental FeSBE, Águas de Lindóia, SP, Brasil, 2008.

6.9. LOBATO, N. S., PARIZ, J. R., TOSTES, R. C., CARVALHO, M.H.C., FORTES, Z.B.

Efeito da metformina nas alterações da resposta vasoconstritora da aorta de ratos obesos: papel do endotélio.

In: XXIII Reunião Anual da Federação de Sociedades de Biologia Experimental FeSBE, Águas de Lindóia- SP, 2008.

6.10. LOBATO, N. S., TOSTES, R. C., CARVALHO, M.H.C., FORTES, Z.B.

Papel do endotélio nas alterações da resposta vasodilatora em ratos obesos e o efeito da metformina: possíveis mecanismos envolvidos.

Hipertensão (ISSN 1519-7522), v. 11, n.4, p.80-80, 2008.

In: XVII Congresso Brasileiro de Hipertensão, Rio de Janeiro, RJ, Brasil, 2008.

6.11. LOBATO, N. S., TOSTES, R. C., CARVALHO, M.H.C., FORTES, Z.B.

Alterações da contração vascular em ratos obesos e o efeito da metformina: possíveis mecanismos envolvidos.

Hipertensão (ISSN 1519-7522), v. 11, n.4, p.80-80, 2008.

In: XVII Congresso Brasileiro de Hipertensão, Rio de Janeiro, RJ, Brasil, 2008.

6.12. LOBATO, N. S., TOSTES, R. C., CARVALHO, M.H.C., FORTES, Z.B.

Reatividade vascular em ratos wistar obesos com resistência à insulina induzida por glutamato monossódico (MSG).

Arquivos Brasileiros de Endocrinologia e Metabologia (ISSN 0004-2730), 2007, v.51, n.3, supl. 1, p.S126-S126.

In: $7^{\circ}$ Congresso Paulista de Endocrinologia e Metabolismo, São Paulo, SP, Brasil, 2007.

6.13. LOBATO, N. S., TOSTES, R. C., CARVALHO, M.H.C., FORTES, Z.B.

Alterações na Reatividade Vascular em Modelo de Resistência à Insulina Induzida por Glutamato Monossódico (Obesidade em Ratos).

Hipertensão (ISSN 1519-7522), v. 10, p.55-55, 2007.

In: XVI Congresso Brasileiro de Hipertensão, Recife, PE, Brasil, 2007.

\section{OUTRAS PUBLICAÇÕES}

7.1. Dissertação de mestrado defendida e aprovada

LOBATO, N. S. Efeito do tratamento com metformina sobre alterações vasculares em modelo de resistência à insulina. $128 \mathrm{f}$. Dissertação (Mestrado em Farmacologia). 
Instituto de Ciências Biomédicas, Universidade de São Paulo, São Paulo, 2008. 


\section{V- $\quad$ ATIVIDADES DE QUALIFICACÃO}

\section{PARTICIPAÇÃO EM EVENTOS CIENTÍFICOS}

1.1. XXV Reunião Anual da Federação de Sociedades de Biologia Experimental FeSBE, Águas de Lindóia - SP, 2010. (Congresso)

1.2. $9^{\circ}$ Congresso Paulista de Diabetes e Metabolismo, Águas de São Pedro - SP, 2010. (Congresso)

1.3. Experimental Biology, Anaheim - CA, EUA, 2010. (Congresso)

1.4. 63rd High Blood Pressure Research Conference, Chicago - IL, EUA, 2009. (Congresso)

1.5. $20^{\text {th }}$ Annual Vascular Biology and Hypertension Symposium, Birmingham - AL, EUA, 2009. (Simpósio)

1.6. Experimental Biology, New Orleans - LA, EUA, 2009. (Congresso)

1.7. V Simpósio de Farmacologia "Prêmio Qualidade Científica Prof. Dr. João Garcia Leme", São Paulo - SP, 2009.(Simpósio)

1.8. V Congresso do Instituto de Ciências Biomédicas, Instituto de Ciências Biomédicas, Universidade de São Paulo, São Paulo - SP, 2008. (Congresso)

1.9. XXIII Reunião Anual da Federação de Sociedades de Biologia Experimental FeSBE, Águas de Lindóia - SP, 2008. (Congresso)

1.10. XVI Congresso Brasileiro de Hipertensão, Rio de Janeiro - RJ, 2008. (Congresso)

1.11. III Simpósio Temático do Departamento de Fisiologia e Biofísica "Sinalização Celular", Instituto de Ciências Biomédicas, Universidade de São Paulo, São Paulo SP, 2008. (Simpósio)

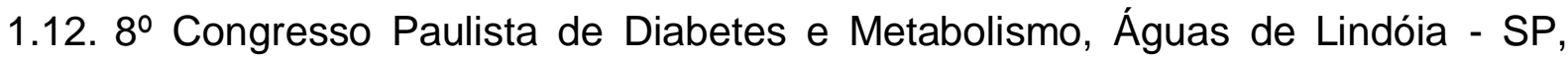
2008. (Congresso)

1.13. IV Simpósio "Ácidos Graxos e Saúde", Instituto de Ciências Biomédicas, Universidade de São Paulo, São Paulo - SP, 2008. (Simpósio)

1.14. XV Congresso da Sociedade Brasileira de Hipertensão, Recife - PE, 2007. (Congresso)

1.15. IV Simpósio de Farmacologia "Prêmio Qualidade Científica Prof. Dr. João Garcia Leme", São Paulo - SP, 2007. (Simpósio)

1.16. $7^{\circ}$ Congresso Paulista de Endocrinologia e Metabolismo, São Paulo - SP, 
2007. (Congresso)

1.17. VII Congresso Regional de Análises Clínicas do Centro-Oeste, Cuiabá - MT, 2005. (Congresso)

1.18. VI Congresso Regional de Análises Clínicas do Centro-Oeste, Cuiabá - MT, 2004. (Congresso)

1.19. II Mostra de Extensão Universitária - UFMT, 2004.

1.20. I Mostra de Extensão Universitária - UFMT, 2003.

\section{CURSOS DE APERFEIÇOAMENTO}

Realização de estágio no Programa de Aperfeiçoamento de Ensino (PAE) da Universidade de são Paulo, na área de Farmacologia, do Instituto de Ciências Biomédicas, com carga horária semanal de 06 horas, durante o primeiro semestre de 2007 (total de horas: 144). Foram desenvolvidas atividades didáticas junto à disciplina BMF-220 - Farmacologia, com os alunos de graduação do curso de Medicina, sob supervisão da Prof. Dra Maria Helena Catelli de Carvalho. 


\section{VI- $\quad$ ATIVIDADES DE ENSINO}

\section{CO-ORIENTAÇÕES CONCLUÍDAS}

\section{INICIAÇÃO CIENTÍFICA}

1.1 Graziela Neves Hagihara.

Estudo do tratamento com metformina nas alterações da reatividade vascular em modelo de resistência à insulina (obesidade):possíveis mecanismos envolvidos. 2008-2009.

Iniciação científica (Bolsa de Treinamento Técnico para Estudantes de Graduação) Universidade de São Paulo.

1.2 Juliana Pariz Risso.

Influência do tratamento com metformina nas alterações vasculares induzidas por obesidade: estudo em ratos. 2007-2007.

Iniciação científica (Programa de Iniciação Científica - PIBIC) - Universidade de São Paulo.

\section{CO-ORIENTAÇÕES EM ANDAMENTO}

\section{MESTRADO}

\subsection{Graziela Neves Hagihara.}

Resposta a angiotensina II em artérias mesentéricas de resistência na obesidade: papel das MAPKs. 2010-atual.

Bolsista da Fundação de Amparo à Pesquisa do Estado de São Paulo - FAPESP, Universidade de São Paulo.

\section{OUTRAS ATIVIDADES DESENVOLVIDAS}

ESTÁGIO no Departamento de Fisiologia do "MEDICAL COLLEGE OF GEORGIA", Augusta-GA, USA. Período: de fevereiro a outubro de 2009, sob a co-orientação da Prof. Dra. Rita de Cássia Tostes e do Prof. Dr. Clinton Webb. 